

$$
249 / 12=
$$


DCSB LIBRARY

$X$-SSO8 8

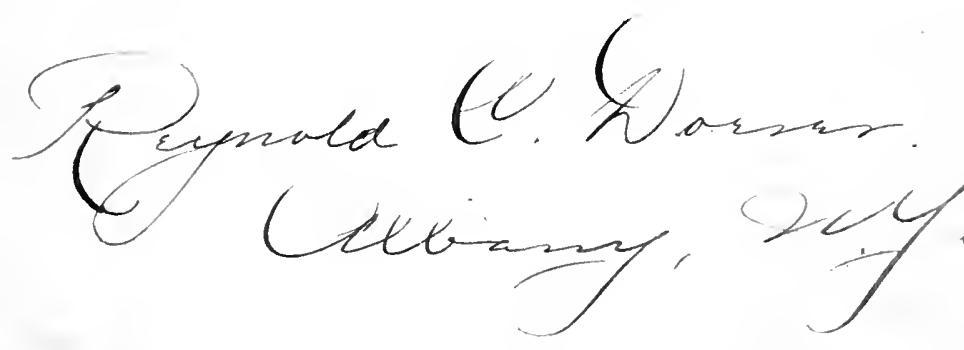


Digitized by the Internet Archive in 2007 with funding from Microsoft Corporation 




\section{THE}

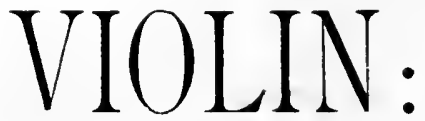

\section{Its Famous Makers and Their}

\section{IMITATORS.}

RY

\section{GEORGE HART.}

WITH

SEVERAL WOOD ENGRAVINGS FROM PHOTOGRAPHS OF THE WORKS OF STRADIUARIUS, GUARNERIUS AMATI, AND OTHERS.

"To perfect that wonder of travel-the locomotive-has perhaps not required the expenditure of more mental strength and application, than to perfect that wonder of music-the Violin." W. E. Gladstonr. 


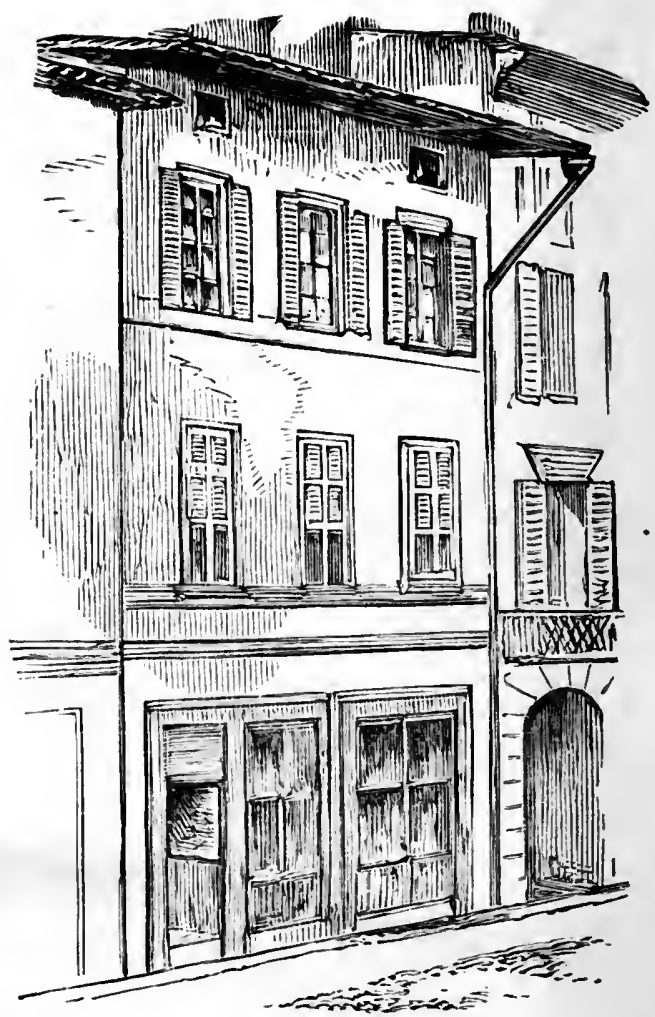

House of Stradivirius, West Side, Piazza Roma, Crkmona. 


\section{CONTENTS.}

Section I. - The Early History of the Violin.......... $1-3$ Section II.-The Construction of the Violin.......... 4- 10 Section III - Italian and other Strings................ II 14 Section IV. - The Italian School.,.................... I5- 20 Section V.-The Italian Varnịsh...................... $2 \mathrm{I}-24$ SEction VI.-Italian Makers......................... 25- 7 I Section VII.-The French School..................... $72-74$ Section VIII._French Makers........................ 75- $\mathrm{S}_{2}$ Section IX.-The English School..................... $8_{3}-8_{7}$

Sectron X.-English Makers............................ 88-105 Section XI.-The German School.......................106-107 Section XII.-German and Dutch Makers.............. Io8-115 Section XIII.-The Violin and its Votaries.............116-132 Section XIV.-Sketch of the Progress of the Viulin. 133-148 Section XV.-Anecdotes and Miscellanea connected with the Viulin $149-178$ 


\section{LIST OF IIIUUSTRATIONS.}

Frovismeck-Antonius Stradiuarius' Houne.

x Gaspart di Salo Violin

2 Giovanni J'solo Maggini Violin................................... $3^{8}$

3 Antonius and Heironymus Amati.................................. 57

4 Nicholas Amati........................................................ 75

5 . Intonius Stradiuarius.............................................. 95

6 Joseph Guarnerius del Jesì........................................... 117

7 Carlo liergonzi....................................................... 33

8 Scrolls-1, Joseph Guiırnerius ; 2, Stradiuarius 1686; 3, Nicholas Amati ; 4, Stradiuarius $1 ; y, \ldots \ldots \ldots \ldots \ldots \ldots \ldots \ldots \ldots \ldots \ldots \ldots$ 


\section{DEDICATION}

\section{To OrIgINAT, Ėdition, 1875.}

\section{Inscribed to the Admirers of the Leading Instrument at Home and Abroad.}

\section{MY FRIENDS :}

For some time I have been in a state of doubt as to which course to pursue-whether to follow the usual custom, and address the reader in a Preface, or to combine my prefatory remarks with a Dedication. It will be seen that I have chosen the latter method. I am aware that inscriptions in connection with books are no longer in vogue; the necessity for them has happily long since passed away. In these free press days, though the writer of a book be the most obscure individual in the paths of literature, yet his pages will not lack readers, always providing they are worth perusal. Though it may appear that I am falling back upon an old custom in inscribing to you the results of my leisure hours, I do so simply because the subject is one which interests but a section of society in this instance, and that section is yourselves.

In placing these pages before you, I must admit that I feel some little anxiety as to the reception awaiting them. I have lived in the atmosphere of Fiddles all my days, and have, perhaps, possessed peculiar advantages for learning much about them; but whether I have succeeded in conveying to the reader information at once new and interesting remains to be seen. The task was undertaken by me at the suggestion of several friends, who felt that there was room for a more detailed work on the subject than as yet existed, and thus induced me to take the pen in hand. Upon your verdict wholly clepends the issue whether I shall have reason to feel indebted to my friends for their counsel or not.

And now a word or two with regard to the contents of the book. For years I have teen impressed with the idea that a work of this kind, illustrated with specimens of the productions of the chief Cremonese makers, would be received with delight by connoisseurs. To know how to carry out this idea with any degree of success was a problem I was long unable to 
solve. Not to trouble you with the various processes which I brought to bear on the subject, I may say that it was at length suggested to me that a combination of plotography and wood engraving would ensure the double requisites of correctness and durability. By this process all the points in the outline of the work could not fail to be in accordance with the original. As many of the instruments were photographed at different times and places, an uniform scale has not been attempted, indeed, the small size of the engravings would preclude the possibility of its adoption forming any safe guide in the matter, the calculation being too minute. In the selection of specimens I have taken those instruments that I deemed would show the various styles to the best advantage; it must be borne in mind, therefore, that they are intended to represent the character of each artist's works, and not to form a catalogue of remarkable instruments, to engrave all of which would be wholly foreign to the purpose of my undertaking.

I feel sure that the Frontispiece will be received with delight by all connoisseurs. In obtaining permission to photograph Paganini's famous Violin, I met with no slight obstacles, but my efforts were at length happily successful. M. Vieuxtemps states that the last time the instrument was removed from the glass-case in which it had rested so many years was upon the occasion of a concert given in aid of the charities of Genoa, when Signor Sivori was permitted to play upon the treasured Violin. Up to that time there was a ribbon around the instrument, which was secured at the back with the Corporation Seal -a very ill-advised mode, it must be confessed, of attacling the insignia of authority. To permit Signor Sivori to use the Violin, the seal and ribbon necessarily had to be removed, and in the performance of this delicate operation the seal carried away with it the lustrous varnish of Joseph Guarnerius. The mark where the wax adihered is distinctly seen in the engraving of the back of the Violin given herewith. The Corporate Seal is now very properly attached to the scroll, from which it hangs by a ribbon.

Before closing my remarks on the illustrations, I nụt mention that I am much indebted to the able assistance I have received from $\mathrm{Mr}$. Petherick, who has superintended that portion of the work. A lover of the Old Masters, he exerted himself to carry ont my views with a zest rare to parallel.

In giving a Sketch of the Progress of the Violin, I have endeavored to touch lightly on the most interesting points relating thereto. To have omitted mention of this branch of the subject would, I felt, have rendered my task incomplete.

The anecdotal portion will, I hope, be found to contain much that is interesting. The anecdotes relating to my own $v$ scation, I hive endeavored to set forth with as much advantage as my power of narrative would permit; and those which I 
DEDICATION.

$v$

have selected from various sources have been such as I deemed congenial to the subject, and least likely to be generally known.

Having rendered you some account of my task, it now only remains for me to subscribe myself,

Yours faithfully,

THE AUTHOR.

14, Princes Street,

Leicester Square, $W$. 



\section{THE VIOLIN.}

Famous Makers and Their Initators.

SECTION I.

The Early History of the Violin.

7 HE early history of the Violin appears to be enveloped in d6 darkness, and, in consequence, the usual diversity of opinion exists on the sulvect. The chief object of the writer of these pages is to throw light on the instrument in its perfected state, and more parlicularly on the masters known and appreciated. The origin, therefure, of the Violin requires but passing notice here. The subject has been most ably treated by M. Fétis, M. de Cousseniaker, and Sandy and Forster conjointly, to whose interesting works the reader is referred if desirous of extending his knowledge in that direction.

Leaving the Cytnara, Lyre, and Lute, together with the various offshoots of those instruments, in the keeping of the antiquarians, we will endeavor to start from the period when that important feature, the Bow, was introduced.

The people of antiquity do not appear to have had any knowledge of instruments played with a bow ; and it is satisfactory to know that upon this point writers on the subject of the early history of the Violin seem agreed, though at variance upon other matters of equal importance. The statue of Orpheus holding a lyre in one hand and a bow in the other has been cited as a proof that the ancients were acquaiuted with the bow ; but upon closer inquiry it will be found that this delineation is wholly insufficient evidence to prove the existence of bow instruments among the people of antiquily. The fact that the development in question is attributed to the restorer of the statue at once disposes of the connection between Orpheus and bow instruments.* The earliest form of bow instruments of which we have any knowledge is the Crwth (Crooth), belonging to Wales. This curious instrument is mentioned by Venantius Fortunatus, Bishop of Poitiers, who lived in the sixth century. It is doubtful whether the Crwth of this period had a bow. It was, possibly, a modified furm of the instrument *Fétis, "History of Music." 
used by the Egyptians, and likewise played with a plectrum. M. de Coussenıaker, in his "Essai sur les Instruments de Musique du Moyen Age," gives the figure of a Crwih of the eleventh century, which has three strings, and is played with a roughly-made bow. From the days of Venantius Fortunatus to the eleventh century is a considerable step, and yet there is no mention anywhere of a bow prior to that of M. de Coussemaker-a fact which certainly tends to strengthen the idea that the bow was introduced long after the sixih century.

The Crwth has undergone many changes. Its earliest form is said to have consisted of a back and sound-board with holes for the hands to pass through, and to have been strung with three strings. M. de Cuussemaker gives another form of Crwth of the thirteenth century, from the Cathedral of Amiens, having six strings-an important improvement. In Worcester Cathedral, according to Carter's "Ancient Sculpture," there is a figure of an angel playing a Crwth of about the twelfth century, having five strings. The addition of one extra string a century later, as shown by M. de Coussemaker, is thus clearly distinguished. The number of strings on this rude instrument seems to have remained unaltered down to 1742 , which is the date of the Crwth exhibited at the Special Exhibition of Ancient Musical Instruments at the South Kensington Museum, in 1872, by Mr. C. Wymme Finch, which has six strings, and measures 22 inclues in length, $9 \frac{1}{2}$ inches in width, and 2 inches in depth, the finger-board being $10 \frac{1}{4}$ inches long. This is said to be the only specimen of the $\mathrm{Crwth}$ in existence, and to judge from its date the Welsh would appear to have used these instruments down to a comparatively recent period. The name Crwth was applied to instruments of the Violin class as late as the commencement of the eighteenth century. Mirston, Middleton, and Ben Jonson mention the "crowd."

We now come to the next order, viz., instruments of the Viol class. These instruments had not the form of the Violins and Violas of our time; they resembled the Mandoline, having pear-shaped backs. M. de Coussemaker mentions an instrument to which no name is attached, hut which is said to have been invented by Albinus. It has fiur strings, is curved somewhat like a Violin in order to give room for the movement of the bow, and its sound-holes are placed at the lower portion of the instrument, near the tail-piece. It is noticed in a MS. of the fourteenth century, a date which brings us a century later than the Crwth of the Cathedral of Amiens.

Mention is made in the fifteenth century of the Vielle, the Rota, and the Rebec, as bowed instruments. At a later period these various species underwent divers changes, and gave birth to the Viol, played on the knee and mounted with five strings; the Treble Viol, also a five-stringed instrument, tuned five notes higher than the knee Viol; and the Bass Viol, strung with 
five strings, and sometimes six, which.is identical with the Viol da Gamba. The Violone, or large Viol * was placed upon a pedestal when played, as also the Accordo, which is the Double Bass of modern times, but differently arranged as regards its strings. It had sometimes as many as seven or more strings, and the finger-board was divided by frets similar to those of the Viol da Gamba. Besides the instruments here enumerated there was the Viol d'Amour, which had strings of wire passing through the bridge and tuned in unison with those passing over it. This instrument was probably the last of the order.

M. Fétis mentions that towards the close of the fifteenth century the French reduced the Viol, and made from it the Violin as it now exists. It is said that the Violin is indicated in the Italian scenes at the end of the sixteenth century under the names of "piccoli Violini alla Francese" ("little Violins of the Frent $h$ fashion"), from which circumstance M. Fétis assumes that to the French people belongs the credit of introducing the Violin. The foundation upon which the assertion rests is somewhat weak, and needs other support to make it worthy of acceptance. If we turn to the Italian School, we find that Gaspard di Salo made Violins, and that he worked between the years $1560-1610$; evidence sufficient to show that Violins were made out of France at the end of the sixteenth century.

The superiority of the Violin over the Viol soon obtained for it the preference, and it rapidly came into general use. Of the ancient Viols, the only specimens that liave been preserved are the Alto or Quinte, the Violone or Violoncelle, and the Accordo or Double Bass, the number of strings having been reduced in each case.

From this slight sketch of the early history of bowed instruments, the reader may probably have gathered sufficient information of a nature likely to prove interesting to him, and we may, therefore, now pass to the construction of the Violin.

* The Violoncello was the Violone of former times. In the earlier editinns of Corelli the Bass part is entitled Violone. 'The Violoncello was originally mounted with five strings, C, G, D, A, D; about 1600 the $D$ string was removed. The former method of stringing was adopted by the Abbe Tardieu. 
SECTION II.

The Construction OF THE Violin.

THE construction of the present form of the Violin has $\int 6$ occupied the attention of many scientific men. It cannot be denied that the subject possesses a charm sufficiently powerful to induce research, as endeavor is made to discover the causes for the vast superiority of the Violin of the seventeenth century over the many other forms of bow instruments which it has survived. The characteristic differences of the Violin have been obtained at the cost of many experiments in changing the outline and placing the sound-holes in various incongruous positions. These and the many similar freaks of inventors in their search after perfection have signally failed, a result to be expected when it is considered that the changes mentioned were unmeaning, and had nothing but novelty to recommend them. But what is far more extraordinary is the failure of the copyist, who, vainly supposing that he has truthfully followed the climensions and general features of the Old Masters, at last discovers that he is quite unable to construct an instrument in any way deserving of comparison with the works of the period referred to. The Violin has thus hitherto baffled all attempts to force it into the "march of progress" which most things are destined to follow. The Violin seems to scorn complication in its structure, and successfully holds its own in its simplicity. There is in the Violin, as perfected by the great Cremonese masters, a simplicity combined with elegance of design, which readily courts the attention of thoughtful minds, and gives to it an air of my'stery that cannot be explained to those outside of the fiddle world. Few objects possess so charming a display of curved lines as the members of the Violin family. Here we have Hogarth's famous line of beanty worked to perfection in the upper bouts, ${ }^{*}$ in the lower bouts, in the outer line of the scroll. in the sound-hole. Everywhere the perfection of the graceful curve is to be seen. It has been asserted by Hogarth's enemies that he borrowed the famous line from an Italian writer named Lomazzo, who introduced it in a treatise on the Fine Arts. We will be more charitable, and say that he obtained it from contemplation of the beauties of a Cremonese Violin.

In looking at a Violin we are struck with admiration at a sight of consummate order and grace: but it is the grace of nature rather than of mechanical art. The flow of curved lines

* A technical term for the sides. 
which the eye detects upon its varied surface, one leading to another, and all duly proportioned to the whole figure, may remind us of the windings of a gentle stream or the twine of tendrils in the trellised vine.

Often is the question asked, What can there be in a simple Violin to attract so much notice? What is it that causes men to treat this instrument as no other, to view it as an art picture, to dilate upon its form, color, and clate? To the uninitiated such devotion appears to be a species of monomania, and attributable to a desire of singularity. It needs but little to show the inaccuracy of such hypotheses. In the first place, the true study of the Violin is a taste which needs as much cultivation as a taste for poetry or any other art, a due appreciation of which is impossible without such cultivation. Secondly, it needs equally with these arts, in order to produce proficiency, that spark commonly known as genius, without which cultivation, strictly speaking, is impossible, there being nothing to cultivate. We find that the most ardent admiration for the Violin regarded as a work of art has ever been found to emanate from those who possessed taste for kindred arts. Painters, musicians, and men of refined minds have generally been foremost among the admirers of the Violin. Much interest attaches to it from the fact of its being an instrument hitherto incapable of improvenent as relates to its form or any material feature. The sole difference between the Violin of the sixteenth century and that of the nineteenth lies in the arrangement of the sound-bar (which is now longer, in order to bear the increased pressure caused by the diapason being ligher than in former times) and the comparatively longer neck, so ordered to obtain increased length of string. These variations can scarcely be regarcled as inventions, but simply as arrangements. Their raison d'étre was the need of adapting the instrument to modern requirements, so that it might be used in concert with others that have been improved, and allow the diapason to be raised. Lastly, it must be said that, above all, the Violin awakens the interest of its admirers by the tones which it can be made to utter in the hands of a skilful performer. It is, without doubt, marvellous that such sounds should be derivable from so small and simplelooking an instrument. Its expressiveness, power, and the extraordinary combinations which its stringing admits of, truly constitute it the king of stringed instruments. These somewhat desultory remarks may suffice to trace the value set upon the Violin both as a work of art and as a musical instrument.

We will now proceed to consider the acoustical properties of the violin. These are, in every particular, surprisingly great, and are the results of many tests, the chief of which has been the adoption of several varieties of wood in the construction. In Brescia, which was undoubtedly the cradle of Violin manufacture, the selection of the pear tree, lemon tree, and ash for 
the material of the sides and back was very general, and there is every reason to believe that Brescia was the first place where such woods were used. It is possible that the makers who chose them for the sides and backs of their instruments considered it desirable to have material more akin to that adopted for the bellies, which was the finest description of pine, and that the result was found to be a tone of great mellowness. If they used these woods with this intention their calculations were undoubtedly correct. They appear to have worked these woods with but few exceptions for their Violas, Violoncellos, and Double Basses, while they adopted the harder woods for their Violins, all which facts tend to show that these rare old makers did not consider soft wood eligible for the back and sides of the leading instrument; and later experiment has shown them to have arrived at a correct conclusion on this point. The experiments necessary to obtain these results have been effected by cutting woods of several kinds and qualities into various sizes, so as to give the sound of a diatonic scale. By comparing the intensity and quality of tone produced by each sample of wood, sycamore has been found to surpass the rest. The Cremonese nakers seem to have adhered chiefly to the use of sycamore or maple, varying the manner of cutting it. First, they made the back in one piece, technically known as a "whole back;" secondly, the back in two parts; thirdly, the cutting known as the "slab back." There being considerable doubt as to the mode of dividing the timber, the woodcuts given will assist the reader to understand it. Fig. I represents the cutting for the back in two pieces-the piece which is separated from the $\log$ is divided. Fig. 2 shows the method adopted to obtain the slab form.

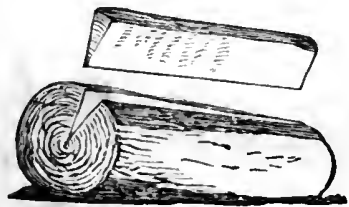

Fig. 1

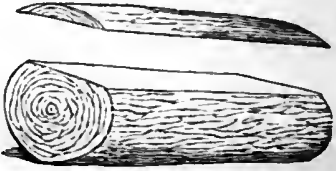

Fig. 2.

Tinis mode of cutting is constantly met with in the works of the Brescian makers and likewise of the early Cremonese. Andrew Amati invariably adopted this form. Stradiuarius rarely cut his wood slab-form. Joseph Guarnerius made a few Violins of his best epoch with this cutting, the varnish of which is of an exquisite orange color, so transparent that the curls of the wood beneath resemble richly illuminated clouds.

There can be no doubt whatever that the Cremonese and Brescian artists were exceedingly choice in the selection of their 
material, and their discrimination in this particular does not appear to have arisen so much from a regard to the beauty as to the acoustic properties of the wood, to which they very properly gave the first place in their consideration. WVe have evidence of much weight upon this interesting point in the frequent piercings found on the works of Old Masters, who seem to have preferred to retain a piece of wood of known acoustic properties rather than to work in a larger or better preserved portion at the probable expense of tone. In a Viola by Bergonzi is an instance of this desire to preserve rare material. Under its lovely varnish may be seen several pieces let in most artistically. The time and care required for such a delicate operation must lave been sufficient to have enabled the artist, had he been so minded, to have made a complete instrument. There is also ample proof that Joseph Guarnerius possessed wood to the exceptional qualities of which he was fully alive, and the same may be said of Stradiuarius, Rugerius, and others. It is scarcely reasonable to suppose that in the seventeenth century there was a dearth in Italy of timber suitable for the manufacture of Violins, and that in consequence these eminent makers were compelled to patch and join their material to suit their purpose. Nor can we think that they did so from an absence of pecuniary means, for they were in the enjoyment of a patronage certainly sufficient to enable them to follow their calling without privation of any kind. Scarcity of pine and sycamore, good and bad, could not have been the cause, since we find Italian cabinet-work of great beauty that was manufactured at this same period. It is, further, improbable that these masters of the art should have expended such marvellous care and toil over their work, pieced as it frequently was like mosaic, when for a trifling sum they could have avoided such a task to their ingenuity by purchasing fresh wood. We are therefore forced to admit that there must have been some cause of great weight which induced them to apply so much time and labour, and that the problem can only be be accounted for by the solution before proposed, viz., that the wood having acoustic properties thoroughly adapted to the old makers' purpose was of greater importance than external appearance, and that the scarcity of suitable wood was such as to make them hoard and make use of every particle. The selection of material was hence considered to be of prime i nportance by these makers, and by careful study they brought it to a state of great perfection. The knowledge they gained of this vital branch of their art is enveloped in a similar obscurity to that which conceals their famous varnish, and in these branches of Violin manufacture rests the secret of the Italian success, and until it is rediscovered the Cremonese will remain unequaled in the manufacture of Violins.

We may now pass to the consideration of the various 
constituent parts of a Violin. It will be found if a Violin be taken to pieces that it is constructed of no less than fifty-eight separate pieces, an astonishing number if factors for so small and simple-louking an instrument. The back is made of sycamore, in one or two pasts; the belly of the finest quality of Swiss pine, and from a piece usually divided; the sides, like the back, of sycamore, in six pieces, bent to the required form by means if a heated iron; the linings, which are used to secure the back and belly to the sides, are twelve in number, sometines made of lime tree, but also of pine; the bass, or sound-bar, is of pine, placed under the left foot of the bridge in a slightly oblique position, in order to facilitate the vibration by giving it the same position as the line of the strings. The old method was to insert it in an exactly straight pusilion, but experience teaches that by this treatment the instrument is muted to some extent The bar of the Vislin not unly serves the purpose of strengtheniny the instrument in that part where the pressure of the bridge is greatest, but forms a purtion of the structure at once curious and deeply interestilig; it may indeed be called the nervous system of the Violin, so exquisitely sensitive is it as to external tuuch. The slightest alteration in its pusition will effect such changes in the tone as often to make a good Violin worthless. Those troublesome notes technically known as "wolf notes" by its delicate arrangement are frequently totally removed, or the malaise is passed to intervals where the disagreeable sound is folt with less intensity. Numerous attempts have been made to reduce these features to a philosophy, but the realization of the coveted discovery appears as distant as ever. The most minute variation in the construction of the instrument necessitates a different treatment of this active agent as regards its conjunction with the bridge; and when it is considered that scarcely two Viulins can be found of exactly identical structure, it must be admitted that the dilficulties in the way of laying down any set of hard and fast rules for their regulation seem to be insuperable.

The next important feature of the internal organism is the sound-post, which serves many purpuses. The sound passes through it to the back, it gives support on the right side of the instrument, and lastly, regulates the power and quality of the sound: If we accept the sound-bar as the nervous system of a Violin, the sound-post may be said to perform the functions of the heart with unerring regularity. The pulsations i,f sound are regulated by this admirable contrivance. If mellowness of quality is sought, a slight alteration of its position or form will produce a favorable change of singular extent ; if intensity of tone be requisite, the sound-post is again the regulator. It must, of course, be understood that its power of changing the quality of the tone is limited in proportion to the constitutional powers of the instrument in each case. It is not pretended that 
a badly constructed instrument can be made a good one by means of this subtle regulator, any more than a naturally weak person can be made robust by diet and hygiene.

The position of the sound-post is usually one- eighth to three-eighths of an inch behind the right foot of the briuge, the distance being variable according to the model of the instrument. If the type be high built, the post requires to be nearer the bridge, that its action may be stronger; while flat instruments, which have a tendency to bring the vibrations closer from back to belly, necessarily require that the post be set further away from the bridge. It is not possible to have any uniform arrangement of the sound-post in all instruments; as we have remarked before in reference to the bass-bar, the variations in the thickness, outline, model, etc., of the Violin are so frequent as to defy identity of treatment; uniformity has been sought for, but without success.

The post can only be adjusted by a skilful workman who either plays himself or has the advantage of having the various adjustments tested by a performer. The necessity of leaving this exceedingly delicate matter in practised hands cannot be too strongly impressed upon the amateur, for the damage done in consequence of want of skill is often irreparable.

There are two methods of setting the sound-post in the instrument : the first fixes it in such a position as to place the grain of the post parallel with the grain of the belly; the second sets it crosswise.

The next important feature to be mentioned is the bridge, which forms no small part of the vibrating mechanism of the instrument, and needs the utmost skill in its arrangement. Its usual position is exactly between the two small niches marked in each sound-hole, but this arrangement is sometimes altered in the case of the stop being longer or shorter. Many forms of bridges have been in use at different periods, but that now adopted is, without doubt, the best. In selecting a bridge great care is requisite that the wood be suitable to the constitution of the Violin. If the instrument is wanting in brilliancy, a bridge having solidity of fibre is necessary; if wanting in mellowness, one possessing soft qualities should be selected.

We now pass to the neck of the Violin, which is made of sycamore or maple. Its length has been increased since the days of the great Italian masters, who seen to have paid but little attention to this portion of the instrument. As relates to its appearance, and the wood used for its manufacture, which was of the plainest description, it may be observed that in those times the florid passages which we now hear in Violin music were in their infancy, the first and second positions being those chiefly used; hence the little attention paid to the handle of the instrument. Modern requirements have made it imperative that the neck should be well shaped, neither too flat nor too round, but 
of a happy medium. The difficulties of execution are sensibly lessened when attention is paid to this requirement.

The finger-board is of ebony, and varies a little in length according to the position of the sound-holes. To form the board properly is a clelicate operation, for if it be not carefully constructed the strings jar against it and the movements of the bow are impeded.

The nut, or rest, is that small piece of ebony over which the strings pass on to the finger-board.

The principal parts of the instrument have now been described, and there remain only the pegs, blocks, purfling, strings, and tail-piece, the sum of which mates up the number of fifty-eight constituent parts, as before mentioned. There is still, however, one item of the construction to be mentioned which does not form a separate portion of the Violin, but which is certainly worthy of notice, viz., the button, which is that small piece of wood against which the heel of the neck rests. The difficulty of making this apparently insignificant piece can only be understood by those who have gone through the various stages of Violin manufacture. The amount of finish given to the button affects in a great measure the whole instrument, and if there is any defect of style it is sure to be apparent here. It is a prominent feature, and the eye naturally rests upon it: as the key-stone to the arch, so is the button to the Violin.

From the foregoing remarks upon the various portions of the Violin it may be assumed that the reader has gained sufficient insight into the process of its manufacture to enable him to dispense with a more minute description of each stage. It is unnecessary to pursue the details any further, unless the reader has resolved to make a Violin with his own hands, in which case he may judiciously peruse Naugin's " Manuel du Luthier," which will be found to contain much useful information.

In conclusion, I cannot refrain from cautioning possessors of good instruments against entrusting them into the barbaric hands of pretended repairers, who endeavor to persuade them into the belief that it is necessary to do this and that and the other for their benefit. The quack doctors of the Violin are legion-they are found in every town and city, ready to prey upon the credulity of the lovers of fiddles, and the injury they inflict on their helpless patients is frequently irreparable. Unfortunately, amateurs are often prone to be continually unsttling their instruments by trying different bars, soundposts, etc., without considering the danger they run of damaging their property instead of improving it. Should your instrument need any alteration, no matter how slight, consult only those who have made the subject a special study. There are a few such men to be found in the chief cities of Europe, men whose love for the instrument is of such a nature that it would not permit them to recommend alterations prejudicial to its well-being. 


\section{SECTION III.}

ItAliAN AND Other Strings.

N the strings of the Violin depends in a great measure the successful regulation of the instrument. If, after the careful adjustment of bridge, sound-post, and soundbar, strings are added which have not been selected with due care and regard to their relative proportion, the labor expended upon the important parts named is at once rendered useless. Frequently the strings are the sbjects least considered when the regulation of a Violin is attempted; but if this be the case, results anything but satisfactory ensue. It is, therefore, important that every violinist should endeavor to make himself acquainted with the different varieties and powers of strings, that he may arrange his instrument with greater facility.

Musical strings are manufactured in Italy, Germany, France, and England. The Italians rank first in this manufacture, their proficiency being evident in the three chief requisites for strings, viz., high finish, great durability, and purity of sound. There are manufactories at Rome, Naples, Padua, and Verona, the separate characteristics of which are definitely marked in their produce. Those strings which are manufactured at Rome are exceedingly hard and brilliant, and exhibit a slight roughness of finish. The Neapolitan samples are smooth and softer than the Roman, and also whiter in appearance. Those of Padua are highly polished and durable, but frequently false. The Veronese strings are softer than the Paduan, and deeper in color. The variations described are distinct, and the more remarkable that each of the four kinds are produced by one and the same nation; as, however, the raw material is identical throughout Italy, the process of manufacture in each case must be looked upon as the differentiating cause. The German strings now rank next to the Italian, Saxony being the seat of manufacture. They may be described as very white and smooth, the better kinds being very durable. Their chief fault arises from their being over-bleached, and hence faulty in sound. The French take the third place in the manufacture. Their strings are carefully made, and those of the larger sizes answer well : but the smaller strings are wanting in durability. The English manufacture all qualities, but chiefly the cheaper kinds; they are durable, but unevenly made, and have a dark appearance.

The cause of variation in quality of the several kinds enu(II) 
merated arises simply from the difference of climate. In Italy an important part of the process of nianufacture is carried on in the open air, and the beautiful climate is made to effect that which has to be done artificially in other countries. Hence the Italian superiority. Southern Germany adopts, to some $\in$ xtent, similar means in making strings; France, to a less degree; while England is obliged to rely solely on artificial processes. It therefure amounts to this result-the further from Italy the seat of manufacture, the more inferior the string.

Strings, although called "catgut," are not made from the intestines of that domestic animal, as is commonly supposed. Whether they were originally so made, and hence derive their name, it is impossible to learn. We may be sure, however, that had the raw material been drawn from that source up to the present time there would have been no occasion to check the supply of the feline race by destroying nine kittens out of ten; on the contrary, the rearing of cats would indeed have been a lucrative occupation. A time-honored error is thus commemorated in a word, whose very origin must be ascribed to want of thought. If the number of cats requisite for the string manufacture be considered for a moment it is easy to see that Shylock's "harmless necessary" domestics are under no contribution in this matter. Strings are made from the intes. tines of the sheep and goat, chiefly of the former. The best qualities are made from the intestines of the lamb, the strength of which is very great if compared with those of a sheep more than a year old. This being so, the chief manufacture of the year is carried on in the month of September, the September string makings being analogous to October brewings. The demand for strings made at this particular season far exceeds the supply, and notably is this the case with regard to the strings of small size, which have to bear so great a strain that if they were not made of the best material there is little chance of their endurance. To enter into a description of the various processes of the manufacture is unnecessary, as it would form a subject of little interest to the general reader; we may, therefore, conclude this brief notice of strings by a few rules to be observed in their selection.

Endeavor to obtain strings of uniform thickness throughout ; a requisite which can only be insured by careful gauging. In selecting the E string, choose those that are most transparent; the seconds and thirds, as they are spun with several threads. are never very clear. The firsts never have more than a few threads in them, and hence, absence of transparency in theil case denotes inferior material. Before putting on the first string, in particular, in order to test its purity, it will be well to adopt Spohr's method, which is to hold between the fingers of each hand a portion of the string sufficient to stretch from the bridge to the nut, and to set it in vibration. If two lines only 
be apparent, the string is free from falseness; if a third line be produced, the contrary conclusion must be assumed. In the case of seconds and thirds we cannot always rely on this test, as the number of threads used in their manufacture frequently prevents, the lines being perfectly clear. The last precaution of moment is to secure perfect fifths, which can only be done by taking care that the four strings are in true proportion with each other. To string a Violin correctly is a very difficult undertaking, and requires considerable patience. The first consideration should be the constitution of the Violin : the strings that please one instrument torture another. Neither Cremonese Violins nor old instruments in general require to be heavily strung: the mellowness of the wood and their delicate construction require the stringing to be such as will assist in bringing out that richness of tone which belongs to firstrate instruments. If the bridge and sound-board be heavily weighted with thick strings, vibration will surely be checked. In the case of modern instruments, heavy in wood, and needing constant use to wear down their freshness, strings of a large size may be used with advantage, and particularly when such instruments are in use for orchestral purposes.

Vast improvements have been effected in the stringing of Violins within the last thirty years. Strings of immense size were used alike on Violins, Violoncellos, Violas, and Double B.asses. Robert Lindley, the king of English violoncellists, used a string for his first very nearly equal in size to the second of the present time, and the sane robust proportion was observed in his other strings. The Violoncello upon which he played was by Forster, and would bear much heavier stringing than an Italian instrument; and, again, he was a most forcible player, and his power of finger quite exceptional. Dragonetti, the famous contra-basso player, and coadjutor of Lindley, possessed similar powers, and used similar strings as regards size. Their system of stringing was adopted indiscriminately. Instruments weakly or strongly built received uniform treatment, the result being in many cases an entire collapse and the most disappointing effects in the tone. It was vainly supposed that the ponderous strings of Dragonetti and Lindley were the talisman by use of which their tone would follow as a matter of course, whereas in point of fact it was scarcely possible to make the instruments utter a sound when deprived of the singular muscular power possessed by those famous players. After Lindley's death his system passed away gradually, and attention was directed to the better adaptation of strings to the instrument, and also to the production of perfect fifths.

We have now only to speak of covered strings, in which it is more difficult to obtain perfection than in the case of those of gut. There are several kinds of covered strings. There are 
those of silver wire, which are very durable, and have a soft quality of sound very suitable to old instruments, and are, therefore, much used by artists; there are those of copper plated, and also of copper without plating, which have a powerful sound; and, lastly, there are those which are made with mixed wire, an arrangement which prevents in a measure the tendency to rise in pitch, a disadvantage common to covered strings and caused by expansion in consequence of the counteraction of the metals; these strings also possess a tone which is a combination of that produced by silver and copper strings. Here again, however, great discrimination is needed, viz., before putting on the fourth string. The instrument must be understood. There are Violins which will take none but fourths of copper, there are others that will be simply crippled by their adoption. It cannot be too much impressed upon the mind of the player that the Violin requires deep and patient study with regard to every point connected with its regulation. So varied are these instruments in construction and constitution, that before their powers can be successfully developed they must be humored, and treated as the child of a skilful educator, who watches to gain an insight into the character of his charge, and then adopts the best means for its advancement according to the circumstances ascertained. 


\section{SECTION IV.}

The Italian School.

$77 \mathrm{HE}$ fifteenth century may be considered as the period - 6 when the art of making instruments of the Viol class took root in Italy - a period rich in men laboring in the cause of Art. The long list of honored names connected with Art in Italy duing the fifteenth, sixteenth, and seventeenth centuries is a mighty roll-call indeed! The memory dwells upon the number of richly-stored ninds that have, within the limits of these three centuries, bequeathed their art treasures to all time; and if here we cannot suppress a comparison of the art world of the present Italy with that of the periods named, still less can we fail to be astonished as we discover the abyss in point of merit into which Italy must be judged to have sunk, when measured by the high standard which in former days she set herself. But perhaps the greatest marvel of all is the rapidity of this decadence when it once set in, as it did immediately after the culminating point of artistic fame had been reached.

To inquire into the many causes of the decline of Art in Italy would be wholly foreign to the purpose of a book on Violins, however capable the writer might he of handling such a subject. Such a capability the writer of these pages entirely disclains ; but it cannot be doubted that such an inquiry is rich in interest, and worthy of skilful treatment.

To reflect for a moment upon the many famous men in Italy engaged in artistic vocations contemporaneously with the great Violin makers cannot fail to be interesting to the lovers of our instrument, for it has the effect of surrounding their favorite with an interest extending beyond its own path. Hence a brief mention of a few luminaries in the art world of the periods named may not be unacceptable to the reader.

If we turn to the days of Gaspard di Salo, Morelli, Magini, and the Amatis, we find that while they were sending forth their fiddles, Raphael Léonardo da Vinci, Titian, and Tintoretto were busily painting their immortal works. Whilst the master-minds of Antonius Stradiuarius and Joseph Guarnerius were occupied with those instruments which have caused their names to be known throughout the civilized world (aye, and $u n$ civilized too, for many thousands of Violins are yearly made into which their cherished names are thrust, after which they are despatched for the negro's use), Canaletto was paint- 
ing lis Venetian squares and canals, Giorgio was superintending the manufacture of his inimitable majolica ware, Venetians whose names are unrecorded, blowing glass of wondrous form and beauty. At the same time, in the musical world, Corelli was writing his gigues and sarabandes, Geminiani penning, probably, the first instruction book for the Violin, Tartini dreaming his "Sonata del Diavolo;" and while Guadagnini and the stars of lesser magnitude were exercising their calling, Viotti, the originator of a school of Violin playing, was writing his concertos, and Boccherini laying the foundation of classical chamber-music of a light and pleasing character. It would be easy to continue this vein of thought, were it not likely to become irksome to the reader; enough has been said to refresh the memory as to the flourishing state of Italian art during these times. What a mine of wealth was then opened up for succeeding generations! and how curious is the fact that not only the Violin, but its music, has been the creature of the most luxurious age of art, for in that golden age musicians contemporary with the great Violin makers were writing music destined to be better understood and appreciated when the Violins then made should have reached their maturity.

That Italy's greatest Violin makers lived in times favorable to the production of works possessing a high dagree of merit cannot be doubted. They were surrounded by composers of rare powers, and also by numerous orchestras. These orchestras, composed mainly of stringed instruments, were scattered over Italy, Germany, and France, in churches, convents, and palaces, and must necessarily have created a great demand for bow instruments of a high class.*

The bare mention of a few of the names of composers then existing will be sufficient to bring to the mind of the reader well versed in musical matters the compositions to which they owe their fame. In the sixteenth century, Palestrina, Guami, and Zarlino were engaged in writing church music, in which stringed instruments took their share; in the seventeenth, lived Stradella, Lotti, Bononcini, Lully, and Corelli. In the eighteenth century, the period when the art of Violin making was at its zenith, the list is indeed a glorious one. At this point we reach the constellation of Scarlatti, Geminiani, Vivaldi, Locatelli, Boccherini, Tartini, Piccini, Viotti, Nardini among the Italians; while in France it is the epoch of Lecler and Gaviniès, composers of Violin music of the highest excellence. Surrounded by these men of rare genius, who lived but to disseminate a taste for the king of instruments, the nuakers of Violins must certainly have enjoyed considerable patronage, and doubtless the artists of tried ability readily obtained highly

* Montagne, whose travels brought him to Verona in 1580 , has recorded that there were Violins as well as Urgans there to accompany the mass in the great church. 
remunerative prices for their instruments, and were encouraged in their march towards perfection both in design and workmanship. Besides the many writers for the Violin, and executants, there were numbers of ardent patrons of the Cremonese and Brescian makers. Among these may be mentioned the Duke of Ferrara, Cardinal Ottoboni, with whom Corelli was in high favor, also the Elector of Bavaria and Charles IX., all of whom gave encouragement to the art by ordering complete sets of stringed instruments for their chapels and for other purposes. By the aid of such valuable patronage the makers were enabled to center their attention on their work, and received reward commensurate with the amount of skill displayed. This had the effect of raising them above the status of the ordinary workman, and permitted them as a body to pass their lives amid comparative plenty. There are, without doubt, instances of great results obtained under trying circumstances, but the genius required to combine a successful battle with adversity with high proficiency in art is indeed a rare phenomenon. Carlyle says of such minds: "In a word, they willed one thing, to which all other things were subordinated and made subservient, and therefore they accomplished it. The wedge will rend rocks, but its edge must be sliarp and single; if it be double the wedge is bruised in pieces, and will rend nothing." It may, therefore, be affirmed that the greatest luminaries of the art world have shone most brightly under circumstances in keeping with their peaceful labors, it not being essential to success that men highly gifted for a particular art should have this strength of will unless there were immediate call for its exercise. We need not go far afield for instances to prove the beneficial effects upon art generally of prosperous circumstances as compared with times of hardship. Well-known cases may be cited in relation to this subject, and notably that of Joseph Guarnerius del Jesù. How marked the disturbance of mind portrayed in the Violins of Joseph Guarnerius which were made during the time that he forfeited his liberty for a political offence! The hand of the great master is stamped upon them, adversity had no solvent which could efface it, yet the connoisseur readily detects absence of finish and other shortcomings in these instruments, all of which are satisfactorily accounted for when the circumstances under which the Violins were made are considered. It is observable that all the specimens made at this period have the same characteristics of the pressure of hard times. On the other hand, how finely wrought are the instruments of a different date, how uniform as regards finish! The curves are executed with a delicacy truly beautiful; the corners are studied as one, not as four. It seems, therefore, impossible to reconcile such marked variations unless we consider the homelier and rougher specimens of Guarnerius as the results of a disturbed mind. Unfortunately, we have no means or procuring 
biographical knowledge of him, or of the other makers. Were it possible to obtain this, how many curious differences of execution noticeable in many of the productions might be accounted for! Gaspard di Salo, the Amatis, and Stradiuarius were makers who seem to have worked with a singular uniformity and evenness of purpose which has left is mark on their works, so much so indeed as to make it exceedingly difficult to discover an instance where this is not manifested. They certainly made instruments upon which exceptional efforts to finish are to be traced but, at the same time, if their labours be regarded as a whole, workmanlike care can never be said to be absent.

Judging from the large number of bow-instrument makers in Italy, more particularly during the seventeenth century, we should conclude that the Italians must have been considered as far in advance of the makers of other nations, and that they monopo!ised, in consequence, the chief part of the manufacture. The city of Cremona became the seat of the trade, and the centre whence, as the manufacture developed itself, other less famous places maintained their industry. In this way there arose ultimately several distinct schools of a character marked and thoroughly Italian, but not attaining the high standard reached by the parent city. Notwithstanding the inferiority of the makers of Naples, Florence, and other homes of the art as compared with the Cremonese, they seem to have received a fair amount of patronage, the number of instruments manufactured in these places of lesser fame being considerable.

To enable the reader to understand more readily the various types of Italian Violins, they may be classed as the outcome of five distinct schools. The first is that of Brescia, dating from about 1520 to 1620 , and embracing the following makers: Gaspard di Salo, Magini, Mariani, Venturini, Budiani, Măteo Bente. and $a$ few others of less note. The next, and most important school, was that of Cremona, dating from 1550 to 1760 , or even later, and including the following makers: Andrea Amati, Jerome Amati, Antony Amati, Nicholas Amati, Jerome Amati son of Nicholas, Andrea Guarnerius, Peter Guarnerius, Joseph Guarnerius the neplew of Andrea, Joseph Guarnerius the son of Andrea, Antonius Stradiuarius, and Carlo Bergonzi. Several well-known makers have been omitted in the foregoing list simply because they were followers of those mentioned, and therefore cannot be credited with originality of design. The makers of Milan and Naples may be braced together as one school, under the name of Neapolitan, dating from 1680 to I800. This school contains makers of good repute, viz., the members of the Grancino family, Carlo Antonio.Testore, Paul. Testore, the Gagliano family, and Ferdinand Landolphi. The makers of Florence, Bologna, and Rome may likewise be classed together in a school that dates from 1680 to 1760 , and 



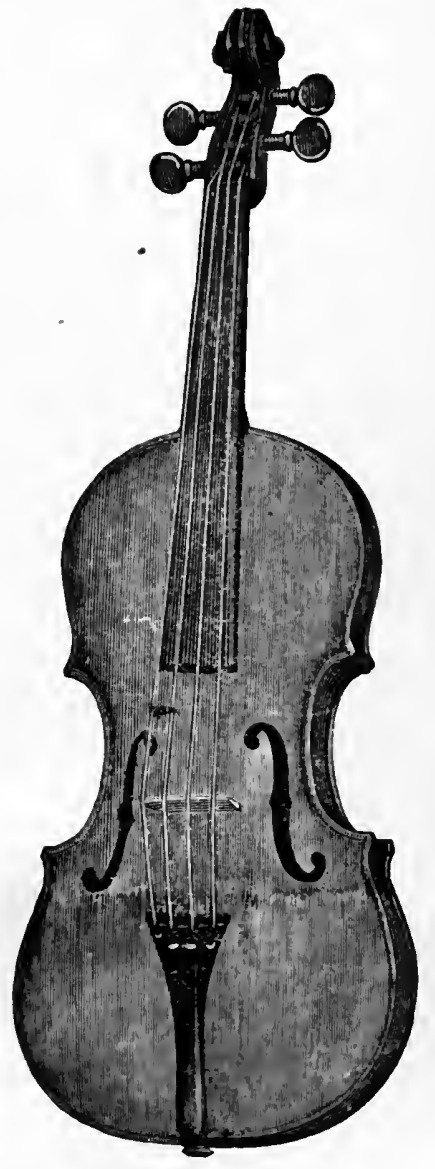

Gastard di Salo. 
includes the following names: Gabrielli, Anselmo, Florentus, Techler, and Tononi. The Venetian school, dating from 1690 to 1764 , has two very prominent members in Domenicus Mon1tagnana and Sanctus Seraphino: but the former maker may, not inappropriately, be numbered with those of Cremona, for he passed his early years in that city, and imbibed all the characteristics belonging to its chief makers.

Upon glancing at this imposing list of makers it is easy to understand that it must have been a lucrative trade which in those days gave support to so many; and, further, that Italy, as compared with Germany, France, or England at that period, must have possessed, at least, more makers by two-thirds than either of those three countries. And this goes far to prove, moreover, that the Italian makers received extensive foreign patronage, their number being far in excess of that required to supply their own country's wants in the manufacture of Violins.

Brescia was the cradle of Italian Violin-making, for the few makers of bowed instruments (among whom were Gaspard Duiffoprugcar, who established himself at Bologna, Dardelli of Mantua, Linarolli and Maller of Venice) cannot be counted among Violin makers with any degree of certainty. The only maker, therefore, of the Violin of the earliest date, it remains to be said, was Gaspard di Salo, to whom belongs the credit of raising the manufacture of bowed instruments from a rude state to an art. There is a certain similarity between the early works of Gaspard di Salo and those of Gaspard Duiffoprugcar, but the link that connects these two makers is very slight, and in the absence of further information respecting the latter as an actual maker of Violins the credit of authorship must certainly belong to Gaspard di Salo.

We are indebted to Brescia for the many grand Doublebasses and Violas that were made there by Gaspard di Salo and Magini. These instruments formed the stepping-stones to Violin-making, for it is evident that they were in use long before the first era of the Violin. The Brescian Violins have not the appearance of antiquity that is noticeable in the Double-basses or Violas, and for one Brescian Violin there are ten Double-basses, a fact which goes far to prove that the latter was the principal instrument at that time. The bowed instruments then in use appear to have been the following: the Viola, which was used under the chin, the Viola da Braccio, a much larger instrument, which was played resting on the knee. the Viola da Gamba, used between the legs, and the Violono. There were both large and small Violonos. The stringing of all these instruments was different to that now in use, and they have been in most cases transformed to suit modern requirements, the large Violas having been reduced, the Viol da Gambas either made into Violas or strung as Violoncellos; there have been also other changes. The Violin would, therefore, seem 
to have appeared during the latter part of the life of Gaspard di Salo.

From Brescia came the masters who established the school of Cremona. The Amatis took the lead, their founder being Andrew Amati, after whom each one of the clan appears to have gained a march on his predecessor until the grand masters of their art, Antonius Stradiuarius and Joseph Guarnerius del Jesù advanced far beyond the reach of their fellow makers or followers. The pupils of the Amatis, Stradiuarius, and Guarnerius settled in Milan, Florence, and other cities previously mentioned as centres of Violin making, and thus formed the distinct character or school belonging to each city. A close study of the various schools shows that there is much in common among them. A visible individuality is found throughout the works of the Italian makers; it is not to be met with in anything approaching the same degree in the similar productions of other nations. Among the Italians each artiste appears to have at first implicitly obeyed the teachings of his master, afterwards, as his knowledge increased, striking out a path for himself. To such important acts of self-reliance may be traced the absolute perfection to which the Italians at last attained. Not content with the production of instruments capable of producing the best tone, they strove to give them the highest finish, and were rewarded, possibly, beyond their expectation. The individuality noticed as belonging in a high degree to Italian work is, in many instances, very remarkable. How characteristic the scroll and sound-hole of each several maker; Master and pupil differ here in about the same degree as the handwriting of father and son, and often more. Although Stradiuarius was a pupil of Nicholas Amati, yet how marked is the difference between the scrolls and sound-holes of these two makers; Carlo Bergonzi worked with Stradiuarius, yet the productions of these two are still more easily known apart. A similarly well-defined originality is found in a more or less degree to pervade the entire series of Italian Violins, and forms a feature of much interest to the connoisseur. 


\section{SECTION $V$. \\ The Italian Varnish.}

A

WORI or two must be said upon the famous varnish of the Italians, which has hitherto baffled all attempts to solve the mystery of its formation. Every instrument belonging to the school of Cremona has it, more or less, in all its marvellous beauty, and to these instruments the resolute investigator turns and turns, promising himself the discovery of its constituent parts. The more its lustre penetrates his soul the more determined becomes his efforts. As y et, however, all such praiseworthy researches have been futile, and the composition of the Cremonese varnish remains a secret lost to the world-as much so as the glorious ruby lustre of Giorgio and the blue so coveted by connoisseurs of china. Mr. Charles Reade truly says, "No wonder, then, that many Violin makers have tried hard to discover the secret of this varnish : many chemists have given anxious days and nights to it. More than once, even in my time, hopes have run high, but only to fall again. Some have even cried 'Eureka' to the public; but the moment others looked at their discovery and compared it with the real thing,

\footnotetext{
'Inextinguishable laughter shook the skies.'
}

At last despair has succeeded to all that energetic study, and the varnish of Cremona is sullenly given up as a lost art."

Declining, therefore, all speculation as to what the varnish is or what it is not, or any nostrums for its re-discovery, we will pass on at once to the description of the different Italian varnishes, which may be divided into four distinct classes, viz., the Brescian, Cremonese, Neapolitan, and Venetian. These varnishes are quite separable in one particular, which is, the depth of their colouring; and yet three of them, the Brescian, Cremonese, and Venetian, have, to all appearance, a common basis. This agreement may be accounted for with some show of reason by the supposition that there must have been a depôt in each city where the varnish was sold in an incomplete form, and that the depth of colour used, or even the means adopted for colouring rested with the maker of the instrument. If we examine the Brescian varnish we find an almost complete resemblance between the material of Gaspard di Salo and that of his coadjutors, the colouring only being different. Upon turning to the Cremonese, we find that Joseph Guarnerius, Stradiuarius, Carlo Bergonzi and a few others used varnish 
having the same characteristics, but, again, different in shade; possibly the method of laying it upon the instrument was peculiar to each maker. Similar facts are observable in the Venetian specinens. The varnish of Naples, again, is of a totally different composition, and as it was chiefly in vogue after the Cremonese was lost, we may conclude that it was probably produced by the Neapolitan makers for their own need.

If we reflect for a moment upon the extensive use which these makers made of the Cremonese varnish, it is reasonable to suppose that it was an ordinary commodity in their days, and that there was then no secret in the matter at all. To account for its sudden disappearance and total loss, is, indeed, not easy. After 1760 , or even at an earlier date, all trace of it is obliterated. The demand for it was certainly not so great as it had been, but quite sufficient to prevent the supply from dying out, had it been possible. The problem of its sudden disappearance may, perhaps, be accounted for without overstepping the bounds of possibility if we suppose that the varnish was composed of a particular gum quite common in those days, extensively used for other purposes besides the varnishing of Violins, and thereby caused to be a marketable article. Suddenly, we will suppose, the demand for its supply ceased, and the commercial world troubled no further about the matter. The natural consequence would be non-production. It is well known that there are numerous instances of commodities once in frequent supply and use, but now entirely obsolete and extinct.

While, however, our attention has been mainly directed to the basis of the celebrated varnish, it must not be supposed that its colouring is of no importance. In this particular each maker had the opportunity of displaying his skill and judgment, and probably it was here, if anywhere, that the secret rested. The gist of the matter, then, is simply that the varnish was common to all, but the colouring and mode of application belonged solely to the maker, and hence the varied and independent appearance of each separate instrument. With regard, however, to the general question as to what the exact composition of the gum was or was not, we shall hazard no further speculation, and are profoundly conscious of the fact that our present guesses have gained no nearer approaches to the re-discovery of the buried treasure.

A description, however, of the various Italian varnishes may not be inappropriate. The Brescian is mostly of a rich brown color and soft texture, but not so clear as the Cremonese. The Cremonese is of various shades, the early instruments of the school being chiefly amber-coloured, afterwards deepening into a light red of charming appearance, later still into a rich brown of the Brescian type, though more transparent, and frequently broken up, while the earlier kinds are velvet like. The Venetian is also of various shades, chiefly light red, and 
exceedingly transparent. The Neapolitan varnish (a generic term including that of Milan and a few other places) is very clear, and chiefly yellow in color, but wanting the dainty softness of the Cremonese. It is quite impossible to give such a description of these varnishes as will enable the reader at once to recognise them; the eye must undergo considerable exercise before it can discriminate the various qualities ; practice, however, makes it so sharp that from a piece of varnishing the size of a shilling it will obtain evidence sufficient to decide upon the rank of the Violin.

And here, before we dismiss the subject of the varnish, another interesting question occurs, What is its effect, apart from any appearance as a cosmetique, upon the efficiency of the instrument? The idea that the varnish of a Violin has some influence upon its tone has often been ridiculed, and we can quite understand that it must appear absurd to those who have not viewed the question in all its bearings. Much misconception has arisen from either pushing this theory about the varnish too far or not far enough. What seems sometimes to be implied by enthusiasts is, that the form of the instrument is of little importance provided the varnish is good, which amounts to saying that a common Violin may be made good by means of varnishing it. The absurdity of such a doctrine is self-evident. On the other hand, there are rival authorities who attach no importance to varnish in relation to tone. That the varnish does influence the tone there is strong proof, and to make this plain to the reader should not be difficult. The finest varnishes are those of oil, and they require the utmost skill and patience in their use. They dry very slowly, and may be described as of a soft and yielding nature. The common varnish is known as spirit varnish; it is easily used and dries rapidly, in consideration of which qualities it is generally adopted in these days of high pressure. It may be described as precisely the reverse of the oil varnish; it is hard and unyielding. Now a Violin varnished with fine oil varnish, like all good things, takes time to mature, and will not bear forcing in any way. At first the instrument is somewhat muffled, as the pores of the wood have become impregnated with oil. This makes the instrument heavy both in weight and sound; but as time rolls on the oil dries, leaving the wood mellowed and wrapped in an elastic covering which yields to the tone of the instrument and imparts to it much of its own softness. We will now turn to spirit varnish. When this is used a diametrically opposite effect is produced. The Violin is, as it were, wrapped in glass through which the sound passes, imbued with the characteristics of the varnish. The result is, that the resonance produced is metallic \& and piercing, and well-calculated for common purposes ; if, however, richness of tone be required, spirit-varnished instruments cannot supply it. From these remarks the reader may. 
gather some notion of the vexed question of varnish in relation to tone, and be left to form his own opinion.

The chief features of the Italian School of Violin makers having been noticed, it only remains to be said that the following list of these artistes is necessarily incomplete. This defect arises chiefly from old forgeries. Labels used as the trade marks of many deserving makers have from time to time been removed from their lawful instruments in order that others bearing a higher marketable value might be substituted. In the subjoined list will be found all the great names, and every care has been taken to render it as complete as possible. 


\section{SECTION VI.}

ItAlian Makers.

7 CEVO, Cremona, about 1640.-School of Amati. Pupil of Giuseppe Cappa. His workmanship is rough, and the material which he used ill-selected.

Albanesi, Sebastianus, Cremona, I 720-I 744.-The instruments of this maker are now rarely met with. They were well made. The pattern is bold and the model flat, and constructed on principles which should render them of good tone. Although made at Cremona, they do not properly belong to the school of that place, but have the characteristics of the Milanese workmanship. Their varnish is quite unlike that of the Cremonese.

Albani, Mathias Botzen, I 7 th century. (See German makers.)

Albani, Paolo, Palermo, I650- I680, made many excellent instruments. He was one of the pupils of Nicholas Amati. The pattern is broad, and the workmanship carefully executed.

Aletzie, Paolo (Monaco, I720-1736). His principal instruments are Violas and Violoncellos, many of which are excellent. The former are mostly of large size. Varnish wanting in mellowness.

Alvani, Cremona. Imitator of Joseph Guarnerius, whom he copied with considerable skill.

Amati, Andrew, Cremona. The date of his birth is unknown, but is supposed to have occurred about I520. This maker claims attention not so much on account of his instruments as from the fact of his having founded the school of Cremona. There is but little known of the early history of Andrew Amati. It is said that he was descended from an ancient family of Cremona, dating back to the eleventh century. There is no direct evidence as to the name of the master from whom he learnt the art of making stringed instruments. If his work be carefully examined, it will appear that the only maker to whose style it can be said to hear any resemblance is Gaspard di Salo, and it is possible that the great Brescian may have instructed him in his art. It is unfortunate that there are no data for our guidance in the matter. These men, like their brothers in art, the painters of olden times, began to live when they were dead, and their history thus passed without record. Andrew Amati may possibly have been self-taught, but there is much in favour of the view given above on this point. His early works are so Brescian in character as to cause them to be 
numbered with the productions of that school. For a general designation of the instruments of this maker the following notes may suffice. The work is carefully executed. The model is high, and, in consequence, lacks power of tone ; but the Violins possess a charming sweetness. The sound-hole is inelegant, has not the decision of Gaspard di Salo, although belonging to his style, and is usually broad. The instruments of Andrew Amati are of various sizes, but the majority of them are small, and thus admirably fitted for the use of young violinists. His varnish may be described as deep golden, of good quality. His method of cutting his material was not uniform, but he seems to have had a preference for cutting his backs in slab form, according to the example set for the most part by the Brescian makers. The sides were also made in a similar manner, the wood used being both sycamore and that known to makers as pear-tree. The instruments of Andrew Amati are now very scarce. Among the famous instruments of this maker were twenty-four Violins (twelve large and twelve small pattern), six Tenors, and eight Basses made for Charles IX., which were kept in the Chapel Royal, Versailles, until October, 1790, when they disappeared. These were probably the finest instruments by Andreas Amati. On the backs were painted the arms of France and other devices, with the motto, "Pietate et Justitia." He died about I 580 .

AMATI, Nicholas, Cremona, brother of Andrew. Very little is known of this maker's instruments. The few met with are inferior to those of Andrew.

Amati, Antonius and Hieronymus, sons of Andrew Amati, Cremona, 1570-1635. Anthony was born in 1550. The date of Jerome's birth is unknown. These skilful makers worked together for many years, and pro-

Antonius et Hieronymus Fr Amati

Cremonen Andrea fil F 1590

form of the instrument known as "Amatese." The early efforts of the brothers Amati have many of the characteristics belonging to the work of their father, Andrew; their sound-hole is similar to his, and in keeping with the Brescian form, and the model which they at first adopted is higher than that of their later and better instruments.

Although these makers placed their joint names in their Violins, it must not be supposed that each bore a propurtionate part of the manufacture in every case ; on the contrary, there are but few instances where such association is made manifest. The style of each was quite distinct, and one was immeasurably superior to the other. Antonius deviated but little from the teaching of his father. The sound-holes even of his latest instruments partake of the Brescian type, and the model is the only particular in which it may be said that a step in advance is 
traceable; here he wisely adopted a flatter form. His work throughout, as regards finish, is excellent.

Jerome Amati possessed in a high degree the attributes of an artist. He was richly endowed with that rare poweroriginality. It is in his instruments that we discover the form of sound-hole which Nicholas Amati improved, and after him, the inimitable Stradiuarius perfected. Jerome Amati ignored the pointed sound-hole and width in the middle portions observable in his predecessor's Violins, and designed a model of extremely elegant proportions. How graceful is the turn of the sound-hole at both the upper and lower sections! With what nicety and daintiness are the outer lines made to point to the shapely curve! Nicholas Amati certainly improved even upon Jerome's achievements, but he did not add more grace: and the essential difference between the instruments of the two is, that there is more vigour in the sound-hole of Nicholas than in that of his father Jerome.

The purfling of the brothers Amati is very beautifully executed. The scrolls differ very much, and in the earlier instruments of these makers are of a type anterior to that of the bodies. Further, the varnish on the earlier specimens is deeper in colour than that found on the later ones, which have varnish of a beautiful orange tint, sparingly laid on, and throwing up the markings of the wood with much distinctness. The material used by these makers and the mode of cutting it also varies considerably. In some specimens we find that they used backs of slab-form ; in others, backs worked whole ; in others, backs divided into two segments. The belly-wood is in every case of the finest description. The tone is far more powerful than that of Andrew's instruments, and this increase of volume of sound is obtained without any sacrifice of the richness of the quality. Antony Amati died, it is supposed, in 1635 , and Jerome in 1638 .

Amat, Nicholas, Cremona. Born September 3rd, 1596, died August I2th, I684. Son of Jerome Amati. It is gratifying in the notice of this famous Violin maker to. be able at Nicholas Amatus Cremónen Hieronymi Fil. ac Antonij Nepos Fecit. I6 once to identify the dates both of his birth and death. Nicholas Amati was the greatest maker in his illustrious family, and the finest of his instruments are second only to those of his great pupil, Antonius Stradiuarius. His early efforts have all the marks of genius upon them, and clearly show that he had imbibed much of the taste of his father Jerome. He continued for some time to follow the traditional pattern of the instruments bearing the labels of Antonius and Hieronymus Amati, and produced many Violins of small size, of which a large number are still extant. He appears to have laboured assidnously during these early years, with a view of making himself thoroughly acquainted with every portion of his art. We find 
several instances in which he has changed the chief principles in construction, particularly such as relate to the arching and thicknesses, and thereby shown the intention which he had from the first of framing a new model entirely according to the dictates of his own fancy. The experienced eye may trace the successive steps taken in this direction by carefully examining the instruments dating from about 1625 downwards. Prior to I625 there is a peculiarly striking similarity in his work and model to that of his father, but after this date we can watch the gradual change of form and outline which culminated in the production of those exquisite works of the art of Violin making known as "grand Amatis" (a name which designates the grand proportions of the instruments of this later date). It may be said that the maker gained his great reputation from these famous productions. They may be described as having an outline of extreme elegance, in the details of which the most artistic treatment is visible. The corners are drawn out to points of singular fineness, and this gives them an appearance of prominence which serves to throw beauty into the entire work. The model is raised somewhat towards the centre, dipping rather suddenly from the feet of the bridge towards the outer edge, and forming a slight groove where the purfling is reached, but not the exaggerated scoop which is commonly seen in the instruments of the many copyists. This portion of the design has formed the subject of considerable discussion among the learned in the Violin world, the debateable points being the appearance of this peculiarity, and its acoustic effect. As regards the former question, the writer of these pages feels convinced that the apparent irregularity is in perfect harmony with the general outline of the great Amati's instrument, and that it pleases the eye. From the acoustical point of view, it may be conceded that it does not tend to increase of power, as the sound is caused to lodge as it were; but, on the other hand, it is probable that the sweetness of tone so common to the instruments of Nicholas Amati must be set to its credit ; for, in proportion as the form is departed from, the sweetness is found to decrease. The sound-hole has all the character of the preceding Amatis, together with increased boldness; in fact, it is a repetition of that of Jerome, with the exception of this difference. The sides are a shade deeper than that of the brothers Amati. The scroll is exquisitely cut. Its outline is perhaps a trifle contracted, and thus is robbed of the vigour which it would otherwise possess. From this circumstance it differs from the general tenour of the body, which is certainly of broad conception. The maker would seem to have been a ware of this defect, if we may judge from the difference of form given-to his earlier scrolls, as compared with those of a later date, in which he seems to have attempted to secure increased boldness, as more in keeping with the work of the body of the instrument. It 
must be acknowledged, however, that these efforts did not carry him far enough in this direction. The wood used by Nicholas Amati for his grand instruments is of splendid quality as regards acoustical requirements ; while, as regards appearance also, it is unexceptionable. Sone of his backs have a wave-like form of great beauty, others have markings of great regularity, giving to the instrument a highly finished appearance. The tellies are of a soft, silken nature, and usually of even grain. A few of them are of singular beauty, their grain being of a mottled character, which, within its transparent coat of varnish, flashes light here and there with strange force.

These, then, are the instruments which are so highly esteemed, and which form one of the chief links in the Violin family. The highest praise must be conceded to the originator of a design which combines extreme elegance with utility; and, simple as the result may appear, the successful construction of so graceful a whole must have been attended with rare ingenuity and most persevering labour.

Here, again, is evidence of the master mind, never resting, ever at work; evidence, too, that mere elaboration of work was not the ne plus ullra of the Cremonese makers. They designed and created as they worked; and their success, which no succeeding age has aspired to rival, entitles them to rank with the chief artists of the world.

On the form of the instrument known as the "grand Amati,"Antonius Stradiuarius exerted all the power of early years ; and the fruits of his labours are, in point of finish, unsurpassed by even his later works. Where Nicholas Amati failed, Stradiuarius conquered; and particularly is this victory to be seen in the scrolls of his instruments during the first period, which are masterpieces in themselves. How bold is the conception, how delicate the workmanship, what a marvel of perfection the sound-hole! But as these Violins are noticed under the head of "Stradiuarius," it is unnecessary to enter into details here. Besides Stradiuarius, many makers of less importance followed the "grand Amati " pattern, among whom may be mentioned Jacobs, of Amsterdam, who takes a prominent place as a copyist. The truthfulness of these copies, as regards the chief portions of the instrument, is singularly striking, so much so, indeed, as to cause them to be frequently mistaken for the original by those who are not deeply versed in the matter. The points of failure in these imitations may be cited as the scroll and sound-hole. The former lacks ease, and seems to defy its author to hide his nationality. 'The scroll has ever proved the most troublesome portion of the Violin to the imitator. It is here, if anywhere, that he must drop the mask and show his individuality, and this is remarkably the case in the instance above-mentioned. A further difference between Amati and Jacobs lies in the circumstance that the latter invari- 
ably used a purfling of whalebone. Another copyist of Amati was Grancino. As the varnish which he used was of a different nature from that of his original, his power of imitation must be considered to be inferior to that of some others. Numerous German makers, whose names will be found under the "German School," were also liege subjects of Amati, and copied him with much exactness; so also, last, but not least, our own countrymen, Forster, Banks, and Samuel Gilkes.

Amat1, Hieronymus, Cremona, 1650 to 1673. Son of Nicholas. His instruments are scarce, and do not resemble those of Nicholas, or, indeed, of the Amati family, except in the sound-hole. The head is quite distinct from the Amati type, being larger, and wanting in grace. The length of these instruments is generally lessened in the lower portion. The varnish is inferior, and shows unmistakeable signs of decadence. With this maker closes the great family of Amatis as Violin makers, dating from 1520 to about 1673 .

Ambrogi, Pietro, Rome, I730. Average merit. Somewhat resembles Balestrieri. The head leans to the German character.

ANselmo, Cremona, I701. The instruments of this maker partake of the Rugerius type. The varnish is very rich in colour and possesses considerable body. Scarce. There are two very excellent Violoncellos by Anselmo in England.

Assalone, Gaspard, Rome. The model is high and the workmanship rough; the varnish yellow, without much body.

BAGATElla, Padua, I8th century. Made both Violins and Violoncellos, a few of which have points of merit. He wrote a pamphlet on a method of constructing Violins by means of a graduated perpendicular line similar to Wettengels; but no benefit has been derived from it.

Balestrieri, Peter, Cremona. Scarce.

BALESTRIERI, Thomas, middle of the I8th century. Said to have been a pupil of Stradiuarius, which is probable. The instruments of Balestrieri may be Thomas Balestrieri Cremonensis

Fecit Mantuæ. Anmo 17 likened to those of Stradiuarius which were made during the last few years of his life, 1730- I 737 . The form of both is similar, and the ruggedness observable in the latter instruments is found, but in a more marked degree, in those of Balestrieri. These remarks, however, must not be considered to suggest that comparison can firly be made between these two makers in point of merit, but merely to point out a general rough resemblance in the character of their works. The absence of finish in the instruments of Thomas Balestrieri is in a measure compensated by the presence of a style full of vigour. The wood which he used varies very much. A few Violins are handsome but the majority are decidedly plain. The bellies were evidently selected with judgment, and have the necessary qualities for the production of good tone. The 
varnish seems to have been of two kinds, one resembling that of Guadagnini, the other, softer and rich in colour. The tone may be described as large and very telling, and when the instrument has had much use there is a richness not by any means common. It is singular that these instruments are more valued in Italy than they are either in England or France. They are, however, fast rising in the estimation of competent judges in the last-mentioned countries, not so much from an artistic point of view as from their peculiarly telling qualities.

Thomas Balestrieri made mostly Violins and Tenors; the latter of excellent proportions, and highly valued by artistes.

Bellos10, Venice, 18th century. Similar to Sanctus Seraphino in pattern, but the workmanship very inferior.

Bente, Matteo, Brescia, latter portion of the 16 th century. Style of Gaspard di Salo.

Bergonz1, Carlo, Cremona, I7 IS-I755. Pupil of Antonius Stradiuarius. That he was educated in Violin making by the greatest master of his art is evidenced Anno 17 Carlo Bergonzi. fece in Cremona. beyond doubt. In his instruments may be clearly traced the teachings of Stradiuarius. The model, the thicknesses, and the scroll, together with the general treatment, all agree in betokening that master's influence. Joseph Guarnerius del Jesù here stands in strong contrast with Bergonzi. All writers on the subject of Violins assume that Guarnerius was instructed by Stradiuarius, a statement based upon no reasons (for none have ever been adduced), and apparently a mere repetition of some one's first guess or error. As before remarked, Carlo Bergonzi, in his work, and in the way in witich he carries out his ideas, satisfactorily shows the source whence his early instructions were derived, and may be said to have inscribed the name of his great master, not in print, but in the entire body of every instrument which he made. This cannot be said of Joseph Guarnerius. On the contrary, there is not a point throughout his work that can be said to bear any resemblance to the sign manual of Stradiuarius. As this interesting subject is considered at length in the notice of Joseph Guarnerius, it is unnecessary to make further comment in this place.

The instruments of Carlo Bergonzi are justly celebrated for both beauty of form and tone, and are rapidly gaining the appreciation of artistes and amateurs. Commercially, no instruments have risen more rapidly than those of this maker; their value has increased within the past twenty years fourfold, more particularly in England, where their merits were earliest acknowledged, a fact which certainly reflects much credit upon our connoisseurs. In France they had a good character years ago, and have been gaining rapidly upon their old reputation, and now our neighbours regard them with as much favour as we do. 
They possess tones of rare quality, are for the most part extremely handsome, and, last and most important of all, their massive construction has helped them by fair usage and age to become instruments of the first order. The model of Bergonzi's Violins is flat, and the outline of his early efforts is of the Stradiuarius type; but later in life, he, in common with other great Italian makers, marked out a pattern for himself from which to construct. The essential difference between these two forms lies in the angularity of the latter. It would be very difficult to describe accurately the several points of deviation unless the reader could handle the specimens for himself and have ocular demonstration; the upper portion from the curve of the centre bouts is increased, and, in consequence, the sound-holes are placed slightly lower than in the Stradiuarian type. Bergonzi was peculiar in this arrangement, and he seldom deviated from it. Again, increased breadth is given to the lower portion of the instrument, and in consequence the centre bouts are set at a greater angle than is customary. The soundhole may be described as an adaptation of the characteristics of both Stradiuarius and Guarnerius, inclining certainly more to those of the former. As a further peculiarity, it is to be noticed that the sound-holes are set nearer the edge than is the case in the instruments of either of the makers nanied. Taken as a whole, Bergonzi's design is rich in artistic feeling, and one which he succeeded in treating with the utmost skill.

Carlo Bergonzi furnishes us with another example of the extensive research with which the great Cremonese makers pursued their art, and a refutation of the common assertion that these men worked and formed by accident rather than by judgment. The differences of the two makers mentioned above as regards form are certainly too wide to be explained away as a matter of mere accident. It is further necessary to take into consideration the kind of tone belonging to these instruments respectively. If Bergonzi's instruments be compared with those of his master, Stradiuarius, or of Guarnerius del Jesù, the appreciable difference to be found will amount to this, that in Bergonzi's instruments there is a just and exact combination of the qualities of both the other two makers named. Is it not, therefore, reasonable to conclude that Carlo Bergonzi was fully alive to the merits of both Stradiuarius and Guarnerius, and deliberately set himself to construct a model that should embrace in a measure the chief characteristics of both of them?

The scroll is deserving of particular attention. It is quite in keeping with the body of the instrument, and has been cut with a decision of purpose that could only have been possessed by a master. It is flatter than usual, if we trace it from the cheek towards the turn, and is strikingly bold. Here, again, is the portrait of the character of the maker. Although by a pupil of 
Antonius Stradiuarius, the scroll is thoroughly distinct from any known production of that maker-it lacks the fine finish and exact proportion; but, on the other hand, it has an originality about it which is quite refreshing. The prominent feature is the ear of the scroll, which being made to stand forth in bold relief gives it a broad appearance when looked at from the front.

The work of Bergonzi, as has been the case with many of his class, has been attributed to others. Many of his instruments are dubbed "Joseph Guarnerius" by the inexperienced; a mistake in identification which arises chiefly from the form of the sound-hole at the upper and lower portions. There is little else that can be considered as bearing any resemblance whatever to the work of Guarnerius, and even in this case the resemblance is very slight. Bergonzi's outline is totally different from that of Guarnerius, and is so distinct and telling that it is sure to impress the eye of the experienced when first seen.

The varnish of Bergonzi is often fully as resplendent as that of Joseph Guarnerius or Stradiuarius, and shows him to have been initiated in the mysteries of its manufacture. It is sometimes seen to be extremely thick, at other times but sparingly laid on; often of a deep, rich red colour, sometimes of a pale red, and again, of rich amber, so that the variation of colour to be met with in Bergonzi's Violins is considerable. We must concede that his method of varnishing was scarcely so pains. taking as that of his fellow-workers, if we judge from the clots here and there, particularly on the deep-coloured instruments ; but, nevertheless, now that age has toned down the varnish, the effect is good. It is interesting to know that Carlo Bergonzi succeeded to the house and connection of his master, Stradiuarius, upon the death of the latter's two sons, Homobono and Franciscus Stradiuarius, and that the family of Bergonzi resided in the now famous house to within a very recent date.

Bergonzi, Nicholas, Cremona. Son of Carlo; succeeded him in his business. He made a great number of Violins of similar form to those of his father. The wood which he selected was of a close nature and hard appearance. The varnish is not equal to that of Carlo; it is thin and cold-looking. The workmanship is very good, being often highly-finished; but yet, what is wanting is character. The scroll is cramped, and scarcely of the Cremonese type. His thicknesses vary.

BERgonzi, Michael Angelo, Cremona, I720-1760. Brother

Michel Angelo Bergonzi Figlio di Carlo fece in Cremona l'Anno 17 of Nicholas. The pattern is large, and partakes of the character of Stradiuarius' instruments.

Bergonzi, Cremona, died in 1838 . Said to have been the son of Michael Angelo, from whom Tarisio learned little points of interest concerning Stradiuarius and his contemporaries.

BORELl, Andreas, Parma, I73.5. His instruments are little known; they resemble those of Giuseppe Guadagnini. 
Budiani, Javietta, Brescia, 16th century. Numbers of the instruments of this maker have betn attributed to Magini, from their double purfling and similarity of construction. It is a common practice to call all double-purfled instruments "Magini," and all those purfled with whalebone "Jacobs."

Camilas, Camile de, Mantua, 17 I4.

CAPPA, Giofreda, Cremona, 1590-1640. Pupil of Antonius and Jerome Amati. Cappa worked during his early years at Cremona. After gaining some TOFREDVS CAPPA FECIT celebrity as a maker, he removed to Piedmont, possibly, that he might have greater scope for the exercise of his talents, it being, no doubt, difficult for him to obtain any important patronage, surrounded as he was at Cremona by so many famous men engaged in the same occupation as himself.

The instruments of Cappa are, even now, little known in England, and twenty years since were recognized only by the most intelligent connoisseurs. The greater number of them consist of works of high merit, and, although not prized at present, must ultimately command prices proportionate to their real value. Their likeness to the instruments of the Amatis is in some instances peculiarly striking, but in others there is a marked dissimilarity. Particularly this is the case in the form of the sound-hole and scroll. The sound-hole is sometimes large, and quite out of keeping with the elegant outline of Amati. The points of difference may be summed up as follows :the sound-hole is larger, and more obliquely set in the instrument; the upper portion of the body has a more contracted appearance; the head, as is the case with most makers, differs most, and, in this instance in no way resembles Amati.

There are few specimens of Cappa that bear their original labels, most of them are counterfeit "Amatis," and hence the great confusion which has arisen, particularly among the halfinformed, concerning their parentage. They are of two patterns, one larger than the other. The large one is, of course, the nore valuable; it is flatter, and altogether better finished. The Violoncellos of Cappa are among the best of the secondclass Italian instruments, and are well worthy the attention of the professor and amateur. The varnish is frequently of very rich quality, its colour resembling that of Amati. The wood is also sinilar to that used by Amati. The backs are whole or in two parts, seldom cut on the cross.

Cassino, Antonius, Modena.

CAstro, Venice, 1680-1720. The wood is of good figure generally. Outline is not good; the middle bouts are too long to be proportionate. Sound-hole roughly worked. Varnish red, the quality of which is scarcely up to the Venetian standard. 
Celionatus, Johannes, Taurini, 1734. Amati school. Yellow varnish. Good workmanship.

Cherutti, Cremona, now living. This maker is deserving of notice, forming, as he does, the last link of the long chain of Cremonese makers. He has made several instruments, some of which were exhibited at the International Exhibition, 1862, and which are of the Amati pattern.

Christophori, Bartolomeo, Florence, 1760.

CirCAPA, Thomaso, Naples, 1730. Resembles Gagliano.

ConTrERas, Joseph, Madrid, 1745. This being one of the few Spanish makers, his name is placed with the Italian, the number of the Spanish being 111sufficient for a separate list. The model of this maker is very good, and the workmanship superior. $\mathrm{He}$ probably lived in Italy during his early life, the style being Italian.

Costa, Pietro della, Treviso, 1660-1700. Scarce.

DARDElli, Pietro, Mantua, I500. Maker of Viols, a few of which are to be found in the cabinets of the curious.

Dominicelli, Ferrara, isth century.

DUifFoPRUGCAR, Gaspard, Bologna. This maker settled in Bologna during the early part of the i6th century. Very little is known of him. He has been put forth as the first maker of the Violin ; but the writer of these pages quite agrees with $\mathrm{Mr}$. Charles Reade that Duiffoprugcar, together with Kerlino and Dardelli, were makers of Viols, not of Violins. In one of the excellent articles contributed by Mr. Reade in 1872 to the Pall Mall Gazetle, he remarks: "The first known maker of the true Tenor, and prubably of the Violin, was Gasparo da Salo. The student who has read the valuable work put forth by Monsieur Fètis and Monsieur Vuillaume might imagine that I am contradicting them here, for they quote as 'luthiers' antecedent to Gasparo da Salo, Kerlino, Duiffoprugcar, Linarolli, Dardelli, and others. These men, I grant you, worked long before Gasparo da Salo; I even offer you an independent proof, and a very simple one-I find that their genuine tickets are in Gothic letters, whereas those of Gasparo da Salo are in Roman type. But I know the works of those makers, and they did not make Tenors nor Violins. They made instruments of of the older family, Viole d'Amore, da Gamba, \&c. Their true tickets are all black-letter tickets, and not one such ticket exists in any old Violin nor in a single Tenor." The case is stated in Mr. Reade's peculiarly clear and decisive manner, and he has left no loophole for his antagonist's escape. Any instrument of a mongrel kind, having a carved head and uncouth workmanship, and in size something between a Tenor and a Violin, has been, as a matter of course, fathered upon these old Viol makers. From an artistic point of view, it is of no consequence to ascertain who made these old fossils, their merits being of the slenderest kind ; it is only historically that any interest can attach to them. 
Eberti, Tomasso, 1750.

FAlCo, Cremona, 1752. Average merit.

Farinato, Paul, Venice, I695-i725.

Ficker, Johann Christian, Cremona, middle of the 18 th century. Although dating from Cremona, has nothing in common with Cremonese work.

FIORILlo, Giovanni, Ferrara, 1780. The style is a mixture of German and Italian, the furmer preponderating. The soundhole in imitation of Stainer. His Violoncellos are among his best instruments.

Florentus, Florinus, Bologna, 1685.

GABRIELLI, Giovanni, Baptista, Florence, about the middle of the I8th century. The instruments of Gabrielli are now Johannes Baptista di Gabrielli

Florentinus Fecit 17 becoming better known and appreciated. They bear evident marks of having been made with extreme care. The model, unfortunately, is often not all that conld be desired, being too rounded. When this is not the case, the tone is excellent. The flat instruments of this maker partake of the tone of Gagliano. The wood is mostly very handsome, and the sides and backs evenly marked. The varnish is wanting in mellowness, but is very transparent, its colour usually being yellow. The Tenors and Violoncellos are superior to the Violins. The scroll is neatly cut, but weak in design.

Gaetano, Pasto, Brescia, I700. Good work. Model a little high. Varnish of soft quality.

Gaetano, Antoniazzo, Cremona, I760. The work is very passable, but the form is entirely at fault. The sound-holes are not in their proper position.

Gagliano, Alessandre, Naples, 1695-1730. Pupil of Antonius Stradiuarius. The family of the Gagliano played no

Alexandro Gagliano Alumnus

Stradivarius fecit Neapoli anno 1725 unimportant part in the art of Italian Violin making. It commences with Alessandro, who imitated his master as regards the form which he gave to his instruments. Alessandro Gagliano upon leaving the workshop of Stradiuarius removed to Naples, a city which afforded him greater scope for the exercise of his talents than Cremona. With others, he felt that his chance of success was very small if he remained on ground occupied by the greatest luminaries of his art. His labours at Naples seem to have been so well rewarded that he caused his sons to follow his calling. There is evidence of their having enjoyed what may be terned a monopoly of the Violin manufacture in and around Naples, there being no record of another maker of importance in that locality at the same period. To the Gagliani we are indebted for the Neapolitan .school. Although in its productions we miss the lustrous varnish and 
handsome wood of Cremona, Naples has furnished us with numbers of instruments of great use.

The works of Alessandro Gagliano are mostly of large pattern and flat model. If we compare them with those of his master, the resemblance is not so great as might be expected if it be remembered that they are copies, and not original works. The sound-holes are broader and more perpendicular than those of Stradiuarius. The scroll is diminutive, and the turn much contracted, and of a somewhat mean appearance. The workmanship of this item is roughly executed, and points to the conclusion that Alessandro Gagliano was not gifted with the power of head cutting. The character of Gagliano's Violins reminds us of those by Stradiuarius made between 1725 and I 730 ; and doubtless it was those instruments which this artist chiefly copied.

The wood used for the backs was generally of a tough nature; the back and sides are often marked with a broad curl. The bellies are of wide and even grain, and very resonant. The varnish is quite distinct from that of Cremona ; it is very transparent, and of various shades, chiefly yellow.

Gagliano, Nicholas, Naples. Son of Alessandro. His Violins and Violoncellos were made with great care, and show that he possessed some amount of originality. They were not after the pattern of his father's instruments. They are narrower than these, and similar to those earlier works of Stradiuarius which come between the true "Amatese" and the long form. The varnish is of a deeper colour than that of Alessandro's, and its quality is not inferior. The scroll is well formed, and is, therefore, superior to that of his father's. The model is a little high.

Gagliano, Ferdinandus, Naples, 1700 to 1735 . Brother of

Ferdinandus Gagliano Filius

Nicolai fecit Neap. 1762 . Nicholas. His work is similar to that of Alessandro. The Violoncellos are excellent instruments.

Gagliano, Januarius, Naples, about i 740 .

Gagliano, Ferdinandus, Naples. Son of Nicholas.

Gagliano, Giuseppe, Naples, 1780. Son of Ferdinandus. Gagliano, Giovanni, )

Gagliano, Antonio, $\}$ Naples. These makers bring the GaGliano, Raphael,

family down to a very recent date as residents in Naples. The merit of belonging to them is of the slightest kind. Many of our English provincial makers have shown themselves superior. The family of the Gagliani, as Violin makers, was the most numerous that the world has seen. The families of fiddle makers share the fate of nations. The days of greatness are followed by those of decline.

Galerzena, Piedmont. Little is known of this maker.

GARANI, Michael Angelo, Bologna, 1700-1720. Has made a few Violas of good quality. 
Garant, Nicolo, Naples. Gagliano type.

Gattanani, Piedmont, 1785. No particular value.

Giordane.

GobetrI, Franciscus (sometimes called Gobit), Venice, $1690-1715$. This is one of the little known makers, a fact which may be attributed to the practice Franciscus Gobetti common some years ago of removing the Fecit Venetiis 1705 original label of an instrument and substitutits familiarity to command attention. ing another bearing a name more likely from

When we see Violins bearing the stamp of genius upon them, and reflecting much credit on the maker, the lovers of the instrument cannot but regret that the author should have been eclipsed, and deprived of his just praise.

Had the name of Gobit been permitted to associate itself with the instruments into which it was originally placed, they would have been as highly valued as any belonging to the Venetian school, with the single exception of Domenicus Montagnana. The admirers of that finished maker, Sanctus Seraphino, may perhaps dispute the justice of this observation, but, having carefully weighed the merits of both Sanctus Seraphino and Gobit, I have no hesitation in awarding to the latter the foremost place. Gobit's style is superior, being more Cremonese than Venetian; and further, his model is preferable.

Gobit has been considered to have been a pupil of Antonius Stradiuarius, possibly with some reason, for his instruments bear a similarity to the early works of the great master. The instruments of this maker, like those of many others of his class, have passed for the works of Rugerius, and sometimes of Amati. There is a slight likeness about the sound-hole to the work of Franciscus Rugerius; but to the skilled in such matters, no feature interchangeable with Amati can be detected.

The workmanship has a uniformly neat execution; the scroll is the least successful part, being weak in character as compared with the body. The varnish is equal to any belonging to the Venetian school, and its beauty is second only to that of Cremona ; its colour is generally a pale red, of considerable transparency. The wood is most handsome. These Venetians were not a little happy in selecting beautiful wood; in fact, it is scarcely possible to discover a single Venetian instrument the wood of which is plain. The tone of Gobit's works is round, without great power; but the quality is singularly sweet. Ere long these instruments will command more attention.

Gofriller, Matteo, Venice, I700. Although this maker worked in one of the principal schools, there is but little of the Italian character in his instruments. The varnish is of the poorest kind. 



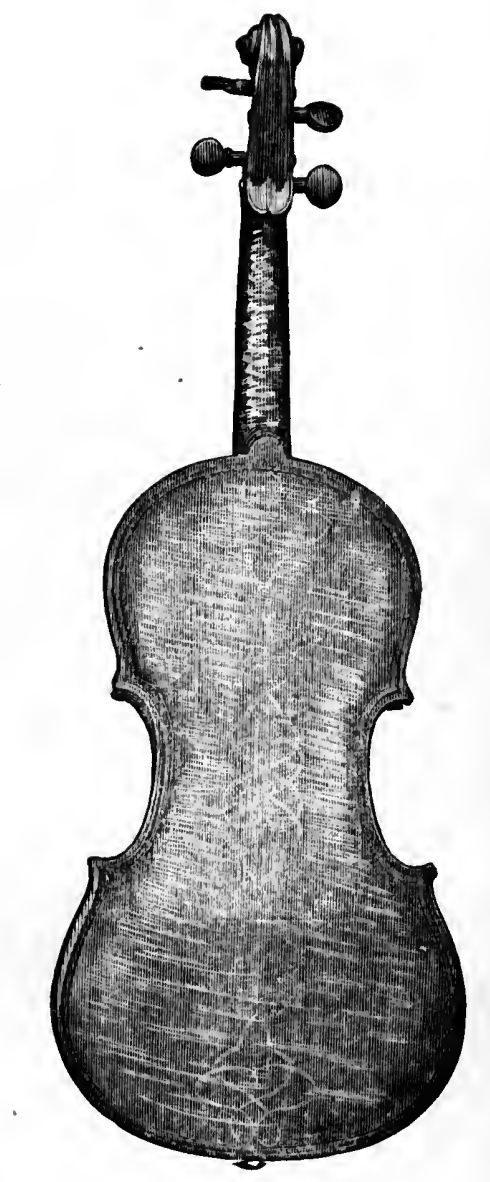

Glovanin Paolo Maggini Violin. . 
Gofriller, Francisco, Venice. Same period as the above-named, and of similar character.

GraGnani, Antonius, Liburni, I7So.

Antonius Gragnani, fecit

Liburni, Anno r78o.

Grancino, Paolo, Milan, 1665-1692. Pupil of Nicholas Amati. The Grancini family, as makers of Violins, commence with this maker, and occupy a similar position, as followers of the Amati pattern, to that of the Gaglianos as imitators of Stradiuarius. Paul Grancino was one of the favourite pupils of Nicholas Amati, and evidently strove to profit by the instructions he received. There is noticeable in his instruments that gradual development of ideas which is always associated with the true artiste. His early works bear the stamp of the mere copyist ; later on the borrowed plumes are less apparent, the dictates of his own fancy are discoverable, but never to such an extent as to permit him to be classed with Stradiuarius, Bergonzi, and Guarnerius, as striking out into entirely untrodden paths.

His Violoncellos are particularly fine instruments; his Violas also are worthy of notice. The wood he used was varied, but is, for the most part, plain. It is curious to observe how various centres of Violin making ran upon different qualities of wood. In Venice the handsomest wood was used, in Milan and Naples the plainest. 'The commercial importance of Venice would, of course, draw to it the largest selection of wood, and thus permit the second and third rate makers to use it, and at the same rate, probably, that a less handsome material would cost the makers of cities further off. The scroll of Paul Grancino has a very decisive character; it is quite distinct from that of the Amatis. From the ear of the scroll the turn is rapidly made, and has an elongated appearance. His best Violoncellos surpass those of Amati in volume of tone, and the quality is often equally rich.

Grancino, Giovanni, Milan, 1694-1720. Son of Paolo. The workmanship is smooth and

Giouanni Grancino in Contrada

Largha di Milano al segno della Corona 16 the form good. The material of his instruments is of a better nature than that used by his father. The model is slightly flatter. The tone is powerful. Varnish mostly yellow.

Grancino, Giovanni Baptista, Milan, 169o. Brother of Giovanni mentioned above. Similar characteristics.

Grancino, Francisco. Son of Giovanni Baptista. Here we have the same falling off as in the case of the Gaglianos, a family beginning with artistes and ending with common workmen.

Guadagnini, Lorenzo, Cremona, 1695-1735. The name of Guadagnini carries with it considerable weight, and their 
Lorenzo Guadagnini

Cremonce Alumnus Stradiuarius

Fecit Anno Domini 17

instruments are rapidly increasing in value. No matter to which of the Guadagnini the instrument may owe its origin; if it bears the name of these makers importance is attached to it, often without due regard to the merits of the particular specimen. The later members of the family have thus received attention measured by the excellence of the works of their forefathers. That this should be so to a certain extent can scarcely excite surprise, nor is it singular in the Italian branch of the art. The great makers of the Guadagnini family were Lorenzo and Johannes Baptista. The former has been considered the chief maker, but if the merits of each be duly weighed, they will be found to be nearly equal. It is probable that I.orenzo has been looked apon as the principal maker, from the association of his name with that of Stradiuarius, a fact which, it must be granted, lends to his name a degree of importance.

The instruments of Lorenzo are exceedingly bold in design, and differ in this respect from those of Johannes Baptista, which retain much of the delicate form of Stradiuarius. Lorenzo frequently changed the style of his sound-hole, giving it the pointed character of Joseph Guarnerius in some instances, and sometimes retaining the type of sound-hole perfected by his master. The model is inclined to flatness, the declivity being of the gentlest kind: the breadth of the design commands admiration. The scroll is certainly not an imitation of that of Stradiuarius; it has considerable originality, and is more attractive on that account than for its beauty. The varnish is not so brilliant as that of Johannes Baptista, but possesses a mellowness foreign to the other members of the family. The tone is powerful, tempered with a rich quality. The works of this maker are rare, and eagerly sought for in England.

Guadagninı, Johamnes Baptista, Placentia, 1710-1750. His relationship to Lorenzo has never been stated, but it is

Johannes Baptista Guadagnini Placentinus fecit Mediolani 1755. probable that they were brothers. Lorenzo has always been regarded as the only pupil of Stradiuarius in the Guadagnini family; but if their respective works be closely examined, it will be found that those of Johannes Baptista more closely resemble the instruments of Stradiuarius than even those of Lorenzo, and one is thus led to the conclusion that Johames Baptista was also a pupil of Stradiuarius. It is quite evident that he considered the model of Stradiuarius as that to be followed, and he does not appear to have changed his views on this point at any time, all his works being in accordance with the teachings of the great master.

Johannes Baptista was particularly happy in the selection 
of his wood, it being invariably of the handsomest nature. The backs of his instruments are generally found to be divided, the markings of the wood being very regular; the bellies are of wood well chosen for tone, the varnish very transparent, and of a brilliant colour. The scroll may be described to be a rough imitation of that of Stradiuarius, and to partake generally of the character of the Stradiuarian scroll from the date of 1728 . The English possess some of the finest specimens of this maker, and were probably the first to recognise their sterling merits.

GuAdagnini, Milan, I740-I770.

Guddagnini, Giovanni Battista, Piacenza, 1754-I785. The instruments of this maker are frequently equal to those of Johannes Baptista. His wood is also excellent.

Guadagnini, Giuseppe, Parma, 1760-isoo. Brother of G. B. Guadagnini. Very good wood; model a trifle more raised than in the instruments of his brother; sound-hole well cut, in imitation of Stradiuarius.

GUadAGN1Ni, Turin, 1768.

Guarnerius, Andreas, Cremona, 1630-1695. The name of Guarnerius is probably known to every possessor of a Violin throughout the world. The famiAndreas Guarnerius Cremona sub- liar style is attached to scores of titulo Sanctæ Teresiæ 16 copies and non-copies every week and despatched to every quarter of the globe. Little did Andrea imagine that he was destined to be the means of lifting his patronymic of Guarnerius to such a giddy height!

Andreas Guarnerius, like Andrew Anati, was the pioneer of the family, and but for his influence we might never have had the extraordinary works of his nephew, Joseph. How full of interest would the smallest events of Andrea's workshop life prove if we could only ascertain them! We know as a fact that in early years Andreas Guarnerius was working at the side of Stradiuarius in the shop of his master, Nicholas Amati. With what delight would any record, or even anecdote, of those golden days in the history of the Violin be received by the lovers of the instrument. The bare idea that these three men, unapproachable in their art, were living in daily close converse is sufficient to awaken interest of a lively nature in the mind of the lover of fiddles. Unhappily, however, no chronicler was at hand to dot down events, of small value when passing, but of great consequence to after time.

Andreas Guarnerius for some years worked upon the model of his master, though he afterwards changed the character of the sound-hole. At the same time the form of the instrument became flatter, and the scroll showed signs of originality. The varnish is much varied, but is generally of a light orange colour of beautiful hue; it sometimes has a considerable body, but when so, lacks the transparency of light- 
coloured varnishes. The Violoncellos are of two sizes, a common arrangement of the Cremonese makers. The wood in the Violoncellos is mostlv very plain, but possesses singular tone-producing qualities. The Violins are of average size, and are among the finest efforts of this maker. The Violins are chiefly of the same size as those of Nicholas Amati. The workmanship is excellent, but has not the fine finish of Amati.

GUarnerius, Joseph, son of Andrea, 1680-1730. This maker possessed a greater amount of originality than Andrea.

Joseph Guarnerius filius Andreæ fecit

Cremonæ sub titulo S. Teresiæ 16

His earliest works evidence that power of thinking for himself which, later, led him to construct instruments entirely distinct from those of his father. The outline is particularly striking. The waist of the instrument is narrowed, rapidly widening, however, from the centre. The result is a curve of much elegance, one of the points which Joseph Guarnerius del Jesù appears to have admired, as he adopted and perfected it. It is here, more particularly, that a resemblance between this maker and his famous kinsmen is to be traced. There are also further strong parallelisms, which will furnish matter for comment in their proper place. To return to the form given to the instruments of Guarnerius, the son of Andrea : the sound-hole has a singular combination of the Amati and the Guarnerius in its conception. We have here a reappearance of the pointed form which originated with the grand old Brescian master, Gaspard di Salo, and was left by him to be revived and perfected by his followers. Andrea's son, in adopting this long-neglected form, showed much judgment. It must be admitted that he improved upon it, and left his cousin, Guarnerius del Jesì, an easy task in completing and perfecting it.

The method of this maker with regard to the setting of tl:e sound-holes in his instruments is peculiar. In his plan it is set in a lower position than is customary. Carlo Bergonzi followed him in this particular, and also in placing the hole a trifle nearer the edge of the instrument than in the general run of instruments. How interesting is it to observe the salient points wherein each maker seems to have adoped some isolated feature from a predecessor!

The varnish is of the richest description, and in numerous instances has been so plentifully used as to cause it to clot in some places ; nevertheless, its rare qualities are never deadened.

The instruments of this truly great maker are being rapidly bought up in all parts of Europe, and their value is, in consequence, much enhanced. He made Violins, Violas, and Violoncellos, the latter being very scarce. The wood used in his Violins and Violas varies, but may be pronounced as generally handsome; that of his Violoncellos, is on the contrary, chiefly 
plain, and the workmanship somewhat careless, but the tone is always fine in quality. It would seem that he had no particular liking to work the larger instruments, and he devoted his time to the smaller specimens, which are, however, patterns of careful handiwork.

The Earl of Harrington possesses a fine specimen of his Violas, from the Gillott collection. Mr. John T. Carrodus, the eminent violinist, formerly used a very fine specimen of his Violins.

Guarnerius, Petrus, Cremona and Mantua, I690-1728. Brother of Joseph Guarnerius. In this maker, again, there is Petrus Guarnerius Cremonensis fecit Mantuæ sub-tit. Sanctæ Teresiæ 16 much originality, his work, together with his model, differing entirely from that of his brother, and in outline from that of his father, Andrea. There is increased breadth between the sound-holes; the sound-hole is rounder and more perpendicular; the middle bouts are more contracted, and the model is more raised. The scroll abounds in individuality of design. The ear is brought out with much effect ; the purfling is splendidly executed, the corners being worked up to that extreme point of delicacy which marks a summit in the works of Nicholas Amati. The purfling is embedded after the manner of Nicholas Amati in his "grand" instruments, but to a greater extent. The varnish is superb. Its quality is of the richest description, and its transparency unsurpassed. Its colour varies; it is sometimes of a golden tint, sometimes of a pale red, on which the light plays with delightful variety.

Petrus Guarnerius used some of the finest wood. The bellies are invariably wide in grain and very even.

Guarnerius, Petrus, Mantua, 1725. Son of Joseph Filius Andrea. He followed to some extent the form of the instruments of his uncle Petrus, from whom, while in Mantua, he probably learnt his art. The work is very good, and his productions are well worthy of the Guarnerian name. The varnish is rich, but not so transparent or so well laid on as to come up to the full standard. The scroll is rather weak.

Guarnerius, Joseph Anthony, better known as Giuseppe del Jesù, his labels having the cypher I ${ }_{\mathrm{H}}^{+}$upon them. It is

Joseph Guarnerius fecit

Cremone Anno 17

I $\stackrel{\text { H S }}{\mathbf{H}}$ not known why he adopted this monogram, but it is possible that he belonged to a religious order in Cremona, common at that period among Italian tradesmen, who banded thcmselves together in various societies bearing religious titles.

This famous maker of Violins was born at Cremona in the year 1683, and died in I745. To M. Vuillaume, of Paris, we are indebted for the identification of the date of his birth, which he succeeded in obtaining in the year 1855 . 
The extract from the register proves that Joseph Anthony Guarnerius, legitimate son of Jolın Baptist Guarnerius and Angela Maria Locadella, was born at Cremona on the 8th of June, $168_{3}$, and was baptized on the 11 th of the same month, in the parish of Saint Donato, at the Chapel of Ease of the Cathedral.

The original of this extract is as follows:-

"'Guarneri (Giuseppe Antonio) figlio de' legittimi conjugi Giovanni Battista Guarueri ed Angela l.ocadella nacrue nella parocchia di San Donato aggregala alla Cattedrale il giorno 8 Giugno 1683 e battezato il giorno 11 del detto mere.' Libro di nali dall 1669 al 1692 G. dalla Catedrale di Cremona, 1 i 19 Setlembri 1855. Signe, Fusetti Giuli Vic ${ }^{\circ}$ "-Fétis' notice of Anthony Stradiuarius.

The father of Guarnerius del Jesù does not appear to have had any knowledge of the manufacture of stringed instruments, and was thus an exception to the majority of a family which numbered many prominent makers within it. It has been asserted on all sides that Joseph Guarnerius del Jesù was a pupil of Antonius Stradiuarius, but in every case this statement has been made without a shadow of proof, either from recorded fact or analogy. That this bare assertion should have so long remained unchallenged is a matter of some surprise to the writer of these pages, who fails to see anything in common between the two makers, with the exception of the varnish, and perhaps the high finish, as apparent in the works of the second epoch of Guarnerius. The following remarks on this point are the result of the most careful consideration of the subject, and may serve to assist the reader in forming an opinion.

Had Joseph Guarnerius received his early instructions from Stradiuarius, should we not expect his instruments to bear the character of the master in some slight degree? The most diligent student will, however, fail to discover an early work of Guarnerius bearing any likeness whatever to the work of Stradiuarius. Among the instruments of the second epoch may be found a few that show some gleam of the desired similarity in respect to high finish; but it would be to the earliest efforts of Guarnerius that we should turn in our endeavour to discover the source of his first instructions. The faint gleam of similarity, then, attaching to the instruments of the second epoch, be it understood, is in no way sufficient to demonstrate that Guarnerius was a pupil of Stradiuarius. Upon turning to other makers, what will be the result if we judge them by the criterion above mentioned? Bergonzi, Guadagnini, Gagliano, and others, whose names it is unnecessary to mention, leave upon their earliest efforts the indelible stamp of the master who first instructed them. To suppose that Guarnerius del Jesù 
formed the single exception to the likeness between the work of master and pupil is scarcely sufficient to satisfy the enquirer.

There are three essential points of difference between Guarnerius and Stradiuarius. The first is the outline of the work, which, as the mere tyro must at once observe, is totally different in their respective instruments. The second is the sound-hole, in which, again, the two do not approach one another; that of Guarnerius is long, and a modified form of that of Gaspard di Salo. The third is the scroll, in which Guarmerius is as distinct from Stradiuarius as it is possible to be.

It may be asked, then, if not from Stradiuarius, from whom did Guarnerius receive instruction? To disagree with what is popularly accepted, and yet to withhold one's own countertheory may, perhaps, tend to weaken one's case. There can be but one method to be pursued if, in the absence of any historical data, we set about the investigation of the question, viz., that of analogy. Starting upon this ground, the first step to be taken is to endeavour to discover the maker whose work and style bear some degree of similarity to those of Joseph del Jesù. If we carefully review the works of the Cremonese makers, it will be found that Guarnerius, son of Andrea, and cousin of Guarnerius del Jesù, is the only maker, above all others, in whose productions we can find the strong similarity needed. Analogy, therefore, would point to him as the instructor of his cousin. Guarnerius, son of Andrea, was del Jesù's senior by many years, and it is far more reasonable to conclude that it was in his workshop that del Jesù was first instructed, than that he was the pupil of a maker whose work he never copied, and whom he never in any way resembled. Enough has been said on this question to enable the reader to judge for himself, and this may the more readily be conceded when it is also admitted that, after all, it is of little importance to determine where the early training of this kingly maker was passed, as he so soon displayed that rare originality which separated hin from his brethren forever.

We will now inquire into the character of Guarnerius del Jesù's model. In forming this, he seems to have turned to Gaspard di Salo as the maker whose path be wished to traverse, and if each point be critically considered, an impression is left that, after well weighing the merits and demerits of Gaspard, he resolved to commence where Gaspard ceased, and carry out the plan left incomplete by the great Brescian maker. To commence with that all-important element, the sound-hole, it will be seen that Guarnerius del Jesù retained its pointed form. Next comes the outline of the body, where, again, there is much affinity to the type of Gaspard di Salo, particularly in the middle bouts. Lastly, the quality of wood selected for the bellies is in both makers similar. In continuing the path trodden by Gaspard, Guarnerius proved himself an artist 
possessed of no little discernment. His chief desire was evidently to make instruments capable of producing a quality of tone hitherto unknown, and that he succeeded is universally acknowledged. Workmanship, as evidenced by the instruments of his first and last epoch, was with him purely a secondary consideration. In the second epoch, his work shows him to have been not unmindful of it. That he brought much judgment to bear upon his work, the vast number of instruments that he has left, and the great variety of their construction, is sufficient to prove. The extent of his researches is surprising, and there is no ground for the assertion frequently made that he worked without plan or reason. The idea that such an artist as Guarnerius groped in the dark savours of the ridiculous; moreover, there is direct evidence, on the contrary, of his marvellous fertility of design. At one period his instruments are extremely flat, without any perceptible rise; at another, the form is raised in a marked manner, and the purfling sunk into a groove; a parallel of this type of instrument is to be found in the works of Peter Guarnerius and Montagnana. At one time his sound-holes were cut nearly perpendicular (a freak which, by the way, has some show of reason, for though it sacrifices beauty, it also prevents the breaking up of the fibres), at another, shortened and slanting, and again are sometimes seen immoderately long. These hastily-marshalled instances are quite sufficient to show the extent of his experiments and the many resources which he adopted in order to produce exceptional qualities of tone.

In order that the reader may better understand the subject, before going further in noting the peculiar features belonging to the instruments of Guarnerius, we will classify his work. M. Fétis, doubtless under the guidance of M. Vuillaume, has divided the career of Guarnerius into three periods-an excellent arrangement, and one that cannot be improved upon. It only remains to point out certain peculiarities omitted in the description of these three stages which M. Fétis gives us. In the first epoch we find instruments of various patterns, the character of the sound-hole being very changeable. At one time there is a strange mixture of grace and boldness; at another, the whole is singularly deformed, and the purfling roughly executed, as though the maker luad no time to finish his work properly. It seems as if he had hastily finished off a set of Violins that he had already tested, eager to lay the stocks for another fresh venture. The second epoch has given us some or the finest specimens of the ait of Violin making. In these there culminates the most exquisite finish, a thoroughly artistic and original form, and the must handsome material. In some cases the lustre of the wood of the backs, set in its chasing of deep amber, that unrivalled varnish, may be likened to the effect produced by the setting summer sun on cloud and 
wave. The reader may pardon a somewhat novel application of the loveliest description of the glow of evening to be found in the compass of the English language, which paints the heavens' colours as-

\author{
"Melted to one vast iris of the west, \\ Where the day joins the past eternity. \\ All its hues, \\ From the rich sunset to the rising star, \\ Their magical variety diffuse. \\ And now they change; a paler shadow strews \\ Its mantle o'er the mountains; parting day \\ Dies like the dolphin, whom each pang imbues \\ With a new colour as it gasps away, \\ The last still loveliest, till-'tis gone,-and all is grey." \\ Brron-Childe Harold, Canto iv. 27-29. Venice.
}

The effect of this beautiful coruscation upon the backs of Violins is obtained by cutting the wood upon the cross, or, as the French term it, sur maille. The most perfect and the handsomest Guarnerius in existence, that in the possession of $R$. D. Hawley, Esq., Hartford, U. S., has the appearance here described. It is also seen, though rarely, on backs divided, when the wood is particularly handsome in curl. The varnish on such instruments is of a rich golden hue, highly transparent ; it is lightly laid on. The size of these works varies; they are sometimes a trifle smaller than the other specimens of Guarnerius. In the last epoch we find Violins of an altogether bolder conception, dating from about 1740 and a little later. They are massively constructed, and have in them material of the finest acoustic properties. The sound-hole loses the pointed form so much associated with Guarnerius; the purfling is embedded. the edges heavy, the corners somewhat grotesque, the scroll has a mixture of vigour, comicality, and majesty, which may force a smile and then a frown from the connoisseur. The comparison may seem a little forced, but the head of a thoroughbred English mastiff, if carved, might give some idea of the appearance sought to be described. Mr. Reade says of these instruments, with much truth, "Such is the force of genius, that I believe in our secret hearts we love these impudent fiddles best, they are so full of chic." "Among the Violins of this period may be mentioned Paganini's and M. Alard's, both rare specimens.

These splendid chef d'auvres are strangely mixed with those commonly known as the "prison fiddles"-a sorry title. The name arose from the story current in Italy that Guarnerius made some fiadles whilst undergoing imprisonment for some political offence-that the gaoler's daughter procured him the necessary materials and implements, which were of the coarsest kind. There is no reason to doubt this story, which the rough character of the work confirms.

These, then, were the three periods of this remarkable 
man's life, and I have now only to point out some other features in his work and material. His selection of wood, when he had the opportunity of exercising his own judgment, was all that could be desired, and the belly wood, in particular, was of the choicest description. He seems to have obtained a piece of pine, of considerable size possessing extraordinary acoustic properties, from which he made nearly the whole of his bellies. The bellies made from this particular wood have a singular stain running parallel with the finger-board on either side, and unmistakable, though frequently scen but faintly. If we may judge from the constant use he made of this material, it would seem that he regarded it as a mine of wealth. The care he bestowed, when working it, that none should be lost, and his constant insertion of it in the place of what had been damaged, afford clear evidence of the value that he set upon this precious piece of wood. I have met with three Violins by Carlo Bergonzi, having bellies evidently cut from the same piece of pine, and these instruments passed as the works of Guarnerius for a long period. The sycamore that he used was varied both in appearance and quality; it is chiefly of a broad description of grain, the whole backs being impressively marked like a tiger's skin. There are a few instances where, in his jointed backs, the markings of the wood are turned upwards.

Upon examining the works of Guarnerius with respect to their thicknesses, it is found that he varied very much as to the quantity of wood left in the several instruments. Notwithstanding these differences, however, it will be found, upon closer comparison of the thicknesses, that there is every reason to be sure that he had a guiding principle in their management. They vary with the quality of the wood; and hard material was treated as needing a slighter solidity than the wood of soft nature.

His workmanship in numerous instances, is, without doubt, careless; but even in the instruments where this negligence is most observed, there is an appearance which at once excites the admiration of the beholder, and forces from the most exacting the admission that, after every deduction on account of want of finish, there remains a style defying all imitation. Who can fail to recognize the quaint head, into which he seems to have thrown such singular character by the mere turn of his chisel, and which, when imitated, always partakes of the ludicrous, and betrays the unhappy copyist who is unable to compass that necessary turn! In matters of the highest art it is always so ; the possessor of genius is constantly showing some last resort, as it were, impregnable to imitation; which resolves itself into this fact-where the master-strokes begin and end, Art begins and ends too.

The sound-hole, again, of Guarnerius always preserves its distinctive character, and a grotesque humour which at once 
pleases the eye, though it is found to vary considerably with the three periods of his life. Again, the button-that portion of the back against which the head of the neck rests, which forms a prominent mark in all Violins, and evidence of style, has a remarkably pronounced development in the Violins of Guarnerius, and, in fact, may be said to give a vitality to the whole work. There are many instances where excellent and original specimens of workmanship have been, speaking artistically, ruined for want of skill in handling that simple factor of the Violin, the button.

Having endeavoured to point out the chief features in the work and style of this remarkable maker, I have only to add that his imitators would far exceed in number all the Violin makers that the city of Cremona ever sheltered. There has ever been a diversity of purpose with these Guarnerius imitators, distinct from those of Stradiuarius and others. They may be divided into three orders, viz., the bona fide copyist, the subtle copyist, and the wholesale copyist. The first sets about making his instrument resemble the original as closely as possible, and when completed, sends it forth as a copy and nothing else. Among these legitimate imitators were Lupot, Gand, Vuillaume, and others. The subtle copyist takes advantage of the disturbed styles belonging to Guarnerius, coupled with his misfortunes, manufactures and translates at will. He "spots" a back on an old fiddle, in which he sees Guarnerius in embryo; he secures it. In his possession is a belly which, with a little skilful nianœuvring of sound-holes and corners, may be accommodated to the back. The sides need well matching in point of colour, workmanship is purely secondary. The scroll he sets himself to carve, giving it a hideous, burglarlike appearance, the inevitable label is inserted, and the Violin leaves the translator's hands a "Prison" Joseph." Now comes the difficulty. How is this "Joseph," unaccustomed to elbow his legitimate namesakes in the world of fiddles, to maintain the character he has assumed? The subtle copyist puzzles his brain without arriving at anything very satisfactory. He resolves to slip it into a sale of household effects. It is described in the catalogue, in glowing terms, as having been in the possession of Geminiani (he not being alive to dispute the assertion). Previous to the sale the instrument is viewed. The knowing ones pass it with contempt. The half-informed turn it over and over, puzzled, and replace it in its case, disconsolate. The thoroughly ignorant look inside, "Joseph Guarnerius Cremonensis faciebat 1724 " in old type stares him in the face; he puts the bow on the strings and demands the maker's name-his thoughts are echoed back in gentle sounds, "Joseph Guarnerius." He returns it to its case, shuts the lid, exultingly sallies forth, congratulating himself again and again upon his good fortune in having at last the opportunity of securing the real 
thing at the price of "a mere song," it being the fixed, fond belief with these individuals that they alone recognize the merits of the thing, a merit they are at liberty to take to themselves. The time of sale arrives. The beauties of the instrument are dwelt upon by the auctioneer; he begs to be permitted to say two hundred guineas to commence with. Silence around. "Well, gentlemen, shall I say one hundred and fifty guineas?" Dogged silence. "Come, come, gentlemen, this is mere trifling. A 'Joseph Guarnerius' for one hundred and fifty guineas ! Shall I say one hundred guineas?'" The customary witty frequenter of salerooms, unable to restrain himself longer, cries out, "I'll give yer a ponnd." The auctioneer sees the whole thing; it is a copy that he is selling, and not the original. The pound bid is capped by another from our friend, who fondly fancies himself behind the scenes. The subtle copyist, seeing his eagerness, bids on his bid, and the 'Joseph Guarnerius del Jesì ' falls with the hanmer to the well-informed individual for ten pounds. He demands possession of it once, in case anothe may be substituted, and retires, perfectly satisfied with his day's work. 'The wholesale copyists are those who manufacture Violins in Bavaria and France in large factories, where the Violins undergo all kinds of processes to make them modern antiques. The wood is put into ovens and baked until it assume; the required brownness, or steeped in strong acids until it becomes more like a piece of charred wood than anything else, the sharp edges removed by the file-the wear of years effected in a few moments by rubbing down those parts subject to friction-ticketed and dated, regardless alike of orthography and chronology, the date being generally before or after the original's existence. These imitations are so barefaced as to render them comparatively harmless.

Guidantus, Giovanni F., Bologna, 1740. Model high. Sound-hole long. Instruments undersized. Purfling badly let in ; the outer form inelegant, particularly the middle bouts.

Guletto.

Juliano, Francisco, Rome, ryor.

KERLiNo, I 449. Maker of Viols. Numerous instruments of the Violin shape have been attributed to this maker, particularly those of quaint appearance, but it is doubtful whether he made any instruments but those of the Viol type.

Landulphus, Carolus Ferdinandus, Milan, 1750. Pupil of Joseph Guarnerius. His works are rapidly increasing in value.

Carolus Ferdinandus Landulphus, fecit Mediolani in Via S. Margaritæ anno 17 arisen as to there being two makers of this name, which is not the case. Those instruments which have the bright red varnish of the Italian makers, his merits were of no ordinary kind. His instruments vary very much, and hence, probably, a confusion has
makers of this name, which is not

Though he belonged to the latest the case. Those instruments which have the bright red varnish 
are certainly the best. The varnish is very transparent, and the wood being strikingly handsome, the effect is most pleasing. The pattern is not a copy of Guarnerius, as often stated, but thoroughly original. His sound-hole cannot be considered an effective one, and is not in keeping with the work. The grooving around the outer edge is in imitation of Peter Guarnerius. The scroll is weak. His Violoncellos are mostly of small size. Some of this maker's instruments are very unfinished, many not being purfled, and having only a single coat of varnish.

Lansa, Antonio Maria, 1674. Copied the Brescian makers.

LiNAROLLI, Venice, 1520. A maker of Viols.

LoLY, Jacovo, Naples, 1627. Of the Grancino type. Yellow varnish. Material very hard.

MAGGiN1, Giovanni Paolo, Brescia, I590-1640. This famous maker followed Gaspard di Salo, and is usually counted as his pupil. There is no anthority Gio Paolo Maggini in Brescia for this statement beyond the similarity of form to be traced in their respective instruments. No Italian maker is more frequently mistaken than Maggini. Any instrument having ornamentation on the back in the shape of purfled scroll-work is at once said to be by Paul Maggini. Barak Norman, the old English maker, thus comes in for a large share of Maggini's patronage, as also a vast number of early German makers, who adopted similar devices ; to the real connoisseur, however, there is no difficulty in distinguishing the work. A more pardonable error is the confusing of Gaspard di Salo and Maggini, which is of frequent occurrence. The Double Basses of these two makers have much in common to the eye of the not deeply versed examiner. Maggini, however, was not so successful as his compeer in the selection of the form of the instruments. In them we miss that harmony of outline belonging to the works of Gaspard, particularly as relates to his Double Basses. Gaspard's Violins are less harmonious in design, and evidence his unsettled views as to the form they should take-a perfectly natural circumstance, when the infantile state of the Violin of his day is considered. The outline of Maggini is broad, but lacks the classic symmetry of the rare old Brescian artist. The form of Maggini is flat, and the means which he adopted in order to obtain a full and telling tone were very complete. - The sides of his instruments are frequently rather shallow, and quite in accordance with the outline. With others who followed him, he evidently recognized the necessity of reducing the height of the sides in proportion to the dimensions of his instrument. The sound-hole of Maggini is long and pointed, admirably set in the instrument, and brimful of meaning. The scroll is antique, but boldly cut, and clearly marks an onward step from the somewhat crude production of Gaspard, the back of which is not grooved, or but 
slightly. Maggini's varnish is of brown or yellow colour, and of yood quality. The instruments covered with the brown varnish are often without any device on their backs, and seldom have two rows of purfling. De Beriot, the famous Belgian violinist, used one of Maggini's Violins, and, in consequence, their value was much increased. Léonard has one of this make, which is highly spoken of.

Maggini, Pietro, Brescia, I630-r68o. Son of Giovanni. These Violins are beautifully made, and frequently surpass those of Giovanni. Like those of the latter, they are double purfled, and also similarly ornamented.

Mantegatia, Petrus Johannes, Mediolani,'1780. Guadagnini character. The work is well done, and the modelling good. His Tenors are among his best instruments.

Maratti, C. B., Verona, i7oo.

Mariani, Antonio, I568. He has the characteristics of Maggini, but the work is inferior and the wood particularly plain.

Mezzadie, Ferrara, $1690-1722$. The pattern is inelegant, and the sound-holes are too close.

Montade, Gregory, Cremona, i73o. Copied Stradiuarius.

Montagnana, Dominicus, Cremona and Venice, 17001740. Pupil of Antonius Stradiuarius. After leaving the workshop of his famous master, he Dominicus Montagnana Sub Signum Cremonæ Venetiis 17 followed his art in Cremona. Many of his instruments were dated from that place. He afterwards removed to Venice, where Violin manufacture was in the most flourishing condition. In this place he soon attained great popularity, and made the splendid specimens of his art with which we are so familiar. The instructions which he had received at Cremona enabled him to surpass all in Venice. $\mathrm{He}$ gained great knowledge of the qualities of material, and of the thicknesses to be observed; and, moreover, he carried with him the superior form of the Cremonese school, and the glorious varuish. Mr. Reade names him "the mighty Venetian," an appellation not a whit too high-sounding, though it may appear so to the half-informed. The truth is, that Montagnana is less known than any of the great makers. For years his works have been roaming about bearing the magic labels of "Guarnerius filius Andreæ," "Carlo Bergonzi," and sometimes of "Peter Guarnerius," although there is not a particle of resemblance between the works of our author and the makers named, whose labels have been used as floats.

Montagnana was in every way original, but the fraud that has foisted his works upon makers who were better known has prevented his name from being associated with many of his choicest instruments, and deprived him of the place which he would long since have held in the estimation of the true con- 
noisseur. This injustice, however, is fast passing away; as ever, genius comes forth triumphant.

The time is near when the "mighty Venetian" and Carlo Bergonzi will occupy"positions little less considerable than that of the two great masters. Already the merits of these makers are daily more appreciated, and when the scarcity of their genuine works is considered, it becomes a matter of certainty that their rank must be raised to the point indicated.

It is much to be regretted that both Montagnana and Bergonzi did not leave more numerous specimens behind them. Would that each had been as prolific as their common master! We should then have inherited a store from which our coming violinists and violoncellists could have possessed themselves of splendid instruments, when those of Guarnerius and Stradiuarius were placed far beyond reach.

In these times, when the love of music is rapidly developing itself among all classes, the question of supply must attract notice. The prime question with respect to Violins of the highest character is not now as to price, but as to the supply of limited and daily decreasing material; and the doubtful point is, not whether purchasers are to be found who may not be unwilling to pay the increased cost consequent upon scarcity, but whether the instruments required will be available in sufficient numbers to satisfy the demand of those quite prepared to gratify their wishes for the possession of an instrument of the first rank. A single glance is sufficient to remind us that the list of makers of the highest class, and particularly of original artists, is scanty indeed. There are a few copyists, it is true, notably Lupot and Panormo, whose instruments must take a considerable position, but on the whole the demand will far exceed the supply. The difficulty here noticed is intensified from the fact of the Violin being, unlike any other musical instrument, sought after as it is for the cabinets of the collector as well as for actual use-a state of things perfectly natural when its artistic beauties are considered. Violinists possibly consider they smart under a sense of wrong at the hands of collectors in thus indulging their taste; but, on the other hand, we have reason to be grateful to the lover of art for having stayed the hand of time in demolishing these treasures.

To return'to the subject of this present notice : it is evident that when Montagnana left the workshop of Stradiuarius, he gave full scope to his creative powers. He at once began to construct upon principles of his own, and thus followed the example of his fellow-worker, Carlo Bergonzi. If comparison be made between the work of Stradiuarius and that of Dominicus Montagnana, with regard to detail, the two makers will not be found to have much in common. It is when Montagnana's instrument is viewed as a whole that the teaching of Stradiuarius is evidenced. A similar assertion may, in a lesser degree, be 
made in the case of Carlo Bergonzi. To dissect the several points of difference is a simple matter. If we begin with the outline, that of Montagnana has not the snıoothness and grace of the Stradiuarian type; the upper and lower curves are flattened, while those of the centre are extended. The soundhole partakes more of the character of Guarnerius; the scroll is larger, and the turns bolder than in the Stradiuarius form. These, then, may be considered to be the chief points wherein, if viewed as separate items, Montagnana seems to have varied from his master: and hence we may obtain some idlea of the amount of ori rinality belonging to this maker-an amount, indeed, not inferior to that of any Cremonese artist that can be cited. The increasing popularity of Montagnana's instruments is sufficient proof that his design was fraught with much that is valuable. In departing from the form of Antonius Stradiuarius, Carlo Bergonzi and Montagnana doubtless intended to bring out, in a stronger degree, certain particular qualities of tone: at the same time we may be sure that they had no idea of attempting to improve upon Stradiuarius in his own field of work, for they must have well known the Herculean character of such a task. On the other hand, had these remarkable makers been mere copyists, they would certainly have handed down to us more instruments moulded in exact accord with the style of their great teacher; while, at the same time, we should have lost many variations, which are at present not only an evidence of their fertility of resource, but also in themselves most pleasing objects. If, in the sister art, Tintoretto had made it his sole business to copy Titian, the world would have been rich in copies of Titian, but poor in Tintorettos.

The varnish of Montagnana has long excited the admiration of connoisseurs throughout Europe. The extreme richness and velvet-like softness which are its characteristics constitute it a fitting countersign of the workmanship of this great maker, an artist of first magnitude. He made Violins, Violas, and Violoncellos. His Violins are of two sizes.

Morella, Morgato, Mantua, 1550. Made several Viol do Gambas of good quality.

Muller, Venice. An esteemed maker of Lutes.

PANormo, Vincenzo, Palermo, born about 1740, died r8r3. This maker was one of the most successful followers of Antonius Stradiuarius. Panormo and Lupot

Vincenzo Panormo, share the palm as faithful copyists of the

di Palermo, Fecit, great Cremonese master. Neither appears Anno 17

to have attempted to create a model of his own; their sole aim was to imitate to their utmost the various patterns of Stradiuarius, Guarnerius, and Amati, but they principally confined themselves to those of Stradiuarius.

Vincenzo Panormo left Italy in early life, and settled for a 
short time in Paris, from which city a few of his instruments are dated. From Paris he removed to London, where he remained many years. He also visited Ireland, where he made, it is said, several beautiful instruments from an old maple billiard table, with which he was fortunate to meet. He was of a restless temperament, which showed itself in continual self-induced changes. He would not, or could not, permit his reputation to grow steadily, by residing long in one place but as soon as fame was within his grasp, he sacrificed the work of years by removing to an entirely new field of labour.

Panormo furnishes us with another example of the certain appreciation, sooner or later, of exceptional talents. No matter how stifling the circumstances under which gifted men have laboured, some time or other their genius is discovered and acknowledged with its due award, if not of fortune, at least of fame. The peculiar circumstances under which Panormo lived, would have been sufficient in the case of most men to dwarf all efforts. Unable to obtain readily that patronage to which his abilities justly entitled him, he removed from city to city, hoping to discover a resting place, in which favour might attend his art. No doubt this was a mistaken course, and one which robbed his work of the attention which a mind undisturbed by the care of existence can bestow; nevertheless his natural gifts had a vitality that could not entirely be suppressed. He worked and toiled for his art and for bare sustenance alternately. His life, like that of many others in the paths of literature and science, was a continued battle with adversity. Such persons are forced to satisfy daily wants by slaving at work which brings them but little credit in after time, and becomes a standard by which they are too often erroneously judged.

Vincenzo Panormo was the slave of many, manufacturing Double Basses and other instruments from the material selected and purchased by his temporary employer, oft-times compelled to carry out some crotchet of the patron much against his own wishes. The wood thus forced upon him was often of the worst description; and in addition, he was frequently obliged to complete his work within a given time. Instruments manufactured under such conditions can scarcely, it may be supposed, add to their makers' reputation. We cannot but regret that he should have been obliged to waste himself on such poor materials. Fortunately, however, in some cases he found time to exercise his skilful powers to their full extent, and has thus bequeathed to us some of the finest specimens of the copyist's art.

His workmanship is of a lighter description than that of Lupot, and is, therefore more graceful. The sound-hole is admirably cut ; and the scroll also well carved. There is on the Continent much confusion with regard to these instruments, which our neighbours are apt to mistake for Cremonese.

PaNSANI, Rome, I 780 . 
PAsta, Gaetano, Brescia, 1700.

Picino, Padua, izi2. High model, dark varnish.

RACCER1S, Mantua.

RAPHAEL, Nella, Brescia, I 740. Copied Maggini.

Reggieri, Cremona. Copied Guarnerius.

Renisto, Cremona, 1738. His label states that he was a pupil of Carlo Bergonzi, but it cannot be said that his instruments show much resemblance to those of Bergonzi. They are more like those of Ruggierius : the model is rather high, and the wood mostly of a plain description; the varnish is of an excellent quality. This maker produced many small-sized instruments.

ROVELL1, 1744.

RUDGER, Cremona, $1650-1700$. This maker is often confused with the family Ruggieri, but is quite distinct. His Violoncellos are very large, and deep in the sides. The varnish is of good quality and dark brown colour. His Violins and Violas are excellent instruments.

RugGierius, Franciscus, Cremona, 1668-1720, surnamed "Il Per." The family of Ruggierius Francesco Ruggieri detto long occupied a foremost place in the il per Cremona 16 city of Cremona as makers of Violins, Violas, and Violoncellos. Their position could have been but little if at all inferior to that of the Amati family. Franciscus, in his earliest works, gives evidence of exceptional artistic feeling, and the sequel of his career, as evidenced by his productions, is a genuine development of the first impulse of his genius. His work belongs to the school of Amati, but though the list of instruments which he has bequeathed to us be a long one, there is no sign of his ever having been a mere copyist. He evidently thought for himself. His sound-hole is a beautiful piece of workmanship, and may be said to come between that of Nicholas Amati and Antonius Stradiuarius, being of the most delicate execution. The outline of his work is very graceful, and the arching admirable. The scroll has quite an equal merit with the body. $\mathrm{He}$ was very successful in selecting his material, much of which is handsome. His varnish, thoroughly Cremonese in character, and of a most beautiful hue, may be equalled, but never surpassed. This maker also knew well how to use his varnish. There is no instance in which it has been laid on in clumsy patches; the surface is always true and even, and, in consequence, the brilliancy of its appearance is perfect.

Rugerius, Guido, Cremona.

Rugerius, Johannes Baptiste, Cremona, and Brescia. The instruments of this maker are of a Io : Bapt. Rogerius Bon : Nicolai

Amati de Cremona alumnus Brixia fecit Anno Domino 725 different pattern to those of Francesco. They are higher modelled, the sound-hole less elegant, and the scroll heavier. They possess, how- 



$$
\$
$$


ever, high merits, and command prices nearly equivalent to those of the instruments of Francesco.

Rugerius, Pietro Giacomo, Brescia, I700-1725. Pattern narrower than those of either Johannes Baptiste or Francesco. Scroll diminutive. Sound-hole resembles that of Francesco. Varnish very beautiful in quality. The Violoncello so long played upon by Signor Piatti is by this maker.

Rugerius, Vincenzo, Cremona, r700-i 730 .

Salo, Gaspard di. He was born in the litile town of Salo, on the lake of Garda, Lombardy. He worked between the years $1550-1612$.

The early history of this famous maker of stringed instruments is, like that of his compeers unrecorded. There can be no doubt that Gaspard di Salo laid the Gaspard di Salo in Brescia. foundation of the Italian style of Violin making. In his works may be traced the gradual development of the theory upon which his followers built their reputation, viz., a well-defined model, excellent materials, and choice varnish. It is to be regretted that his immediate followers, with the exception of Paul Maggini, departed from the path so successfully trodden by this great pioneer. But for this deviation, the works of the early Amatis and a few others would have occupied a higher position than that which they now command. They were men possessing great abilities, and might easily have carried out the designs of the great Brescian maker. They appear, however, to have arrived at a different conclusion as regards the form of their instrument from that shaped by Gaspard di Salo. Their works show an evident preference for the high model, and thus undid much that Gaspard had accomplished after long study of the subject. It is clear that Gaspard only arrived at his conclusions after painstaking labour, for he commenced with the high form, and gradually, as experience taught, lowered it. It is further remarkable that the later members of the Amati family pursued the same course as Andrew Amati (though in a less degree), after which they awoke, as it were, to the reasonableness of the example set by Gaspard, and gave us those instruments so highly thought of by the connoisseur, the form of which has much in common with that adopted by Nicholas Amati, and perfected by Antonius Stradiuarius. Anthony Amati does not appear to have been so willing to follow the path taken by his brother Jerome, in reference to modelling. Long after Jeronie had ceased working the high model Anthony continued to adopt it.

It has been before remarked that Gaspard di Salo did not arrive at his conclusions without mature consideration. In fact, a long and deliberate process of experiment may be traced in his instruments. We find that at various times his Violins and Violas were treated differently to the Violoncellos and Double 
Basses. The Violins are found to be high in model, while his Double Basses and Violoncellos, evidently of the same date, are flat. He would seem to have been desirous of testing the powers of either model, and it is possible that he fostered the idea of varying the construction of each of the four species in the family of stringed instruments according to the part which should be allotted to it. To treat each part of the stringed quartett in four distinct ways is certainly an error, for they are to be looked upon as gradations of one and the same instrument; nevertheless, the attempt of Gaspard, although mistaken, offers but another instance of his prolific ingenuity and unwearied diligence. All praise is due to the great Brescian maker for having opened up as a pioneer so wide a field of research. The Cremonese artists followed up his clue, and brought the Violin to the highest state of excellence.

The chief characteristics of the works of Gaspard di Salo are, the sound-holes, shortened centre-bouts, scroll, and peculiar choice of material. The sound-hole is brim-full of originality. Its length at first strikes one as somewhat crude, but as the eye becomes more acquainted with the general form of the instrument, it is seen to be in perfect harmony with the primitive outline. With this sound-hole commences the pointed form to which Guarnerius, nearly a century and a half later, gave such perfection. The centre-bouts are very quaint, being remarkably short. The material used for the larger instruments is mostly of pear-wood, or wood of that description, the quality of which is particularly fine. In the selection of this wood he showed a still minuter discrimination, using it generally for Double Basses and Viols da Gamba, and not for Violins or Violas; few specimens of the latter have backs of pear-wood. His work was bold, but not highly finished; no other result could be looked for at so early a date. The grain of the bellies is usually very even and well defined. His Tenors and Double Basses are remarkable instruments, the latter appearing in two sizes, the smaller of which is admirably suited for chamber use. Signor Dragonetti, the late eminent Double Bass player, possessed three or four Double Basses by this maker, of various sizes. The most celebrated of these instruments was presented to him by the monks of the monastery of St. Mark, Venice, about the year 1776 , and was returned to the donors, after Dragonetti's death, in 1846. Another was bequeathed by Dragonetti to the late Duke of Leinster. A third is in the possession of the Rev. Geo. Leigh Blake. Dr. Steward, of Wolverhampton, has two fine specimens of Gaspard's Tenors. Among his chamber Double Basses, the instrument which has been so long in my possession is regarded as the most perfect example. It was numbered with the rarities of Louis Tarisio's collection, and considered by him as the chef d'ceuvre of the maker. Among his Violins, the instrument 
owned by W. Tyssen Amhurst, Esq., is unique; the infancy of the Violin at this period is better seen here than any specimen with which I am acquainted.

Sanctus Seraphino, Venice, I710-i748. This maker is chiefly famed for the exquisite finish of his workmanship, surpassed only by that of Stradiuarius. The Sanctus Seraphin modelling of his instruments varied. There Utinensis fecit are instances, particularly in the case of his Venetijs Ann. 17 Violins, where he has entirely set aside the Stainer form, and copied Amati. These Violins are wonderfully like the work of Franciscus Ruggierius. The varnish upon them, of a rich red, is of so unexceptionable a quality, that one is compelled to look twice before being satisfied as to the author. The greater number, however, of his instruments are of the German character, the sound-hole, scroll, and outline all hinting of Stainer. These Venetians were wonderfully fortunate in obtaining handsome wood, and in this respect Sanctus Seraphino was pre-eminent, for his sides and backs are simply beautiful to perfection. His method of cutting the wood was invariably to show the grain in even stripes. The scroll is well cut in point of workmanship, but the style is poor. Sanctus Seraphino cannot be regarded as having displayed originality in any shape, and he thus forms an exception to the great majority of Italian makers. His instruments are either copies of Amati or of Stainer; there is, of course, a strong Italian flavour about his Stainer copies, which lifts them above the German school of imitators, and hence their higher value. $\mathrm{He}$ branded his instruments above the tail-pin, a practice common with two Venetians only, viz., Tononi and Sanctus. He used an ornamental label of large size. The Violoncello in the possession of H. B. Heath, Esq., is a charming specimen of Seraphino's work, I may say unequalled.

Sancti, Giovanni, Naples, 1700-1730. Copied Amati. Varnish very hard. Workmanship indifferent.

SANoNI, Giovanni Raptista, Verona. His instruments are seldom met with in England. High model.

Sanzo, Milan. Similar to Grancino.

Sapino, Cremona, I640. A follower of Cappa, and consequently, in the school of Amati. Many of his instruments are well made, and his varnish good.

STORIONI, Laurentius, Cremona, I780-I798. The last of the old makers who evinced any powers of originality. Although there is an almost total absence of refineLaurentius Storioni Fecit ment in his works, there is much that is Cremone 17 clever, which has already caused these instruments to be valued very highly. He appears to have made Joseph Guarnerius del Jesù his idol. Although his instruments cannot be considered as copies, yet there is evidence of his having made use of the salient points 
belonging to Guarnerius, which he fitted, as it were, to his own model. He had much of the disregard of mere appearance which Guarnerius so often displayed, and seems to have been guided by similar fancies. His freak was to place his soundholes in all sorts of ways, scarcely twice alike. His outline is always vigorous, but without thought of synmetrical appearance. There is not an instrument of his make that could have been made upon a mould-they were built from the blocks, and the result, as may be expected, is not graceful. M. Vieuxtemps, some years ago, possessed himself of a Storioni Violin, now belonging to Mr. Proctor, and, having carefully regulated it, succeeded in bringing forth its great powers. His hearers were so delighted that attention was at once directed to this neglected maker. These instruments are highly thought of in Italy. The varnish is not of the Cremonese description, but partakes of the Neapolitan character. The purfling is usually narrow and roughly worked; the scroll is stiff, and the same absence of finish observable. The material he used was invariably good in point of acoustical properties, though not handsome. Storioni does not appear to have made many Tenors or Violoncellos-the latter are rarely met with.

Stradiuarius, Antonius, Cremona; born in I644; died, December, 1737 .

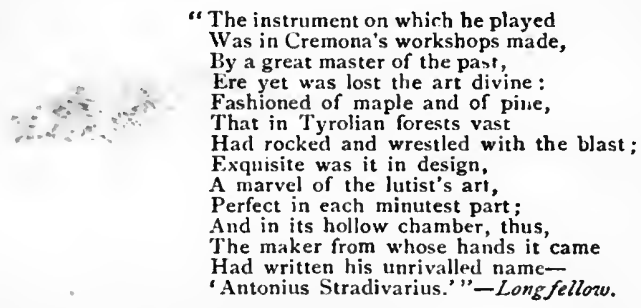

The renown of this remarkable maker of Violins is beyond that of all others; his praise has been sung alike by poet, artist, and musician. His magic

Antonius Stradiuarius Cremonensis

Faciebat Anno 17

name is ever rising to the lips in the presence of the " king of instruments ;" its sound is as familiar to the humble player as to the finished artist. He has received the undisputed homage of two centuries, and time seems but to add to the number and devotion of his liege subjects : he is as little likely to be dethroned to-day as Shakespeare.

Although many interesting particulars concerning Antonius Stradiuarius have been obtained from time to time, there is 
wanting that which alone can fully satisfy his admirers, viz., connected records of the chief events of his life. Every endeavour has been made to supply in some way this deficiency by consulting documents relating to the city of Gremona during the 17 th and 18 th centuries, but nothing of much consequence has been discovered.

With a patience worthy of reward, the librarian at Cremona searched for the will of Stradiuarius, but as no proper register seems to have been kept until long after the date of our hero's death, the difficulty of tracing out any particular document is well nigh insurmountable, and the librarian's efforts have not, as yet, succeeded. Although the contents of the will might throw but faint light upon the doings of the testator, they would probably give particulars that would link together much of the information which we already possess. That the wil! is in existence there can be but little doubt, and patience may yet have its reward.

A short time since, the exact spot where Stradiuarius was buried was made known by the researches of Signor Sacchi, a Cremonese conversant with the annals of his native city. This was an interesting addition to the meagre information previously handed down to us touching Stradiuarius. It had long been known that a family grave was purchased by Stradiuarius in the Church of St. Domenico, in the year 1729 ; but in the certificates from the Cathedral of Cremona it is stated that he was buried in the tomb of Francesco Vilani (Vitani), no mention being made of St. Domenico. The exact words are, "Buried in the Chapel of the Rosary, in the parish of St. Matthew." The omission of the name of the church wherein this chapel stood has led to the belief that the precise spot where the mortal remains of Stradiuarius rest was unknown. Signor Sacchi finds that the historians of Cremona (but especially Panini, in his "Report on the Churches of Cremona, 1762 ") mention that the Church of St. Domenico was in the parish of St. Matthew, and that the only chapel known by the name of "The Rosary" was the third on the right entering the Church of St. Domenico.

An important point is mentioned by the historian above quoted, viz., that about the year 1720 the Parish Church of St. Matthew being judged too small to admit further burials in its interior, the Church of St. Domenico (its subsidiary church) was chosen, as a place of burial for the parishioners, for which purpose it was used down to about 1780 , and that Stradiuarius purchased there the grave mentioned. This statement is confirmed by the MS. left by the Abbate Lancette to the city of Cremona, wherein we find unquestionable evidence in a letter of Count Cozio de Salabue to Paolo Stradiuarius (a cloth merchant, youngest son of Antonius) dated I 775, in which, after mention of the price to be paid for all the instruments, models, tools, 
\&c., left by Antonius, we read, "I am glad to receive from you exact information that the church in which your father was buried is that of St. Domenico." In another letter, written by the same Count Cozio a year later, occur the words, "I have ascertained beyond doubt that Stradiuarius died in Cremona, and was buried in the Church of St. Domenico, in the year 1737, aged nearly 94 years." The stone with the inscription, "Sepolcro di Antonio Stradivari E. suoi Eredi. An. 1729," is now preserved in the Town Hall of Cremona, and is an object of much interest to the many visitors.

The Church of St. Domenico was, in consequence of its decayed condition, demolished about the year 1869 .

It has been ascertained that Stradiuarius had a family of four children: three sons, named Francesco, Omobono, and Paolo, and a daughter named Catarina, who is referred to in an extract from the burial register (1730-1750) of Cremona, of which we give the subjoined translation: "Catharine, daughter of the late Antonio Stradivari, dwelling in the parish of the Cathedral of Cremona, died in the year 1748, at about the age of 70 years, and was buried in the Church of St. Domenico." Omobono and Francesco Stradiuarius followed the occupation of their father, and carried on the business in the same house for some time after his death. They were succeeded by Carlo Bergonzi. Paolo Stradiuarius was a dealer in cloth, and became possessed of the tools and effects of his father, which he disposed of to the Count Cozio de Salabue. Among these was a Violin made by Stradiuarius, on the label of which is given his age (92 year.s) and the date, 1736 . "George Eliot" is thus within the mark in describing our hero as-

\footnotetext{
"That plain white-aproned man who stood at work, Patient and accurate. full fourscore years: Cherished his sight and touch by temperance; And, since keen sense is love of perfeciness, Made perfect Violins, the needed paths

For inspiration and high mastery."
} Stradivari, by George Eliot.

M. Fétis, in his notice of Anthony Stradiuarius, remarks, "The life of Anthony Stradiuarius was as tranquil as his calling was peaceful. The year 1702 , alone, must have caused him much disquiet, when, during the war concerning the succession, the city of Cremona was taken by Marshal Villeroy on the Imperialist side, retaken by Prince Eugène, and finally taken a third time by the French ; but after that period Italy enjoyed a long tranquillity, in which the old age of the artist glided peacefully away. We know but little respecting that uneventful existence. Polledro, late first Violin at the Chapel Royal of Turin, who died a few years ago at a very advanced age, declated that his master had known Stradiuarius, and that he 
was fond of talking about him. He was, he said, tall and thin, habitually covered with a cap of white wool, and of cotton in summer. He wore over his clothes an apron of white leather when he worked, and as he was always working, his costume scarcely ever varied. He had acquired more than competency by labour and economy, for the inhabitants of Cremona were accustomed to say, "As rich as Stradiuarius !" The house he occupied stands in the Piazza Roma, formerly called the square of St. Domenico, in the centre of which was the church of the same name. The house is still in good condition, and is the principal place of interest in the old city of Cremona to the many admirers of Stradiuarius who visit the seat of Violinmaking in olden times.

It is somewhat singular that the Cremonese take but little apparent interest in the matter, and have expressed themselves as being astonished at the demonstrations of respect which their French and English visitors pay to the hallowed spot. The better-informed Cremonese have some acquaintance with the name of Stradiuarius; but to create any enthusiasm among them from the fact of his having been a Cremonese, or from the historical associations which connect him with that city, would be difficult. After the display of considerable patience and determination, Signor Sacchi, in conjunction with a few Cremonese, managed to raise sufficient enthusiasm among the inhabitants, a few years since, to permit the authorities to name a street after Stradiuarius, and another after Amati. This was much opposed at the time. The citizens of Cremona are, however, not quite singular in this respect. It has been remarked that our American friends show far greater interest in Stratfordupon-Avon and its memories than we ourselves do. I must confess that I have great respect for the genuine enthusiast.

The Cremonese have scarcely an idea of the extent of veneration with which we admirers of the art.regard their illustrious citizen. They will be astonished to hear that "Stradiuarius" forms the Christian name of some Englishmen. A well-known dealer some years since determined to commemorate his admiration for the great maker, and, accordingly, named his descendant "Stradiuarius Turner." We have stepped out of the ordinary path of house nomenclature, and have adopted the cherished name of "Stradiuarius," to the bewilderment of the passer by, whose unmusical soul fails to be impressed by it. To crown our seeming eccentricities (in the eyes of our Italian friends), I may mention that the magic name has found its way into circles where little interest is taken in Stradiuarius himself. Very recently the following appeared in the profane pages of a newspaper: "Waterloo Purse.-E. Mr. Goodlake's Gilderoy beat Earl of Stair's Stradivarius, and won the Purse;" the result showing that Stradiuarius was evidently out of place in such company. 
In the absence of direct information concerning the life of Stradiuarius, we must turn to his instruments for such evidence as we require; and these, happily, give us a greater insight into his career than would be readily inagined. I am not a ware that there has ever appeared a Violin of Stradiuarius in which it is stated that he was a pupil of Nicholas Amati, or that this assumption has been maintained on any other grounds than the indisputable evidence furnisled by the early instruments of this great maker. Never has affinity in the art of Violin manufacture been more marked than that between Stradiuarius and Nicholas Amati during the early life of the former. I have, in another place, remarked upon the almost invariable similarity occurring between the works of master and pupil, and have used this canon in refutation of the doctrine that Joseph Guarnerius del Jesì was ever a pupil of Antonius Stradiuarius. We will proceed to examine the characteristics of the earliest productions of Stradiuarius, in order that the reader may judge of the extent and value of this fancied resemblance." Although we have not met with a single instance of a Stradiuarius Violin bearing the maker's name prior to I668, we have seen instruments bearing the signature of Nicholas Amati, which can be readily recognized by the practised judge as having been the work of Stradiuarius, in some cases in toto (in which case, as may easily be imagined, they have no longer been allowed to sail under false colours, but have had their proper certificate of birth attached to them); in other cases, and more frequently, in part, as when the beautiful scroll of Stradiuarius is met with on the body of an Amati, or the sound-hole of such an instrument shows that it has been cut by the hand of Stradiuarius. We will not, however, consider these instruments as typical of the maker, but pass on to the period when we assume that Stradiuarius left the workshop of Amati, the year 1668. At this point we find that his whole work is in accordance with the plans of Amati (not as seen in the latter's grand pattern, but in his ordinary full-sized instrument); the arching is identical, the corners are treated similarly, the sound-hole is quite Amati-like in form, yet easily distinguished by its extreme delicacy, the scroll a thorough imitation of Amati, and presenting a singular contrast to the vigorous individuality which Stradiuarius displayed in this portion of his work a few years later. Enough has been said to enable the reader to recognise the connection which must have existed between Amati and Stradiuarius, to admit of such marked resemblances. It should be observed that in these earlier specimens there is a singular absence of handsome wood; the acoustical properties of the material are very good, but it has little figure in it, and is often cut on the cross.

The next period is that dating from 1686 to 1694 . We here observe a marked advance in every particular. The form is 
flatter, the arching differently treated. The sound-hole, which is a masterpiece of gracefulness, reclines more. The curves of the middle bouts are more extended than in this maker's later instruments. The corners are brought out, although not prominently so. Here, too, we notice the change in the formation of the scroll. He suddenly leaves the form that he had hitherto imitated, and follows the dictates of his own fancy. The result is bold and striking, and often leaves the impression on the mind that it partakes much of the character belonging to the bodies of instruments of his latter period. Though it may seem daring and presumptuous criticism, I have often been impressed with the idea that these scrolls would have been more in harmony with his later works than those to which they belong. The reader will be enab!ed to form a pretty correct notion of the different characters pervading the scrolls of Stradiuarius by referring to an engraving of them given in the earlier edition of this work. The varnish on the instruments belonging to the period under consideration is very varied. Sometimes it is of a rich golden colour, deliciously soft and transparent ; in other instances he has used varnish of a deeper hue, which might be described as light red, the quality of which is also very beautiful. IVe find this varnisl chiefly on those instruments where lue has made his backs in two parts, and also on whole backs. The purfling is narrower than that afterwards used.

We now arrive at the time when Stradiuarius made, together with the form of instrument just described, that known to connoisseurs as the "long Strad." WV have here a totally differently constructed instrument ; it is less graceful, although there is no absence of the masterly hand throughout the work. It has received the title of "long Strad" not from increased length, as the name would imply, but from the appearance of additional length, which its narrowness gives it, and which is particularly observable between the sound-holes. The dimensions of these instruments vary considerably; in some the width across the lower portion is but a shade less than that of his full size "Amatese" instruments, but in the upper part the dimension is more marked. On these, again, there is much variation in the tone of the varnish, many having his beautiful amber-coloured varnish, others a pale red, of great transparency. In the year 1687 he made the quatuor of instruments for the Spanish Court, inlaid with ivory, and having a beautiful scroll work running round the sides and scroll. The Viola belonging to this quatuor has lost its ivory work, a blemish which is to be regretted, destroying as it'does the completeness of the set. He also made about this period some very small Violins with similar designs, instruments evidently made to order.

Fortified with the vast experience which these variously 
constructed instruments had enabled him to gather, he would seem to have marshalled all his forces in order to enter on an entirely new campaign, one that should be alike glorious to himself and his art. That he succeeded in achieving all that he could have desired my readers will have an opportunity of judging by the evidence I propose to offer. It was about the year 1700 when Stradiuarius entered upon a new era in his art. All his past labours appear to have been only measures preliminary to that which he proposed afterwards to accomplish, and were made for the purpose of testing, to the minutest degree, the effects of particular modifications in the form and thicknesses of his works.

If we stay to consider for a moment the field of research traversed by Stradiuarius before entering upon what may be not inaptly named the golden period of his life, artistically considered, we shall be better enabled to appreciate his labours.

Starting from the days when he left the workshop of Nicholas Amati, we find him following implicitly in the footsteps of his master. About 1686 he makes use of the more commendable points belonging to the works of former years, adding others of great beauty and utility. At this period he begins to make his originality felt, continuing in this vein with but little intermission down to about the year 1694, when he again gives forth fresh evidence of his power to create, as shown in the "long Strad." In expending his powers on these instruments of diminished proportions, it might occur to the mind of the observer that he was undoing much that he had accomplished; but I do not consider that such was the case. His project in making these instruments together with those of larger dimensions evidences in my opinion a desire that he had of fairly testing the results of changed methods of construction.

From this brief summary of the varied styles given to the works of this true artist, the reader may gather some idea of the solidity of the foundation which he laid, before trusting himself to raise those works which have become monuments to his memory.

That which I have termed the golden period of Stradiuarius, commenced about 1 7oo, at which period he had reached his 56 th year: a time of life when it is a rare occurrence to find genius asserting itself with any degree of power-a time, if not of waning, at least of resting, when the mind usually stays from giving forth originality bearing the freshness of earlier years; but Stradiuarius, with a few other notable instances in the field of art, forms an exception to this rule, and he proves to us that his talent was then in its full vigour, and ripe for new achievements. George Eliot's fancy well contrasts the painter Naldo-

" Knowing all tricks of style at thirty-one, And weary of them; while Antonio At sixty-nine zurought placidly his best." 
From about 1700 his instruments show to us much of that which follows later. The outline is changed, but the curves blending one with another are beautiful in the extreme. The corners are treated differently. The wood used for the backs and sides is most handsome, having a broad curl ; the cutting adopted is chiefly that shown in figure $\mathrm{r}$. The scrolls are of bold conception and finely executed. The varnish also is very rich, and leaves nothing to be desired.

It is not possible to convey to the reader by means of mere description anything approaching an adequate notion of the surpassing gracefulness of the entire work of this epoch. The eye must be made the channel to the mind. If the work is present, then, with the aid which these remarks will afford, the reader may gain, by careful study, much valuable insight into the beauties and genius of this famous artist, together with much useful information.

But during this period of his maturity, even, we find that Stradiuarius did not absolutely confine himself to making instruments exactly alike; on the contrary, it is easy to point out certain variations, the meaning of which he certainly well understood. We find him guided throughout this period by his usual ideas as regards grandeur of outline and degrees of thickness; but the rotundity of the model, the shape that he gave to the sound-hole, the method of setting the sound-hole in the instrument, although, as before remarked, all executed with a breadth of purpose which his earlier efforts fail to show, may be cited as instances of variations. I have no hesitation in hazarding an explanation of the reasons that prompted him to these differences of construction. It is my firm conviction that these great makers had certain guiding principles as regards the nature and qualities of the wood they used, and that Stradiuarius in particular made the subject a special study. If this be granted, I do not think there is any great difficulty in understanding the meaning of the differences pointed out. If we admit that Stradiuarius constructed his instruments upon philosophical principles, it will be clearly recognised that the chief element of variation in the treatment of any particular instrument must be the difference of quality in the material employed; and that a method eminently successful, when applied to wood of a certain texture and character, would ensure as eminent a failure if applied indiscriminately in all cases. To obtain wood sufficient for two bellies that should be alike in every particular is impossible, though cuttings should be made from the self-same piece; and we find that the more the material varies in its nature, so much the greater the variations - a rule which helps the view advanced considerably. In another place I have stated that scarcity of sycamore in the days of these old makers is impossible to understand, but scarcity of a particular kind of sycamore is easy to comprehend. 
I may even carry this view further. Does it seem possible that such a consummate artist as Stradiuarius, whose cunception of the beautiful, as regards the blending of lines, was so masterly, would have been content to expend his loving care over wood which he knew must necessarily mar the effect of his iabours, when he could have obtained hindsome material and made all complete? He might have had a cart-load of handsome wood in appearance, but handsome wood combined with acoustical properties he deemed needful, was another matter. With what extraordinary care he pernitted himself to use the lovely wood he did possess! There are several instances where he has used during one year four or five distinct cuttings of wood, more particularly as regards the sycamore. These several cuttings include often the handsomest and the plainest. A year or so later we find him again making use of wood from the same cuttings, which proves satisfactorily that he did not work up one piece before commencing with another. He would seem to have kept back the handsonest wood for certain important commissions. I have seen three Stradiuarius Violins of 1714 , with backs having but little figure, yet this was the year in which he made the "Dolphin," which has long been regarded by the chief connoisseurs in Europeas the chef d'auvre of Stradiuarius. From the days when it was in the possession of the Marquis de la Rosa to the present time, its beauty has excited the admiration of the fiddle wurld. The splendour of the wood is unsurpassed in any Violin, ancient or modern, and it was named the "Dolphin" from the richness and variety of the tints it gives to the varnish. The model is perfection; its solidity of construction and glorious varnish all tend to make it matchless. Its beauty is of a kind that does not require the eye of the skilled comnoisseur to recognise it; it causes those to exclaim whose knowledge is limited to being aware that it is a fiddle. His making this superb work of art in the same year in which he made instruments having wood quite opposite in figure, bears out, I consider, what I have before stated, viz., that Stradiuarius jealously guarded the material he possessed having both handsome figure and valuable acoustical properties. Mr. Charles Reade says of these "Strads:" "When a red Stradiuarius Violin is made of soft, velvety wood, and the varnish is just half worn off the back in a rough triangular form, that produces a certain beauty of light and shade which is, in my opinion, the ne plus ultra. These Violins are rare; I never had but two in my life."

Passing to the last period of this great maker, we enter upon the consideration of a set of instruments very distinct from those of an earlier date, and which have given rise to a zrreat divergence of opinion. Some have gone to the extent of denying the authenticity of these works, as far as they relate to Stradiuarius; others, again, admit that portions of these instru- 
ments are from his hand, and finished by his sons or Carlo Bergonzi. There are, doubtless, many exceedingly crudelooking instruments passing under his name, bearing dates ranging from 1730 to 1737 , in the making of which he has taken no part; but, on the other hand, to deny that there are any works of Stradiuarius having these dates is, to my mind, absurd. He must be an ill-informed judge of Violins who fails to recognise the hand of the master in several splendid specimens of this period. It nust be borne in mind that Stradiuarius had reached a great age when he made these instrunents in 1730 , viz., 86 years. It would not be reasonable to expect to find the high finish belonging to the instruments made from $\mathrm{r}$ zoo to 1725, but even in these there is a finish distinct from that of either his sons or Bergonzi. But, beyond this, there is recognisable the splendid form, the masterly scroll, the perfect sound-hole-a repetition of his early work, but more massive treatment. To say that Omobono Stradiuarius, Franciscus Stradiuarius, or Carlo Bergonzi had any share in these notable works, evidences a very ill-formed judgment, and, indeed, total ignorance of the style of those to whom these instruments are attributed. The work of Carlo Bergonzi is now pretty well understood; in England, particularly, we have some glorious specimens. I need only ask the unbiassed connoisseur if he can reconcile one of these instruments with those of Stradiuarius of the period named. I have no hesitation in saying that there is not a single feature in common. The work of the sons of Stradiuarius is less known, but it is as characteristic as that of Bergonzi, and quite as distinct from that of their father as his, if not more so. The outline is rugged, the modelling distinct, the scroll a ponderous piece of carving, quite foreign to Stradiuarius the elder, and the varnish, though good, is totally different from the superb coats found on the father's works of late date.

Having now exhausted the subject of the various styles of "Stradiuarius," I close this notice with a few interesting items relating to the famous maker, extracted from manuscripts written by Desiderio Arisi in the year 1720. These MSS. are preserved in the Town Museum at Cremona, and I am indebted to Signor Sacchi for extracting and translating them. The MSS. of Arisi comprise a series of short biographies of Cremonese worthies. It is said he was intinuate with Stradiuarius, and he would seem to have noted many events which Stradiuarius related to him.

"On the roth of November, 1702, the Marquis Giovanni Battista Tozalba, General of Cavalry and Governor of Cremona, sent for Stradiuarius, and after complimenting him for his peculiar genius, commissioned him to make two Violins and a Violoncello, which were sent as presents to the Duke of Alba."

"In the year 1707, the Marquis Desiderio Cleri wrote by order of King Charles III. of Spain commissioning Stradiuarius 
to make six Violins, two Tenors, and one Cello for the royal orchestra."

"Stradiuarius made also a complete set of bow instruments, which he intended to present to King Philip V. of Spain, on the occasion of the king passing through Cremona, but he was dissuaded, and the instruments are still in his possession" (I 720$)$.

"In the year 1716, his Serene Highness the Duke of Modena instructed Stradiuarius to make a Violoncello."

Stradiuarius, Franciscus, Cremono, 1720-1743. Son of Antonius Stradiuarius. Worked with his brother Omobono for several years. Many of the

Franciscus Stradivarius Cremonensis

Filius Antonii faciebat Anno $3 \mathbf{7 4 2}^{2}$ later works of Antonius Stradiuarius have been most erroneously attributed to his sons.

The character of the work is wholly distinct. I can well understand the common error of attributing the instruments of Franciscus Stradiuarius to Carlo Bergonzi, there being many points in common, but that so many marked specimens of the works of Antonius should be deemed apocryphal is beyond my comprehension. The work of Franciscus is altogether less finished, but at the same time it shows the hand of the master. The design is bold and original. The sound-hole is quite unlike that of Antonius. The tone of Franciscus's instruments is invariably very rich and telling.

Stradiuarius, Omobono, Cremona, 1720-1742. Brother of Franciscus.

\section{Omobonus Stradivarius figly Antoy}

Cremone fecit, Anno 1740.

Sursano, Spiritus, Coni, I714-1735.

TeChler, David, Rome, I680-i743. A highly esteemed maker. He worked in Venice, Salzburg, and Rome, chiefly in the latter city. His instruments vary in form, some having a markedly German style: they are high modelled, and the sound-hole partakes of the Stainer character. These were probably made in Salzburg to the order of his patrons. Those instruments which date from Rome are of the Italian type, and are so much superior to the others that it seems difficult to reconcile varieties so distinct as the work of the same man. 'They are finely formed, have splendid wood, and rich varnish of a yellowish tint; the bellies are of a mottled character, similar to those of Nicholas Amati at one period of his career. His Violoncellos are among his finest instruments. They are mostly of large size.

'Testore, Carlo Giuseppe, Cremona, about I690 to 1720. He copied Guarnerius with much success; it is possible that he was a pupil of that famous maker. These instruments are rapidly increasing in value. The work in his best instruments is highly finished. 
Testore, Carlo Antonio, Milan, 1730, son of Giuseppe. Copied Joseph Guarnerius and Anuati. These instruments are bold and well made; their tone is excellent.

Testore, Paolo Antonio, Milan, I 740. Brother of Paolo Antonio. Copied Guarnerius. The varnish is mostly yellow; frequently unpurfled.

Tonon I, Felice, Bologna. These instruments are rather high built. The varnish is very good.

Tononi, Guido, Bologna. Made a few Violins of the Amati form.

Tononi, Carlo Antonio, Venice, r7oo. The model varies very much; those of the flat pattern are excellent instruments. They are large, and beautifully made. The varnish, though inferior to that of Sanctus Seraphino, is similar. These Violins are branded above the tail-pin.

ToNoni, Giovanni, Venice. Same çharacteristics.

TORTOBEllo, Rome, i68o.

VETTRINI, Brescia, early. Wood very handsome. Golden varnish. Well modelled.

Vimercati, Paolo, Venice, I7 Io. Similar to Tononi.

ZanetTo, Peregrino, Brescia, 1550. A maker of Viols da Gamba.

ZANTr, Alessandro, Mantua, 1765. He copied Peter Guarnerius; but had little knowledge of varnishing, if we are to judge from the few instruments of this maker that are extant. 


\section{SECTION VII.}

The French School.

ग $\mathrm{H}^{\mathrm{H}}$

HE French have long occupied a foremost place in the production of articles needing delicate workmanship, and it is, therefore, not surprising that they should at an early period have turned their attention to the art of Violin making, which requires in a high degree both skilful workmanship and artistic handling. The Freuch manufacture of instruments of the Violin class appears to have commenced about the same period as the English manufacture, viz., in the early part of the 17 th century, Médard and Tywersus being among the early French makers, and Rayman and Wise their fellows in England. The primitive French makers, like their English brethren, copied the Brescian and early Cremonese artists, whose model they adhered to down to the days of Barak Norman, when the two nations parted company, as regards having a common type, the French continuing the path they had hitherto taken, and which they have fullowed, with scarcely any deviation, to the present time. The English departed from the Italian form for that of the German of Jacobus Stainer, which they adopted, with but few exceptions, for nearly a century, recovering the Italian about the middle of the r8th century. It is remarkable that French makers should have restrained themselves from following the pattern of the famous German maker when his name was at its height, and his instruments were in such demand. That in not adopting the then popular form they were rightly guided, experience has clearly demonstrated. When we scan the works the French have left us, and consider the advantage they had in keeping to the Italian form, we cannot but feel disappointed in finding so few meritorions instruments among them. There appears to have been many makers who were quite unconcerned as to whether their instruments possessed merit becoming the production of a true artist; their chief aim would seem to have been to make in dozens, in other words quantity in place of quality. If the early French makers are carefully studied, it will be seen that Bocquay, Pierray, and one or two of their pupils are the only makers deserving of praise. It must be admitted that the shortcomings on the part of the makers of the first period were adequately supplied by those of the second period, which takes in the king of Frencl artists, Nicholas Lupot. The old French school, originating with Médard and 
Tywersus, includes the following nakers:-Nicholas Renault, of Nancy, Médard, also of Nancy, Bourdat, of Mirecourt, Dumenil, Bertrand, Bocquay, Gaviniés, Chapuy, Ouvrard, I'aul Grosset, Despont, Saint Paul Saloman, Véron, with others of less importance. Many of these makers had a fair amount of ideas, which, had they been well directed, might have led to fume. Others contented themselves with copying, without giving any play to their fancy. There was one feature which several of the old French makers were most successful in, that of varnishing. It will be found that many of the instruments liy Bocquay, Pierray, and a few others have varnish upon them closely resembling that of the Venetian school ; it is full-bodied, very transparent, and rich in colour. Many of their works are covered with a very inferior quality of varnish, which has caused some confusion respecting the merit due to them as varnishers, they being frequently judged by their inferior instruments, without reference to the good ones. It is evident that they made two qualities of varnish, so as to suit the price they were to obtain, as was commonly done in England by the Forsters, Banks, and Wamsley, where similar confusion exists. The Italians happily avoided this objectionable system. Their works are of one uniform quality in point of varnish. This divergence may possibly be accounted for by the difference of climate. In Italy, oil varnish judiciously used would dry rapidly, whereas in France or England the reverse is the case ; hence its more sparing use.

We will now glance at the second French school of makers, commencing with De Comble, who may be regarded as the founder of the modern French school. Learning his art in Italy, and, it is said under Stradiuarius, he brouglit to France an entirely distinct knowledge from that theh possessed by the makers mentioned above. His instruments certainly bear the stamp of genius, although they are copied from the Italian, and chiefly from Stradiuarius. The form which he introduced into France was at once seen to be so far superior to anything the French had hitherto been accustomed to, that it soon induced them to tread the same path. The next maker was Pique, who manufactured some excellent Violins and Violas, in point of workmanship, and, had he been equally successful in varnishing, would have been probably held in the same estimation as Nicholas Lupot, his fellow-workman; but there is this to be said, that Pique opened up the ground for Lupot. He slowed what might be done in copying, and, possibly caused Lupot to turn his attention to the matter of varnishing, that their instruments might be more complete. From these makers sprung quite a little school of its own, comprising Gand, the father of the present Gand, in Paris, who succeeded to the business of Lupot, and Bernadel, with several others less known. Mention must not be omitted of another successful copyist, Sylvestre, 
of Lyons. He has left some charming specimens of his art. They are lighter in character than the works of Nicholas Lupot, and resemble the work of Stradiuarius from 1680 to 1710 ; while, as every feature is artistically handled, and free from the common practice among French makers of preparing the wood in order to darken it, they are instruments which must become valuable as age acts upon them.

It only remains now to mention Salle, Vuillaume, Chanot, and Gand, all copyists of more or less note, who may be said to complete the modern French school. With these makers end, as far as it is possible to learn, the manufacture of Violins in France of a better class. Those made by thousands yearly at Mirecourt are not Violins in the eyes of the connoisseur. They are made as the common cabinet work is produced in England, by several workmen, each taking a portion, one making the backs, another the sides, another the belly, and so on with the other features, the whole being arranged by a finisher. Such work must necessarily be void of any artistic nature ; they are like instruments made in a mould, not on a mould, so painfully are they alike. This Manchester of fiddlemaking has doubtless been called into being by the great demand for cheap instruments, and has answered thus far its purpose, but it has certainly helped to destroy the gallant little bands of makers who were once common in France, Germany, and England, among whom were men who were guided by reverential feelings for the art, irrespective of the gains they reaped by their labours. The number of instruments yearly made in Mirecourt amounts to many thousands, and is yearly increasing. They send forth repeated copies of Amati, Maggini, Guarnerius, and Stradiuarius, all duly labelled and dated, to all parts of the world, frequently disappointing their simpleminded purchasers, who fondly fancy they have thus become possessed of the real article at the trifling cost of a few pounds. They have recently sent forth a new kind of modern antique in Violins, which is causing a revolution in the Mirecourt manufacture, and is more deceptive than the stereotyped article which has been so long in the market. It has the appearance of having been boiled in some mixture of acids, giving it the aged look of the genuine thing to the inexperienced eye. It is blackened and charred in the most merciless manner, and sends forth a smell of a most disagreeable nature. The whole thing is over-done, and the results, in point of tone, are far more disastrous than in the common French copies.

In the following list of French makers will be found those generally known, and their leading characteristics. 



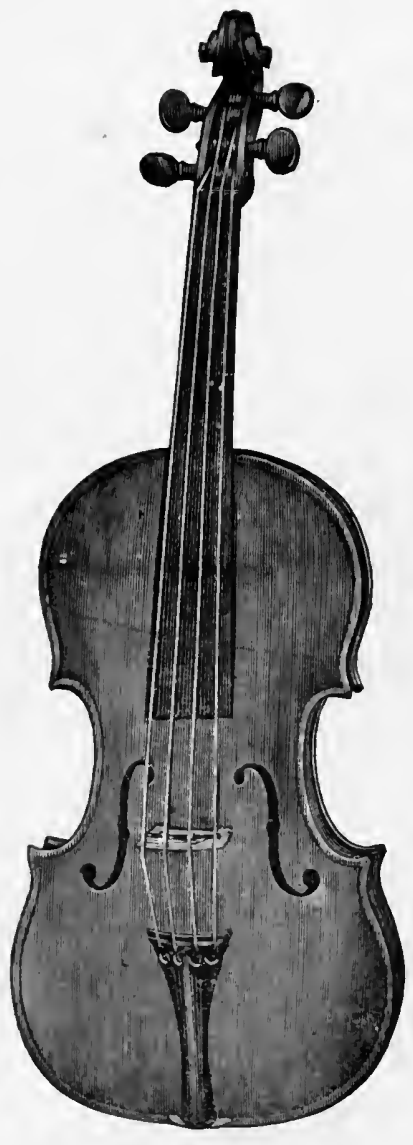

Nichozas Amatr. 


\section{SECTION VIII.}

FRENCH MAKERS.

7 LDRIC, Paris, 1830. Copied Stradiuarius with average ability. He was, perhaps, better known as a dealer in Cremonese instruments. He was one of the earliest
French makers who dealt with Louis Tarisio, the famous Italian connoisseur.

BENOIT, Brussels, 1758.

BoCQUAY, Jacques, Paris, 1700-1730. One of the first of the old French school. He, with a few of his contemporaries, inherited a good amount of the Italian character

Jacques Boquay, rue d'Argenteuil,

a Paris, 1723 of workmanship introduced into France by Nicholas Rénault, a well-known French maker, who probably passed his early life among the Italians. Bocquay, with others whose names are mentioned in this list of French makers, used varnish closely allied to that of Cremona ; its colour is a warm brown, very transparent and of a soft nature. He made many instruments of small size. The model is often that of Jerome Amati, but slightly more arched; the sound-hole is more rounded and less striking. The scroll can scarcely be considered a copy of Jerome Amati's; it is well cut, but lacks the force of the Italian. The tone is sweet, without much power.

BERroIt, Brussels, I750.

BERTRAND, I 8 th century. A very good maker, in the style of Jacques Bocquay. The varnish is not equal to that of the maker named.

BERNADEL, Paris. The instruments of this maker are made with care, and the wood judiciously selected. They are similar to those of Gand.

Borvis, Claude, I $7_{\text {th }}$ century. Careful workmanship. The thicknesses not very correct.

Bourdat, Sebastian, Mirecourt, 1620. One of the earliest Violin makers in Mirecourt, who possibly, in conjunction with Tywersus, founded the manufacture in that now widely-known town.

Boullangier, London, now living. Has made several excellent copies, particularly Tenors.

Breton, Le, Paris. Common-place instruments. Large pattern, usually stamped with name inside.

CASTAGNERY, isth century. He made several Violoncellos of good quality. Varnish of a light colour. 
Castagnery, Jean Paul, Paris, 1635-1665. One of the best makers of the old French school.

Castagnery, Andrea, Paris.

Ciranot, Georges, Paris, now living. Throughout life has been a most indefatigable worker. He has made a very large number of copies of Stradiuarius and Guarnerius, chiefly of the former, which are also the best. They are well constructed instruments, and the wood is of an excellent description. He has long been known as a dealer in Cremonese instruments, and many notable rarities have been in his possession. He retired from active pursuits some few years since, and now divides his time between fiddles and farming. The instruments of this maker will at no distant date be valued much more than they are at the present time.

Chanot, George, London. Son of Georges Chanot, Paris. Assisted Charles Maucotel, and a short time afterwards started in business on his own behalf.

Chanot, -, Paris. Another son of Georges Chanot, Paris.

Chanot. Sons of George Chanot, London.

Chapuy, Augustinus, Paris about 1765. His instruments are chiefly of large pattern; nearly all are branded on the button, in a similar manner to those of the Testore family. Chapuy differed greatly in his work. In those instances in which he used plenty of wood we have instruments of a good kind and worthy of attention. There are many, however, having his brand that are scarcely fit to be called Violins, so inferior is the work and wood.

CheVrier, Paris.

Claudot, Charles, possibly dated from Mirecourt. The workmanship is heavy; varnish mostly yellow. His instruments are good for orchestral purposes. His name is generally found stamped on the back inside.

CuNI, I8th century.

DAvid. Maker to the court of Louis XVI.

DE Comble, Ambroise, Tournay, 1730-1760. Was one of the best makers of the old French school. It is said that he

Fait a Tournay par Ambroise de Comble, 1750 worked in the shop of Antonius Stradiuarius, and judging from the character of the work, together with that of the varnish, I think it not unlikely that he did receive instructions from the great Cremonese maker. The varnish is quite of the Italian type; the colour often a rich red, with much body. His instruments are inclined to roughness as regards workmanship, and therefore are not pleasing to the eye. There is a resemblance to the instruments of Stradiuarius after $\mathbf{1 7 3 2}$ in form though not in workmanship, and he would therefore seem to have copied those late instruments. They may be described as of large pattern, flat model, and having an abundance of wood. They are deserving of attention both from the 
professor and the amateur, the workmanship being skilful and the material excellent. The tone is large, and frequently possesses the richness so much admired in the works of the Italians. This quality is traceable to the soft and flexible nature of the superior varnish with which these instruments are covered. Several Violas and Violoncellos are extant which were made by De Comble.

Despont, Antoine, Paris, early in 18th century. Made several excellent instruments of various patterns.

FALAISE. Copied the Amatis and Stradiuarius. The workmanship may be likened to that of Pique. Varnish yellow and thin. Thicknesses well observed. There is no indication of a resort to any maturing process. Wood frequently handsome.

FENDT, Paris, I780. A maker well known among connoisseurs ; related to the Fendts who worked in London.

Fleury, Benoist, Paris, i 718 .

FoURRIER, Nicholas, Mirecourt.

GaND, François, Paris. He became the pupil of Nicholas Lupot in the year 1802 . During his apprenticeship he proved himself an excellent maker, and was much valued by his famous instructor. He married the daughter of Lupot, and succeeded him in the Rue Croix des Petits Champs in the year 1824. The career of François Gand was one of much activity. As a repairer of the works of the great masters he early obtained a high reputation, and perhaps restored more valuable instruments than any repairer of his time. The care he took and the judgment he exercised in endeavouring to bring together the various broken parts of an imperfect instrument, that the original appearance might be maintained as closely as possible, cannot be too highly praised. He often accomplished seeming impossibilities. Splintered cracks were by his ingenuity closed as though no fibre had been severed, while at other times, pieces. were inserted so deftly that the most experienced eyes fail to detect their presence. It was with him a labour of love, and he did not scruple to spend days over work on which others would spend hours. He made many Violins, several of which were given as prizes at the Paris Conservatoire. They are well made instruments, but have a heavy appearance scarcely to be expected from the hands of so skilled a repairer. They are good serviceable instruments for professional use in orchestras and for practice. Time may, however, mellow them sufficiently for lighter purposes. He died in the year 1845 , leaving two sons.

GAND, Eugenè, Paris. Son of François.

GAND, Paris.

Gavinies, Paris, 1734. Old French school. Well made; capital varnish; good wood.

Gavinies, rue

S. Thomas du Louvre,

a Paris, 1734 . 
Grosset, Paul. Pupil of Claude Pierray.

Guersan, Louis, 1766. Made many excellent instruments.

Ludovicus Guersan prope Comcediam Gallicam, Lutctiz, Anno 1766.

Lagetro, Paris, $\mathrm{I} 7$ th century. Chiefly of the Amati pattern. LAMBERT, Nancy, 18th century.

Leclatr, Paris.

Lous, Geneva. Copied Stradiuarius, but indifferently.

LOUVET.

LUPOT, François, Stuttgard. The father of Nicholas, the famous maker. François removed with his son to Orleans in the year 1785 , where they obtained good patronage.

LUPOT, Nicholas, son of François, born at Stuttgard in $175^{8}$, removed with his father to Orléans in 1785 , where he remained nine years. He established him-

N. Lupot fils, Luthier, rue d'Illiers, a Orleans, l'An $\times 79$ r self in Paris in 1794, his fame having reached that city some time before. The attention which he soon received from the musical world of Paris proved to him that his removal was advantageous. He had not long been in

Paris before he was honoured with

Nicholas Lupot, Luthier, rue de Grammont; a Paris, l'an 1798

the patronage of the Conservatoire of Music, an honour which is attended with many benefits, the chief of which is the making of a Violin annually to be awarded as a prize to the most successful student among the Violinists. By this arrangement the maker has an Nicholas Lupot, Luthier, rue Croix opportunity of exercising to the des-petits-champs, a Paris, $\mathrm{I}^{\prime}$ an 1817 best advantage all the skill of which he is capable, as he is at once aware that the attention of the public is directed to the constructor of the prize as well as to the receiver, and that an immediate road to popularity is thus opened. Lupot's appointment as maker to the Conservatoire was enjoyed by his successor, François Gand, and is still retained by the latter's two sons, in conjunction with Bernadel. Nicholas Lupot may be justly termed the French Stradiuarius. He was an artist in every sense of the word. He regarded the works of Stradiuarius with the utmost veneration. While, however, he laboured unceasingly to imitate him, he scorned all those mischievous maturing processes common to the majority of French copyists; he never desired that his copy should pass with the unwary as the original; in fact, of such a fraud his high sense of honour rendered him incapable. There is not an instance in which he did not varnish the copy all over, leaving time to do its work of wear, although by so doing he doubtless sacrificed much in his own time, inasmuch as all new Violins so varnished have a crude appearance, notwithstanding any amount of high finish expended upon them. 
What, however, Lupot lost in his day has been awarded to his name a hundredfold since. He seldom occupied himself in copying Guarnerius or Amati, although there are a few beautiful examples met with now and again in which he adopted these forms. Stradiuarius was his idol, and from the fact already mentioned, that he is most rarely found to be working on any other model than that of Stradiuarius, he would seem to be specially aware of his own peculiar fitness for the great master's design. Every feature of Lupot's instruments was clearly a matter of study with him. It cannot be said of him, as of most other makers, that certain points are good, while others are weak. Every portion of his work contributes to the harmonious whole. The outline is perfect; the sound-hole is executed in a masterly manner; the model, purfling, and scroll of equal merit. He was untouched in his own day, and his productions have never been approached since. It may safely be said that Lupot is the king of modern makers, and as time rolls on the more will his works be valued. The varnish of Lupot is peculiar to him. Its qualities are good, being free from hardness. Though it is not of the Italian type, neither is it of the kind usually met with on the Violins of his contemporaries : it may be described as a quality of varnish coming between the Italian and French. Its property of tone is very mellow, and its colour varies between light and dark red. Age has wonderfully assisted in heightening its lustre, and although it will never rank with the varnish of Cremona, yet it will occupy a foremost place among the varnishes of modern times. It is said that many instruments having the name of Pique in them are the work of Lupot, and this misnomer is accounted for by the story that Pique purchased them in an unvarnished state, and varnished them with his preparation. Be this as it may, it is certain that the varnish of Pique has not served to benefit these instruments ; on the contrary, it has derogated considerably from their value. The tone of Lupot's instruments improves yearly. The quality is round and telling, and free from roughness. He died in Paris in I824, aged 66, and was succeeded in his business by his son-in-law, François Gand. MEDARD, Nicholas, Nancy. One of the early French
makers.
MEDARD, Franciscus, Paris, I710. Stradiuarius pattern,
good varnish. MEDARD, Nicholas, Nancy. One of the early French
makers.
MEDARD, Franciscus, Paris, I7 Io. Stradiuarius pattern,
good varnish.

Franciscus Medari

fecit Parisiss r 710.

MEdard, Jean, Nancy. Similar to the above.

Miremont, Paris. Exhibited at the Paris Exhibition a Violin with a second sound bar. Experiments of this nature are harmless enough when performed upon modern instruments, but cannot be too strongly deprecated when old and 
rare works are subjected to such levity. An American, some years since, patented an invention where a second sound bar was made to run from block to block, and for the insertion of this freak many valuable Violins were so wantonly sacrificed that their original blocks were cut down. The results, as might be expected, were anything but satisfactory, and necessitated the removal of the improvement and the substitution of entirely new blocks. The invention of Miremont has shared a similar ignominious fate; but, fortunately, few old instruments were subjected to the torture which ripped open their bellies in order to add a new organ to their interior.

By all means preserve your Violins from falling into the hands of enthusiastic inventors!

Miremont has made several excellent Violins, copies of Stradiuarius and Guarnerius.

Modessier, Paris, i81o. Made several instruments of large pattern, excellent for orchestral purposes. Wood of good quality.

NAMY, Paris, 1800.

Nicholas. The instruments of this maker are chiefly of large size, the outline being after that of Stradiuarius. They are mostly stamped on the back, inside. Colour, yellow ; tone very powerful, and admirably adapted for the orchestra.

NigGeL, Paris, i 7 th century.

Ouvrard, pupil of Claude Pierray.

Paul, Saint, Paris, 17th century. Chiefly copied Amati. In the style of Bocquay.

Pichol, Paris.

Pier ay, Clande, Paris, 1725. Was an excellent workman, and many of his productions partake of the Italian character to a considerable extent. They are of two pat-

Claude Pierray, proche la Comedie

a Paris, 1725. terns, the majority being large. Amati would seem to bave been his model, but his instruments can scarcely be considered copies of that maker, the outline only being retained, while the other features are dissimilar. The wood is rarely handsome, but its quality is good. The thicknesses are variable. The work is of average merit. Varnish is of a pale red colour, of good quality.

PIERROT, Lyons.

Piete, Noel, Paris, i780. Made manyViolins, having good points.

PIQue, Paris, I792. As a copyist of Stradiuarius, this maker approached, perhaps, nearest to Nicholas Lupot. It has

Pique, rue de Grenelle

St. Honore, au coin de celle des 2 Ecus, a Paris, 1790 been supposed that many Violins bearing the name of Pique were made by Lupot, and varnished only by Pique. This, however, is pure conjecture, which the marked dissimilarity between 
the works of Pique and that of Lupot at once disposes of. There are several specimens of Pique's instruments upon which have beell lavished care and skill of a very high order. Each feature is brought out, while, at the same time, that common error of the copyist, exaggeration, is avoided. The scrolls are well executed both in point of finish and style; the sound-hole also is cut with precision. Many of his instruments have whole backs of well-chosen material ; the bellies are all of fine quality of wood. The instruments of Pique have long been esteemed, and will grow in reputation.

Pons, Paris.

Pons, Grenoble, 1790.

Rambeaux, Paris, 1840-I860. Was a clever repairer, and gifted with excellent judgment in his treatment of the works of the old masters. He was at one time in the workshop of Gand.

RANT.

REINAULT, I6th century.

Remy, London, I840. Originally from Paris. Copied the old masters with average ability but unfortunately adopted the pernicious practice of preparing the wood, making his instruments prematurely old without the qualities of healthy age.

Salle, Paris, 1830. Made several copies of Guarnerius, many of which are excellent. He was also a clever restorer of old instruments, and had a critical eye for the works of the old Italian masters, in which he dealt to some extent.

Salzar. Made Violins of the character of Chapuy, but with inferior varnish.

SAUNIER, I740.

SoQuer, Louis, Paris, I750. Neat workmanship. Narrow pattern; long middle bouts; yellow varnish.

Sylvestre, Lyons, 1835. A maker of rare abilities. The finish of his instruments is of the highest order ; indeed, it would be difficult to find any maker within the range of the modern French school who has surpassed him in delicate workmanship. It may be said of him, as of many others, that extreme fineness of work is obtained often at the expense of character; to develope both necessarily needs the mind of a Stradiuarius. Sylvestre was fortunate in procuring wood of beautiful quality ; there is scarcely an instrument of his which is not handsome. He copied Stradiuarius. It is to be regretted that so few of his works are to be met with.

Theress, London.

Thibout, Paris, 1824. A well-known dealer in rare Italian instruments. To him belongs the merit of having encouraged Louis Tarisio to bring to Paris his Cremonese gems. When Tarisio paid his first visit to Paris the reception that he met with, was not of such a nature as to warrant his returning; but having ultimately decided upon once more visiting the French capital, he met with Thibout, who, by earnest solicitation, 
prevailed on him to remove his rich wares permanently to Paris.

Tyiversus, 16th century. Probably the earliest maker of Violins in France. He worked near Mirecourt.

Vaillot, Paris.

VAller, Marseilles, 1700.

Veron, Paris, 1720-1750.

Vuillaume, John, Mirecourt, 1700-I 740 .

Vuillaume, J. B., Paris, born 1799, died 1875. There are upwards of 2,500 Violins which bear his name. Many of these he made throughout. The early ones are much appreciated, and having been wisely varnished all over at first, now begin to show the good results of such handling. The career of Vuillaume was singularly eventful. Commencing life from the first stage of the ladder, he gradually mounted to the highest by the help of the usual nurses of fortune, skill and perseverance. He was a great lover of Cremonese instruments, and was intimately associated with Tarisio. At the death of the celebrated Italian connoisseur he purchased the whole of his collection. Among then were the "Stradiuarius" exhibited at the Exhibition of 1862, and the Double-Basses by Gaspard di Salo and Carlo Bergonzi, the latter of which is at present in my possession.

Vuillaume, N. F., Brussels. Brother of the above. Well known both as a maker and connoisseur. 


\section{SECTION IX.}

\section{The ENglish School.}

T $\mathrm{T}$ is somewhat remarkable that the Continental writers on the Violin should have omitted to mention any English maker, either ancient or modern. Such an omission must have occurred either from want of information concerning our best makers, or, if known, they must have been deemed unworthy of the notice of our foreign friends. There is no mention of an English maker in Fetis's treatise on Antonius Stradiuarius, although numerous very inferior German and Italian makers are quoted. The same omission is also, conspicuous in "Luthomonographie" and "Otto on the Construction of the Violin." It may be that Continental connoisseurs have credited themselves with the works of our best makers, and expatriated them, while they have inexorably allowed bad English fiddles to retain their nationality. However, it is my desire that my foreign brothers should be enlightened on this point, and in all candour informed of the array of makers that England has at different times produced, and is yet capable of producing, did but the new Violin command the price that would be a fair return for the time and skill required in the production of an instrument at once useful and artistic. It will be my endeavour to show forth the qualities of those of our makers whose names, as yet, seem never to have crossed the Channel, so that when these pages on the English school are read by distant connoisseurs, and the merits and shortcomings of the makers therein are fairly weighed by them, the good shall be found so to outweigh the indifferent as to entirely change the opinions formed of us as makers of the leading instrument.

Until within the last 30 years makers of Violins in England would appear to have been comparatively numerous, if we take into consideration the undeveloped state of stringed instrument music at that period in this country. Among those makers were many of no ordinary genius, men who worked lovingly, guided by motives distinct from commercial gain, as long as they were allowed to live by their work. When, however, the - duties on foreign musical instruments were removed, the effect was to partially swamp the gallant little band of fiddle makers, who were quite unable to compete with the French and German makers in price (not excellence, be it distinctly understood, for we were undoubtedly ahead of our foreign competitors, both in 
style and finish at this period). The prices commanded by many English makers previous to the repeal of the duty were thoroughly remunerative. Five to twenty pounds were given for English Violns, while Violoncellos and 'ienors commanded prices proportionately high. The English Violin makers were thus enabled to bestow artistic care in the making of their instruments. When, however, they were suddenly called upon to compete on equal terms with a legion of foreign manufacturers, the result was not so much that their ardour was damped, as that they themselves were extinguished, and served as another instance of the truth of the adage that the good of the many is the bane of the few.

In matters of magnitude, whether artistic or otherwise, competition is undoubtedly healthy, their being always a small body of patrons who are willing to check the tendency to deteriorate, common to all productions, by encouraging the worker with extra remuneration, in order that a ligh degree of excellence may be maintained; but in matters confined to a small circle, as in the case of Violin making, the number of those willing to encourage artistic workmanship is so minute as to fail even to support one maker of excellence, and thus, when deprived suddenly of its legitimate protection, the art, with other similar handicrafts, must drift into decadence. If we look around the Violin world, all is much the same. In Italy there are 110 Stradiuariuses in embryo, in France no coming Lupot, in Germany no Jacobus Stainer, and in England no future Banks or Forster. Why so? The answer is twofold. Partly there is fault in the demand, arising from the marked preference of this age for cheapness at the expense of goodness; partly, too, there is fault in the supply, a foolish desire on the part of the makers to give maturity to their instruments, wherein they always completely fail, and yet will not give up their conceit. Here, again, were we dealing with matters of more magnitude, the evil influence would be lessened, the artistic impulses would still be felt, though in a less degree; whereas, so contracted is the circle of the Violin world, that inder any stress the support given to makers willing to bestow an artist's care on their work is totally inadequate.

The case of modern Violin makers is unfortunate. Old Violins being so immeasurably superior to modern productions, the demand must necessarily set steadily for the former, and the modern maker has only the few patrons of new work to support him. It cannot be expected that the players of to-day should patronize the modern Violin in order that the next generation should reap the benefit. Years since it was quite a different matter. The makers were well paid-for their work, and new instruments were then made to supply wants similar to those which the horrid Mirecourt copy fulfils at present. As with other things, so is it also with Violins; if they are to be 
produced with the stamp of artistic merit, they must be paid for accordingly; without patronage the worker necessarily becomes careless. Finding that his skill fails to attract attention, he gradually sinks down into the mere routine of the ordinary workman. IVhen Italy slone brightest in art, the patronage and remuneration which the workers received was considerable. Had it been otherwise, the powers of its Raphael, its Cellini, and last (though not least to the admirers of the Violin), its Stradiuarius would have remained simply dormant. Art, like commerce, is regulated in a great measure by supply and demand. In Raphael's day, sacred subjects were in demand; the Church was his great patron, and thus aided him in bringing forth the gift which nature had implanted within him. In modern times, landscape painting became the favoured subject, particularly in England ; the result of which preference has been to place us in the foremost rank in that branch of art. The stage furnishes another instance of the effect that patronage has in bringing forth latent talent. If the history of dramatic art be traced, it will be found that its chief works were written when the tastes of an appreciative public could be securely counted upon. As it waned so the writers of merit became rarer, or perhaps it would be more correct to say, the plays produced became less meritorious, "the authors being constrained to pander to the prevailing taste.

As further evidence of the effect of patronage on art, a case in point is found in the fabric of Venetian glass. The Venetians, centuries ago, became famous for their works in glass, and the patronage they enjoyed was world-wide; but their country being thrown into an unsettled condition, capital drifted from it, until the blowing of glass, together with other industries, was comparatively extinguished. Within the past few years the art of making glass has shown signs, even in Venice itself, of reviving with all its former vigour in the workshops of Salviati, the success of which is due in great measure to English capital.

With regard to English Violin manufacture, there would be no reason why Violins should not, at the present moment, be produced in England which should fully reach the standard of merit maintained in our forefathers' days, if only the patronage of the art occupied a larger area. The present dearth of English makers does not arise from any national want of talent for this particular handicraft; in fact, we have plenty of men quite as enthusiastic as our foreign friends for a vocation which in England also must be pronounced to be alike venerable in its antiquity and famed for the dexterity of its genius.

The earliest makers of Viols in England seem to have been Jay, Smith, Bolles, Ross, Addison, and Shaw, names thoroughly British. We may take this as good evidence that the making of Viols in England originated with the English, 
and was not commenced by settlers from the Continent. Doubtless the form of the English Viol and its brethren was taken from the Brescian makers, there being much affinity between these classes of instruments. In the few Violins extant by Christopher Wise the Italian character about them is very striking. In them we see a flat model, excellent outline, and varnish of good quality. The Viols of Jay have the same Italian character. Later on we have nanies of some reputation-Rayman, Urquhart, and Barak Norman. In the absence of any direct evidence as regards the nationality of these makers it is requisite to endeavour to trace the style belonging to their works. It will be observed that there was a great improvement in the style of work and varnish of instruments made in England commencing with the time of Rayman, and it is probable that this step in advance was obtained from intercourse with Italy or the German Tyrol. Starting with Rayman, there is a German ring in the name which makes me think that he came from Germany, and, if so, brought with him the semi-Italian character of work common to the makers who lived so near Brescia. If the work and style of Rayman be carefully examined, it will be seen that it embraces much in common with the inferior Brescian makers. The outline is rugged, the sound-hole is of that Gothic form peculiar to Brescia, the liead is distinct from that of the early English type. At the same period Urquhart made instruments of great merit, the varnish of which is superior to that of Rayman's, but is evidently composed of similar ingredients. Its superiority may have arisen from a different mode of mixing only. The name of Urquhart has a North British sound, and it is probable that he was born in Scotland, and settled in London as an assistant to Rayman, who would impart to him the style of foreign work.

The semi-Italian character pervading the instruments made in England at this period seems to have culminated in the productions of Barak Norman, whose best works bear even a more marked Brescian cliaracter than those of Rayman. The model varies very much, sometimes being high, at other times very flat ; in the latter case the results are instruments of the Maggini type. Barak Norman frequently doubled-purfled his instruments, and inserted a device in the purfling, evidently following Maggini in these particulars. With Barak Norman ends the list of English copyists of the Brescian makers.

We now arrive at the copyists of Jacobus Stainer and the Amatis, a class of makers who possessed great abilities, and knew how to use them. The first name to be mentioned is Benjanin Banks, of Salisbury, who may with propriety be termed the English Amati. He was the first English maker who recognised the superior form of Amati's model over that of Stainer, and devoted all his energies to a successful imita- 
tion. Too much praise could not be lavished on Banks for the example which he selected for himself and his fellow makers.

Next follow the names of Forster, Duke, Hill, Wamsley, Betts, Gilkes, Hart, and Kennedy, together with those of Panormo, Fendt, and Lott, who, although not born in England, passed the greater part of their lives here, and therefore require to be classed with the English school. The mention of these makers will bring the reader to the present time.

Upon scanning this goodly list there will be found ample evidence that we in England have had makers of sufficient merit to entitle us to rank as a distinct school, a school of no mean order. We may, therefore, assume that Continental writers who from time to time have published lists of makers of the Violin, and have invariably ignored England, have erred through want of information regarding the capabilities of our makers, both ancient and modern.

The following list will be found to enumerate nearly the whole of the English makers, and the distinctive character of their separate works. 


\section{SECTION X.}

\section{ENGLISH MAKERS.}

\section{BSAM, Thomas, Wakefield, is 33 . \\ Made by \\ Thomas Absam, Wakefield, Feb. 14, \\ 1833 .}

Adams, Garmouth, Scotland, 1800.

Addison, IVilliam, London, 1670.

Aireton, Edward. Was originally employed in the workshop of Peter IVamsley, at the "Harp and Hautboy," in Piccadilly. He made a great many excellent Violins and Violoncellos, and chiefly copied Amati. Varnish of fair quality; colour, yellow. He died, at the advanced age of 80 , in the year 1807 .

AlDRED, 1560. One of the earliest makers of Viols in England, who possessed a considerable reputation.

Askey, Samuel, London, 1825.

BAINES, 1780 .

BAKER, Oxford, 18th century.

Ballantine, Edinburgli and Glasgow, i85o.

BANkS, Benjamin, Salisbury, born 1727 , died 1795 . To this famous maker must be given the foremost place in the English school. He was a thorough artist, and would Benjamin Banks not have been thought lightly of had he worked

Fecit in Cremona's school, and been judged by its

Salisbury. standard. This may be considered excessive praise of our native nuaker ; tut an unprejudiced judge of work need only turn to the best specimens of Bank's instruments, and he will confess

Benjamin Banks,

Alusical Instrument Maker,

In Catherıne Street, Salisbury, 1780. whose histories have never reaclied the light to which their names have attained. How interesting would it be to obtain the name of his master in the knowledge of making instruments! No clue whatever remains by which we could arrive at a satisfactory conclusion on this point. That he was an enthusiast in his art is certain, and also that he was aware to some 
extent that he possessed talent of no mean description. This is evidenced by the fact that many of his instruments are branded with the letters B. B. in several places, as though he felt that sooner or later his works would be highly esteemed and would survive base imitations, and that by carefully branding them he might prevent any doubt as to their author. Many of his best instruments are found to have no brand: it would seem, therefore, that he did not so mark them for some time. He appears to have early formed an attachment to Nicholas Amati, and laboured unceasingly in imitation of him, until he copied him with an exactness difficult to surpass. Now that time has mellowed his best works, they might pass as original Amatis with those not perfectly versed in the characteristics of the latter. Many German makers excelled as copyists of Amati, among others Schönger, of Erfürt, and Massert; but these makers failed in their varnish, whereas Banks was most happy in this particular, both as regards colour and quality. If his varnish be closely examined, its purity and richness of colour is readily seen. It has all the characteristics of fine Italian varnish, being beautifully transparent, mellow, and rich in its varieties of tints. It must be distinctly understood that these remarks apply only to the very finest works of this maker, there being many specimens which bear the label of Banks in the framing of which he probably took but a small share, leaving the chief part to be done by his son and others. Banks cannot be considered as having been successful in the use of his varnish on the bellies of his instruments, as he has allowed it to clog the fibre, a blemish which affects the appearance very much, and has been the means of casting discredit on the varnish among those unacquainted with the real cause. The modelling is executed with skill, thicknesses being carefully arranged throughout. Fortunately, too, for his instruments, sufficient wood has been left in them to enable time to exert its beneficial effects, a desideratum overlooked by many makers of good repute. The only feature of his work which can be considered as wanting in merit is the scroll, which is somewhat cramped, and fails to convey the meaning intended, viz., the following of Amati; but as this is a point having reference to appearance, and, therefore, solely affecting the connoisseur, it may be passed over lightly, and the more so when we consider that Banks was not the only clever workman that has failed in head cutting. He made Violins, Tenors, and Violoncellos, all excellent; but the latter have the preference. His large Violoncellos are the best; those of the smaller pattern are equally well made, but lack depth of tone. The red-varnished instruments are the favourites.

BANks, Benjamin, son of the above, born in September, 1754 ; died, January, I 820 . Worked many years with his father 
at Salisbury, afterwards removed to London, and lived at 30 , Sherrard Street, Golden Square.

BANks, James. Brother of the above. For some years carried on the business of his father at Salisbury, in conjunction with his brother Henry. They ulti-

James and Henry Banks,

Musical Instrument Makers

and Music Sellers,

18 Salisbury. 02 mately sold the business and removed to Liverpool. The instruments of James and Henry Banks are of average merit.

BARNes, Robert, 1780. Worked with Thomas Smith at the Harp and Hautboy in Piccadilly. Afterwards partner with John Norris.

BARRETT, John, 1718. An average workman, who followed the model of Stainer. His shop James Barrett. at the Harp and Crown in Piccadilly, 17bore the sign of the Harp and Crown. Barrett was one of the earliest copyists of Stainer, and in the chain of English makers is linked with Barak Norman and Nathaniel Cross. The Made by John Barrett at ye Harp and Crown in Piccadilly, London, $17-$

BARTON, George, I81o. wood is generally of a very good quality, the varnish yellow.

BETTS, John, born 1755 , at Stamford, I.incolnshire, died in I823. Became a pupil of Richard Duke.

Jo. Betts, No. z, near Northgate the

Royal Exchange,

London, $17-$ He commenced business in one of the shops of the Royal Exchange, where he soon enjoyed considerable patronage. The business was carried on by his descendants till within the last few years.

John Betts does not appear to have made a great number of instruments, but employed many workmen, whose names will be found noticed in their order, into whose instruments he inserted his trade label. He was, perhaps, the earliest London dealer in Italian instruments.

BETTs, Edward, also a pupil of Richard Duke, copied his master with considerable skill. Of course in trying to imitate Duke he was copying Amati. Richard Duke having spent his life in working after the Amati pattern, without attempting to model for himself. The care bestowed by Edward Betts on his instruments was of no ordinary kind. The workmanship throughout is of the most delicate description; indeed, it may be said that neatness is gained at the expense of individuality in many of his works. Each part is faultless in finish, but when viewed as a whole the result is too mechanical, giving as it does the notion of its having been turned out of a mould. Nevertheless, this maker takes rank with the foremost of the English copyists, and in his instruments we liave as good specimens of 
undisguised work as can be readily found. They will be yearly more valued.

Bolles. Made Lutes and Viols.

Воотн, William, I779, Leeds.

Bоoтн, son of the above, Leeds.

BOUCHER, London, 1764 .

Brown, James, London, born 1670 , died 1834 . Worked with Thomas Kennedy. 1860.

Brown, James, London, son of the above, born 1786 , died Banks.

Canusac, London, I788. Associated with the sons of

CARTER, John, London, r789, worked with John Betts.

Challoner, Thomas, London. Similar to Wamsley.

Clark, London. Little known.

COLE, Thomas, London, 1690.

\section{Thomas Cole, near Fetter Lane in Holborn, 16-}

Cole, James, Manchester.

Collier, Samuel, $175^{\circ}$.

Collier, Thomas, 1775.

COLlingwoOd, Joseph, London, 1760.

Conway, William, i 750.

Basses.

CorsBy, Northampton, I780. Chiefly made Double-

Corsby, George. Lived upwards of half a century in Princes Street, Leicester Square, where he worked and dealt in old instruments.

Cramond, Charles, Aberdeen.

CRASK, George, Manchester. Has made a great number of instruments of the common class, having similar characteristics with the modern copies.

Cross, Nathaniel, London, I720. Worked with Barak Norman.

CROWTHER, John, I760-I8Io.

CUTHBERT, London, 17 th century. Maker of Viols and Violins. Many of the latter have merit. Model flat, and wood of good quality. Very dark varnish.

Davidson, Hay, Huntley, i87o.

Davis, Richard. Worked with Norris and Barnes.

DAv1s, William, London. Succeeded Richard Davis in the business now carried on by Edward Withers.

Dearlove, Mark, Leeds.

Dearlove and Fryer,

Musical Instrument Manufacturers,

Boar Lane. Leeds, 1828 . 
Delany, John, Dublin. Used two kinds of labels, one of them very small-

Made by John Delany,

No. 17, Britain Street,

Dublin. 1808.

In the other, which is much larger, he is overflowing with goodwill to the human family, and stalwart confidence in his own abilities, which were of a very slender and apocryphal kind.

Made by John Delany

In order to perpetuate his memory in future ages.

Dublin $18 \mathrm{c} 8$.

Liberty to all the world

black and white.

Dennis, Jesse, London, 1805. Worked with John Crowther.

Dickenson, Edward, London, 1750. Made instruments of average merit. The model is high.

\author{
Edward Dickinson, \\ Maker, at the Harp and Crown in the Strand, \\ near Exeter Change, \\ London. 17-
}

Dickeson, John, I750-1780, a native of Stirling. $\mathrm{He}$ would seem to have lived at various places, some instruments dating from London and some from Cambridge. He was an excellent workman, and chiefly copied Amati. His work much resembles that of Cappa.

Dition, London, 1720.

Dond, Thomas, son of Edward Dodd, of Sheffield. $\mathrm{He}$ was not a maker of Violins. Numerous instruments bear his name, but they are the work of John T. Dodd, L Lott and Bernard Fendt. The merit of Violın, Violoncello and Bow Maker,

New Street, Covent Garden. these instruments is of the highest order, and they are justly appreciated by both player and comnoisseur. Thomas Dodd deserves to be mentioned in terms of high praise, notwithstanding that the work was not executed by him, for his judgment was brought to bear upon the manufacture during its various stages, and more particularly in the varnishing, in which he took the liveliest interest. He had a method of mixing colours, the superior qualities of which he seems to have fully known, if we may judge from the note on his labels, which runs thus: "The only possessor of the recipe for preparing the original Cremona varnish. Instruments improved and repaired." This nudoubtedly savours of presumption, and is certainly wide of the truth. Nevertheless there is ample 
evidence that the varnish used by Thomas Dodd was very excellent, and had a rich appearance rarely to be met with in instruments of the English school. Dodd was encouraged in the art of varnish-making by persons of taste, who readily admitted the superior qualities of his composition, and paid him a handsome price for his instruments. He was thus enabled to gratify his taste in his productions by sparing no means to improve them. He ultimately attained such a reputation for his instruments as to command no less a sum than $£ 40$ or $£ 50$ for a Violoncello. Commanding such prices, it is evident that he spared no expense, or, what was to him a matter of still greater importance, no time. He was most particular in receiv-. ing the instrumens in that incomplete stage known in the trade as "in the white," $i . e$., without varnish. He would then carefully varnish them with his own hands, guarding most warily the treasured secret of the composition of his varnish. That he never departed from this practice may be inferred from the fact that the varnish made by the workmen in his employ, apart from the establishment, for their own instruments, is of an entirely different stamp, and evidently shows that they were not in their master's secrets.

The instruments bearing the Dodd label are not valued to the extent of their deserts, and there can be but little doubt that in the course of time they will be valued according to their true merits. They were made by men of exceptional talent, who were neither restricted in price nor material. Under such favourable conditions the results could not fail to be good.

DoDD, Thomas, London. Son of Thomas Dodd, musical instrument dealer, of St. Martin's Lane. The-father was not a maker of Violins, but possessed excellent judgment, both as regards work and makers, which enabled his son to profit considerably during his early years whilst working with Fendt and Lott. DORANT, William, London, $18 \mathrm{I} 4$.

DukE, Richard, 1768. The name of this maker has long been a household word with EngRichd. Duke, Londini fecit $17-$ lish Violinists, both amateur and professional. Who has not got a friend who is the fortunate owner of a veritable "Duke?" The fame of his majesty Antonius Stradiuarius himself is not greater than that of Richard Duke in the eyes of many a Fiddle Richard Duke, Maker, Holborn, London. Anno 17fancier. From his earliest fiddling days the name of Duke became familiar to him; he has heard more of him than of Stradiuarius, whom he somehow confuses with Cremona. He fondly imagines that Cremona was a celebrated maker and Stradiuarius' something else; inquires, and becomes more confused, and returns again to "Duke," with whom he is thoroughly at home. 
Many excellent judges have wondered how it came to pass that Richard Duke should have been so highly valued, there being, in their estimation, so little amongst his remains worthy of the reputation be gained. The truth is, that no maker, with the exception of the great Cremonese artists, has been so persistently counterfeited. The name of Duke has been stamped upon every wretched nondescript, until judges who had not the opportunity of seeing the genuine article mistook the copies for the original, and hence the confusion. When, however, a really fine specimen of Duke is once seen, it is not likely to be forgotten. As copies of Amati such instruments are scarcely surpassed, varnish, work, and material being of the best description. The copies of Stainer were not so successful.

Duke, Richard, London. Son of the above.

Duncan, Aberdeen, 1762.

EgLiNGToN, London, 1800.

Evans, Richard, London, 1750 . His label is a curiosity-

$$
\begin{aligned}
& \text { Maid in the Paris of } \\
& \text { Lanühengel, by Richard } \\
& \text { Evans, Instrument Maker, } \\
& \text { in the year 17- }
\end{aligned}
$$

FENDT, Bernard, born at Innsprück, in the Tyrol, in 1756, died 1832. He was evidently born a Fiddle maker, genius being stamped in a more or less degree upon all his works. To Thomas Dodd belongs the credit of bringing his talent into play. Dodd obtained the services of Fendt upon his arrival in England, which the latter reached at an early age. He remained with Dodd many years, frequently making instruments with John Frederick Lott. The instruments so made bear the label of Thomas Dodd. Lott being also a German, reciprocity of feeling sprung up between him and Fendt, which induced Lott to exchange the business to which he was brought up for that which his fellow countryman, Fendt, had adopted, and henceforth to make Violins instead of cabinets. By securing the services of these admirable workmen, Dodd reaped a rich harvest. He found in them men capable of carrying out his instructions with an exactness that could not have been surpassed. Dodd was unable to use the tools himself, but in Fendt and Lott he had men who were consummate masters of them. When the instruments were finished as far as construction was concerned, they were clothed in coats of the master's livery-" "Dodd's varnish," the secret of making which he kept carefully to himself. With these coats of varnish upon them the work was doubly effective, and every point of excellence was made to shine with the happiest effect. Upon leaving the workshop of Thomas Dodd, Bernard Fendt worked for John Betts, making many of those copies of Amati which are associated with the name of Betts, and which have so high a value. 



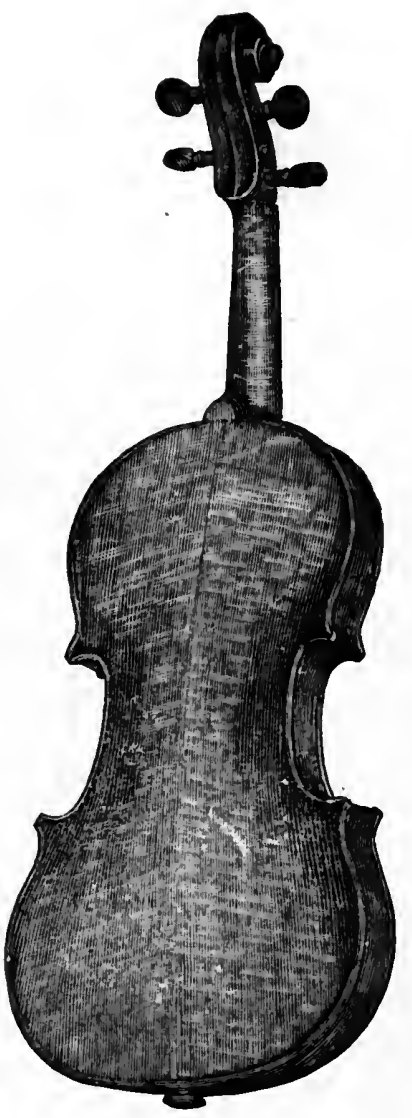

Antonilis Stradiuarius. 
Although Fendt was German by birth, his style of work cannot be considered as German in character. Having early quitted his post of trade in Paris for England, and having in this country placed himself under the guidance of Dodd, who steadfastly kept before his workmen the originals of the great Italian masters for models, his work acquired a distinctive stamp of its own, and in its turn gave rise to a new and independent class of makers.

FENDT, Bernard Simon, London, born in ISoo, died in 185I. Son of the above. He was an excellent workman. It is to be regretted that he did not follow the example set by his father, and let time do its work without interruption upon his instruments. Had he done so they would, in many instances, have been equal to those of his parent ; but, unfortunately, he worked when the mania for obtaining supposed maturity by artificial means was at its height, and shared the general infatuation, and, in consequence, very frequently destroyed all the stamina of his instruments. Subsequently he became a partner of George Purdy, and carried on a joint business at Finch Lane, in the City of London, from whence most of his best instruments date, having removed to the West End about 1843 . He was a most assiduous worker. The number of Violins, Tenors, Violoncellos, and Double-Basses that he made was very great; indeed, his reputation would have been greater had he been content to have made fewer instruments and have exercised more general care. His copies of "Guarnerius" are most numerous, numbering some hundreds. They are mostly varnished with a glaring red colour, of a hard nature. He made many good Double-Basses of the Gaspard di Salo form, the varnish of which is superior to that of his Violins. He made also an excellent quartett of instruments-Violin, Viola, Violoncello, and Double-Bass, for the Exhibition of 1851 . They were certainly the best contemporary instruments exhibited, but he failed to obtain the prize medal.

FENDT, Martin, London, born in r812. Brother of the above. Worked for Betts.

FENDT, Jacob, London, born 1815, died 1849. Third son of Bernard Fendt. The best maker among the sons of Bernard. His instruments are beautifully finished, and free from the stereotyped character belonging to those of his brother Bernard. As specimens of the imitator's art they are unequalled. One cannot but regret that such a consummate workman should have been obliged to waste his energies in making new work resemble that of a hundred years before. The patronage that he obtained was not of much value, but had he brought his work into the market in its natural condition he would not have lived by his trade. He was, therefore, compelled to foster that which he no doubt felt to be degrading. The copies of Stradiuarius by Jacob Fendt are among his best efforts. The 
work is well done; the discoloration of the wood cleverly managed, the effects of wear counterfeited with greater skill than was ever done before or since, and finally, an amount of style is thrown into the work which transcends the ingenuity of any other copyist. Had he been allowed to copy the form of the old masters, as Lupot did, without imitating the actual wear of the instrument, we should have had a valuable addition to our present stock of instruments of the Panormo class.

FENDT, Francis, London. Fourth son of Bernard.

FENDT, William, London, born 1833 , died 1852 . Son of Bernard Simon Fendt. Was an excellent workman, and assisted his father in the manufacture of several of his Double-Basses.

Ferguson, Donald, Huntley, Aberdeenshire.

Findlay, James, Padanaram.

FIRTH, Leeds, I836.

Forster, William, born in $17 \mathrm{I}_{3}$, died I8OI. The family of the Forsters, of which the subject of this

William Forster, Violin Maker, in Brampton. notice was the first as a maker of stringed instruments, have played no unimportant part in the history of Violins. The attention they commanded as makers both from artists and amateurs has probably never been equalled in England. Their instruments claimed attention from the moment they left the makers' hands, their construction being excellent in every way. William Forster was a native of Brampton, in Cumberland, where he followed the trade of a spinning-wheel maker, occupying his spare time in the making and repairing of Violins and musical instruments generally. His labours, as far as they relate to Violin-making, appear to have been of a very unpretending nature, but they served to impart a taste for the art to his son William, who was the best maker of the family.

GORSTER, William, London, born I 739, died I808. Son of William Forster mentioned above.

William Forster, Violin Maker,

in St. Martin's Lane, London, 17Worked with his father at Brampton, in Cumberland, making spinning-wheels and Violins - two singularly diverse occupations. It was, however, to the latter industry he gave the most atiention, and he soon became the great maker of his neighbourhood. $\mathrm{He}$ also continued to add another string to his bow, viz., that of playing country dances at the village festivities. Thus armed with three occupations, he must have been well employed. He seems to have early discovered that his abilities required a larger field in which to show themselves to advantage, and accordingly took the usual course in such circumstances - came to the Metropolis, in which he settled about the year 1759. He soon obtained employment at a musical instrument seller's on Tower Hill, and gave up then and for ever the making of spinning-wheels, while by 
throwing all his soul into the manufacture of Violins he soon gave his master's patrons the highest satisfaction. He ultimately cominenced business on his own behalf in the neighbourhood of Duke's Court, St. Martin's Lane, where his abilities attracted considerable attention, and secured him the patronage of the dilettanti in the musical world. For several years he followed the path trodden by the makers of the period, and copied Stainer. His instruments of this date are very excellent both in workmanship and material, but are not equal to those of the Amati pattern, which he commenced to make about the year 1770 . These are beautiful works, and have a great charm from their being so varied. Some are copies of Antonius and Hieronymus Amati, variously modelled; others are copies of Nicholas Amati. The wood and varnish also varies very much, but the high standard of goodness is well maintained throughout. His varnish was, during the last twenty years of his life, very fine in quality, and in the manufacture of it he is said to have been assisted by a friend who was an excellent chemist. He made only four Double-Basses, three of which were executed for the private band of George III. Forster's instruments were the favourite equipment of Robert Lindley, and their value in his day was far higher than at the present moment. When Lindley died, attention was turned to Italian Violoncellos, and a vast number having been brought to England, the value of Forster's productions was very considerably depreciated; now, however, that the cultivation of stringed instrument music has been so much extended, they are rapidly rising again to their former level, Italian instruments being a luxury not obtainable by every one, and age having so benefited the tone of Forster's Violoncellos as to render them excellent substitutes.

Forster, William, London, born in 1764 , died 1824 . Son

William Forster, Junr.

Violin, Violincello, Tenor \& Bow Maker,

18- Also Music Seller No. 43

to their Royal Highnesses the

Prince of Wales and the Duke of Cumberland. of William Forster, the second of the family. Although this maker did not attain to the celebrity of his father, $h$ is instruments are often fully as good. The

workmanship is very neat, and the modelling excellent; the varnish being equal to that on his father's instruments.

Forster, William, London, born in 1788 , died I824. Son of William Forster, mentioned above. He was a very good workman: he made but few instruments.

Forster, Simon Andrew, London, born in ISor, died about 1869. Brother of IVilliam, mentioned above. He learned his business from his father and Samuel Gilkes, who worked for William Forster. He made several instruments between the years 1828 and 1840 , which are of average merit. 
FrankLand, London.

Furber, London. There were several makers of this family, some of whom worked

John Furber, Maker, 13, John's Row, Top of Brick Lane, Old St., Saint Luke. 1813 .

for Betts, of the Royal Exchange. Many of their instruments are excellent, and should unquestionably be more valued than they are.

GibBs, James. Worked for Samuel Gilkes and others.

Gilkes, Samuel, London, born in 1787 , died in 1827 . Was born at Morton Pinkney,

Gilkes,

From Forster's,

Violin and Violoncello Maker, 34, James Street, Buckingham Gate, Westminster. in Northamptonshire. He became an apprentice of Charles Harris, whose style he followed with much success. Upon leaving Harris he engaged himself to William Forster, making many instruments for him, retaining, however, all the features of the style of Harris. In the year 1810 he left the workshop of Forster, and commenced business on his own account in James Street, Buckingham Gate, where the few instruments bearing his name were made. Too much cannot be said in praise of this excellent maker; he was a thorough artist, and the exquisite finish of his works evidence that the making of them was to him a labour of love. Anlati was his favourite model.

Gilkes, William, London, born I811, died 1875. Son of Samuel Gilkes. Has made a great number of instruments of various patterns, chiefly Double-Basses.

GovGH, Walter. An indifferent workman.

HARDIE, Matthew, Edinburgh, dates from 1815. He was the best maker Scotland has had. The model is that of Amati ; the work throughout excelient. The linings are mostly of cedar. Hardie.

Hardie, Thomas, Edinburgh. Worked with Matthew

HARHAM, London, $1765-1785$.

HARE, Joseph, London, about 1726. Copied Stainer. Little known.

HARR1S, Charles, London, 1800 . This maker is known only to a few dealers, as he made chiefly for the wholesale merchants of his day. His name was rarely affixed to his instruments, but those thoroughly acquainted with his work agree in giving him a foremost place among the makers of this country. He was, like many other makers of that period, engaged in two occupations differing very much from each other, being at the same time a Custom-house officer and a maker of Violins. The former circumstance brought him into contact with mercantile men, and enabled him to obtain commissions to make Violins for the export trade. His business 
in this direction so increased that he obtained the services of his relative, Samuel Gilkes, as his assistant. He copied chiefly Amati and Stradiuarius, the latter admirably. Many of these copies are not inferior to those of Lupot. He never aimed at producing a counterpart of the instrument that he copied by resorting to the use of those deleterious means to indicate upon the surface of an instrument the ravages of time. He faithfully copied the form, and thus did what Lupot was doing at the same period. The exquisite finish of these instruments is remarkable, and as they are covered with a fine quality of varnish, they have every recommendation of appearance.

HART, John Thomas, born Decenber i 7 th, ISo5, died January Ist, IS74. He was articled to

John Hart, Maker,

14, Princes St., Leicester Square,

London. Anno I8Samuel Gilkes in May, IS20, of whom he learned the mechanical branch of his profession. He afterwards centred his attention upon the peculiar characteristics of the

Cremonese and Italian Violin makers generally, and in a comparatively brief space of time obtained an extensive acquaintance in that direction. His unerring eye and powerful memory of instruments once brought under his notice secured for him the highest position among the connoisseurs of his time. Commencing business at a period when the desire to possess instruments by the famous Italian makers was becoming general among amateurs, and being peculiarly fortunate in securing an early reputation as a judge of them, he became the channel through which the greater part of the rare Italian works passed into England, and it has been frequently said that there are very few distinguished instruments in Europe with which he was unacquainted. Among the remarkable collections that he brought together may be mentioned that of the late Mr. James Goding, the remnant of which was dispersed by Messrs. Christie and Manson in I $\$ 56$; the small but exquisite collection of Mr. Charles Plowden, consisting of four Stradiuariuses and four Guarneriuses, with other instruments of less merit, the whole of which again passed into Mr. Hart's possession upon the death of their owner; and, lastly, a large portion of the well-known collection of the late Mr. Joseph Gillott, sold by Christie and Manson shortly after the famous sale of pictures belonging to the same gentleman. This collection of Violins realised upwards of $f 4,000$. To mention individually the gems comprised in this array of Cremona's handiwork would be a difficult task, but among them may be noticed the Guarnerius known as the "King," the Stradiuarius Viola, formerly Lord Macdonald's ; the beautiful Stradiuarius Violin, long in the possession of the late Mr. P. Roberts, and now belonging to Mr. John Adam. HeEsom, Edward, London, 1748. Copied Stainer. 
Hıll, Joseph, London. Pupil of Peter Wamsley. His Violoncellos and Tenors are well made instruments.

Joseph Hill, Maker, at the Harp and Flute,

in the Hay Market,

London.

Hill, IVilliam, London, I74r. Son of the above. Very good work.

William Hill, Maker, in Poland Street, near Broad Street, 17 -

Hill, ,oseph, London, I80o-1840. Son of the above.

Hils, Lockey, London, $1800-1835$. Brother of the above. Made many excellent instruments.

Hil., IVilliam Ebsworth, London, now living. Son of Lockey Hill. Has made several instruments in his younger days, but, like the rest of our English makers, has discovered that new work was unremunerative, and turned his attention to repairing and dealing in old instruments, whereby he enjoys his full share of patronage from the Violin world. He exhibited at the Exhibition of 1862 a Violin and Tenor, to prove that Violin making was not quite extinguished in England.

Holloway, J., London, 1794.

Hume, Richard, Edinburgh, 16th century. A maker of Lutes, \&c.

JAYE, Henry, London, I $7^{\text {th }}$ century. Maker of Viols, which are capital specimens of the work of the period. The varnish is excellent. work.

JAy, Thomas, London. Related to the above. Excellent

JAx, Henry, London, I750. A maker of Kits chiefly. At this period these juvenile Violins were

Made by Henry Jay, in Long Acre, London. 1746. A few years ago a very choice collecin much demand by dancing masters.
A few years ago a very choice collec-
tion of these instruments was made by an Irish gentleman residing in Paris, who obtained specimens from all parts of Europe.

Johnson, John, London, 1750 . His violins are dated from Cheapside.

$$
\begin{aligned}
& \text { Made and Sold by John Johnson, } \\
& \text { at the Harp and Crown, in Cheapside, }
\end{aligned}
$$

17 London. 53.

KENNEDY, Alexander, London, 1700-1786. IVas a native of Scotland. He was the first maker of Violins in his family, which became rather famous in the manufacture, and lasted nearly two centuries.

Alexander Kennedy, Musical Instrument

Maker, living in Market Street, in Oxford,

Road, London. 17- 
Kennedy, John, London, born 1730; died 1816. Nephew of Alexander Kennedy. Made Violins and Tenors.

KenNedy, Thomas, London, born I784; died about 1870. Son of the above. This maker made probably more instruments than any two English makers that could be mentioned, if we except that prolific workman Craske.

LENTZ, Johann Nicolaus, London, 1803. He used mostly one kind of wood, viz., close grained maple. Varnish nearly opaque.

\section{Johann Nicolaus Lentz, fecit} near the Church, Chelsea. 1803 .

Lewis, Edward, London, 1700 . The work is well executed throughout, and the varnish superior.

LOTT, John Frederick, 1775-IS53. Was a German by birth. He was engaged in the cabinet business early in life. $\mathrm{He}$ was induced by Fendt to turn his attention to making Violins, and ultimately obtained employment under Thomas Dodd, making many of the Violoncellos and Double-Basses that carry the label of Dodd within them. His work was of a most finished description. His Double-Basses are splendid instruments, and will bear comparison with Italian work. His varnish was far from equal to his finish. The time he spent in making these instruments was double that which any other English maker expended over similiar work. There is not a single portion of any of his Double-Basses that has been carelessly made; the interior is as beautifully finished as the exterior. The machines on many of his Basses were made by himself, a very unusual circumstance. The scrolls are finely cut. He was certainly the king of the English Double-Bass makers, and his name will long live among Contra-Bassists.

LotT, George Frederick, London, born 1800 ; died 1868. Son of the above. Many years with Davis of Coventry Street. Was an excellent judge of Italian instruments, and a clever imitator.

LOTT, John Frederick, London, younger brother of the above, died about 1871 . IVas articled to Davis. Has made many clever imitations. He was also an ardent lover of Cremonese instruments, and thoroughly understood their characteristics.

Macintosh, Dublin. Succeeded Perry and Wilkinson. Dier about 1840 .

MarShall, John, London, 1750.

Johannes Marshall (in vico novo juxta

Covensam hortum) Londini. Fecit 17-

Martin, London, i80o.

MIER, London, 7786. 
Millar, Alexander, St. Andrew's.

MORRISON, John, London, I780-I823.

MURDOCH, Alexander, Aberdeen.

NAYLOR, Leeds, i8th century.

Norborn, John, London, 1723.

NoRMAN, Barak, London, I688-1740. The instruments of

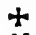

Barak Norman and

Nathaniel Cross, at the Bass Viol in St.

Paul's Church Yard,

London. Fecit 172this maker are among the best of the Oid English school. His instructor in the art of Viol and Violin making is unknown, but judging from the character of his work it is very probable he learned from Thomas Urquhart. This opinion is strengthened upon examining his earliest instruments. We there find the same peculiarities which mark the individuality of Urquhart. Later in life he leaned much to the model of Maggini.

During his early years he was mucl esteemed as a maker of Viols, many of which have all the marks of careful work upon then. On all these instruments will be found his name, surrounded with a design in purfling, under the finger board, or his monogram executed in purfling. The same trade token will be found on his Violoncellos. All endeavours to discover any existing Violoncello, or record of one, anterior to Barak Norman have failed, and, consequently, it may be assumed that Barak Norman was the first maker of that instrument in England. Here, again, is evidence of his partiality for the form of the Naggini, both father and son, as he copied these makers in nearly all his Violoncellos. All the Violoncellos of Barak Norman have bellies of splendid quality; the modelling is executed skilfully, due care having been observed in leaving sufficient wood. His Violas are fine instruments. Many of these were made years before he began the Violoncellos, a fact which satisfactorily accounts for the marked difference in form peculiar to them. The build is higher, and the sound-hole German in character; the varnish is very dark. About the year I 7 I5 Barak Norman entered into partnership with Nathaniel Cross, carrying on the joint business at the sign of the "Bass Viol," St. Paul's Churchyard. In a Viol da Gamba owned by Nalter Brooksbank, Esq., of Windernere, is a label in the handwriting of Nathaniel Cross, by which he adds the power of speech to the qualities of the quaint Gamba; the words are, "Nathaniel Cross wrought my back and belly." The sides and scroll being the work of his partner.

NoRRIS, John, London, born 1739; died 1818. Articled to

Made by Norris and Barnes, Violin, Violoncello, and Bow Makers,

To their Majesties.

Coventry Street, London.
Thonas Smith, the successor of Peter Wamsley. Similar work to that of Thomas Smith. He became a partner of Robert Barnes. 
Pamphilon, Edward, London, i 7 th century. The Violins of this maker were formerly much prized. Edward Pamphilon, The model is very high, and the appearance April the $3^{\text {rd, }}$ 1685. Somewhat grotesque. It is to be regretted that the splendid varnish often found on these instruments was not put upon better work.

PANORMo, Vincent. (See Italian School.)

Panormo, Joseph, London. Son of Vincent Panormo. His work was excellent. His Violoncellos are decidedly superior to his Violins.

Panormo, George Lewis, London. Brother of the above. Made Violins of the Stradiuarius pattern.

PaNormo, Louis, London. Made Guitars chiefly.

PARKER, Daniel, London, I 8 th century. This is another maker of the English school, who was possessed of exceptional talent, and whose instruments are well worthy of attention from those in search of good Violins at a moderate cost. To Parker belongs, in conjunction with Benjamin Banks, the merit of breaking through the prejudice so long in favour of preference for the Stainer model.

The date of his instruments extend from the year 1740 to 1785. He left his Violins thick in wood, which has certainly enhanced their value now that time has ripened them. He used excellent material, which is often very handsome. The varnish is of a mellow quality, and fairly transparent. A large number of these Violins have been passing under other makers' names, and but little noticed.

PEARCE, James, London, I8th century.

PEMBerton, Edward, London, I66o. This maker has been often mentioned as the author of a Violin said to have been presented to the Earl of Leicester by Queen Elizabeth, and to snit this legend Pemberton's era has been put back a century. The date given above will be found in the Violins of this maker.

PeRry and Wilkinson, Dublin, 17 - to 1830 . The instruments bearing the label of these makers are invariably excellent both in tone, material and finish.

POWELL, London, I8th century.

Made by Thoma

Powell, No. 18, Clema.

Lane, Clare Market.

1793.

Preston, John, York, I8th century.

John Preston, York, 2791 Fecit. 
Rayman, Jacob, London, 1 th century. The subject of this notice was probably a Jacob Rayman dwelling in Blackman German from the Tyrol, who Street, Long-Southwark. 164r. Settled in England about 1620, and may be considered as the founder of Violin making in this country, there being no trace of any British Violin maker previous to Jacob Rayman, at ye Bell that time. His work is quite different Yard in Southwark, from that of the old English Viol makers, London, 2648. and thoroughly Tyrolean in character. Violins were common in Germany and Italy at this period, and in coming to England he very likely felt that a new field of labour was open to him. The instruments of Rayman are of a somewhat rough exterior, but full of character. The form is flat, considering the general style of the work. The sound-holes are striking, although not graceful in any way. The scroll is diminutive, but well cut. The varnish is very fine.

Rook, Joseph, London, 1800.

Ross or Rosse, London, I562. Made Viols and Bandoras.

Ross, London, 16oo. Son of the above.

SHAw, London, 1655 .

SimpSON, London, I 785 .

\author{
John Simpson, \\ Musical Instrument Maker, \\ At the Bass Viol and Flute, \\ in Sweeting's Alley, \\ Opposite the East door of the Royal Exchange, \\ London.
}

Smith, Henry, London, I629. Maker of Viols.

Smith, Thomas, London. Pupil of Peter Wamsley, and his successor at the Harp and Hautboy.

Made by Thos.'Smith, at the Harp and

Hautboy, in Piccadilly, London. 1756.

Smiти, William, London, about 1770.
William Smith,
Violin Maker,
Hedon. 1786 .

TAYLOR, London, about r8oo. A maker of much merit. Instruments of the character of Panormo.

THOMPSON, London, 1749 .

Robert Thompson, at the Bass Violin, in Paul's Ally, St. Paul's Church Yard. 
THOROWGOOD, Henry, London. Little known.

ToBIN, Richard, London, i8oo. Pupil of Perry, of Dublin. A beautiful workman. His instruments are much appreciated by the best judges. In cutting a scroll he was unequalled amongst English makers.

TOBIN, London. Son of the above.

URQUHART, London, 17th century. Nothing is known concerning the history of this excellent maker. The style may be considered as resembling that of Jacob Rayman, and it is possible that he worked with him. His varnish is equal to that on many Italian instruments.

VALENTINE, William, London, now living. Made many Double-Basses for Mr. Hart, which are highly valued.

Wamsley, Peter, London, I8th century. One of the finest English Violoncello and Viola makers. His copies of Stainer are very superior.

Made by Peter Wamsley, at ye Golden Harp, in Piccadilly,

London. 17Davis.

Withers, Edward, Coventry Street. Succeeded William Soho.

Withers, Edward. Son of the above. Wardour Street,

Young, London, about 1728. Lived in St. Paul's Churchyard. Purcell has immortalised father and son in the first volume of his Catches.

"You scrapers that want a good fiddle well strung,

You must go to the man that is old while he's Young;

But if this same fiddle you fain would play bold,

You must go to his son, who'll be Young when he's old.

There's old Young and young Young, both men of renown,

Old sells, and young plays, the best fiddles in town;

Young and old live together and may they live long,

Young, to play an old fiddle; old, to sell a new song." 


\section{SECTION XI.}

The German School.

THE Germans do not appear to have commenced making d6 Violins until long after the Italians at Brescia. "liere is no trace of any German Violins of the time of (jaspard d) Salo, Mariani, or Maggini the elder. This is certainly remarkable, and the more so when we consider low near were the German makers of Lutes, \&c., to the old ltalian town where Violins were being made. It is evident from this nonproduction of Violins that the Tyrolese were content with their Viols and Lutes, and did not recognise the wonderful effects of the little Violin until it had become pretty nearly perfected by the Italians. The manufacture of Lutes and Viols in Germany had in 1650 , or a little later, reached its zenith, and the exquisite pieces of workmanship, in the shape of Lutes, Viols da Gamba, and Viols d'Amour, richly inlaid with mother-of-pearl, ivory, and tortoiseshell, made at this period, evidence the higl state of the art. Among the Viol and Lute makers of this time were Jean Kohl and Possen, of Munich ; Meusidler, of Nurt nuberg ; and Mohr and Tielka, of Hamburg, the two latter ordinarily making Viols, and the rest Lutes.

The earliest maker of the true Violin in Germany was, perhaps, Fichold; and next came Matthias Albani, the father of the celebrated maker of that name. If we look at the instruments of this Albani, we at once observe that there is a conspicuous incompleteness in outline and model. We are reminded of the Pamphilons of our own country; not that there is any resemblance in either form or outline in the productions of these several makers, but there is the same undeveloped character in their works, which is a gauge of the imperfect state of the manufacture at the time. The followers of Albani were very numerous; all adopting the exaggerated height of belly and deep modelling of that maker. Among these may be mentioned Johann Schorn, of Inspruck (whose Violins, by the way, are mostly attributed to the elder Albani), Schonger, Scheinlein, Hassert, and others of less repute. When Jacobus Stainer returned from Italy, whither he had travelled to receive instruction, he, to a great extent, changed the system of modelling so long in vogue in Germany. Although so great a maker, he was seemingly unable to free himself entirely from the proclivities common to his countrymen who were Violin makers. There remained, after all Stainer's changes, the 
German sound-hole and extra arching, \&c. Yet it must be readily admitted that the example which Stainer put before his countrymen was of great value, and served to set a new fashion for the whole cause of Violin manufacture in Germany. The exceptional merits of this famous German artist were soon recognised, and his followers were legion. Among them were Sebastian Kloz, George Kloz, Egidius Kloz, and other members of that, perhaps the largest, family of Fiddle makers that the world has had (had they been as good as they were numerous, what stores of prized Violins would have been bequeathed to us !); Reiss, of Bamberg; Rauch, of Breslau ; and Leopold Withalm, of Nuremberg, who was one of Stainer's best imitators; and others less known.

There were several German makers-led, possibly, by the example of Stainer and Albani the younger, who turned their attention to Italy, as furnishing models superior to their own, and thus combined the styles of both countries; while they endeavoured to copy closely the Italian masters, without attenupting to be original. Nicholas Amati was the maker whom these men chiefly copied, and most successfully did they perform their task. These copies, however, did not meet with the success to which they were entitled, and the popularity of Stainer's mode was then so great that the instruments made upon other systems than his found no favour in the Fatherland. The makers who were faithful copyists of the Italian masters were Ruppert, Bachmann, Jauch, and Eberle, of Prague.

When we consider the vast number of makers forming the German school, we cannot fail to feel surprised that the number of really good artists was not much larger; and our surprise increases when the close proximity of the Tyrolese workers to the chief Italian centres of the manufacture of Violins is also considered. If the names of Jacobus Stainer, Withalm, and Albani be excepted, the list is singularly destitute of makers famous for originality. The Germans were certainly great in the manufacture of the old stringed instruments, but seem to. have made a poor beginning in the making of Violins. The form selected was bad, and they failed to improve upon it to any great extent. It would be quite impossible to furnish "any thing approaching a complete list of German makers, their numbers being so extended, and so many of their instruments being anonymous, and withal so weak in character, that it is hard to discern them. Every care, however, has been taken to render the following list as complete as possible. With this school is classed that of Holland, which has produced so few makers that it seems unnecessary to arrange them in a separate list. 


\section{SECTION XII.}

\section{German Makers.}

7 LBANI, Matthias, Botzen, born, 1621; died, 1673. One of the earliest German makers. The form is somewhat like Stainer's, but higher and heavier in construction. The varnish is very rich. Wood of good quality.

AlBANI, Matthias, Botzen, about r65o. Soll of the above. This maker should, perhaps, have been

Mathias albani in bulsani

Thiroli fecit anno $16-$

classed with those of Italy, his style being quite Italian; but as he was the son of the well known German maker, it "was thought best that his name should follow that of his father under the head of German makers. The difference between the two Albanis is very great, and the son has shown but faint marks of having been tutored at all by his parent in the art of Violin making. He wisely decided to visit Cremona, in order, no doubt, to receive instruction there under Amati, and from this circumstance he gave to his work that Italian air which is so pleasing to the connoisseur. This maker is often credited with the work of the elder Albani, it having been supposed that there was but one of that name. The model is good, and the workmanship throughout demands high praise. Botzen.

Albani, Sicily, 1633. Probably related to the Albanis of

Alletsee, P., Munich, 1727.

ArtmanN, Wegman, near Gotha, i8th century. Was originally a joiner. Copied Amati very cleverly. The varnish is frequently of amber colour.

BachmanN, Berlin, I8th century. The work is clean, and not without style.

BAUCHE, Leipsic.

BECKMAN, Stockholm, about 1700. The work is rough.

BINTERNAGLE, Gotha, I 8th century. Copied Amati chiefly. There are a few of his instruments which are on the model of Stradiuarius, and are highly valued in Germany.

BREMEISTER, J., Amsterdam, about 1700 . The pattern is pinched and unsightly. Work, of average merit.

BUCHSTADTER, Ratisbon, I8th century. His Violins vary very much. Some have excellent wood, others very indifferent. When one of his best instruments can be procured it is a good substitute for a second-class Italian. 
Christa, Joseph Paul, Munich, 1730.

Josephus Paulus Christa, Lauten

und Geigenmacher in München. 17-

DARChe, Aachen. Imitator of the old masters.

DIEHL, Nicholas, Darmstadt, I690.

DiEhL, Hamburg.

DURFEL, Altenburg, I8th century. A well-known German Double-Bass maker.

Eberle, Jean Ulric, Prague, 1750. Was a good copyist of the Italian masters.

Edlinger, Prague, I7I2.

EDLINGER, Joseph Joachim, Prague. Son of the above.

ElsLer, Joseph, Mayence, I720-1750. Made many good Viols da Gamba.

ERNST, François Antoine, Bohemia, I745-1765.

FEBBRE, Amsterdam, 1762. Made Violoncellos.

FichrL, Martinus, Vienna, 1757. Large pattern ; excellent varnish; wood of good quality.

Fichtold, Hans, i6i2.

FICKER, Johann Christian, Cremona, I720. Said to have lived in the midst of the greatest makers the world has had ; if so, he certainly did not make himself acquainted with the art of Violin making as understood in Cremona. His instruments may have been made at Mittenwald, and dated from Cremona.

FICKER, Cremona, I789.

FISCher, Zacharie, Würtsburg, 1730. This maker introduced the baneful practice of baking the wood for the manufacture of Violins.

FREV, Hans, Nuremberg, 1450. A celebrated maker of Lutes and Viols. He was the father-in-law of Albert Durer.

FRITZ, Hans, Nuremberg.

FritzsChe, Samuel, Leipsic, I790.

GalbuserA, C. A., I83o. Made Violins of Guitar shape; a method which has been often tried but has never succeeded. Chanot, a French amateur, and George Lott, London, made instruments of this form.

GEDLER, Johann Benedict, Fissen, I8th century.

GEDLER, Johann Antony, Fissen, I8th century. Viols.

GERLE, Jean, Nuremberg, I550. Maker of Lutes and

GrIMM, Berlin, now living.

Grobitz, Warsaw, i8th century.

GuGEMmos, Bavaria, indifferent work.

Hamberger, Joseph, Presburg, I845.

HAmm, Johann Göttfried, Rome, I8th century. Made instruments of a wide pattern, often with ivory edges, and branded inside with his initials. 
Hansel, John Anthony, Leipsic. made.

HASSERT, Eisenach, 18th century. Instruments well

HASSERT, Rudolstadt, 18th century.

Helmore, Charles, Prague, 1735-1750. Pupil of Eberle. .

Hildebrant, Michael Christopher, Hamburg, I77o.

Hillmer, I840.

HOFFMANn, Martin, Leipsic, I8th century.

Hornstainer, Matthias, Mittenwald. Similar to Kloz

HüLLER, Augustine, Shœneck, 1775.

HUMEL, Christian, Nuremberg, ahout 1709.

HüNGER, Christopher Frederick, Leipsic, 1780. One of the best German makers.

JACoBI, Meissen. A famous Lute maker.

JACOBS, Amsterdam, 1690-1740. A close imitator of Nicholas Amati. Few makers have been more mistaken than Jacobs; so exact was he in following the model of Amati, that numbers of his Violins are passed by the inexperienced as original. He mostly selected the grand pattern of Amati for his model, which gave him full scope for the exercise of his powers. He selected wood as nearly as possible resembling that found in the works of Nicholas Amati. The backs are mostly of even grain, and compact; the modelling can only be found fault with near the purfling, where its sharpness at once catches the attention of the critic in these matters, and divulges the true author. The varnish, though good, is not equal to that of Amati. The scroll is inferior to the body in merit. The purfling is of whalebone, like that of most of the Dutch makers.

JACoBs, Amsterdam, probably a son of the above. Excellent varnish of a deep red, very transparent, full of character, but wanting in finish. Purfling embedded.

KAMBL, Johann Cornelius, I640.

John Andreas Kambl Churfürft!.

Hof Lauten und Oeigenmacher

in München.

Kiaposse, Sawes, St. Petersburg, 1750.

KiRschschlag, Tyrol, I78o. Court.

KOHL, Jean, Munich, I580. Lute maker to the Bavarian

Kolditz, Matthias Johann, Munich, I720.

Mathias Joannes Koldjz,

Lauten und Geigenmacher in

München 17-

Kolrker, Paris, i8th century. 
KLotz, Joseph, Tyrol.

KLoz, Matthias, Tyrol, I670-1696. Pupil of Stainer. The work is good, but the varnish poor. Much of the wood that he used was cut at the wrong season, and is consequently wormeaten. It is an error to give Matthias the foremost place in this large family of Violin makers-his son Sebastian was his superior.

KLOz, Sebastian, Tyrol, son of Matthias Kloz. The instruments of this maker are highly valued;

Sebastian Kloz, in Mittenwald, An 17they are superior in pattern and style to those of his father. The model is flat as cumpared with most Violins of the German school. The varnish varies, but it sometimes appears to be of the quality belonging to that of Albani.

KLoz, George, Tyrol, brother of Sebastian Kloz. Instruments well made, chiefly yellow in colour; wood often wormeaten.

KLOz, Egitia, Tyrol, brother of the former.

KNITL, Joseph, Mittenwald.

KNITTING, Mittenwald, 1760.

KRINER, Joseph, Mittenwald, 1786.

LIDL, Antonie, 1700.

Marer, Andrea Ferdinand, Salzburg, 1750.

MALDONNER, Bavaria, 18th century.

MaNSIELL, Leonard, Nuremburg, 1728.

Mayer, Andrea Ferdinand.

\section{Andreas Ferdinandus, Mayrhof \\ Laut, und Geigenmacher \\ in Salkbïrg. Anno 17 -}

Lutes.

Meusidler, Jean, Nuremburg, 1550. Made Viols and

MOHR, Philip, Hamburg, 17th century. Made Viols da Gamba, \&c.

OHBERG, Johann, Stockholm, I773. Workmanship of average merit. Varnish mostly of yellow colour.

OTT, Jean, Nuremberg, 15 th century. Lute maker.

Oтто, Jacob Augusti1s, Gotha, 1762-1830.

Отто, Gotha, son of Jacob Augustus.

Otтo, Cologne.

PARTH, Andreas Nicholas, Vienna, r8th century.

Pfretzschner, Gotlob, Cremona, 1750. Very commonplace.

Pfretzschner, Carl Frederick, Cremona, son of the former; no merit.

Plack, F., Schoenback, I730-1745.

PlatNer, Michael, Rome; nbout I720. This maker should have been included with the Italians. His style and varnish remind us of Techler. 
Possen, Lauscrim, Bavaria, 1550. Maker of Viols and Rebecs.

RAF, Bavaria, I8th century.

Rambouts, Peter, Amsterdam. High model, capital varnish.

Rauch, Jacques, Mannheim, 1720-1745.

Ravcr, Sebastian, Hamburg, 1725. High model, instruments not well finished.

RavCH, Breslau.

REICHEL, Johann Gottfried, Absom, isth century.

REICHEL, Johann Conrad, Newkirch, isth century.

Roth, Christian, Augsburg, i7th century.

RUPPERT, Francis, Erfurt. Instruments of little value.

Scheinlein, Matthias Frederick, Langenfeld, born 1710, died $177 \mathrm{r}$. High built; varnish dark.

Scheinlein, Jean Michael, Langenfeld, son of the former. Similar characteristics.

SCHLICK, Leipsic.

SCHMIDT, Cassel, I800-1825. Copied Stradiuarius indifferently; wood poor, thicknesses incorrect.

SCHÖNGER, Francis, Erfurt, I8th century.

SCHÖNGER, George, Erfurt, ISth century. Made several good instruments of the Albani type.

SchORN, Johann, Inspruck, isth century. An excellent maker; the varnish is similar to that of Albani; the modelling high.

Schorn, Jacob, Salzburg. Good work, and varnish equal to that of Johann Schorn.

Schotr, Martin, Prague. Instruments of little value.

SPEILER, Tyrol.

STAiner, Jacob, Absom, born about 1620 . The celebrity of this maker is second only to that of the great Cremonese artists. His admirers in Germany

Jacobus Stainer in Absom prope Oenipontum. 16and England were, at one time, more numerous than those of the principal Italian. To the connoisseur of to-day such ^hallucination will seem inexplicable; and he is driven to the conclusion that the Fiddle admirers of past days were incapable of appreciating true beauty of form and its bearing upon sound, or else that fashion made its influence felt on the Fiddle world as elsewhere. It would be absurd to deny that the greatest German maker of Violins that ever lived was a man of rare abilities, because it is indelibly written on his chief works that he was a thorough artist. Therefore an expression of surprise that Jacobus Stainer has been estimated higher than even Stradinarius by the Germans and English, must not be understood as a reflection in any sort whatever on his abilities, as it refers only to the form that he chose to give to his works. To account for the apparent inconsistency in the 
works of Staincr, and to strike tlie balance between, his exceptional abilities un tire one side and his model on the other, is not easy. His form was nut a burrowed one; it is as origiual as that of Stradiuarius, a fact which makes it more than ever unintelligible that he should have been content with it. To arrive at anything approaching to a satisfactory solution, we must endeavour to trace the history of this model. Jacobus Stainer was born in the Tyrol, and passed there his early years, and probably received his first instructions from one of the old Tyrolean Lute and Viol makers, at a period when they raised their model, and introduced into the German school the scooping round the sides of the backs and bellies, the inelegant sound-hole, the harsh outline, and uncouth scroll. As experience ripened his understanding, he felt that these characteristics of the German school were not such as could be moulded with advantage by any artist, whatever his talent might be, and resolved to do his best to unlearn much that he had acquired. In order to do so with any chance of success, but one course was open to him, that of studying the Italian masters on their own ground. The course to which he was thus led evidences his sagacity and thoroughly artistic nature. To leave those who patronised him, and looked up to him, and to visit Cremona for the purpose of humble study, must have needed no little enthusiasm, for it is impossible that he could have travelled with any other motive than that indicated. He must have been well aware that his style could find no favour with the Italians, and therefore that he was precluded from any possibility of employment which would yield more than bare maintenance. It has been hitherto stated that his journey to Italy was undertaken when very young. With this view I do not concur. In all cases where there is an absence of direct evidence, opinions can only be formed from particular analogies bearing on the case under consideration. Now in the case of Stainer we have nothing to guide us but his variations of style, and dates of time and places. What is the result of a careful investigation of every particle of evidence that we can glean? The style is ever Gernan, although the great maker is head and shoulders above all his countrymen who followed his art. I am thus forced to believe that had so excellent an artist visited Italy in his youth, as reported, there would have remained but the faintest trace of his German origin. That men of less ability should be unable to entirely sever themselves from their national style of work, even under the most favourable circumstances for such a release, I can readily understand (it is an incapacity which has been exemplified over and over again), but Jacobus Stainer was not one of these ordinary men; he had not his superior in the school of Cremona as a finished workman, with the single exception of Antonius Stradiuarius. I believe, therefore, that the German style was deeply rooted 
within him when he ceased to be young, and that his subsequent visit to Cremona was not undertaken until he recognised the inferiority of the school in which he had been bred, as compared with that of the Cremonese. That he did not go far enough in his "second thought," is pretty well acknowledged on all sides. His originality was conceived in the German school, amid the worst examples, and it was too late to undo what had gone before. Here, then, lies, I consider, the key to the seeming anomaly that so great a maker as Stainer should have adopted and clung to so clumsy a model. That his stay in Cremona had a marked effect upon his style is clear enough. Who but an artist located in Cremona could have made those exquisite Violins known as "Elector Stainers?" The wood selected for its rare loveliness, the finished workmanship, and charming rose-coloured varnish, render these works of art, of which one glimpse is a never-fading memory. These works show the diligent zeal with which Stainer laboured in his studies of the Italian masters. He contrived to give these instruments an air of grace quite foreign to the best efforts of his brother German makers. In the sound-hole and scroll is observable his seeming desire to leave behind the German preferences; and although it must be admitted that he was but partially successful in his endeavours to stamp out early tendencies, the connoisseur cannot but be impressed with the fertile resources of the artist's manipulation. Had such skill been exercised on a form nearer akin to the Italian, the result would have been perfect.

The history of Jacobus Stainer is enveloped in obscurity. The dates of his birth and death are unknown, and, indeed, nearly all that is related of him rests upon tradition. Amonyst the rumours concerning this maker may be mentioned that of his having been a pupil of Nicholas Amati. In all notices of Jacobus Stainer this statement is made without any reasonable -support. It is certain there is no direct evidence in support of it, neither is it shown that his work is founded on that of Amati. I am satisfied that Stainer was assisted by neither the Brothers Amati nor Nicholas Amati, and I am strengthened in this opinion by the steadfastly German character of a model which no pupil of Amati could have persisted in using, even though based on his earliest traditions. That Stainer went to Cremona the labels in a few of his works testify, but there is no mention of his having been with any maker in particular to my knowledge.

There is another rumour concerning Jacobus Stainer which savours of romance. It is said that in consequence of the great grief he experienced upon the death of his wife he withdrew from the world, and became an inmate of a Benedictine monastery, and that he made within its walls the famous instruments known as Elector Stainers, which he presented to the 
twelve Electors. Whether he made them to order in the usual manner, whether he presented them, or where he made them, matters little; they are works of great merit, and need no mysterious surroundings to call attention to them. The followers of Stainer have been numerous, and are mentioned in the lists of German and English makers. Probably no maker is more mistaken than Stainer: the array of German instruments called by his name is at least ten times greater than the number he actually made. Nearly every high-built tub of a Violin sails under his colours. Instruments without any resemblance whatever to those of Stainer are accepted by the multitude as original Jacobus Stainers. Much of this has arisen from the variety of style and work said to have been shown in the instruments of this maker. That this marked variety exists I do not believe. The pattern varies, but the same hand is' traceable throughout.

Statelman, Daniel, Vienna, 1730-1750. Good work, model of Stainer; poor varnish.

Statelman, Johann Joseph, Vienna, I sth century. Copied Stainer; average merit.

Straube, Berlin.

Strauss, Joseph, Neustadt, 1750.

V1BRECHT, Gysbert, Amsterdam, I700.

VOGEL, Wolfyang, Nurembury.

VOGLER, Johann George, Wurzburg, 1750.

Joann Georg Vogler, Lauten-

und Geigenmacher in Würczburg. 17-

WAGNER, Joseph, I730.

Weickert, Halle, I 800.

WEISS, Jacob, Salzburg, 18 th century.

Jacob Weiss, Lauthen und

Geigenmacher in Salkburg.

Wenger, G. F., Salzburg, i 8 th century.

WeymanN, Cornelius, Amsterdam, I8th century.

Withali, Leopold, Nuremburg, 18th century. One of the best imitators of Stainer. The wood is frequently handsome, the work finished with great care. Varnish, although wanting the delicacy of that of Stainer, is excellent ; its colour is mostly pale red. Nearly all his instruments are branded with his initials inside. 


\title{
SECTION XIII.
}

\author{
The VIOLIN AND its Votaries.
}

\begin{abstract}
"Have not the wisest men in all ages, not excepting Solomon himself, have they not had their hobby-horses : their running horses, their coins and their cockle shells, their drums and their trumpets, their fiddles." - Tristram Shandy.
\end{abstract}

$\prod \mathrm{HE}$ leading instrument is singularly favoured. It may be $\int 6$ said to have a double existence. In addition to its manifold capabilities, it has its life of activity on the one hand, and inactivity on the other. At one time it is cherisled for its power of giving pleasure to the ear, at another for the gratification it affords to the eye. Sometimes it is happily called upon to perform its double part-giving delight to both senses. When this is so, its existence is indeed a happy one. The Violin thus occupies a different position to all other musical instruments. Far more than any other musical instrument it enters into the life of the player. It may almost be said to live and move about with him; the treasure-house of his tenderest and deepest emotions, the symbol of his own better self. Moreover, the Violin is a curiosity as well as a mechanical contrivance. Thus, it is cherished, perhaps, for its old associations -it may have been the companion of a valued friend, or it may be prized as a piece of artistic work, or it may be valued, independently of other associations, for the simple purpose for which it was made, viz., to answer the will of the player when touched with the bow. The singular powers centred in the Violin have been beautifully expressed by Oliver Wendell Holmes, who says :- "Violins, too. The sweet old Amati! the divine Stradiuarius! played on by ancient maestros until the bow hand lost its power, and the flying fingers stiffened. Bequeathed to the passionate young enthusiast, who made it whisper his hidden love, and cry his inarticulate longings, and scream his untold agonies, and wail his nonotonous despair. Passed from his dying hand to the cold virtuoso, who let it slumber in its case for a generation, till, when his hoard was broken up, it came forth once more, and rode the stormy symphonies of royal orchestras, beneath the rusling bow of their lord and leader. Into lonely prisons with improvident artistes; into convents from which arose, day and night, the holy hymns with which its tones were blended; and back again to orgies, in which it learned to howl and laugh as if a legion of devils were shut up in it; then, again to the gentle dilettante who calmed it down with easy melodies until it answered him softly 



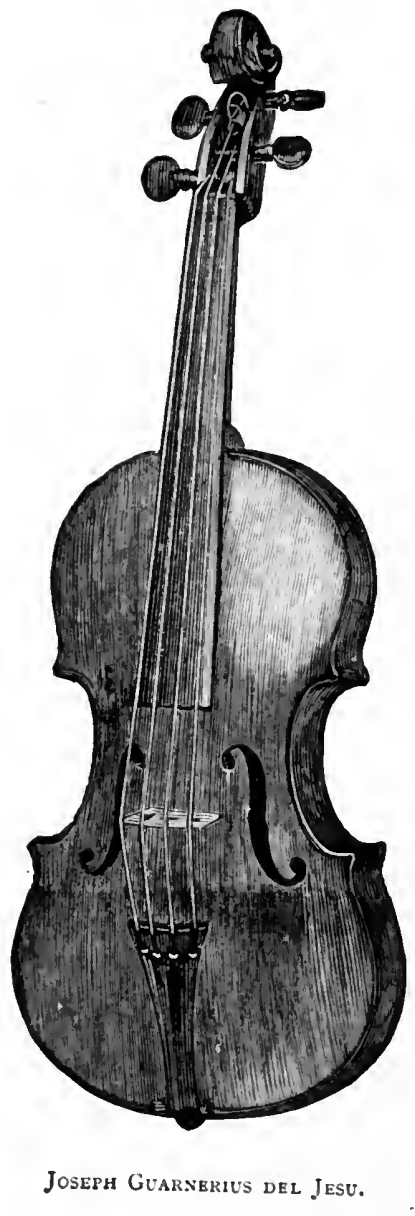


as in the days of the old maestros, and so given into our hands, its pores all full of music, stained, like the meerschaum, through and through with the concentrated hue and sweetness of all the harmonies which have kindled and faded on its strings." The gifted author of the "Autocrat of the Breakfast Table" has evidently made himself acquainted with the various life phases of a Violin.

The fancy for the Violin as a curiosity has been a matter of slow growth, and has reached its present proportions solely from the intrinsic merits of its object. The Violin has not come suddenly to occupy the attention of the curious, like many things that might be named which have served to satisfy a taste for the collection of what is rare or whimsical, and to which an artificial value has been imparted. In those days when the old Brescian and Cremonese makers flourished, the only consideration was the tone-producing quality of their instruments; the Violin had not then taken its place among curiosities. The instruments possessing the desired qualities were sought out until their scarcity made them legitimate food for the curious. Beauties, hitherto passed over, began to be appreciated, the various artistic points throughout the work of each valued maker were noted, and in due time Violins had their connoisseurs as well as their players.

Besides Italy, England, France, and Germany have each had their great men in the Fiddle world, whose instruments have ever been classed as objects of vertu. Mace, in his "Musick's Monument, " published in 1676 , gives, perhaps, the earliest instance of curiosity prices in England. "Your best provision (and most compleat).will be a good chest of Viols; six in number, viz., two Basses, two Tenors, and two Trebles, all truly and proportionately suited; of such there are no better in the world than those of Aldred, Jay, Smith; (yet the highest in esteem are) Bolles and Ross (one Bass of Bolles I have known valued at $£(\mathrm{roo})$. These were old. Our knowledge in these old days must have been very limited in all matters touching music, but from the above curious extract we glean that the Fiddle family was receiving some attention. The makers in England, whose instruments seem to have reached curiosity prices are Bolles, Jay, Barak Norman, Duke, Wamsley, Banks, and Forster; the value attached at different periods to the works of these men has nearly approached the prices of Cremonese work. Of course the high value set upon the instruments of the makers above named was confined to England.

Turning to France, we find that many of the old French makers' instruments brought prices greatly in excess of their original cost. The favourite French makers were Médard, Bocquay, Pierray. Gaviniès, of the old school ; and Lupot and Pique of the modern.

In Germany there have been makers whose works have 
brought very high prices. Stainer, Albani, Withalm, Scheinlein, are names that will serve to associate high values with German work. In the case of Jacobus Stainer, the celebrity of his instruments was not confined to Germany ; they were highly prized by the English and French, and at one period were more valued than the best Amatis. It was not until the vast superiority of Italian Violins over all others was thoroughly recognised, that the love of the instrument as a curiosity reached its present climax. In Italy, the value set upon the chief Cremonese works, though great, was comparatively insignificant, as far as the Italians themselves are concerned, when France and England came into competition with them for the possession of their Amatis, Stradiuarius, Guarnerius, and other gems, they at once yielded the contest.

The introduction of Italian instruments into Great Britain was a matter of slow growth, and did not assume any proportions worthy of notice until the commencement of the present century, when London and Paris became the chief marts from whence the rare works of the old Italians were distributed over Europe. By this time the taste of the Fiddle world had undergone a considerable change. The instruments in use among the dilettanti in France and England had hitherto been those built on the German model of the school of Jacobus Stainer. The great German maker was copied with but little intermission for upwards of a century dating from about 1700 to 1800 , a period of such considerable extent as to evidence the popularity of the model. Among the Germans who were following in the footsteps of Stainer were the family of Kloz, Withalm, Statelmann, and others of less repute. In England there was quite an army of Stainer worshippers. There was Peter Wamsley, Barrett, Benjamin Banks, the Forsters, Richard Duke, and a whule host of little men. Among the makers mentioned, there are three, viz., Banks, Forster and Richard Duke, who did not copy Stainer stedfastly. Their early instruments are of the German form, but later they made many copies of the Cremonese. To Benjamin Banks we are indebted for having led the English makers to adopt the pattern of Amati. He had long laboured to popularise the school which he so much loved, but met with little encouragement in the beginning, so strong was the prejudice in favour of the high model. However he triumphed in the end, and completely revolutionised the taste in England, till our Fiddle fanciers became total ab-Stainers! Then commenced the taste for instruments of flat form. Where were they to be found? If the f $\mathrm{w}$ by the early English makers be excepted, there were none but those of the Italians to be had, and perhaps, a few old French specimens. Attention was thus directed to the works of the Cremonese: and the year I800 or thereabouts, may be put down as the time when the tide of Italian Violins had fairly set in towards France and England. 
The instruments by the Amatis were those chiefly sought after ; the amount of attention they commanded at this period was probably about equal to that bestowed upon the works of Stradiuarius and Guarnerius at the present time. Violins of Amati and other makers were then obtainable at prices of a nominal character. The number in Italy was far in excess of her requirements, the demand made upon them for choir purposes in former days had ceased, and the Violins were thus quite out of proportion to the players. The value of an Amati in England in 1799 and 1804 , may be gathered from the following extracts from the day-book of the second William Forster, who was a dealer as well as maker:- "20th April, 1799. A Violoncello by Nicholas Amati, with case and bow, $£$ I7 I7s. od. ;" and further on-" 5 th July, 1804 , an Amati Violin, $\mathscr{L}_{3} \mathrm{I}$ Ios. od." These prices were probably less than those which William Forster received for many instruments of his own make. It is certain that these low prices did not long continue; the price increased in due proportion to the vanishing properties of the supply. The call for Violins by the Amatis was so clamorous as speedily to affect this result; the prices for them were doubled, trebled, and often quadrupled, until they no longer found a home in their native land. The value set on them by the French and English so far exceeded that which the Italians themselves could affurd, even though inclined to indulge in such things, that the sellers were as eager to sell as the buyers to buy. During the time of this scramble for the instruments of Cremona, the theory of the flat model was fast gaining ground. The circulation of the works of Cremona among the players of France and England led to a comparison of the various forms, and it was found that the elevated model was inferior in every way when tested by the works of the great Italian makers. Hitherto no distinction had been drawn as regards value among the productions of the several members of the Amati family. Andrea had been looked upon as equivalent to Jerome, Antony, or Nichulas ; but attention now began to be directed towards the works of the brothers, and to those of Nicholas in particular, as the flat model gained in the appreciation of the Fiddling world. Grand Amatis became the coveted Fiddles; they were put up frequently at thrice the value of the smaller patterns-a position they still maintain. The taste for the flat form having thus been developed, the works of Antonius Stradiuarius came to the front, slowly but surely; their beauties now became known outside the circle in which they had hitherto been moving : a circle made up chiefly of royal orchestras (where they were used at wide intervals), convent choirs, and private holders, who possessed them witl.out being in the least aware of their merits. They were now eagerly susught by solnists in all parts of Europe, who spread their fame f.ır and wide. Their exquisite furm and finish capti- 
vating the dilettanti, the demand increased to an extent far beyond that commanded by the works of the Amatis at the height of their popularity.

There were a few Stradiuarius instruments in England when Amati was the favourite maker, and their value at that period may be estimated from the fact that Cervetto, the father of the famous violoncellist was unable to dispose of a Stradiuarius Violoncello for five pounds, a circumstance which shows how blind our forefathers were to the merits of the greatest maker the world has had. Among the artistes of the early part of the present century who used the instruments of Stradinarius were Boccherini, Viotti, Rode, Kreutzer, Habeneck, Mazas, Lafont, and Bailliot.

About the year I820 the fame of Joseph Guarnerius as a great maker was published beyond Italy, chiefly through the instrumentality of Paganini. That wondrous player came to possess a splendid specimen of Guarnerius del Jesù, dated 1743 , now sleeping in the museum at Genoa, which Paganini used in his tour through France and England. He became the owner of this world-famed Violin in the following curious manner. A French merchant (M. Livron) lent him the instrument to play upon at a concert at Leghorn. When the concert had concluded, Paganini brought it back to its owner, when M. Livron exclaimed, "Never will I profane strings which your fingers have touched ; that instrument is yours." A more fitting present or higher compliment could not have been offered. The names of Amati and Stradiuarius becane familiar to the musical world gradually, but Guarnerius, in the hands of a Paganini, came forth at a bound. This illustrious Violin was often credited with the charm which belonged to the performer; the magical effects and sublime strains that he drew forth from it nust, it was thought, rest in the Violin. Every would-be violinist, whose means permitted him to indulge in the luxury, endeavoured to secure an instrument by the great Guarnerius. The demand thus raised brought forth those gems of the Violin maker's art now in the possession of wealthy amateurs and a few professors. When the various works of the gifted Guarnerius were brought to light, much surprise was felt that such treasures should have been known only to a handful of obscure players, chiefly in the cluturches of Italy. The Violin used by Paganini belongs to the last period of the great maker, and, consequently, is one of those bold and massive instruments of his grandest conception, but lacks the beautiful finish of the middle period. The connoisseurs of those days had associated Joseph Guarnerius with the Violin of the type of Paganini's only; their surprise was great when it was discovered that there were three distinct styles in the works of Guarnerius, one evidencing an artistic grandeur, together with a high finish, but little inferior to those of Antonius Stradiuarius. The 
marked difference between these epochs of Guarnerius manufacture has led to a great amount of misconception. Thirtyyears since, the world possessed little information on the subject, and the connoisseur of those times could not believe it possible that these varied styles emanated from one mind. The opportunities given to the connoisseur of later days of comparing these various instruments of the several epochs of Guarnerius have set at rest all doubts concerning them. Theyno longer require dates or labels; they are as easily distinguished and classed as the works of Amati or Stradiuarius.

Attention was claimed for the works of Maggini by the charming Belgian violinist, Charles de Bériot, who, early: admiring the large proportions and powerful tone of Maggini's instruments, decided to use one for public playing. That an artist so refined as de Bériot, and one who attached so much importance to that sympathy between the Violin and player which should make it the vehicle for presenting its master's inward feelings, should have selected a Violin of large size, and adapted for giving forth a great volume of tone, was a matter of surprise to a great many of his contemporaries. Those who judged only from his school of playing anticipated that he would have selected Amati as embodying the qualities he so passionately admired. It is certain, however, that he succeeded in bringing the penetrating power of his Maggini thoroughly. under his control. In the instruments of Maggini, de Bériot doubtless recognised the presence of vast power, together with no inconsiderable amount of purity of tone, and to bring forth these qualities to the best advantage was, with him, a labour of love. The popularity of Maggini's Violins rapidly raised their value. Instruments that, before de Bériot made them widely known, might have been purchased for ten pounds, realised one hundred. The Violin known as "De Bériot's Maggini" remained in his possession till within a short time of his death, when it was disposed of to his friend and patron, the Prince de Chinay, it is said, for the enormous sum of six hundred pounds, a price far in excess of the average value of Maggini's instruments. In this instance, the association of de Bériot with the instrument is sufficient, perhaps, to account for the rare price set upon it.

We now reach the time when Carlo Bergonzi began to be regarded as a maker of the first-class. As a Cremonese maker, he was one of the latest to receive the attention to which his exceptional merits fairly entitled him. To English connoisseurs belongs the credit of appreciating this great maker.

The recognised merits of the makers already named naturally caused a demand for Italian instruments generally. If the masters could not be had the pupils must be found, hellce, a whole host of Italian makers, quite unknown in England fifty years since, became familiar to the connoisseur. The works 
of Guadagnini, Gagliano, Grancino, Sanctus Seraphino, Montagnano, and others, whose names it is unnecessary to give, passed from Italy into France and England, until the various schools of Italian Violin manufacture were completely exhausted. When we look back, it is surprising that so much has been achieved in such a brief space of time. The knowledge of Italian works in I800 was of the slenderest kind, both in France and England; in less than three-quarters of a century those countries have contrived to possess themselves of the finest specimens of Cremonese instruments, together with those of other Italian schools. We here have an example of the energy and skill that is brought to bear upon particular branches of industry when once a demand sets in. Nen of enterprise rise with it unnoticed, and lead the way to the desired end. In the case of Italian Violins it was Louis Tarisio who acted as pioneer-a being of singular habits, whose position in the history of the Violin, considered as a curiosity, is an important one. This remarkable man was born of humble parents, wholly unconnected with the musical art. In due time he chose the trade of a carpenter, whose vocation he followed with assiduity, if not with love. He amused himself during his leisure hours in acquiring a knowledge of playing on the Violin, an accomplishment that was destined to exercise a considerable influence on his future life, far greater than contemplated by the young carpenter. That his playing was not of a high order may be readily imagined: it was confined chiefly to dance music, with which he amused his friends, fiddling to their dancing. His first Violin was a very common instrument, but it served to engender within him that which afterwards became the ruling passion of his life. His study of this little instrument was the seed from which grew his vast knowledge of Italian works. So much was his attention absorbed by the form of the instrument that any skill in playing upon it became quite a secondary consideration. He endeavoured to see all the Violins within his reach, and to observe their several points of difference. The passion for old Violins, thus awakened, caused him to relinquish his former employment entirely, and to devote the whole of his attention to the art which he so loved. He soon became aware of the growing demand for Italian works, and felt that, possessed with a varied and proficient knowledge of the different styles of workmanship belonging to the Italian schools of Violin making, he could turn his present acquirements to a profitable as well as pleasurable use. He resolved to journey in search of hidden Cremonas. His means were, indeed, very limited. His stockin-trade consisted only of a few old Violins of no particular value. With these he commenced his labours, journeying in the garb of a pedlar, on foot, through Italian cities and villages, and often playing his Violin in order to procure the bare means 
of existence. Upon entering a village he endeavoured to ingratiate himself with the villagers, and thus obtained information of the whereabouts of any inlabitants who were possessed of any member of the Fiddle family, his object being to examine and secure, if possible, such instruments as were possessed of any merit. It can readily be conceived that at the commencement of the present century, numbers of valuable Cremonese and other instruments were in the hands of very humble people. Louis Tarisio knew that such must be the case, and made the most of his good fortune in being the first connoisseur to visit them. His method of trading was either to sometimes exchange with the simple villagers, giving them a Violin in perfect playing order for their shabby old instrument that lacked all the accessories. It was indeed the case of Aladdin's Lamp, and as potent were these Fiddles as the wonderful lamp or ring itself. In the possession of Louis Tarisio they drew forth from the purses of the wealthy, gold that would have enabled the humble villagers to have ceased labour. It is an axiom, however, that everything on this earth is of value providing it is in its proper place, and these rare old instruments, in the keeping of the poor peasants, could scarcely be considered to be in their proper element; their ignorant possessors were alike unable to appreciate their sterling worth, as works of art, or their powers of sound. In thus putting it I have no wish to be accused of lax morality. Louis Tarisio. after gathering together a number of old rarities, made for his home, and busied himself in examining the qualities of his stock, selecting the best works, which he laid aside. With the residuum of those instruments he would again set out, using them as his capital wherewith to form the basis of future transactions among the peasantry and others. He visited the numerous monasteries throughout Italy that he might see the valuable specimens belonging to the chapel orchestras. He found them often in a condition ill becoming their value, and tendered his service to regulate and put them into decent order; services gladly accepted and faithfully performed by the ardent connoisseur. By the handling of these buried treasures, his knowledge and experience were greatly extended. Makers hitherto unknown to him became familiar. When he met with instruments apparently beyond the repairer's skill, he would make tempting offers of purchase, which were often accepted. Having accumulated many instruments of a high order during these journeys, he began to consider the best means of disposing of them. He decided upon visiting Paris. He took with him the Violins he valued least, resolving to make himself acquainted with the Parisian Fiddle market before bringing forth his treasures. It is said that he undertook this journey on foot, depriving himself often of the common necessaries of life, that he might have more money to buy up his country's Fiddles. 
His first visit to Paris was in 1827 , an eventful year in the history of Italian Violins, as far as relates to Paris. Upon arriving in the French capital, he directed his steps to the nearest luthier, one Aldric, to whom he had been recommended as a purchaser of old instruments of high value. Upon arriving at the shop of M. Aldric, Tarisio hesitated before entering, feeling suddenly that his appearance was scarcely in keeping with his wares, his clothes being of the shabbiest description, his boots nearly soleless, and his complexion, naturally inclined to blackness, further darkened by the need of ordinary ablutions. However, he set aside these thoughts, and introduced himself to the luthier as having some Cremona Violins for sale. Aldric regarded him half contemptuously, and with a silence intended to convey to Tarisio that he heard what he said, but did not believe it. The Italian, to the astonishment of the luthier, was not long in verifying his statement; he opened his bag and brought forth a beautiful Nicholas Amati, of the small pattern, in fine preservation, but having neither finger-board, strings, nor fittings of any kind. The countenance of the luthier brightened when he beheld this unexpected specimen of the Italian's wares. He carefully examined it, and did his best to disguise the pleasureable feelings he experienced. He demanded the price. The value set on it was far in excess of that he had anticipated; he erroneously arrived at the probable cost from an estimate of the shabby appearance of the man. He had been comforting himself that the Italian was unaware of the value put upon such instruments. He decided to see further the contents of the bag before expressing an opinion as to the price demanded for the Amati. Violins by Maggini, Rugerius, and others, were produced-six in number. Tarisio was asked to name his price for the six. After much giving and taking they became the property of the luthier. This business was not regarded as satisfactory by Tarisio; he had over-estimated the value of his goods in the Paris market; he had not learned that it was he himself who was to create the demand for high-class Italian instruments by spreading them far and wide, so that their incomparable qualities might be observed. He returned to Italy with his ardour somewhat cooled; the ready sale at the prices he had put upon his stock was not likely to be realised, he began to think. However, with the proceeds of his Paris transaction he again started in search of more Cremonas, with about the same satisfactory results. He resolved again to visit Paris, and take with him some of his choicest specimens. He reached the French capital with a splendid collection-one that in these days would create a complete furore throughout the world of Fiddles. He extended his acquaintance with the Parisian luthiers. Among these were $M$. Vuillaume, Thibout, and Chanot senior ; they were all delighted with the gems that Tarisio had brought, and 
encouraged him to bring to France as many more as he could procure, and at regular intervals. He did so, and obtained at each visit better prices.

This remarkable man may be said to have lived for nought else but his Fiddles Mr. Charles Reade, who knew him well, says, * "The man's whole soul was in Fiddles. He was a great dealer, but a greater amateur; he had gems by him no money would buy from him." It is related of him that he was in Paris upon one occasion, walking along the Boulevards with a friend, when a handsome equipage belonging to a French magnate passed, the beauty of which was the talk of the city. Tarisio's attention being directed to it by his friend, he calmly answered him that "he would sooner possess one 'Stradiuarius' than twenty such equipages." There is a very characteristic anecdote of Tarisio, which is also related by Mr. Reade in his article on "Cremona Violins," entitled the "Romance of Fiddledealing:" - "Well, one day Georges Chanot, senior, made an excursion to Spain, to see if he could find anything there. He found mighty little, but coming to the shop of a Fiddle-maker, one Ortega, he saw the belly of an old bass hung up with other things. Chanot rubbed his eyes, and asked himself was he dreaming? the belly of a Stradiuarius Bass roasting in a shop window? He went in, and very soon bought it for about forty francs. He then ascertained that the Bass belonged to a lady of rank. The belly was full of cracks; so, not to make two bites of a cherry, Ortega had made a nice new one. Chanot carried this precious fragment home and hung it up in his shop, but not in the window, for he was too good a judge not to know the sun will take all the colour out of that maker's varnish. Tarisio came in from Italy, and his eye lighted instantly on the Stradiuarius belly. He pestered Chanot till the latter sold it him for a thousand francs, and told him where the rest was. Tarisio no sooner knew this than he flew to Madrid. He learned from Ortega where the lady lived, and called on her to see it. 'Sir,' says the lady, 'it is at your disposition.' That does not mean much in Spain. IVhen he offered to buy it, she coquetted with him, said it had been long in her family; money could not replace a thing of that kind, and, in short, she puf on the screw, as she thought, and sold it him for about four thousand francs. What he did with the Ortega belly is not known; perhaps sold it to some person in the toothpick trade. He sailed exultant for Paris with the Spanish Bass in a case. He never let it go out of his sight. The pair were caught by a storm in the Bay of Biscay; the ship rolled; Tarisio clasped his Bass tight and trembled. It was a terrible gale, and for one whole day they were in real danger. Tarisio spoke of it to me with a shudder. I will give you his real words, for they struck

*Cremona Violins, "Pall Mall Gazette."-August, 1872. 
me at tive time, and I have often thought of them since. ' $A h$, sny poor Mr. Reade, the Bass of spain was all but lost!'

- IVas not this a true connoisseur-a genuine enthusiast? Observe, there was also an ephemeral insect called Luigi 'Tarisio, who would have gone down with the Bass; but that made no impression on his mind. De minmmis non cural Ludovicus.

"He gut it safe to Paris. A certain high prest in these mysteries, called Vuillaume, with the help of a sacred vessel, called the glue-pot, soun re-wedded the back and sides to the belly, and the Bass now is just what it was when the ruffian Ortega put his finger in the pie. It was sold for $20,000 \mathrm{fr}$. $(f 800)$. I saw the Spanish Bass in Paris twenty-five years ago, and you can see it any day this month you like, for it is the identical Violoncello now on show at Kensington numbered i88. Who would divine its separate adventures, to see it all reposing so calm and uniform in that case-Post tot naufragta tutus."

The love of Tarisio for the masterpieces of the great makers was so intense, that often, when he had parted with the works he so admired, he never lost sight of them, and waited a favourable opportunity for again making himself their owner.

It is related of him that upon one occasion he disposed of a beautiful Stradiuarius in perfect preservation to a Paris dealer. After having done so he hungered for it again. For years he never visited Paris without enquiring after his old favourite, and the possibility of its again being offered for sale, that he might regain possession of it. At last his perseverance was rewarded, inasmuch as he heard that it was to be bought. He instructed his informant to obtain for him a sight of it. The instrument was fetched, and Tarisio had scarcely patience enough to await the opening of the case, so anxious was he to see his old companion. He eagerly took up the Violin, and turned it over and over, apparently lost to all about him, when suddenly his keen eyes rested upon a damage it had received, which was hidden by new varnish. His heart sank within him; be was overcome by this piece of vandalism. In mingled word: of passion and remorse he gave vent to his feelings. $\mathrm{He}$ placed it in its case, remarking sadiy that it had no longer any charm for him.

In the year 185I Tarisjo visited England, when Mr. John Hart, being anxiuns that he should see the chief collections of Cremonese instruments in this country, accompanied him, amongst others, to the collection of the late Mr. James Goding, which was then the finest in Europe. The instruments were arranged on shelves at the end of a long room, and far removed from them sat the genuine enthusiast, patiently awaiting the promised exhibition. Upon Mr. Goding taking ont his treasures he was inexpressibly astonished to hear his visitor calling out the maker of each instrument before he had had time to 
advance two paces towards him, at the same time giving his host to understand that he thoroughly knew the instruments, the greater number having been in his possession. Mr. Goding whispered to a friend standing by, "Why the man must certainly smell them, he has not had time to look." Many instruments in this collection Tarisio seemed never tired of admiring. He took them up again and again, completely lost to all around -in a word, spell-bound. There was the "King " Guarnerius -the Guarnerius known as Lafont's-the beautiful Bergonzi Violin-the Viola known as Lord Macdonald's-General Kidd's Stradiuarius Violoncello-the Marquis de la Rosa's AmatiOle Bull's Guarnerius - the Sanctus Seraphino Cello-and other remarkable instruments too numerous to mention. Who can say what old associations these Cremona gems brought to his memory? For the moment, these Fiddles resolved themselves into a diorama, in which he saw the chief events of his life played over again. With far greater truthfulness than that which his unaided memory could have supplied, each Fiddle had its tale to relate. His thoughts were carried back to the successful energies of his past.

Tarisio may be said to have lived the life of a hermit to the time of his death. He had nopleasures apart from his Fiddles; they were his all in this world. Into his wretched lodgings near the "Porta Tenaglia," in Milan, no living being but himself was ever permitted to enter. His nearest neighbours had not the least knowledge of his occupation. $\mathrm{He}$ mounted to his attic without exchanging a word with any one, and left it securely fastened to start on his journeys in the same taciturn manner. He was, consequently, regarded as a mysterious individual, whose doings were unfathomable. The time, however, has arrived when the veil hiding the inner life of this remarkable man should be lifted, and here I am indebted for particulars to Signor Ceruti, of Cremona, who received them from a reliable source. Tarisio had been seen by his everwatchful neighbours to enter his abode, but none had noticed him quit it for several days. The door was tried and found locked; no answer was returned to the sundry knockings. That Tarisio was there the neighbours were convinced. The facts were at once brought under the notice of the municipal authorities, who gave instructions that an entry should be made by force into the mysterious man's apartment. The scene witnessed was indeed a painful one. On a miserable couch rested the lifeless body of Lonis Tarisio; around, everything in the utmost disorder. The furniture of the apartment consisted mainly of a chair table, and the couch upon which lay the curpse. A pile of old Fiddle-boxes here and there, Fiddles hung around the walls, others dangling from the ceiling. Fiddle backs, Fiddle heads and bellies in pigeon holes ; three DoubleBasses tied to the wall, covered over with sacking. This was 
the sight that met the gaze of the authorities. Little did they imagine they were surrounded with gems no money would have bought from their late eccentric owner. Here was the famous "Messie" Stradiuarius, which had never had a bow on its strings, some half dozen other Stradiuarius Violins, Tenors, and Violoncellos, the Chamber Gaspard di Salo Double-Bass in my possession, and the Rugerius now belonging to $J$. $R$. Bridson, Esq., besides nearly Ioo Italian instruments of various makers. All these were passed over by the visitors as so much rubbish in their search for something more marketable. At last they alighted upon a packet of valuable securities together with a considerable amount of gold. A seal was placed upon the apartment pending inquiries as to the whereabouts of the dead man's relatives. In due time, some neplews came forth and laid claim to the goods and chattels of the Italian Fiddle connoisseur.

The death of Tarisio being communicated to Vuillaume, of Paris, he soon set out for Milan, and had the good fortune to secure the whole of the collection at a price, no doubt, which left him a handsome profit upon the transaction, besides the pleasurable feeling in becoming the possessor of such a varied and remarkable number of instruments.

Having given the reader all the information I have been able to collect concerning Tarisio, I will only add that he had advantages over all other connoisseurs, inasmuch as he found the instruments mostly in their primitive condition, and free from any tampering as regards the labels within them. He was thus enabled to learn the characteristics of each without fear of confusion. The days of taking out the labels of unmarketable names and substituting marketable counterfeits had not arrived.

Another Italian, named Turina, encouraged by the success of Louis Tarisio's traffic in old Violins, endeavoured to follow in his footsteps, and was fortunate in securing a few fine works, of which he readily disposed in Paris. He wanted, however, the keen judgment of Tarisio, and soon found himself behind in the race.

The principal buyers of Italian instruments on the Continent, when dealing in this class of property was in its infancy, were, Aldrich, M. Chanot, senior, Thibout, Gand, Vuillaume of Paris, and Vuillaume of Brussels. In London, among others, were Davis, Betts, Corsby, and John Hart. There is yet another, the omission of whose name would be a blemish in any notice of the Violin and its connoisseurs. I refer to Mr. Charles Reade, the novelist, who in early life took the highest interest in old Italian Violins. We are indebted to him in a great measure for bringing into this country many of the most beautiful specimens we possess. Impressed with the charms of the subject, he visited the Continent for the pleasure it 
afforded him of bringing together choice specimens, and thus opened up the intercuurse between England and the Continent fur the interchange of old Violins which continues to this day. It would be difficult to tind an instance where the intricacies of the subject were so quickly mastered as in his case. Without assistance, but solely from his own observation, he gained a knowledge which enabled him to place himself beside the chief Continental connoisseurs, and compete for the ownership of Cremonese masterpieces. These were the men who laid bare the treasures of Cremona's workshops, and spread far and wide love and admiration for the fine old works. Connoisseurship such as theirs is rare. To a keen eye was united intense love of the art, patience, energy, and memory of no ordinary kind, all of them attributes requisite to make a successful judge of Viulins.

In England the early collectors were the late Duke of Cambridge, the Earl of Falmouth, Duke of Marlborough, Lord Macdonald, and a few others. Later, Andrew Fountain. Esq., of Narford, Norfolk, became the owner of several fine Italian instruments, and made himself better acquainted with the subject, perhaps, than any amateur of his time. Among the Stradiuarius Violins which Mr. Fountain possessed was that of Habeneck, the famous professor at the Paris Conservatoire in the early part of the present century (from whom he purchased it), the date of which is 1737, the year of Stradiuarius' death. Another very tine specimen of the late period, 1734, was also owned by him, a Violin of grand proportions, in a high state of preservation, and of the riclest varnish. This instrument is numbered with those of IV. Tyssen Amhurst, Esq. The Guarnerius Violins that he possessed were of a very high class. Among these may be mentioned a very small Violin by Joseph Guarnerius, probably uni jue, which instrument was exhıbited among the Cremonese Violins at the South Kensington Museum in I872, together with another of the same size by Stradiuarius, and a third by the brothers Amati.

The number of rarities brought together by the late $\mathrm{Mr}$. James Goding was in every respect remarkable. At one period he owned twelve Stradiuarius Violins, and nearly the same number by Joseph Guarnerius, all high-class instruments. It wuuld take up too much time and space to name the particular instruments which were cumprised in this collection. The remnant of this group of Cremonese Fiddles was dispersed by Messrs. Christie and Manson, in I856. Mr. Plowden's collection was another remarkable one, consisting of eight instruments of the highest class.

The late Joseph Gillott was a collector, who, in point of number, exceeded all others. He did not confine himself solely to the works of the greatest makers, but added specimens of every age and clime; and at one time he must have 
had upwards of 500 instruments, the chief part of which belonged to the Italian school. When it is remembered that the vast multitude of stringed instruments disposed of by Messrs. Christie and Manson, in I872, did not amount to one-half the number originally owned by Mr. Gillott, some idea of the extent of his collection may be gained. Among the many curiuus instances of the love of collecting Violins, which sometimes possess those unable to use them, perhaps that of $\mathbf{M r}$. Gillutt is the most singular. About the year 1848 , he conceived the notion of bringing together this mammoth collection; and in about four years had made himself master of the largest number of Italian instruments ever owned by a single individuxl. He suddenly relinquished the pursuit he had followed with such persistency; he disposed of a great number, and laid the remainder aside in his steel-pen works at Birmingham, where they slumbered for upwards of twenty years. The time at last arrived when this pile of Fiddles was to be dispersed; it fell to my lot to classify them, and never shall I forget the scene I witnessed. Here, amid the din of countless machines busy shaping magnum bonums, swan-bills, and divers other writing implements, I was about to feast my eyes on some of the choicest works of the old Italian Fiddlemakers. Passing through offices, warehouses, and workshops, I found myself at a door which my conductor set himself to unlock, an act not often performed, I felt assured, from the sound which accompanied his deed. To adequately describe what met my eyes when the door swung back on its hinges, is beyond my humble powers of description. Fiddles here! Fiddles there! Fiddles everywhere! in wild disorder. I interrogated my friend as to the cause of their being in such an unseemly condition, and received answer that he liad instructions to remove most of the instruments from their cases and arrange them, that I might better judge of their merits. I was at a luss to und-rstand what he meant by arranging, for a more complete disarrangement could not have been effected. Not wishing to appear unmindful of the kindly intentions of my would-be assistant, I thanked him, inwardly wishing that this disentombment had been left entirely to me. The scene was altogether so peculiar and unexpected as to be quite bewildering. In the centre of the room was a large wareliouse table, upon which were placed in pyranids upwards of seventy Violins and Tenors, stringless, bridgeless, unglued, and enveloped in the fine dust which had crept through the crevices of the cardboard sarcophagi in which they had rested for the past quarter of a century. On the floor lay the bows. The scene might not inappropriately be compared to a post-mortem examination on an extended scale. When left alone I began to collect my thoughts as to the best mode of conducting my enquiry. After due consideration I attacked pyramid No. I, 
from which I saw a head protruding which augured well for the body, and led me to think it belonged to the higher walks of Fiddle life. With considerate care I withdrew it from the heap, and gently rubbed the dust off here and there, that I might judge of its breeding. It needed but little rubbing to make known its character; it was a Viola by Joseph Guarnerius, filius Andrea, a charming specimen (now in the ownership of the Earl of Harrington). Laying it aside, I pulled out from the pile several others belonging to the same class. Being too eager to learn of what real merits of this huge pile of Fiddles consisted, I rapidly passed from one to the other without close scrutiny, leaving, that for an after pleasure. So entirely fresh were these instruments to me, that the delight I experienced in thus digging them out, may be well understood by the connoisseur. After thus wading through those resting on the table, I discovered some shelves upon which were a number of cases, which I opened. Here were fine Cremonese instruments in company with raw copies-as curious a mixture of good and indifferent as could be well conceived. Not observing any Violoncellos, when my attendant presented himself, I enquired if there were not some in the collection. I was unable to make him understand to what I referred for some little time, but when I called them big Fiddles, he readily understood. He had some faint idea of having seen something of the kind on the premises, and started off to make enquiry. Upon his return, I was conducted to an under warehouse, the contents of which were of a varied character. Here were stored unused lathes, statuary, antique pianos. parts of machinery, pictures and picture-frames. At the end of this long room stood, in stately form, the "big Fiddles," about fifty in number-five rows, consequently ten deep. They looked in their cases like a detachment of infantry awaiting the wurd of command! Years had passed by since they had been called upon to take active service of a parific and humanising nature in the ranks of the orchestra. Had they the power of speech what tale of heroism might they have furnished of the part they played at the "Fall of Babylon," and the "Siege of Corinth," eh! and the "Battle of Waterloo," (Beethoven, OD. 9I). A more curious mixture of art and mechanism could not easily be found than that which the contents of this room exhibited. With what delight did I proceed to open these long-closed cases! The character of the Violins naturally led me to anticipate much artistic worth in the Violoncellos, and I had not judged erroneously. Bergonzi, Amati, Andrea Guarnerius, Cappa, Grancino, Testore, Landulphus, and men of less note; were all well represented in this army of big Fiddles. Having glanced at the merits and demerits of these instruments, I observed to my conductor that I imagined I had seen all. "No," he answered; "I was 
about to mention that there are a few Violins at Mr. Gillott's residence, and perhaps we had better go there at once." I readily assented, and in due time reached Edgbaston. There seemed no doubt as to the whereabouts of these instruments, and I was at once ushered into the late Mr. Gillott's bed-room. Pointing to a long mahogany glazed case occupying one side of the chamber, the attendant gave me to understand I should there find the Violins. At once I commenced operations. Pushing aside the first slicling door, I saw a row of those cardboard cases made to hold the Violin only, which many of my readers will doubtless remember seeing at the time of the sale at Messrs. Christie's. By this time it may be readily imagined that an idea had taken possession of my mind, that I had not, after all, seen the best portion of the collection. The circumstance of Violins being deposited in the sleeping apartment of their owner was sufficient to give birth to this conjecture. Upon removing the lid of the first cardboard case, my eyes rested on a charming Stradiuarius of the Amati period, a gem of its kind. Gently laying it on the table that I might examine it later, I opened the next case. Here rested a magnificent Joseph Guarnerius, the instrument now owned by Lord Dunmore, date $173^{2}$. Pursuing my delightful occupation, I opened another case, the contents of which put the rest completely in the shade-here rested the Stradiuarius, date 1715 , the gem of the collection. Unable to sustain my curiosity, I rapidly - pened sixteen cases in all, from which I took out six Stradi"rrius, two Guarnerius, one Bergonzi, two Amatis, and five Violins of a high class.

It was observed at the time of the sale of this remarkable collection, that "Every well-ordered display of fireworks should have its climax of luminous and detonating splendour, throwing into the shade all the preliminary squibs, crackers, and rockets, the Catharine wheels, the Roman candles, and the golden rain. The French, with modern propriety, term this consummation a bouquet." I cannot find anything more applicable than this word to the scene I have attempted to describe. It only remains for me to say, in reference to this array of Fiddles, that I passed a week in their company, and a more enjoyable one I have never had during my professional career. 



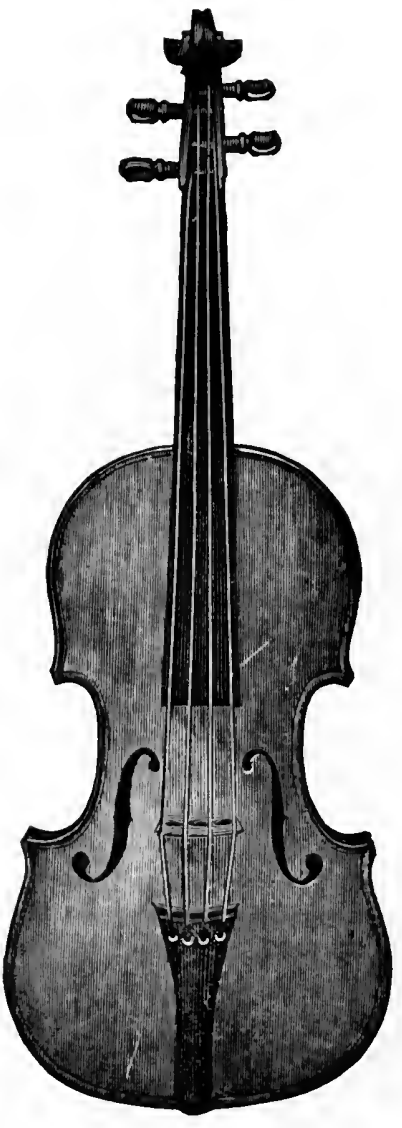

Carlo Bergonzt. 


\section{SECTION XIV.}

Sketch of the Progress of the Violin.

$\Gamma^{\mathrm{T}}$ may be said that the Violin made its appearance about the middle of the 16th century. Mention is made by Fétis of a Rebec, or Violin with three strings, by Andreas Amati, bearing the date of 1546 , and this strengthens me in my belief that it was after this date that the instrument was equipped with four strings. There are several instances where mention is made of Violins and Violin-playing prior to the period above named, but they are not such as to carry conviction to the mind that they refer to the instruments now recognised as the Violin. Leonardo da Vinci, the famous painter, who died in 1523, is spoken of as having been a celebrated performer on the Violin. The instrument he used is described as having had a neck of silver, with the singular addition of a carved horse's head.* This description, however, is sufficiently anomalous to make one rather sceptical, as to whether the instrument denoted possessed any particular affinity to the present Violin.

Julian Tiburtino and Louis Lasagrino, who were in high favour as musicians at Florence about 1530 , are also mentioned as Violin players, but were probably, performers on the small Viol.

Bombet, in lis letters on Haydn, says: "Symphonies, therefore, were only an air played by the Violin instead of sung by an actor. The learned will tell you that the Greeks, and afterwards the Romans, had no other instrumental music; at least, it is certain that none was known in Europe before the s! mphonies of Lully, but that $\mathrm{u}$ hich is necessary for dancing ; and this imperfect music, in which one part only executed the melody, was performed in Italy with but a small number of instruments. Paul Veronese has preserved to us the form of those which were in use in his time in the famous 'Cena di San Giorgin.' which is at once the largest and most pleasing picture in the Museum of Paris. In the foreground, in the vacant space of the semicircle formed by the table, at which the guests of the marriage of Cana are seated, Titian is plaving on the DoubleBasc, Panl Veronese and Tintoret on the Vinloncello; a man with a cross on his breast is playing on the Violin, Bassano is

* "Lives of Haydn and Mozart," translated from the French by L. A, C. Bomet. $18 \times 8$. 
blowing the Flute, and a Turkish slave the Sackbut." * I have not been able to ascertain whether the instruments above named have been accurately described, but if the author is corrent, we have reliable evidence that the Violin was in use prior to 1550 . There is, however, considerable doubt about the proper nomenclature of the instruments. In a picture it is difficult to distinguish Viols from Violins, and still more so to define the mode of stringing, which is an important poitst in settling the class to which the instrument belongs. There was an instrument that was in use prior to 1600 which had much in common with our Violoncello, and yet cannot be identified with it, since it had five strings, whereas, from about the middle of the i 7 th century, the Violoncello was an instrument of definite character, and possessed four strings only. If Tintoret and Paul Veronese used an instrument having the shape of the Violoncello with four strings, then, clearly, that instrument dates back much further than has been hitherto imagined. Leaving, however, these interesting historical points fur the consideration of connoisseurs, I will proceed to notice the earliest player on the Violin, of whom we have any account worthy of attention, viz., Baltazarina, a native of Piedmont. He removed to France in the year 1577 , whither he was sent by Marshal Brissac to superintend the music of Catharine de Médicis. He delighted the court as much by his skill on the Violin as by his writing of ballet music.

About the year $\mathrm{I}_{5} \mathrm{~S} 3$ a new species of music made way in Italy which exercised a marked effect on the progress of the Violin, namely, that of the concert orchestra. It was chiefly cultivated at Venice and Ferrara. At the latter place the Duke of Ferrara maintained a great number of musicians in his service. At this period there were no concerts of a public character; they were given in the palaces of the wealthy, and the performers were chiefly those belonging to their private bands.

The opera, in which instruments were used to accompany the voice, began to be put upon the stage of the public theatres in Italy about the year 1600 . The first opera ever printed with music is said to have been "L'Orfeo de Monteverde," represented at Mantua in 1607 . The orchestral accompaniment for the opera in those times differed essentially from the róle of modern days. Particular instruments were selected to accompany each character; for instance, ten Treble Viols to accompany Eurydice, two Bass Viols to Orpheus, and so on. $\left.N_{1}\right)$ mention is made of Violins further than that two small Violins (duri Violini piccoli alla Francese) are to accompany the -haracter of Hope, from which it is inferred that a band of Viusus was not much later. At this period, masses for voices with accompaniments for Violins, written by Bassani, Carissimi, and others, were performed in the Italian churches.

* This instrument, mentioned in the Bible, gave rise to the Trombone of the Italians. 
In the "Harmonie Universelle" of Mersennus, published in 1636, mention is made of the king's band of 24 Violins. These were not of one size, but consisted of Treble, Tenor, and Bass Violins, and the Tenors being of three sizes. The music played at this time did not extend beyond the register of the first position. Mersennus is very lavish of his praise for the king's band of Violins, and remarks :-

"But if you wish to hear the upper alone, what can be more elegant than the playing of Constance, what more vehement than the playing of Boccan? what more delicate and 1ender than the neat touches of Lazarin and Foucard? Join the bass of Leger to the acute sounds of Constance, you will have all the harmonic numbers complete."

It is to the introduction of the Sonata that the rapid progress in the cultivation of Violin-playing may be attributed. Giovanni Battista Bassani excelled in this species of composition. His knowledge of the finger-board and bow was superior to that of any writer for the instrument, previous to Bassani's great pupil, Corelli. The sonata was originally written for two Violins and a Bass, with a Thorough-Bass for the Organ; it was thus played in the churches. Prior to this, Violins played extempore flourishes in accompaniment of the chants. The sonata was afterwards adapted to chamber use. In this branch of composition Corelli shone forth with considerable lustre, and gave to the culture of the Violin an impetus of much force. It was at Rome that his first twelve Sonatas were published about 1683 . In 1685 the second set appeared, entitled "Balletti da Camera;" five years later the third set were published. The genius of Corelli may be said to have revolutionized Violin playing. He had followers in every part of Italy. There was Clari at Florence, Vitali at Modena, Visconti at Cremona (who, it is said, tendered his advice to.Stradiuarius upon the construction of his instrument-advice, I fancy, little needed), Veracini at Bologna, and a host of others.

We must now retrace our steps somewhat, in order to allude to another Violinist who considerably infunenced the progress of the leading instrument out of Italy, viz.. Jean Baptiste Lully. The son of a Tuscan peasant, born in the year 1633, Lully's name is so much associated with the romantic in the history of Violin playing that he has been deprived in a great measure of the merits justly his due for the part he took in the advancement of the instrument. The story of Lully and the stew-pans*

* Lully having shown a disposition for music, received some instructions on the rudimenis of the art from a priest. The Chevalier de Guise, when on his travels in Italy, had been request ed by Mademoi-elle de Montpensier, niece of Louis XIV., to procure for her an Italian boy as a page, and happening to see Lully at Florence, he chose him for that purpose, nn account of his wit and vivacity, and his skill in playing on the guitar. The lady, however, not liking his appearance, sent him into her kitchen, where he was made an under scullion, and amused himself by arranging the stew-pans in tones and semitones, upon which he would play various airs, to the utter dismay of the cook. 
hristles with interest for juvenile musicians, but the hero is often overlooked by graver people on account of his culinary associations. When Lully was admitted to the Violin band of Louis XIV. he found the members very incompetent : they could not play at sight, and their style was of the worst description. The Sonatas and airs for Violins common at that period in France were poor in the extreme; the Treble part had all the melody, the Bass and Tenor were mere accompaniments. Lully contributed much to the improvement of French music. In his overtures he. introduced fugues, and was the first who, in the choruses, made use of the side and kettle drums. He wrote several operas and many compositions for the church, all of which served to raise the musical taste in France. To him also belongs the credit of having founded the French national opera.

We will now endeavour to trace the progress of the Violin in England. It is gratifying to learn that we were, even in the primitive age of Violin playing, not without our national composers for the instrument. One Rogers wrote airs in four parts for Violins so early as 1653 (the year Corelli was born). John Jenkins wrote twelve sonatas for two Violins and a Bass, printed in London in 1664 , which were the first sonatas written by an Englishman. In I660, Charles II. established his band of 24 Violins. During his residence on the Continent he had frequent opportunities of hearing the leading instrument, and seems to have been so much impressed with its beauties that he set up for himself a similar band to that belonging to the French Court. In the year I668, Thomas Britton, known as the "small-coal man" (from his having kept a stable in Clerkenwell where he retailed that branch of commerce), gave the first series of concerts in this country, and a long series it was, extending over a period of 46 years. The shape the movement took was that of a musical club, which was maintained at Britton's expense.

\footnotetext{
“ Tho' mean thy rank, yet in thy humble cell, Did gentle peace and arts unpurchased dwell. Well pleased, A pollo thither led his train, And music warbled in her sweetest strain. Cyllenius too, so fables tell, and Jove Came willing guests to Poor Philemon's grove. Let useless pomp behold, and blush to find So lo'w a station, such a liberal mind." *
}

Thus, the first germ of the great musical societies gave a marked impulse to the culture of stringed music in England. Attention was at once turned to the subject: its humanising effects were recognised, and parties met in several places for the practice of chamber music. The performances consisted chiefly of Sonatas for two Violins and a Bass, a species of composition which had a long life, to judge from the number of works of this character and date still extant.

*'These verses were written by Mr. John Hughes, who was a frequent performer on the Violin at Britton's concerts. (Hawkins). 
I have now to mention a Violinist whose talents raised the instrument greatly, particularly in England, viz., Francesco Geminiani. He was instructed by Corelli, and imbibed much of his master's breadth of style. He came to England in the year 1714 . In 1716 he published a set of twelve sonatas, which attracted some notice at the time from their novelty. In these he plunged into difficulties deemed then very unusual, but withal his compositions were elegantly written. He afterwards wrote and published solos and concertos, besides a "Treatise on Good Taste," "Rules for Playing in Good Taste," and the "Art of Playing on the Violin," the latter being the first instruction book for the instrument deserving of the name. The instrumental music at this period was composed for four Violins, Tenor, Violoncello, and Double-Bass, and was called the Concerto Grosso, a mode of composing introduced by Giuseppe Torelli of Verona.

Having lightly sketched the progress of the Violin in England down to about the year 1750 , it will, perhaps, be better to take up the thread of the instrument's progress in Italy, which we brought to the davs of Corelli.

The first half of the I 8 th century was rich in Italian Violinists and writers for the instrument, of whom the chief was Giuseppe Tartini, born in 1692 . Dr. Burney says of his compositions: "Though he made Corelli his model in the purity of his harmony and simplicity of his modulation, he greatly surpassed that composer in the fertility and originality of his invention; not only in the subjects of his melodies, but in the truly cantabile manner of treating them. Many of his adagios want nothing but words to be excellent pathetic opera songs. His allegros are sometimes difficult; but the passages fairly belong to the instrument for which they were composed, and were suggested by his consummate knowledge of the fingerboard and the powers of the bow. As a harmonist, he was, perhaps, more truly scientific than any other composer of his time, in the clearness, character, and precision of his basses, which were never casual, or to the effect of habit or auricular prejudice and expectation, but learned, judicious, and certain." It would be difficult to add to this judgment of the compositions of Tartini. The truth of Burney's remarks are better understood at this moment than when penned. During the space of nearly a century the sonatas of Tartini lay dormant, and only within the past few years have their beauties been again recognised. Such works as Tartini's are all-important links in the chain of musical progress.

Pietro Locatelli, a pupil of Corelli, introduced a style of playing quite in advance of his time. His compositions abound with novel combinations, double stops, harmonics, and arpeggios are displayed with wonderful results. Burney says that "Locatelli had more hand, caprice, and fancy than any 
Violinist of his time." He was a voluminous writer of Caprices and Sonatas. His "Art de Nuovo Modulazione" is probably his greatest work.

The immediate follower of the style of Locatelli was Lolli, born 1728 , who wrote pleasing airs and used novel effects, but failed to go further. It was one of his feats to play on one string, a performance very properly held in contempt in our day, as it has neither sense nor grace to recommend it. Probably Lolli was the first to offer this bait to the public in order to catch their money.

Felice Giardini was another musician of the style of Locatelli.* He was.born at Turin, in the year 1716 . His performance at Naples and Bérlin excited considerable notice. In 1742 he visited England, and created some sensation, his style being new to the British public.

Mestrino was also a follower of Locatelli. His compositions consist chiefly of concertos.

The writings of Bruni stand forth as compositions of an original character, and mark the progress attained by the Violin music of this date. His trios are very bright and pleasing, and his writings for the Viola are among the best that we have for that instrument. He was born at Piedmont, in the year 1759 .

Boccherini, probably, did more towards furthering the cultivation of stringed instrument music than any composer of his day, with the exception of Haydn. There are in his compositions, movements of varied styles well written for their respective instruments. His quintetts are among his chief productions, and their elegance and brilliancy is remarkable. The part allotted to his own instrument, the Violoncello, often bristles with difficulties, and hence it is that these compositions are so seldom heard. Boccherini was the first composer that wrote quintetts with two Violoncello parts.

We now reach a stage in the history of the progress of the Violin, the importance of which cannot be over-estimated; I refer to the influence which the compositions of Giovanni Battista Viotti exerted upon the cultivation of our instrument. With the famous Viotti sprang up a school of Violin playing as marked in style as that introduced by Corelli. Viotti was a pupil of Pugnani, and owed his success to the rare teaching of that master. Pugnani possessed an imagination of no ordinary kind, and Viotti, having imbibed much of his instructor's vein, has made the most of it in his compositions. The sensation that Viotti created in Paris was great. His varied style, his rich tone, and elegance in playing, were far beyond anything that the Parisian public had previously experienced. With Viotti was ushered in a new era in solo playing. His concertos

*In " Les Maitres Classiques," collected by M. Alard, and the " Hohe Schule," collected by Ferdinand David. will be found some of the best examples of this composer, as well as of many others noticed here. 
exhibit the capabilities of the instrument in elegantly constructed passages, such as none but a master of the Violin could pen. He wrote upwards of 20 Concertos. Those in A minor, in $G$, in $D$, and in $E$ minor being the favourites, and, to this day, highly esteemed by Violinists of every school. His duos and trios are pleasing and effective, and, though long since superseded by works of greater erudition, they form a landmark in the history of the progress of the instrument.

Campagnoli, born in $75 \mathrm{I}$, was a composer of rare ability. Had he written nothing but the Studies on the Seven Positions of the Violin he would have left enough to mark the character of his genius. Happily, he has bequeathed to us many other writings. His "Fantasias and Cadences," forming a book of upwards of roo pages, is a work full of interest to the Violinist. His modulations are singularly effective. He has also written some studies for the Viola, and, lastly, a "Violin school." I cannot but think that Campagnoli's educational compositions have not received the attention which they merit, and that they are laid aside as being old-fashioned. There is, I grant, a certain quaintness in his writings, but this much may be said of many other compositions whose beauties are not neglected on that account. It would be difficult to find material more solid than that afforded by the writings of Campagnoli, if the foundation of Violin playing of the highest character is to be laid.

We reach the pinnacle of the Italian school of Violin playing in the wondrous Paganini, born the ISth February, I784, died May 27th, 1840. It is needless to recount the extraordinary achievements of this remarkable man. M. Fétis and others have collected the most interesting particulars relative to Paganini and his compositions, and to their entertaining accounts the reader can turn for information. It is sufficient to mention that Paganini carried the marvellous in Violin playing as far as seems possible. The number of his imitators has been enormous, and many of them, withal, so barbarous as to render anything savouring of "à la Paganini" contemptible. The compositions of Paganini are no longer Paganini's when played by others. He, above all Violinists that ever lived, possessed an individuality in his style of playing which has hitherto defied decent imitation.

From Paganini to his pupil, Camilla Sivori, is the next step in my notice. The artistic career of Sivori has been a glorious one. Elegance of style and charming purity of tone are qualities peculiarly his.

Antonio Bazzini both as a solo Violinist and composer for the instrument has achieved lasting fame.

Having endeavoured to lightly sketch the history of Italian performers, and of Italian music bearing on the instrument, to the present time, it remainis to notice a remarkable follower of the Italian school of Violin playing in the Norwegian, Ole 
Bornemann Bull. The executive skill of this famous Violinist was of the highest order, and perhaps no other artist, with the exception of Paganini, gained such a world-wide renown.

It is now necessary to refer to the course of events touching the Violin in France. As the influence of Viotti resulted in a remodelling of the French style of playing, our survey will make it necessary to go back the greater part of a century, and to take up the point where we parted company with Lully.

Jean Marie Lecler, the pupil of Somis, is here the first Violinist dęserving of mention. He was born at Lyons in 1697. In 17.29 he visited Paris, where he was engaged at the opera. Lecler was the originator of the school of French Violin playing. He wrote several sonatas for two Violins and Bass, besides other compositions. The difficulties occurring in many of these writings are of no ordinary character, and if they were rendered with anything approaching to exactness the progress made on the Violin must have been very rapid between the days of Lully and Lecler.

Pierre Gaviniès claims attention both as an executant and composer. There is a freshness about his compositions which has caused many of them to be recently roused from their long sleep, and re-issued in the improved garb of a modern edition. His best known works are the 24 Studies, Concertos, and Sonatas.

Although there were several Violinists in France of average abilities between the time of Gaviniès and that of Rode, they scarcely claim attention in this somewhat hasty sketch; and I will therefore pass to the players linked with Viotti. To commence with Rode, the pupil of Viotti. He was born at Bordeaux in 1774. Fètis remarks "from Corelli to Rode there is no hiatus in the school, for Corelli was the master of Somis, Somis of Pugnani, Pugnani of Miotti, and Viotti of Rode."

His well-known 24 caprices, and his concertos, and airs, are much admired by all Violinists for their elegance and effectiveness. Paganini played the concertos of Rode publicly upon several occasions. Bailliot and Kreutzer were associated with Rode at the French Conservatory of Music, and likewise in the compilation of the well-known Instruction Book written expressly for the use of the pupils at the Conservatory. Bailliot was famed for his admirable bowing and refined playing. Kreutzer is, of course, better known from his 40 Studies than from anything else that he has written. His concertos partake more of the study than the name they bear, and are valued accordingly.

Lafont was instructed by both Rode and Kreutzer, and held a high position among the Violinists of his time.

Francis Antoine Habeneck was a pupil of Bailliot at the Paris Academy of Music, where the distinguished himself, and became a professor. Among his pupils were Tolbecque, 
Cavillon, Alard, and Sainton. Few professors have had the pleasurable task of instructing such a goodly Quartett. M. Alard occupies one of the chief positions as a protessor in Paris, and possesses a high reputation as a composer for his instrument. M. Sainton settled in London in IS45, shortly after which he became principal professor of the Violin at the Royal Academy of Music, and leader under M. Costa, a position which he still retains. He has written several effective Fantasias.

It now remains for me to notice the Belgian branch of the French school, which may be said to have commenced with Charles de Beriot, one of the most delicious players we have had. As a composer for his instrument, he opened up entirely fresh ground; he banished all that was dry, and gave us those fresh and pleasant Airs varies and Morceaux de salon, teeming with novel effects. It can never be said that De Beriot alarmed the amateur with outrageous difficulties; on the contrary, he gave them passages easy to execute, full of effect, and yet withal astonishing to the listener. De Beriot has probably made more amateur Violinists than any composer of his time.

In Henri Vieuxtemps we have a thorough master of his art. His Concertos are compositions worthy of the title they bear; they do not consist of a number of difficulties strung together without meaning, but are properly constructed works. He has written many Fantasias, all of which are the delight of good Violinists. His compositions being most difficult to render, they are chiefly known among artists, but in these days of rapid development in Violin playing among amateurs, a new and wide field will certainly be opened for them ere long.

From Belgium to Poland may appear a wide step in my discourse, but it is not so. Although the Polish Violinists retain a certain amount of originality in style of playing and in their compositions, it is to the French school they belong. Lipinski, Wieniawski, Lotto, were all educated in the Paris school.

Lipinski has written a good deal for his instrument, and instructed many well-known players.

Wieniawski and Lotto have both gained high positions among the soloists of our time.

Adolplie Pollitzer settled in London many years since, and occupies a leading position among our resident Violinists.

Having lightly touched upon the various heads of the French school, I must again take up the thread of the English history of the instrument from about $175^{\circ}$, at which period we may trace a growing admiration for Violin playing, notwithstanding the disparagement which this accomplishment received from different notabilities. Foremost among the revilers stands Lord Chesterfield, who considered playing upon any musical instrument to be illiberal in a gentleman. The Violin would seem to have been regarded by his lordship with a supreme 
amount of displeasure. His opinion of Violinists savoured greatly of that held by the framers of the statute passed in the reign of Elizabeth touching minstrels, who were to be included among "rogues, vagabonds, and sturdy beggars" when wandering abroad. Lord Chesterfield says, "Music is usually reckoned one of the liberal arts, and not unjustly, but a man of fashion who is seen piping or fiddling at a concert degrades his own dignity. If you love nusic, hear it ; pay Fiddlers to play for you, but never Fiddle yourself." Such was Lord Chesterfield's advice to his son. It is quite evident that he had no notion of the exquisite enjoyment derivable from being an executant in a quartett, the conversational powers of which have been so frequently noticed. That Lord Chesterfield's strictures discouraged the practice of the Violin in the higher circles of society is very probable, appearing as they do in a work which was held in the light of a text-book upon the conduct of a gentleman for some considerable time. Happily, the hollowness of much of his advice came to be recognised, and he who deemed cards and dice a necessary step towards fashionable perfection, and ordained that Fiddlers were to be paid to play for you as substitutes for your own personal degra-. dation, came to be remembered, possibly, more on account of the laxity of his precepts than for any other reason.

In the days of Lord Chesterfield lived Michael Christian Festing, who was particularly zealous in the cause of music. He was a pupil of Geminiani, and wrote several solos. Festing still further carried out the idea of Britton the "small-coal man," by bringing together a number of noblemen and gentlemen amateurs for the practice of concerted music. They met at the "Crown and Anchor" tavern in the Strand, and named their society the "Philharmonic." So much for his furtherance of the art. It now remains to notice the great boon which Festing conferred upon his brother professors and their descendants. It is this which has given his memory lasting life in the annals of English music.

We are indebted to Festing as the chief instrument for the formation of the Royal Society of Musicians, which he may be said to have founded in the year 1738 . This society derived its origin from the following curious circumstance. Festing being one day seated at the window of the Orange Coffee House, then at the corner of the Haymarket, observed a very intelligent looking boy, who was driving an ass and selling brickdust. The lad was in a deplorable condition, and excited the pity of the kind-hearted musician, who made enquiries concerning him, and discovered that he was the son of an unfortunate professor of music. Struck with grief and mortification that the forlorn object before him should be the child of a brother musician, Festing resolved to attempt something for the boy's maintenance. Shortly after, with the help of other benevolently- 
disposed persons, he raised a fund for the support of decayed musicians and their families, and thus laid the foundation of the society, which is the first of its kind in Europe. Handel was one of its first and principal members, and left it a legacy of $\oint_{1,000}$. Little did Festing and his supporters dream that their society, humble enough in 1738 , would grow into a society possessing $£ 80,000$ in 1874 , a sum which, however high sounding, is yet insufficient to permit the committee to dispense the full amount of good desired.

Returning again to our subject, we find that in Festing's life-time there were several patrons of the art, the chief of whom was the Prince of Wales, the Duke of Cumberland, and Earl Mornington. We may now glance at the period when Salomon came to England, in $178 \mathrm{r}$. Too much stress can scarcely be laid upon the good effected by Salomon's talents for the progress of music, and more particularly in behalf of instrumental music. We are everlastingly indebted to this musician for the spirit and enterprise which he displayed, in bringing to England, at 110 trifling pecuniary risk, the immortal Haydn. Salomon having established a series of twenty concerts in the year, it occurred to him that to invite the famous musician to London, would aid his enterprise. He communicated with Haydn offering him fifty pounds for each concert. These terms were accepted, and Haydn set out for London in the year 1790 , at the age of fifty-nine. He remained in England over a year, and composed the celebrated "Twelve Symphonies" known as the Salomon set. Salomon was one of the promoters of the Philharmonic Society, and led the orchestra at the first concert given by the Society in $18 \mathrm{r} 3$. Enough has been said to show the nature of the part he took in the development of music in England. Enjoying the friendship of those who moved in the higher circles of society, where his polished manners and high attainments ever made him a welcome guest, he was enabled to command such patronage as to make his laudable ventures successful.

Among the violinists of Salomon's day, resident in England, were William and Francis Cramer, to whom severally was assigned the leadership of the Ancient Concerts and of the Opera.

The next Violinist who gained some celebrity was Nicholas Mori, born in London in the year 1796 . He was associated with the formation of the Royal Academy of Music, in Tenderden Street, and became the principal instructor on the Violin at that Institution. Spagnoletti and Kieswetter each contributed their share towards the advancement of the instrument during their stay in this country. The names of Dando and Henry Blagrove bring us to the players of our own time; these thoroughly representative English Violinists have done much to raise the standard of the public taste. It is said that Mr. Dando gave 
the first public quartett concert in this country, which took place in 1835 ; from which circumstance we may glean some idea of the rapid strides we have made in the appreciation of chamber music during the past forty years. The work so well commenced by Mr. Dando, was made complete, artistically speaking, by the formation of the Musical Union. The long roll of celebrated continental artistes introduced at the Society's concerts sufficiently stamps its character. All that remained to be done was to make the quartett popular, and to bring it within the reach of all. This has been achieved by the indefatigable labours of Mr. Chappell in his Monday Popular Concerts. For some time the public failed to appreciate Mr. Chappell's scheme, but the enterprising director, nothing daunted, continued his course, and has now the gratification of being besieged in his citadel at St. Jame's Hall, from the commencement of the season to its close.

Before closing our remarks on the progress of Violin play. ing in England, we have still to mention a few other names in connection with this subject. Henry C. Cooper is a Violinist who takes rank with the chief representatives of the English Soloists, and during a long professional career has achieved much success. He set on foot, together with his coadjutors, M. Sainton, Hill, and Signor Piatti, the Quartett Association, the concerts of which were given at Willis's Rooms during several seasons. The career of Mr. John Carrodus, has been watched by his brother artistes with much interest. As a pupil of Herr Molique, he gave early signs of exceptional talents : it was felt that he must inevitably come to the front; all that was predicted, and even more, has come to pass. He now has a commanding position among the foremost Violinists of our time, both as a soloist and leader. With the names of Messrs. Henry and Alfred Holmes, I come to the close of the English branch of the subject. The brothers Holmes attracted the notice of Spohr, who was so delighted with their abilities that he composed and dedicated three Duets for two Violins to them. Mr. Henry Holmes settled in London some years since, and has been successful both as a player and a composer.

I have not found it convenient to refer to the German school of Violin-playing previous to this, on account of its distinctive character. The Italian school passed into France with Viotti ; indeed, there was even an earlier connection between Italy and France in this respect, through Lully. The Italian school was also linked with the English through Geminiani and Giardini ; but of the German school it may be said that its individuality is so marked as to necessitate its being considered apart.

That the Germans are indebted to the Italians for their early acquaintance with music is, I imagine, conceded on all sides; but it is only in the earliest stage of the art that any such indebtedness can be said to exist, as they soon struck out a 
course abounding in originality. The first name of any note in connection with the Violin in Germany is that of Graun, who was born in the year 1700 . He became concert master to the King of Prussia, and excelled as a Violinist. His pupil, Francis Benda, next claims attention. Dr. Burney says of him: "His manner was neither that of Tartini, nor of Veracini, nor that of any other leader, it was purely his own, though founded on the several models of the greatest masters;"' and Hiller tells us that "his tones were of the finest description, the clearest and most euphonius that can be imagined." These remarks point to the statement that I have made above of the early distinctive character of German Violin playing. Benda published studies for his instrument, and also several solos and other works, all of which are admired for their good taste and cantabile style.

About this period appeared the admirable compositions for the Violin of that great master of his art, John Sebastian Bach -works differing essentially from those of his contemporaries.

"He was not of an age, but for all time."

To describe the character and beauties of Bach's Violin writings belongs only to the deeply learned in the science of music. To enter upon so critical a subject is neither within my province nor capacity. As an amateur Violinist an an observer of all that relates to the Violin, I may refer, however, to the vast amount of good which the compositions of Bach have exercised upon the cultivation of Violin play ing, and the marvellous development that they have received at the hands of many of our leading Violinists. To this happy state of things we are largely indebted to the incomparable Herr Joachim; but for him these treasures might have remained hidden behind a cloud of airs variés, fantasias, and what not, for many a year to come. Herr Joachim has made the Sonatas of Bach familiar to thousands who a few years since scarcely knew of their existence. The difficulties which abound in these solid writings could only have heen written by a master perfectly acquainted with the capabilities of the instrument. Many a tyro who plunges into the stream of Bach's crotchets and quavers soor finds himself encompassed by a whirlpool of seeming impossi. ilities, and is frequently heard to exclaim that the passages are impracticable. Vain delusion! Bach was himself a violinist, and never penned a passage the rendering of which is impossible. The ease and grace with which a Joachim makes every note heard and felt, induces many a one to wrestle vith Bach, the more so when it is found that the great author has confined himself to the lower positions of the instrument. Vain delusion number two! Bach exacts more on terra firma than many later writers have claimed in their wildest aerial flights.

From Bach to Handel is an easy step in our discourse. They were born within a year of each other, and were possessed 
of minds of similar calibre, though differently exercised. It would not, perhaps, be over-strained to call them respectively the Nelson and Wellington of music. It is curious, too, that like those heroes of war, these harbingers of peace, it has been said, met but once, an event which Dr. Burney mentions as having occurred at Salzburg, where, on their going together to the Cathedral, they found it so full that they could scarcely get to the organ-loft; and when one of them opened the organ it was not possible for more persons to crawl into the church. Those, however, who could not gain admission into the interior of the building procured ladders and placed them at the windows in order to gratify their ears.

The compositions of Handel materially advanced the Violin. His Overtures, Trios, Sonatas, and Concerto.j, were all received with the utmost attention, and led on to works by later composers, which would probably never have existed but for Handel's example. Stamitz, who introduced the modern form of Overture, was a Violinist, and also played on the Violoncello and Tenor.

We now reach the time when the Symphony was perfected by Haydn, who, following the steps of Bach, brought this branch of the art to a degree of perfection hitherto unknown, and ultimately formed a model scarcely equalled. The influence of this composer on the progress of the Violin cannot be overestimated. The quartetts of $\mathrm{Hay} \mathrm{dn}^{\mathrm{d}}$ are too well known to need more than mention here. The Quartetts of Giardini and Pugnani were laid aside to give place to these inspired compositions. The following amusing comparison drawn by a lady between the quartetts of Haydn and the speech of articulate humanity appears in Bombet's "Letters on Hayddn," and though pretty well-known will lose nothing by repetition:-

"In listening to the quartetts of Haydn, this lady felt as if present at a conversation of four agreeable persons. She thought that the first Violin had the air of an eloquent man of genius, of middle age, who supported a conversation, the subject of which he had suggested. In the second Violin she recognised a friend of the first, who sought by all possible means to display him to advantage, seldom thought of himself, and kept up the conversation, rather by assenting to what was said by the others than by advancing any ideas of his own. The Alto was a grave, learned, and sententious man. He supported the discourse of the first Violin by laconic maxims, striking for their trutl. The Bass was a worthy old lady, rather inclined to chatter, who said nothing of much consequence, and while she was talking the other interlocutors had time to breathe. It was, however, evident that she had a secret inclination for the Alto, which she preferred to the other instruments."

It may be said that the foregoing extract is more funny than just. Probably this is the case; however, I make use of it as 
throwing some light on the enjoyment derivable from listening to a quartett, without reference to its critical bearings.

Resuming our subject again: Haydn wrote eight easy Sonatas for Violin and Pianoforte, but they are not of sufficient importance to cause them to be much played. Haydn used frequently to take the Tenor part in his quartetts.

Leopold Mozart, born in 17 I9, the father of the illustrious musician, was a Violinist, and wrote a "Method" for his instrument. He died in 1787 .

To the great Mozart, Violinists owe much ; his compositions for the instrument raised it considerably. It is unnecessary to give here a detailed list of his writings in which the Violin takes part-they are happily known to most players. Mozart played the Violin from boyhood, and was taught by his father. It is gratifying to know that nearly all the great composers played upon stringed instruments, if not with proficiency, yet enough to enable them to make pleasurable use of their acquirements. Sebastian Bach, Handel, and Mozart were Violin players; Haydn and Mendelssoln could take their Tenor part in a quartett, and lastly Beethoven used to amuse himself with the Double-Bass. Their compositions evidence a practical knowledge of stringed instruments as distinct from theory. The glorious compositions of Beethoven for the Violin need no comment here; their beauties have formed the theme of the ablest critics, and I have no desire to contribute my humble mite to their exhaustive remarks.

With Fesca we again come among the Violinists. He was born at Magdeburg, in $\mathrm{I}_{7} \mathrm{~S} 9$. His quartetts are very pleasing compositions; they are chiefly solo quartetts.

The next Violinist claiming attention is the highly gifted Louis Spohr, the greatest composer for the Violin that ever lived who combined in his own person high executive powers with a rare fecundity of classical composition. The concertos of Spohr belong entirely to a different class from those of Viotti, Kreutzer, and others, inasmuch as Spohr's music is not merely written to display the beauties of the instrument, but also to give the noblest specimens of its orchestration. His duos for two Violins, his Tenor and Violin duo and quartetts, are all too well known to need more than passing mention.

From Spohr has grown up a school of Violin playing of a very distinctive character. Bernard Molique was endowed with great p.rwers both as a performer and a composer for his instrument. His concertos are compositions of the highest order, and require for their rendering a finished artist.

Joseph Mayseder was a Violinist of a different order to that of Spohr or Molique. His style was exceedingly brilliant ; and in writing Polonaises for his instrument he probably has not been equalled.

Mayseder may also be said to have created a school of his 
own, and owing to the circulation that his compositions obtained in England, his style was introduced among a great number of our countrymen.

Kalliwoda wrote and played very much in the Mayseder manner. His airs and variations are especially brilliant compositions ; his overtures are also much admired for their sparkling and dramatic character.

I come now to notice one of the greatest artists of our time - Herr Ernst-whose playing was impassioned in the highest degree. He made the Violin express his innermost thoughts in tones of such delicious tenderness as his hearers can never forget. By nature noble, generous and affectionate; the shade and substance of each trait was faithfully reflected in his exquisite playing. His compositions are among the finest solo writings we have. To mention his "Otello," "Airs Hongrois," "Le Prophète," and his "Studies," will be sufficient to call to the mind of most Violinists the high character of his compositions.

It now only remains for me to briefly allude to the German artists each Concert Season makes us familiar with. First and foremost is the mighty Herr Joachim, a host in himself. His able coadjutor Herr Strauss is justly admired for his intellectual rendering of the works of the great masters, and the artistic spirit he invariably displays. Herr Wilhelmj is regarded as one of the first players of our time, his executive powers being of the highest order. 


\title{
SECTION XV.
}

\author{
Anecdotes and Miscellanea connected with \\ THE VIOLIN.
}

THE MISSING SCROLL.

T'T has often happened that portions of valuable instruments detached from the original whole have been once more recovered and reinstated in their proper place. The following is an amusing instance of this.

A well-known amateur, belonging to the generation now fast passing away, was the fortunate possessor of a Stradiuarius Violin, which he had occasion to take to the Fiddle doctor for an operation quit $€$ unknown to the students of the Royal College of Surgeons, but well understood by the members of the fraternity to which I have the honour to belong, namely, decapitation. This, in the Fiddle language, means the removal of the old neck and the splicing of a brand new one in its place. It is an operation wholly unattended with the horrors of human surgery. Again and again a time was appointed for the completion of this delicate insertion, but in vain,-it was a case of hope deferred. The owner of the Stradiuarius becoming wearied with this state of things, determined to carry off his cherished instrument in its dismembered condition. Placing the several portions in paper, he left the Fiddle doctor's establishment, considerably annoyed and excited. Upon reaching home his recent ebullition of temper had entirely passed away, and he calmly set himself to open the parcel containing his dissected "Strad," when, to his utter dismay, he failed to find its scroll. The anguish he suffered may be readily conceived by the lover of Fiddles. Away he started in search of his Fiddle's head, dead to all around him but the sense of his loss; he demanded of everyone he met whether they had by chance picked up the head of a Fiddle. The answers were all in the negative; and many were the looks of astonishment caused by the strange nature of the question and the bewildered appearance of the questioner. At length he arrived at the house of the Fiddle doctor, whose want of punctuality had brought about the misfortune. Here was his forlorn hope! He might possibly have forgotten to put the scroll into the parcel. His doubts were soon set at rest; the scroll had been taken with the other parts of the instrument. Completely overcome with sorrow and vexation, he knew not how to endeavour to recover his loss. He ultimately decided 
to offer a reward of five pounds, and to await the result as contentedly as he could.

A few hours after the dejected owner of the Violin had left the shop of the Fiddle-doctor, an old woman, the keeper of an apple-stall in the neighbourhood, entered and offered for sale a Fiddle's head. The healer of Violins, taking it into his hands, was agreeably astonished to recognise in it the missing headpiece, and eagerly demanded of the seller whence she had obtained it, and what might be its price. "Picked it up in the gutter," she answered; and two shillings was the modest value she set upon her find. Without a moment's hesitation the money was handed to the vendor of Ribston pippins, and away she trudged in high glee at the result of her good luck. The Fiddle Asculapius, equally gleeful at the course of events, resolved to avail himself of the opportunity afforded him of gratifying a little harmless revenge upon the fidgety amateur's haste in removing the "Strad" before the alterations had been completed. He therefore determined to keep the fact of the discovery to himself for a short time. Advertisements multiplied, and the reward rapidly rose to twenty guineas. Having satisfied his revengeful feelings, the repairer duly made known the discovery of the missing scroll, to the intense gratification of its owner. Finally, the repairer refused to accept any portion of the reward upon one condition, viz., that he was allowed to complete his work-a condition readily conceded.

\section{ANOTHER WANDERING SCROLL.}

Among the collection of valuable Violins belonging to the late James Goding, Esq., was a Stradiuarius dated I7 Io, which had been deprived of its original scroll, and bore a supposititious figure-head by David Techler, owing to a piece of vandalism perpetrated by an eccentric amateur. The original scroll had found its way to an Italian Violin of some merit, the value of which was considerably enhanced by the newly acquired headpiece, which gave to the whole instrument an air of importance to which it could lay no claim till it carried on its shoulders a lead belonging to the aristocracy of Fiddles. During a period of about twenty years this mongrel Fiddle became the property of as many owners, and ultimately fell into my liands. Leaving this instrument, we will follow the history of the Stradiuarius, date I 7 Io. At the dispersion of Mr. Goding's collection by Messrs. Christie and Manson, in the year 1856 , a widely-known amateur purchased the Violin for the sum of eighty pounds, the loss of its scroll preventing the realisation of a higher figure. Sixteen years after this event the purchaser applied to me for a Stradiuarius scroll that he might make his instrument complete. The mongrel Violin described above being in my possession, decapitation was duly performed and the Stradiuarius received 



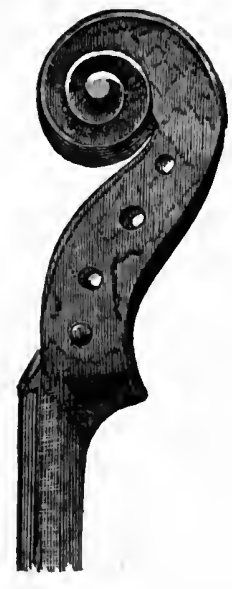

Joskph Guarnerivs.

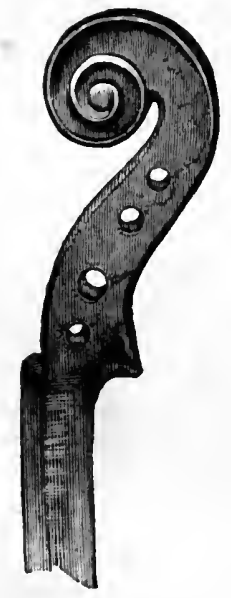

Stradiuarius, 1709 .

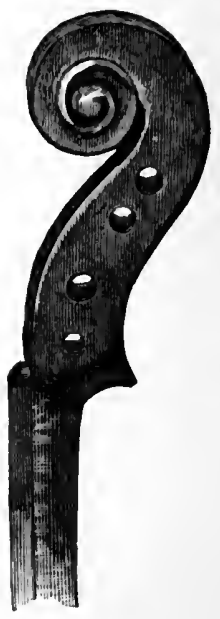

Stradiuarius, 1686 .

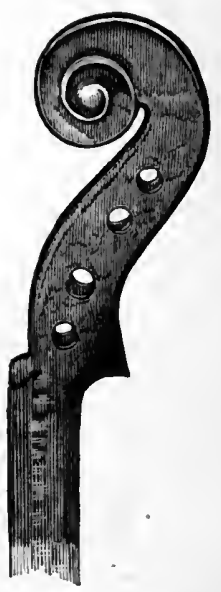

Nicholas Amati. 
its head again. Here was a fortuitous course of circumstances ! This exchange of heads took place without my being at all aware that the "Strad" scroll had returned to its original body; but on my mentioning the circumstance to my father, he informed me to my astonishment and delight that if the head of the mongrel Fiddle had been placed on the Stradiuarius, date I7Io, from the Goding collection, it was now, as the effect of recent transmigration, on its own legitimate body!

\section{A MONTAGNANA INSTRUMENT SHOT THROUGH THE BODY IN THE REVOLUTION OF 3848 .}

An enthusiastic amateur was playing the Violin in a house in one of the leading thoroughfares in Paris at the outbreak of the Revolution in 1848 . His ardour was so great that the cannonading failed to interrupt him in his pleasurable pursuit; he fiddled on, regardless of all about him, like Nero while his capital was in flames, and even left the window of his apartment open. Presently a whizzing noise, terminating in a thud above his head, arrested his attention. Upon his looking up he saw the mark of a bullet in the ceiling. Aroused to a sense of his danger, he closed the windows. Being about to put his Montagnana into its case, his astonishment may be imagined, when he discovered a hole through the upper side and a corresponding chink in the belly, both as sharply cut as though a centre-bit had done the work. His Violin bore witness to his miraculous escape; the bullet lodged in the ceiling had taken his Montagnana in its course. The instrument referred to in this anecdote has been in my possession more than once.

\section{FIDDLE MARKS AND THE CREDULOUS DABBLERS.}

It is said a drowning man will catch at a straw; the truth of the remark applies to the half-informed in Fiddle connoisseurship. It is very amusing to note the pile of nothings that these persons heap up under the name of "guiding points " in relation to Fiddles. I will endeavour to call to mind a few of these. I will begin with those little pegs seen on the back of Violins near the button, and at the bottom; the position of these airy nothings without habitation or name, "is deemed indisputable evidence of certain makers' handicraft." One is supposed to have put his pegs to the right, another to the left; another used three, four and so on. I have frequently heard this remark-"Oh it cannot be a Stradiuarius, because the pegs are wrong!"”

The purfling also forms an important item in the wiseacres' collection of landmarks; certain makers are supposed to have invariably used one kind of purfling, no variation being allowed for width or material adopted. Original instruments are pro- 
nounced spurious, and spurious original, by this test. All Fiddles purfled with whalebone are dubbed "Jacobs," and no other maker is credited with using such purfling.

The back of a Violin is another very important item with these individuals. Particular makers are supposed to have only made whole backs, others double backs, others again are thought to be known only by the markings of the wood. There is another crotchet to be mentioned. Some will tell you they will inform you who made your Violin by taking the belly off, and examining the shape of the blocks and linings. Rest assured if the maker cannot be seen outside, he will never reveal himself in the inner consciousness of a Fiddle. Measurement is another certain guiding point with these dabblers ; the measuring tape is produced and the instrument condemned if it does not tally with their erroneous theory.

\section{A STOLEN "STRAD."}

It has often been remarked that to steal a valuable Violin is as hazardous as to steal a child ; its identity is equally impregnable, in fact, cannot be disguised, save at the price of entire demolition. To use a paradox, Violins, like people, are all alike, yet none are alike. The indelible personality of the best Violins has been a powerful agent in the cause of morality, and has deterred many from attempting to steal them. We have, however, instances of undiscovered robberies of valuable instruments, and notably that of the fine Stradiuarius which belonged to a well-known amateur, an attaché at the British Embassy at St. Petersburg. The Violin in question was numbered with the Plowden collection. I disposed of it to the amateur above mentioned in 1868 , for the sum of $£ 350$; it was a magnificent Violin, date 1709 , in the highest state of preservation, and would realize at this moment upwards of five hundred guineas. In the year 1869 the owner of it was appointed to the embassy at St. Petersburg, and removed thither. He was a passionate lover of the Violin, and an excellent player. One evening he was playing at a musical party. After he had finished he placed his "Strad" in its case as usual, which he closed, without locking it. The next day he was amusing himself with a parrot, which bit him on the lip; the wound appeared very unimportant, but exposure to the cold brought on malignant abscess, and he sank and died. In due course his representatives arrived at St. Petersburg, and took charge of his property, which was brought to England. Some twelve months afterwards a relative who took much interest in valuable Violins, was visitiug the family of the deceased gentleman, and asked to be allowed to see the Stradiuarius, 1709. The case was sent for and duly opened. When the Violin was handed to the visitor he remarked there must be some mistake, and suggested that the 
wrong case had been brought, the instrument he held having no resemblance whatever to the Stradiuarius, not being worth a sovereign. Enquiries were set on foot, and it was satisfactorily proved that the case had never been opened since it had been brought to England; neither had it left the custody of the late owner's nearest relative, who had kept it secured in a chest. The next day after the occurrence of the event related above, I was communicated with, and asked if I could recognise the Stradiuarius in question. It is unnecessary to record my answer. I might with an equivalent amount of reason have been asked if I should know my own child. The double case was formally opened and the Violin described above was taken out. "Is that the Stradiuarius?" I scarcely knew, for the moment, whether my interrogator was in earnest, so ridiculous was the question. It remains only to be said that the Russian authorities were memorialised and furnished by me with a full description of the instrument; but to this moment its whereabouts has never been discovered.

\section{QUICK RECOVERY OF A STOLEN TENOR.}

Many years since a young man brought to us a Tenor, which he offered for five pounds, saying that his father had sent him to dispose of it, as he was in straitened circumstances. The instrument was a very fine Nicholas Amati, and well known to us as the property of a near neighbour in the same business. as ourselves. The would-be seller was questioned, and, his answers being anything but satisfactory, we detained him while our neighbour was communicated with. The case in which the Viola was kept in its lawful home was opened and was found to be empty. The Amati was received by the owner with much delight, and the thief handed over to the arm of the law. The man had been employed for a few days as an assistant porter. Little did he think he was carrying a detective in the form of a Tenor!

\section{LIVING STRADIUARIUSES.}

The following amusing incident occurred not long since. A passionate lover of Fiddles being in Milan, made the acquaintance of an Italian who, like himself, was a lover of the bow. They had not long met before the theme of their mutual delight was broached; the beautiful features in the works of the great masters were dwelt upon, their respective points of genius discriminated, until the freemasonry of Fiddle-connoisseurship was exhausted. Enquiries were exchanged as to the whereabouts of remarkable specimens, when suddenly the Italian's face brightened, and gave indication that a happy thought had crossed his mind, as he remarked: "By the way, I can introduce you to a friend who has in his possession some 
singularly choice specimens of Stradiuarius, of various dates, all in splendid condition, and having heads of a very marked character. There can be no mistake about their originality, it asserts itself to the merest tyro ; indeed, I am not aware that it has ever been called in question." His companion was on his feet before he finished speaking, eagerly demanding where these choice "Strads" were to be seen. The distance being but a few streets off, it was agreed that they should start at once. On arriving at a house in the Via Meravigli, the Italian enquired of the servant if his master was at home. Being assured of this, the Fiddle connoisseurs were shown into an apartment, where they anxiously awaited the host. Presently he entered, and the usual exchange of courtesies having been gone through, the Italian, with the utmost gravity, enquired after the Stradiuariuses, and received answer that they never were better; his companion, who was burning to feast his eyes on them, begged that he might have the pleasure of seeing them. The host, flattered by the interest taken in his "Strads" by his visitor, acquiesced, left the room, and brought in his collection, which, if not unique, was in every way original. It consisted of five Stradiuariuses - three bors and two girls. Unable longer to restrain his laughter, the Italian broke forth into one of those hearty peals which terminate only when the risible faculties are completely exhausted. Signor Stradivari, the happy parent of the collection just usherfd into the room, regarded his visitor with astonishment, in which he was joined by the specimens of various dates, all being in complete ignorance of the harmless joke. Ultimately the countenance of Signor Stradivari began to assume anything but a pleasing appearance, as he had failed to comprehend what there was about his cherished ones to excite such ungovernable mirth. When the joke was explained, it is needless to say that the wit's friend, the connoisseur, suffered some disappointment, but soon heartily joined in the laugh raised at his expense. Signor Stradivari and his family were not long kept behind the curtain, and soon added their laugh to that of the rest of the company.

\section{A CINDERELLA ViOlONCElLO.}

A somewhat curious change in the ownership of a Violoncello, occurred many years since. My father (Mr. John Hart), was walking along Oxford Street, when he heard the sounds of a Violoncello, a Violin, and a Cornet, which were being played in a side street. His curiosity being excited, he became one of the group of listeners. The appearance of the Violoncello. greatly pleased him; it was covered with a thick coating of resin and dirt, but its author was clearly defined nevertheless. When the players had concluded their performance, Mr. Hart asked the wandering Violinist if he was disposed to sell his 
instrument. "I have no objection, if I can get enough to buy another and something over," was the answer. The terms not being insurmountable, a bargain was struck, and the dealer in Fiddles walked away, taking his newly-acquired purchase under his arm. The itinerant trio having become a duet, gave up work for that day. The lookers-on moved off, after having exhibited considerable interest in the scene which had occurred.

Reaching home with his charge, Mr. Hart was in the act of removing the accumulated dirt of many a hard day's work from the Violoncello, when Robert Lindley entered, and asked what might be the parentage of the instrument about which so much pains were being taken. "A Forster," was the reply; and at the same time the circumstances of the purchase were related. Lindley was much amused, and expressed a wish to possess the rescued instrument, though it had been much injured. The price was agreed upon, and the Violoncello thus passed from the most humble to the most exhalted player in one day.

\section{THE PAINFUL OPERATION.}

An ardent lover of the Violin, and possessor of a charming Stradiuarius, which he prizes next to his own existence, had occasion to submit the cherished object to the judgment of a well-known Fiddle-doctor, on account of a slight derangement of its interior organism. Before the coverlet was removed from the patient, the learned doctor was well lectured and catechised as to the system that he adopted in his healing profession. Having passed through this ordeal to the entire satisfaction of the owner of the Violin, the coverlet was lifted, and the instrument given over to the repairer, who was then finally cautioned and implored to handle it tenderly. The preliminary examination was at once proceeded with. Gentle taps upon the chest of a Fiddle-patient are equivalent to the use of the stethescope upon the chest of ordinary mortals. These taps were given in rapid succession, until a weakness showed itself. The owner looked enquiringly at the doctor, anxious for the delivery of his opinion. "There is no help for it -the belly must come off." With great reluctance the owner consented. He resolved to remain by the Violin during the operation, painful though it would be to his feelings. He seated himself in a chair viewing the ominous preparations of horrible implements, \&c., with the utmost concern. At length all was ready ; the knife was heard to begin its work. and the usual crackling sound showed that the operation had began. A piteous groan was uttered by the Violin's lcring master, and as the knife went round the belly, shriek after shriek did he utter. At last, when upon the completion of the painful operation, the doctor turned to submit the interior of the instrument to his patron, he was astonished to find he had swooned. 


\section{"GUARNERIUS" AT A DISCOUNT.}

With what tenacity do persons often cling to the fond belief that undoubted Raphaels, Cinque Cento bronzes, dainty bits of Josliua Wedgwood's ware, and old Cremonas, are exposed for sale in the windows of dealers in unredeemed pledges, brokers' shops, and divers other emporiums! It is the firm conviction of these amiable persons, that scores of gems unknown, are awaiting in such cosy lurking places the recognition of the educated eye for their immediate deliverance to the light of day.

The quasi bric-a-brac portion of the general dealer's stock is dexterously arrayed in his window, and not allowed to take up a prominent position among the wares displayed. To expose treasures would be a glaring act of indiscretion, inasmuch as it would tend to the belief that the proprietor was perfectly cognisant of the value of his goods, whereas he is imagined by the hypothesis to be profoundly ignorant on the subject. Pictures, bronzes, china, and Fiddles, with their extremely modest prices attached, lie half-hidden behind a mountain of goods of a diametrically opposite nature. There they may rest for days, nay, weeks, before the individual with the educated eye, for the good of all men, detects them. Sooner or later, however, he makes his appearance, and peers into every nook of the window, shading his eyes with his hands. Something within arrests his attention, his nose gets flattened against the glass in his eagerness to get nearer the object. He enters the establishment, and asks to be allowed to look at an article quite different to the one he has been so intent upon; his object being that the dealer may not awaken to a sense of the coveted article's value by a stranger seeming to be interested in it. After examining the decoy bird, he returns it, and carelessly asks to look at the article. Whatever the value set upon it may be, he tenders exactly the half, the matter being usually settled by what is technically known as "splitting the difference." Delighted with his purchase, he carries it home, and persuades his friends he has got the blind side of the dealer, and is in possession of the real thing for the fiftieth part of what others give for it. He proceeds to enlighten his friends on the subject, telling them to follow his example, which they invariably do.

Scarcely a day passes without my hearing of a Cremona having been secured in the manner I have attempted to describe. My experience, however, teaches me that the whole thing is a delusion, and that the thoroughbred Cremona does not fall away from the companionship of its equals, once in the space of a lifetime, and that when this does happen, the instrument rarely falls to the bargain-hunter.

The following exceptional incident will, I hope, not be found wanting in interest as bearing on this theme. A votary of the Violin purchased an old Fiddle for some two or three 
pounds, from a general dealer in musical instruments in his neighbourhood. He was well satisfied with his acquisition; and after subjecting it to a course of judicious regulation, so great were the improvements effected that the vendor regretted having sold it for such a trifling sum, and the more so, when it was whispered about that the instrument was a veritable Amati -a report, by the way, far and wide of the mark, as it was simply an old Tyrolean copy.

Some little time after the occurrence related, the lover of Violins heard that the same individual seller from whom he purchased the imagined Amati, had secured a job lot of some half-dozen old Fiddles; the remnant of an old London musicseller's stock; and that he was offering them for sale. Our hero decided to pay another visit, and judge of the merits of the new wares with a view to a second investment. Upon presenting himself to the local seller of Violins, he was at once informed that if he selected any instrument from the lot, he must be prepared to pay $f_{10}$, the dealer having no intention of again committing his former error in selling a Cremona for some forty shillings. Upon this understanding the visitor proceeded to exanine the little stock, which he found in a very disordered condition-bridgeless, stringless, and dusty. Among the whole tribe, however, was a Violin which seemed to elbow its way to the front of the group, and clamour for the attention of which it appeared to deem itself worthy. Unable to resist its seeming appeal, the intending purchaser decided to remove it from the atmosphere of its companions, and begged that he might be permitted to take the importuning Fiddle and string it in order to test its qualities. His request being acceded to, he carried it away. Upon reaching home, he took it from its case and gently removed the dust of years. The varnish appeared to him as something very different to any he had ever seen before on a Violin; and being an artist by profession, qualities of colours were pretty well understood by him. With the Violin posed on his knee, somewhat after the manner seen in the well-known picture of Stradiuarius in his workshop, he thus communed with himself: "I have never seen the much spoken of Cremonese varnish, but if this instrument has it not, its lustre must indeed be more wondrous than my imagination has painted." After again and again examining the Violin, he retired to rest but not to sleep. The Fiddle persisted in dodging him whichever way he turned on his couch. At the dawn of day-five o'clock - he was up with the Fiddle again on his knee, thinking he might have been labouring under some infatuation the night before, which the light of day might dispel. Convinced he was under no such delusion, he soon made for the music-seller's establishment, whom he delighted by paying the price demanded for the Violin. It was now time, he felt, to obtain professional advice on the matter; in due course he paid 
me a visit; upon his opening the case I was unable to restrain ny feelings of surprise, and denmanded if he had any idea of the value of the violin. "None, whatever," he answered. Without troubling the reader further, 1 informed him that his Violin was an undoubted Joseph Guarnerius, of considerable value. He then recounted the circumstances attending its purchase, with which the reader is familiar.

\section{DOMENICO DRAGONETTI-HIS GASPARD DI SALO.}

Signor Dragonetti succeeded Berini as primo basso in the orchestra of the chapel belonging to the monastery of San Marco, Venice, in his eighteenth year. The procurators of the monastery, wishing to show their high appreciation of his worth, presented the youthful playtr with a magnificent Contra-Bass, by Gaspard diSalo, which had been made expressly for the chapel orchestra of the convent of St. Peter, by the famous Brescian maker.

Upon an eventful night, the inmates of the monastery retired to rest, when they were awakened by deep rumbling and surging sounds, which they concluded was the preface of a terrific thunderstorm. Unable to find repose whilst these noises rent the air, they decided to visit the chapel; and the nearer they got to it, the louder the sounds became. Regarding each other with looks of mingled fear and curiosity, they reached the chapel, opened the door, and there stood the innocent cause of their fright, Domenico Dragonetti, inmmersed in the performance of some gigantic passage of a range extending from the nut to the bridge, on his newly-acquired Gaspard. For some time neither "Drago" nor his nocturnal visitors were aware of the presence of each other. The monks stood regarding the performer in amazement, possibly mistaking him for a second appearance of the original of Tartini's "Sonata del Diavolo," his Satanic Majesty having substituted the Contra-Bass for the Violin. Upon this instrument, Dragonetti played at his chief concert engagements, and though frequently importuned to seli it by his numerous admirers, declined to do so; in fact, though for the last few years of his life he gave up public perfornance, he resolutely refused most tempting offers for his treasuref. Soo-to use an auctioneer's phrase, "having been offered in two places," and respectfully declined. In his youthful days he decided that his cherished Gaspard should return to the place from whence he obtained it, the monastery of San Marco, and this wish was accordingly fulfilled by his executors in the year 5846 . The occasion was one of much iuterest; it was felt by Iragonetti's friends and admirers that to consign the instrument upon which he bad so often astonished and delighted them with the magic tones he drew from it, to the care of those who possibly knew nothing of its merits, was matter for regret. 
Being desirous of furnishing the reader with all the information possible relative to Signor Dragonetti's instrument, I communicated with Mr. Samuel Appleby, who was his legal adviser, and probably better acquainted with him than any other person in this country. He very kindly sent me the following particulars, which are interesting:

"MY DEAR SIR,

"Your letter of yesterday needs no apology, as it

"Brighton, 2nd July, 1875 . will afford me pleasure at any time to give you any information in my power respecting the late Signor Dragonetti, having known him well from 1796 to his death.

"His celebrated Gaspard di Salo instrument, or ContraBass, was left by his will to the Fabbrici (or churchwardens) for the time being, of the church of St. Mark's, at Venice, to be played upon only on festivals and grand occasions. I was present on one of such festivals, which lasted three days, in July, I852. I then saw the Basso, which was played on in Orchestra No. I, there having been two bands for which music had been composed expressly.

"In April, 1875, being again in Venice, I enquired from the Verger of St. Mark's if Dragonetti's Violone was in the church, and I could see it. The reply was in the affirmative, but as the Fabbrici had the care of the instrument, under lock and key, it would be necessary to see them and get their consent for its production. As this would cause me some little trouble, I left Venice without carrying out my intention.

"Dragonetti by his will left me his Amati Double Bass, which is now in this house, and I believe the only one of that make in England, and consequently highly prized by,

$$
\text { "Mr. Hart." "Yours truly, "SAmuel Appleby. }
$$

\section{PLEASURES OF IMAGINATION.}

A lady belonging to Convent Garden Theatre, who had never heard Paganini, requested leave to be present at one of the rehearsals of his concerts. It happened that Paganini did not bring his Violin with him, but borrowed one from a member of the orchestra, and instead of playing, made a kind of pizzacato obbligato. After the rehearsal was finished, the lady addressed Mr. Cooke: "Oh, dear, Mr. Cooke, what a wonderful man he is! I declare, I may say, that till this morning I never knew what music was capable of." Cooke replied, "Indeed, madam, he is truly wonderful; but allow me to observe that on this occasion you are indebted rather to your imagination than your ears for the delight you have experienced." "How, Mr. Cooke?" 
"Why, madam, this morning Paganini has not played at allhe has not even touched a bow." "Extraordinary!" exclaimed the lady; "I am more than ever confirmed in my opinion of him ; for if without playing he can affect in such a manner, how much more wonderful are the sensations he must produce when he does play!"

THE BETTS STRADIUARIUS.

The Bibliomaniac tells us of Caxton, Aldine and Baskerville editions, having been exposed for sale by itinerant booksellers, men who in opening their umbrellas opened their shops. Collectors of pictures, china, and Fiddles, have each their wondrous tales to tell of bygone bargains, which are but the echoes of that of the Bibliomaniac's. It is doubtful, however, were we to search throughout the curiosities of art sales, whether we should discover such a bargain as Mr. Betts secured, when he purchased the magnificent Stradiuarius which bears his name, for twenty shillings. About half a century since, this instrument was taken to the shop of Messrs. Betts, the well-known English Violin makers in the old Royal Exchange, and disposed of for the trivial sum above-mentioned. Doubtless its owner believed he was selling a brand new copy, instead of a "Stradiuarius" made in 1704, in a state of perfection. Frequently importuned to sell the instrument, Mr. Betts persistently declined, though it is recorded in Sandy and Forster's work on the Violin, that five hundred guineas were tendered more than once, which in those days must have been a tempting offer indeed! Under the will of Mr. Betts it passed to his family, who for years retained possession of it.

About the year $185^{8}$ it became the property of M. Vuillaume, of Paris, from whom it was purchased by M. Wilmotte, of Antwerp. Several years later it passed to C. G. Meier, Esq., who had waited patiently for years to become its owner. The loving care which this admirer of Cremonese Violins bestowed upon it was such, that he would scarcely permit any person to handle it. From Mr. Meier it passed into my possession in the year 1878 , which change of ownership brought forth the following interesting particulars from the pen of Charles Reade, the novelist and lover of Fiddles :-

\section{THE BETTS STRADIUARIUS.}

To the Editor of the Globe.

"SIR,-As you have devoted a paragraph to this Violin, which it well deserves, permit me to add a fact which may be interesting to amateurs, and to Mr. George Hart; the last purchaser. M. Vuillaume, who could not speak English, was always assisted in his London purchases by the late John Lott, 
an excellent workman, and a good judge of old Violins. The day after this particular purchase, Lott came to Vuillaume, by order, to open the Violin. He did so in the sitting-room whilst Vuillaume was dressing. Lott's first words were, "Why it has never been opened !' His next, 'Here's the original bass-bar.' Thereupon out went M. Vuillaume, half dressed, and the pair gloated over a rare sight, a Stradiuarius Violin, the interior of which was intact from the maker's hands. Mr. Lott described the bass-bar to me. It was very low and very short, and quite unequal to support the tension of the strings at our concert pitch, so that the true tone of this Violin can never have been heard in England before it fell into Vuillaume's hands. I have known this Violin forty years. It is wonderfully preserved. There is no wear on the belly except the chin-mark; in the centre of the back a very little, just enough to give light and shade. The corners appear long for the epoch, but only because they have not been shortened by friction, like other examples of the time. For the same reason the edges seem high, but only because they have not been worn down. As far as the work goes, you may know from this instrument how a brand-new Stradiuarius Violin looked. Eight hundred guineas seems a long price for a dealer to give; but after all, here is a Violin, a picture, and a miracle all in one; and big diamonds increase in number; but these spoils of time are limited for ever now, and, indeed, can only decrease by shipwreck, accident, and the tooth of time. - I am, Your obedient servant. " I9, Albert-gate, May 9.

Charles Reade."

\section{LEIGH HUNT ON PAGANINI.}

“' 'I projected,' says Leigh Hunt, 'a poem to be called 'A day with the reader.' I proposed to invite the reader to breakfast, dine and sup with me, partly at home and partly at a country inn, to vary the circumstances. It was to be written both gravely and gaily; in an exalted, or in a lowly strain, according to the topics of which it treated. The fragment on Paganini was a part of the exordium :

'So played of late to every pissing thought,

With finest change (might I but half as well

So write!) the pale magician of the bow, etc.

'I wished to write in the same manner, because Paganini with his Violin could move both the tears and the laughter of his audience, and (as I have described him doing in the verses) would now give you the notes of birds in trees, and even hens feeding in a farm-yard (which was a corner into which I meant to take my companion), and now melt you into grief and pity, or mystify you with witchcraft, or put you into a state of lofty triumph like a conquerer. That phrase of smiting the chord-

'He smote; and clinging to the serious chords

With godlike ravishment,' etc. 
was no classical commonplace; nor, in respect to impression on the mind, was it exaggeration to say, that from a single cinord he would fetch out-

- The voice of quires, and weight

Uf the built organ.'

'Paganini, the first time I saw and heard him and the first moment he struck a note, seemed literally to strike it, to give it a blow. The house was so crammed, that being among the squeezers in the standing-room at the side of the pit, I happened to catch the first glance of his face through the arm a-kimbo of a man who was perched up before me, which made a kind of frame for it; and there on the stage, in that frame, as through a perspective glass, were the face, bust, and the raised hand of the wonderful musician, with his instrument at his chin, just going to commence, and looking exactly as I have described him.

- His hand

Loading the air with dumb expectancy

Suspended, ere it fell, a nation's breath.

He smote; and clinging to the serious chords

With godlike ravishment drew forth a breath

So deep, so strong, so fervid, thick with love-

Blissful, yet laden as with twenty prayers,

That Juno y earned with no diviner soul,

'To the first burthen of the lips of Jove.

Th' exceeding mystery of the loveliness

Sadden'd delight; and with his mournful look

Dreary and gaunt, hanging his pallid face

'Twixt his dark flowing locks, he almost seemed

Too feeble, or, to melancholy eyes,

One that has parted with his soul for pride

And in the sable secret liv'd forlorn.'

'To show the depth and identicalness of the impression which he made upon everybody, foreign or native, an Italian who stood near me said to himself, after a sigh, "O Dio!" and this had not been said long when another person, in the same manner uttered, "O Christ!" Musicians pressed forward from behind the scenes to get as close to him as possible: and they could not sleep at night for thinking of him." -Timbs's Anecdote Biography.

\section{THACKERAY ON ORCHESTRAL MUSIC.}

"I wish I were a poet; you should have a description of all this in verses, and welcome. But if I were a musician! Let us see what we should do as musicians. First, you should hear the distant sound of a bugle, which sounds should float away: that is one of the heralds of the morning, flying southward. Then another should issue from the eastern gates; and now the grand reveillé should grow, sweep past your ears (like the wind aforesaid), and go (nn, dying as it goes. When as it dies, my stringed instruments come in. These to the left of the orchestra break into a soft slow movement, the music 
swaying drowsily from side to side, as it were, with a noise like the rustling of boughs. It must not be much of a noise, however, for my stringed instruments to the right have begun the very song of the morning. The bows tremble upon the strings, like the limbs of a dancer, who, a-tiptoe, prepares to bound into her ecstacy of motion. Away! The song soars into the air as if it had the wings of a kite. Here swooping, there swooping, wheeling upward, falling suddenly, checked, poised for a moment on quivering wings, and again away. It is waltz time, and you hear the Hours dancing to it. Then the horns. Their melody overflows into the air richly, like honey of Hybla ; it wafts down in lazy gusts, like the scent of the thyme from that hill. So my stringed instruments to the left cease rustling, listen a little while, catch the music of those others, and follow it. Now for the rising of the lark! Henceforward it is a chorus, and he is the leader thereof. Heaven and earth agree to follow him. I have part for the brooks-their notes drop, drop, drop, like his : for the woods-they sob like him. At length, nothing remains but to blow the hautboys; and just as the chorus arrives at its fulness, they come maundering in. They have a sweet old blundering 'cow song' to themselvesa silly thing, made of the echnes of all pastoral sounds. There's a warbling waggoner in it, and his team jingling their bells. There's a shepherd driving his flock from the fold, bleating; and the lowing of cattle. Down falls the lark like a stone; it is time lie looked for grubs. Then the hautboys go out, gradually ; for the waggoner is far on lis road to market ; sheep cease to bleat and cattle to low, one by one; they are on their grazing ground, and the business of the day is begun. Last of all, the heavenly music sweeps away to waken more westering lands, over the Atlantic and its whitening sails." "An Essay without end."

\section{A ROYAL AMATEUR.}

"The late Francis the First, Emperor of Austria, was a passionate lover of music, and played admirably on the flute. His greatest pleasure was to perform the trios and quartetts ot the old masters. One of the household physicians of the court excelled on the Tenor. As imperial etiquette did not permit a simple physician to accompany the Emperor in his pieces unless he had the entrée at court, Francis first created his doctor a baron and then a privy councillor, thus giving him his petites and grandes entrêes. By the help of his Tenor-playing our medical musician insinuated himself so successfully into the good graces of the Emperor, that he became almost the rival of Metternich, and all the other ministers courted his friendship. Such was the rise of the celebrated Baron Still. But for his Viola, this all-powerful favourite of Francis the First would have lived and died an obscure physician."-Critique Mfusicale. 


\section{VIOLINS FROM A MEDICAL POINT OF VIEW.}

"Music and the sounds of instruments-says the lively Vignent de Marville-contribute to the health of the body and the mind ; they assist the circulation of the blood, they dissipate vapours, and open the vessels, so that the action of perspiration is freer. He tells a story of a person of distinction, who assured him, that once being suddenly seized by violent illness, instead of a consultation of physicians, he immediately called a band of musicians, and their Violins played so well in his inside that his bowels became perfectly in tune, and in a few hours were harmoniously becalmed." -D' Israeli's Curiosities of Literature.

\section{POPE PIUS IX. AND THE MUSICIAN.}

"An Italian composer, named Peregrini, was a fellowstudent of Mastai Ferretii, now the occupant of the Papal chair. Since their quitting college, Fortune abandoned the maestro, whilst she smiled upon the Priest. One day Pius IX. received the following letter:- 'Most Holy Father-I know not if you recollect that $I$ had the honour of being your fellowstudent at college, and that your Holiness has often done me the honour of playing duos with me on the Violin; and that the execution of them was not always irreproachable, at least on my part, which so displeased your Holiness at the time that you deigned to apply certain corrections to my fingers. I have taken the liberty of revealing myself to your recollection, and to pray you to take under your protection one who can never cease to remember the happy moments he has passed with him whose apostolic virtues have raised him to the throne of Saint Peter.' The Pope replied, 'I have never forgotten your name, my son; come to me at Rome, and we will again play duets together, and if you have not progressed in your studies, I shall know how again to correct you." -Hogarth's Musical Herald.

\section{DR. JOHNSON AND THE VIOLIN.}

“Dr. Johnson was observed by a musical friend of his to be extremely inattentive at a concert, whilst a celebrated solo player was running up the divisions and sub-divisions of notes upon his Violin. His friend, to induce him to take greater notice of what was going on, told him how extremely difficult it was. 'Difficult do you call it, sir !' replied the Doctor: 'I wish it were impossible." "-Seward's Anecdotes of Dr. Johnson.

"In the evening our gentleman farmer, and two others, entertained themselves and the company with a great number of tunes on the Fiddle. Johnson desired to have 'Let ambition fire thy mind ' played over again, and appeared to give a patient attention to it ; though he owned to me that he was very insensible to the power of music. I told him that it affected me to 
such a degree, as often to agitate my nerves painfully, producing in my mind alternate sensations of pathetic dejection, so that I was ready to shed tears; and of daring resolution, so that I was inclined to rush into the thickest part of the battle, 'Sir,' said he, 'I should never hear it, if it made me such a fool." "-Boswell's Life of Johnson.

DR. JOHNSON ON THE DIFFICULTY OF PLAYING THE FIDDLE.

"Goldsmith: 'I spoke of Mr. Harris, of Salisbury, as being a very learned man and in particular an eminent Grecian.'

"Johnson: 'I am not sure of that. His friends give him out as such, but I know not who of his friends are able to judge of it.'

"Goldsmith: 'He is what is much better: he is a worthy humane man.'

"Johnson: 'Nay, sir, that is not to the purpose of our argument; that will as much prove that he can play upon the Fiddle as well as Giardini, as that he is an eminent Grecian.'

"Goldsmith: "The greatest musical performers have but small emoluments; Giardini, I am told, does not get above seven hundred a year.'

"Johnson: "That is indeed but little for a man to get, who does best that which so many endeavour to do. There is nothing, I think, in which the power of art is shown so much as in playing on the Fiddle. In all other things we can do something at first ; any man will forge a bar of iron if you give him a hammer: not so well as a smith, but tolerably; and make a box, though a clumsy one : but give him a Fiddle and a Fiddlestick, and he can do nothing." "-Boswell's Life of Johnson.

\section{DR. JOHNSON'S EPITAPH ON PHILIPS, THE WELSH VIOLINIST.}

"Johnson and Garrick were sitting together, when among other things Garrick repeated an Epitaph upon Phillips, by a Dr. Wilkes, which was very commonplace, and Johnson said to Garrick, 'I think Davy, I can make a better.' Then stirring about his tea for a little while in a state of meditation, he almost extempore, produced the following verses :

$$
\begin{aligned}
& \text { "' Philips, whose touch harmonious could remove } \\
& \text { The pangs of guilty power or hapless love: } \\
& \text { Rest here, distress'd by poverty no more, } \\
& \text { Here find that calm thou gav'st so oft before; } \\
& \text { Sleep undisturbed within this peaceful shrine, } \\
& \text { Till angels wake thee with a note like thine!' }
\end{aligned}
$$

The prose part is curious :

"Near this place lies Charles Claudius Philips, whose absolute contempt of riches, and inimitable performances on the Violin, made him the admiration of all that knew him. He was born in Wales, made the tour of Europe, and after the experience of both kinds of fortune, died in 1732." 


\section{ARTISTIC ENTHUSIASM.}

Boucher, the French Violinist, used to introduce in his concertos long extemporaneous cadenzas. Sometimes he was so wrapped up in his arpeggios, that the band and audience were forgotten. Upon one occasion, Boucher played a concerto at the end of a tedious concert. He never played better, and the immense applause he received inspired him to such a degree, that at the pause Boucher began a cadenza, introducing nearly all the motives which had been heard at the concert. He went on, he played for ten minutes-twenty minutes. At last the band went away, and soon after the audience, but Boucher never looked up, and still continued his cadenza. At last the proprietor of the room approached Boucher, and bowing to the astonished Violinist, shewed him a key, saying, "My dear sir, it is very late, everybody is gone. When you have finished, please to shut the door."

\section{"A MUSICIAN}

Is like an Echo, a retail dealer in sounds. As Diana is the goddess of the silver bow, so is he the lord of the wooden one; he has a hundred strings to his bow ; other people are bowlegged, he is bow-armed; and though armed with a bow he has no skill in archery. He plays with cat-gut and Kit-Fiddle. His fingers and arms run a constant race; the former would run away from him did not a bridge interpose and oblige him to pay toll. He can distinguish sounds as other men distinguish colours. His companions are crotchets and quavers. Time will never be a match for him, for he beats him most unmercifully. He runs after an Italian air open-mouthed, with as much eagerness as some fouls have sought the philosopher's stone. He can bring a tune over the seas, and thinks it more excellent because far-fetched. His most admired domestics are Soprano, Siciliano, Andantino, and all the Anos and Inos that constitute the musical science. He can scrape, scratch, shake, diminish, increase, flourish, \&c.; and he is so delighted with the sound of his own Viol, that an ass would sooner lend his ears to anything than to him; and as a dog shakes a pig, so does he shake a note by the ear, and never lets it go till he makes it squeak. $\mathrm{He}$ is a walking pillory, and crucifies more ears than a dozen standing ones. He often involves himself in dark and intricate passages, till he is put to a shift, and obliged to get out of a scrape-by scraping. His Viol has the effect of a Scotch Fiddle, for it irritates its hearers, and puts them to the itch. He tears his audience in various ways, as I do this subject; and as I wear away my pen, so does he wear away the strings of his Fiddle. There is no medium to him : he is either in a flat or a sharp key, though both are natural to him. He deals in third minors, and major thirds; proves a turncoat, and is often in the majority 
and minority in the course of a few minutes. He runs over the flat as often as any Newmarket race-horse ; both meet the same fate, as they usually terminate in a cadence; the difference isone is driven by the whip-hand, the other by the bow-arm; one deals in stakado, the other in staccato. As a thoroughbred hound discovers, by instinct, his game from all other animals, so an experienced musician feels the compositions of Handel or Corelli.-Yours, Timothy Catgut, Stamford."-Monthly Mirror

\section{ORIGIN OF TARTINI'S "DEVIL'S SONATA."}

"One night in the year 1713 ," says Tartini, "I dreamed that I had made a compact with his Satanic majesty, by which he was received into my service. Everything succeeded to the utmost of my desires, and my every wish was anticipated by this my new domestic. I thought that on taking up my Violin to practise, I jocosely asked him if he could play on that instrument. He answered, that he believed he was able to pick out a tune ; and then, to my astonishment, began to play a sollata, so strange and yet so beautiful, and executed in so masterly a manner, that I had never in my life heard anything so exquisite ; I could scarcely breathe for amazement. Awakened by the violent emotion, I instautly seized my Violin, in the hope of being able to catch some part of the ravishing melody which I had just heard, but all in vain. The piece which I composed according to my scattered recollection is, it is true, the best of my works. I have called it the 'Sonata del Diavolo,' but it is so far inferior to the one I heard in my dream, that I should have dashed my Violin into a thousand pieces, and given up music for ever, had it been possible to deprive myself of the enjoyments I derive from it."

\section{GEORGE IV. AND HAYDN.}

"The Prince of IVales (George IV.) invited him to his brother's country seat. Here he stayed two days, and had much music with the royal family. They made him sing, while the Prince accompanied, 'very tolerably,' on the Violoncello; and Sir Joshua Reynold; also commenced his portrait which was destined to hang in the Prince's private sitting room."

\section{SPOHR AND HIS GUARNERIUS.}

"Shortly before my leaving Brunswick I had a case made worthy of the splendid Violin I had brought from Russia, viz., a very elegant one; and in order to protect this from injury, I had packed it up in my trunk, between my linen and clothes. I therefore took care that this, which contained my whole estate, should be carefully fastened behind the carriage with cords. But, notwithstanding, I thought it necessary to look out fre- 
quently, particularly as the driver told me several trunks had been cut down froni behind carriages. As the carriage had no window at the back, this continual looking out was a very troublesome business, and I was therefore very glad when, towards evening, we arrived between the gardens of Göttingen, and I had convinced myself for the last time that the trunk was still in its place. Delighted that I had brought it so far in safety, I remarked to my fellow-traveller: "My first care shall now be to procure a good strong cluain and padlock for the better security of the trunk.'

"In this manner we arrived at the town gate, just as they were lighting the lamps. The carriage drew up before the guard-house. While Beneke gave our names to the sergeant, I anxiously asked one of the soldiers who stood round the carriage, 'Is the trunk still secured?' 'There is no trunk there,' was the reply. With one bound I was out of the carriage, and rushed out through the gate with a drawn huntingknife. Had I with more reflection listened awhile, I might, perhaps, have been fortunate enough to hear and overtake the thieves running off by some side-path. But in my blind rage I had far overshot the place where I had last seen the trunk, and only discovered my over-haste when I found myself in the open field. Inconsolable for my loss, I turned back. While my fellow-traveller looked for the inn, I hastened to the policeoffice and requested that an immediate search might be made in the garden houses outside the gate. To my astonishment and vexation I was informed that the jurisdiction outside the gate belonged to Weende, and that I must address my request there. As Weende was a half-a-league from Göttingen, I was compelled to abandon for that evening all further steps for the recovery of my Guarnerius. I passed a sleepless night in a state of mind such as, in my hitherto fortunate career, had been wholly unknown to me. Had I not lost my splendid Guarnerius, the exponent of all the artistic excellence I had till then attained, I could have lightly borne the loss of the rest. On the following morning the police sent to inform me that an empty trunk and a Violin-case had been found in the fields behind the gardens. Full of joy, I hastened thither, in the hope that the thieves might have left the Violin in the case, as an object of no value to them; but unfortunately it did not prove so. The bow of the Violin, a genuine Tourte, secured in the lid of the case, had remained undiscovered." - Spohr's Autobiography. (Longman and Co., 1865).

\section{THE ETTRICK SHEPHERD AND THE VIOLIN.}

"But the pleasantest part of our fellowship is yet to describe. At a certain period of the night, our entertainer (the renowned Timothy Tickler) knew by the longing looks which 
I cast to a beloved corner of the dining-room, what was wanting. Then with ' $\mathrm{O}$, I beg your pardon Hogg, I was forgetting,' he would take out a small gold key that hung by a chain of the same precious metal to a particular button-hole, and stalk away as tall as the life, open two splendid Fiddle-cases, and produce their contents, first the one, then the other; but always keeping the best to himself. I'll never forget with what elated dignity, there was a twist of the lip, and an upward beam of the eye, that were truly sublime. Then down we sat, side by side, and began-at first gently, and with easy motion, like skilful grooms, keeping ourselves up for the final heat, which was slowly but surely approaching. At the end of every tune we took a glass, and still our enthusiastic admiration of the Scottish tunes increased-our energies of execution redoubled till, ultimately, it became not only a complete and well-contested race, but a trial of strength, to determine which should drown the other. The only feeling short of ecstacy, that came across us in these enraptured moments, were caused by hearing the laugh and joke going on with our friends, as if no such thrilling strains had been flowing. But if Tym's eye chanced to fall on them, it instantly retreated upwards again in mild indignation. To his honour be it mentioned, he has left me a legacy of that inestimable Violin, provided that I outlive him. But not for a thousand such would I part with my old friend."-Altrine Tales. Hogg's Reminiscences of Former Days.

\section{THE FIDDLE TRADE.}

(By permission of Messhs. W. \& R. Chambers).

"There is, for instance, Old Borax, whom those who want to know whereabouts to look for-within the shadow of St. Martin's Church.

"Borax makes but little demonstration of his wealth in the dingy hole that serves him for a shop, where a Double-Bass, a couple of Violoncellos, a Tenor or two hanging on the walls, and a half-a-dozen Fiddles lying among a random collection of bows, bridges, coils of catgut, packets of purified resin, and tangled horsehair in skeins, serve for the insignia of his profession. But Borax never does business in his shop, which is a dusty desert from one weeks end to another. His warehouse is a private sanctum on the first floor, where you will find him in his easy chair reading the morning paper, if he does not happen to be engaged with a client. Go to him for a Fiddle, or carry him a Fiddle for his opinion, and you will hardly fail to acknowledge that you stand in the presence of a first-rate judge. The truth is, that Fiddles of all nations, disguised and sophisticated as they may be to deceive common observers, are naked and self-confessed in his hands. Dust, dirt, varnish, and bees-wax are thrown away upon him; he knows the work of every man, 
of note or of no note, whether English, French, Dutch, German, Spaniard, or Italian, who ever sent a Fiddle into the market, for the last 200 years ; and he will tell you who is the fabricator of your treasure, and the rank he holds in the Fiddle-making world, with the utmost readiness and urbanity-on payment of his fee of one guinea.

"Borax is the pink of politeness, though a bit of a martinet after an ancient and punctilious model. If you go to select a Fiddle from his stock, you may escape a lecture of a quarter of an hour by calling it a Fiddle, and not a Violin, which is a word he detests, and is apt to excite his wrath. He is never in a hurry to sell, and will by no means allow you to conclude a bargain until he has put you in complete possession of the virtues, and failings, if it have any, of the instrument for which you are to pay a round sum. As his Fiddles lie packed in sarcophagi, like mummies in an Egyptian catacomb, your choice is not perplexed by any embarras de richesses; you see but one master-piece at a time, and Borax will take care that you do see that, and know all about it; before he shows you another. First unlocking the case, he draws the instrument tenderly from its bed, grasps it in the true critical style with the fingers and thumbs of both hands a little above the bridge, turning the scroll towards you. Now and then he twangs, with the thumb of his left hand, the third or fourth string, by way of emphasis to the observations, which he feels bound to makeinstinctively avoiding, however, that part of the strings subject to the action of the bow. Giving you the name of the maker, he proceeds to enlighten you on the peculiar characteristics of his work; then he will dilate upon the remarkable features of the specimen he holds in his hand-its build, its model, the closeness and regularity of the grain of the wood of which the belly was fashioned; the neatness, or, wanting that, the original style of the purfling-the exquisite mottling of the back, which is wrought, he tells you, "by the cunning hand of nature in the primal growth of the tree'-twang. Then he will break out into placid exclamations of delight upon the gracefulness of the swell-twang-and the noble rise in the centre-twangand make you pass your hand over it-to convince yourself; after which, he carefully wipes it down with a silk handkerchief. This process superinduces another favourite theme of eulogium - namely, the unparalleled hue and tone (of colour) imparted by the old Italian varnish-a hue, he is sure to inform you, which it is impossible to imitate by any modern nostrumstwang. Then he reverts to the subject of a Fiddle's indispensables and fittings; discourses learnedly on the carving of scrolls, and the absurd substitution, by some of the German makers, of lions' heads in lieu of them; hinting, by the way that said makers are asses, and that their instruments bray when they should speak-twang. Then touching briefly on the 
pegs, which he prefers unornamented, he will hang lingeringly upon the neck, pronounce authoritatively upon the right degree of elevation of the finger-board, and the effects of its due adjustment of the vibration of the whole body-harmonic, and, consequently, upon the tone. Then jumping over the bridge, he will animadvert on the tail-piece; after which, entering at the $f$ holes - not without a fervent encomium upon their graceful drawing and neatness of cut-twang-he will introduce you to the arcanum mysterii, the interior of the marvellous fabricpoint out to you, as plainly as though you were gifted with clairvoyance, the position and adaptation of the various linings, the bearings of the bass-bar, that essential adjunct to quality of tone-twang-and the proper position of the sound-post. Lastly, he will show you, by means of a small hand-mirror throwing a gleam of light into its entrails, the identical autograph of the immortal maker-Albani, Guarnerius, or Amati, as the case may happen - with the date printed in the lean old type, and now scarcely visible through the dust of a couple of centuries, 'Amati Cremonæ fecit 1645,' followed by a manuscript signature in faded ink, which you must take for granted.

"Borax has but one price; and if you do not choose to pay it, you must do without the article. The old fellow is a true believer, and is accounted the first judge in Europe ; Fiddles travel to him from all parts of the continent for his opinion, bringing their fees with them ; and for every instrument he sells, it is likely he pronounces judgment upon a hundred. It is rumoured that the greatest masterpieces in being are in his possession.

"A dealer of a different stamp is Michael Schnapps, well known in the trade, and the profession too, as a ravenous Fiddle-ogre, who buys and sells everything that bears the Fiddle shape, from a Double-Bass to a dancing-master's pocketable Kit. His house is one vast warehouse, with Fiddles on the walls, Fiddles on the staircases, and Fiddles hanging like stalactites from the ceilings. To him the tyros resort when they first begin to scrape ; he will set them up for ten shillings, and swop them up afterwards, step by step, to ten or twenty guineas, and to ten times that amount if they are rich enough and green enough to continue the experiment. Schnapps imports Fiddles in the rough, under the designation of toys, most of which are the production of his peasant-countrymen bordering on the Black Forest; and with these he supplies the English provinces and London toy and stationers' shops. He is, further, a master of the Fiddle-making craft himself, and so consummate an adept in repairing, that nothing short of consuming fire can defeat his art. When Pinker, of Norwich, had his Cremona smashed all to atoms in a railway collision, Schnapps rushed down to the scene of the accident, bought 
the lot of splintered fragments for a couple of pounds, and in a fortnight had restored the magnificent Stradiuarius to its original integrity, and cleared I5o guineas by its sale. But Schnapps is a humbug at bottom-an everlasting copyist and manufacturer of dead masters, Italian, German and English. He has sold more Amatis in his time, than Amati himself ever made. He knows the secret of the old varnish; he has hidden stores of old wood-planks of cherry-tree and mountain-ash centuries old, and worm-eaten sounding boards of defunct harpsichords, and reserves of the close-grained pine hoarded for ages. He has a miniature printing press, and a fount of the lean-faced long-forgotten type, and a stock of the old ribbed paper torn from the fly-leaves of antique folios; and, of course, he has always on hand a collection of the most wonderful instruments at the most wonderful prices, for the professional man or the connoisseur.

"'You vant to py a Pfeedel,' says Schnapps. 'I sall sell you de pest-dat ish, de pest for de mowny. Vat you sall gif for him?'"

"“Well, I can go as far as ten guineas,' says the customer.

" "Ten kinnis is goot for von goot Pfeedel; bote besser is tventy, tirty, feefty kinnis, or von hunder, look you; bote ten kinnis is goot-you sall see.'

"Schnapps is all simplicity and candour in his dealings. The probability is, however, that his ten-guinea Fiddle would be fairly purchased at five, and that you might have been treated to the same article had you named thirty or forty guineas instead of ten.

"I once asked Schnapps if he knew wherein lay the excellence of the old Italian instruments.

"'Mein Gott!-if I don't, who de teifil does?'

"Then he went on to inform me, that it did not lie in any peculiarity in the model, though there was something in that ; nor in the wood of the back, though there was something in that; nor in the fine and regular grain of the pine which formed the belly, though there was something in that; nor in the position of the grain running precisely parallel with the strings, though there was something in that ; nor in the sides, nor in the finger-board, nor in the linings, nor in the bridge, nor in the strings, nor in the waist, though there was something in all of them; nor yet in the putting together, though there was much in that.'

"'Where does it lie, then, Mr. Schnapps?'

"'Ah, der henker! hang if I know.'

" ' Has age much to do with it, think you ?'

" Not mosche. Dere is pad Pfeedels two hunder years ole as vell as goot vons; and dere is goot Pfeedels of pad models, vitch is made fery pad, and pad Pfeedels of de fery pest models, and peautiful made as you sall vish to see.' 
"This is the sum total of the information to be got out of Schnapps on that mysterious subject. On other matters he can pronounce with greater exactness. He knows every Cremona in private or professional hands in the whole kingdom; and where the owner bought it, if he did buy it; and what he gave for it, or from whom he inherited it, if it came to him as a heirloom. Of those of them which have passed through his hands, he has got fac-similes taken in plaster, which serve as exemplars for his own manufactures. Upon the death of the owner of one of these rarities, Schnapps takes care to learn particulars; and if the effects of the deceased come under the hammer, he starts off to the sale, however distant, where, unless some of his metropolitan rivals in trade have likewise caught the scent, he has the bidding all his own way, and carries off the prize.

"The inundation of German Fiddles, which may be bought new for a tew shillings, has swamped English makers of cheap instruments, of which there are by this time five times as many in the market as there is any occasion for. Hence it is that Fiddles meet us everywhere; they cumber the toy-shop; they house with the furniture dealer; they swarm by thousands in the pawnbrokers' stores, and block out the light from his windows; they hang on the tobacconists' walls; they are raffled at public-houses; and they form an item in every auctioneer's catalogue.

"Meanwhile the multiplication of rubbish only enhances the value of gold; and a Fiddle worthy of an applauding verdict from old Borax is more difficult of acquisition than ever. So I shall keep my Cremona."

Dr. Abercrombie recommends "Careful classification of the insane, so that the mild and peaceful melancholic may not be harassed by the ravings of the maniac: the importance of this is obvious ; but of still greater importance," he continues, "it will probably be, to watch the first dawnings of reason, and instantly to remove from the patient all associates by whom his mind might be again bewildered." The following case, mentioned by Pinel, is certainly an extreme one, but much important reflection arises out of it :-

"A musician confined in the Bicétre, as one of the first symptoms of returning reason, made some slight allusion to his favourite instrument. It was immediately procured for him; he occupied himself with music for several hours every day, and his convalescence seemed to be advancing rapidly. But he was then, unfortunately, allowed to come frequently in contact with a furious maniac, by meeting him in the gardens. The musician's mind was unhinged: his Violin was destroyed; and he fell back into a state of insanity which was considered as confirmed and hopeless." - Abercrombie's Inlellectual Powers. 
"An old English author of the name of Simpson, a master of music of some eminence in the reign of Charles II., has, in a work entitled 'The Division of the Violin,' drawn from the theory of music a singular illustration of the doctrine of Trinity in Unity. 'When I further consider,' he says, 'that three sounds placed by the interval of a third one above another, do constitute one entire harmony, which governs and comprises all the sounds that by art or imagination can at once be joined together in musical accordance, that I cannot but think a significant emblem of that Supreme and Incomprehensible Three in One, governing, comprising, and disposing the whole machine of the world, with all its included parts, in a most perfect and stupendous harmony." '-New Cyclopadia of Anecdote.

"Puppo, the Violinist being in Paris in 1793, was summoned before the Committee of Public Safety on suspicion, when the following interrogatories were put to him. 'Your name?' 'Puppo.' 'What were you doing during the time of the tyrant?' 'I played the Violin.' 'What do you do now ?' 'I play the Violin.' 'And what will you do for the nation?' 'I will play the Violin.'"'

\section{A MOTTO ON A CREMONA.}

"In silvis viva silva ; cano'ra jam mor'tua cano."

"Speechless, alive, I heard the feathered throng;

Now, being dead, I emulate their song."

"Sir Walter Scott's barristers possess among their gentlemanly embellishments a knowledge of stringed instruments. Who can forget that the young Templar, Master Lowestoffe ("Fortunes of Nigel," chap. xvi., 138) "performed sundry tunes on the Fiddle and French Horn" in Alsatia; and that Counsellor Pleydell, on the eventful night in "Guy Mannering" (chap. xlix. 255) being a "member of the gentlemen's concert in Edinburgh," was performing some of Scarlatti's sonatas with great brilliancy upon the Violoncello to Julia's accompaniment upon the harpsichord?

\footnotetext{
"Busts, cameos, gems-such things as these Which others often show for pride,

1 value for their power to please And selfish churls deride:

One Stradivarius, I confess.

Two meerschaums, I would fain possess."
}

Extract from Oliver Wendell Holmes' Lines on Contentment.

The "Monthly Mirror," of March, I80o, says that Gainsborough, the great painter, was a famous player on Violin and Violoncello, then called Viol-di-gamba; and that Abel, the 
chief Bass-player composed a fugue expressly for Gainsborough. The same periodical suggests that the high notes of the Violin are neither pleasant nor certain; the Fiddle, it thinks, should be only played in lower keys! In fact it is Queen Elizabeth's answer to Sir W. Raleigh's-

"Fain would I climb but that I fear to fall."-

"If thy heart fail thee do not climb at all."

TO A BAD FIDDLER.

"Old Orpheus play'd so well he mov"d old Nick, Whilst thou mov'st nothing-but thy Fiddlestick."

Corelli's Violin was made in 1578 , and passed into the possession of Giardini; it was kept in a case painted by Annibale Caracci.

\section{ON THE TREATMENT OF THE VIOLIN.}

In a letter from the celebrated Tartini.

"The letter here presented to our readers was published by Dr. Burney, in 1779, under the following title: "A Letter from the late Signor Tartini to Signora Maddalena Lombardini (afterwards Signora Sirmen). Published as an important lesson to performers on the Violin. 'Translated by Dr. Burney.' 'This little tract having become scarce, and its practical value to the artist coming recommended to us by so high a name, we have been induced to reprint it in our journal.

$$
\begin{aligned}
& \text { "'A letter, \&c., } \\
& \text { ""Padua, March 5, } 1760 .
\end{aligned}
$$

" My very much esteemed Signora Maddalena,

" Finding myself at length disengaged from the weighty business which has so long prevented me from performing my promise to you, a promise which was made with too much sincerity for my want of punctuality not to afflict me, I shall begin the instructions you wish from me, by letter; and if I should not explain myself with sufficient clearness, I entreat you to tell me your doubts and difficulties, in writing, which I shall not fail to remove in a future letter.

"'Your principal practice and study should, at present, be confined to the use and power of the bow, in order to make yourself entirely mistress in the execution and expression of whatever can be played or sung, within the compass and ability of your instrument. Your first study, therefore, should be the true manner of holding, balancing, and pressing the bow lightly, but steadily, upon the strings; in such a manner as it shall 
seem to breathe the first tone it gives, which must proceed from the friction of the string, and not from percussion, as by a blow given with a hammer upon it. This depends on laying . the bow lightly upon the strings at the first contact, and on gently pressing it afterwards, which, if done gradually, can scarcely have too much force given to it, because, if the tone is begun with delicacy, there is little danger of rendering it afterwards either coarse or harsh.

"Of this first contact and delicate manner of beginning a tone you should make yourself a perfect mistress in every situation and part of the bow, as well in the middle as at the extremities; and in moving it up as well as in drawing it down. To unite all these laborious particulars into one lesson, my advice is, that you first exercise yourself in a swell upon an open string, for example, upon the second string; that you begin pianissimo, and increase the tone by slow degrees to its fortissimo; and this study should be equally made with the motion of the bow up and down, in which exercise you should spend at least an hour every day, though at different times, a little in the morning and a little in the evening; having constantly in mind, that this is, of all others, the most difficult and the most essential to playing on the Violin. When you are a perfect mistress of this part of a good performer, a swell will be very easy to you; beginning with the most minute softness, increasing the tone to its loudest degree, and diminishing it to the same point of softness with which you began, and all this in the same stroke of the bow. Every degree of pressure upon the string which the expression of a note or passage shall require will by this means be easy and certain; and you will be able to execute with your bow whatever you please. After this, in order to acquire that light pulsation and play of the wrist, from whence velocity in bowing arises, it will be best for you to practise every day one of the Allegros, of which there are three in Corelli's solos, which entirely move in semiquavers. The first is in $\mathrm{D}$, in playing which you should accelerate the motion a little each time, till you arrive at the quickest degree of swiftness possible; but two precautions are necessary in this exercise-the first is that you play the notes staccato, that is, separate and detached, with a very little space between every two, they should be played as if there was a rest after every note. The second precaution is, that you first play with the point of the bow; and when that becomes easy to you, that you use that part of it which is between the point and the midddle; and when you are likewise mistress of this part of the bow, that you practise in the same manner with the middle of the bow ; and above all, you must remember in these studies to begin the Allegros or flights sometimes with an up-bow, and sometimes with a down-bow, carefully avoiding the habit of constantly practising one way. In order to acquire a greater 
facility of executing a swift passage in a light and neat manner, it will be of great use to you if you accustom yourself to skip over a string between two quick notes in divisions. Of such divisions ycu may play extempore as many as possible, and in every key, which will be both useful and necessary.

"With regard to the finger-board, or carriage of the left hand, I have one thing strongly to recommend to you, which will suffice for all ; and that is, the taking of a Violin part, either the first or second of a concerto, sonata, or song-anything will serve the purpose-and playing it upon the half-shift, that is, with the first finger upon $G$ on the first string, and constantly keeping upon this shift, playing the whole piece without moving the hand from this situation, unless $A$ on the fourth string be wanted, or D upon the first ; but in that case, you should afterwards return again on the half-shift, without ever moving the hand down to the natural position. This practice should be continued till you can execute with facility upon the halfshift any Violin part not intended as a solo, at sight. After this advance the hand on the finger-board to the whole-shift with the first finger upon A on the first string, and accustom yourself to this position till you can execute everything upon the whole-shift with as much ease as when the hand is in its natural situation; and when certain of this, advance to the doubleshift, with the first finger upon $B$, on the first string: and when sure of that likewise, pass to the fourth position of the hand, making $\mathrm{C}$ with the first finger upon the first string; and indeed this is a scale in which, when you are firm, you may be said to be a mistress of the finger-board. This study is so necessary, that I most earnestly recommend it to your attention.

"I 'I now pass to the third essential part of a good performer on the Violin, which is the making of a good shake, and I would have you practise it slow, moderately fast, and quick ; that is, with the two notes succeeding each other in these three degrees of adagio, andante, and presto; and in practice you have great occasion for these different kind of shakes; for the same shake will not serve with equal propriety for a slow movement as for a quick one; but to acquire both at once with the same trouble, begin with an open string, either the first or second, it will be equally useful ; sustain the note in a swell, and begin the shake very slow increasing in quickness, by insensible degrees, till it becomes rapid. But you must not vigorously move immediately from semiquavers to demisemiquavers, as in this example, or from these to the next in degreethat would be doubling the velocity of the shake all at once, which would be a skip, not a graduation; but you can imagine between a semiquaver and demisemiquaver intermediate degrees of rapidity, quicker than the one, and slower than the other of these characters; you are therefore to increase in velocity by the same degrees in practising the shake, as in 
loudness when you make a swell. You must attentively and assiduously persevere in the practice of this embellishment, and begin at first with an open string, upon which if you are once able to make a good shake with the first finger, you will with the greater facility acquire one with the second, the third and the fourth, or little finger, with which you must practise in a particular manner, as more feeble than the rest of its brethren. I shall, at present, propose no other studies to your application ; what I have already said is more than sufficient, if your zeal is equal to my wishes, for your improvement. I hope you will sincerely inform me whether I have explained myself clearly thus far; that you will accept of my respects, which I likewise beg of you to present to the Prioress, to Signora Teresa and to Signora Chiara, for all whom I have a sincere regard; and believe me to be, with great affection,

" Your obedient and most humble servant,

"Giuseppe Tartini.",

"The Harmonicon.". 


\section{INDEX.}

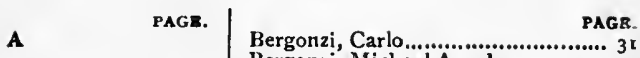

Absam, Thomas.......................... 88

Acevo........................................... 25

Adams ........................................... 88

Addison, William............................... 88

Aireton, Edward............................... 88

Albanesi, Sebastianus...................... 25

Albani, Matthias Botzen................... 25

Albani, Matthias (i.)....................... 108

Albani, Matthias (ii.)......................108

Albani, Paolo..................................... 25

Albani.............................................. 108

Aldric.............................................. 75

Aldred................................................ 88

Aletzie, Paolo..................................... 25

Alletsee, P.....................................108

Alvani................................................ 25

Amati, Andrew............................ 25

Amati, Antonius and Hieronymus.... 26

Amati, Nicholas.............................. 26

Amati, Nicholas.............................. 27

Amati, Hieronymus............................ 30

Amateur, A Royal............................ $6_{3}$

Ambrogi, Pietro.................................. 30

Anecdotes and Miscellanea................. 49

Anselmo.......................................... 30

Artistic Enthusiasm............................166

Artmann.........................................108

Askey, Samuel................................. 88

Assalone, Gaspard........................... $3^{\circ}$

\section{B}

Bachmann.....................................108

Bad Fiddler, To a............................175

Bagatella........................................... 30

Baines,................................................. 88

Baker.............................................. 88

Balestrieri, Peter............................ 30

Balestrieri, Thomas........................... 30

Ballantine.......................................... 88

Baltazarina.......................................1 34

Banks, Benjamin............................. 88

Banks, James.................................. 90

Barnes, Robert.................................. 90

Barrett, John... ................................ go

Barton, George.................................. go

Bass, The Double.............................. 3,6

Bass Viol.......................................... 2

Bauche............................................... 108

Beckman........................................ 108

Bellosio............................................. $3^{\mathbf{x}}$

Benoit............................................. 75

Bente, Matteo............................... $3^{\mathrm{I}}$
Bergonzi, Michael Angelo............... 33

Bergonzi, son of M. Angelo.............. 33

Bergonzi, Nicholas......................... 33

Bernadel........................................... 75

Berroit................................................ 75

Bertrand...................................... 75

"Betts Stradiuarius "...........................160

Betts, Edward................................. 90

Betts, John.......................................... 90 90

Binternagle.......................................108

Bocquay, Jacques.......................... 75

Bolles.............................................. $9^{\natural}$

Booth, William................................ 9i

Booth................................................ 9 $9^{\text {I }}$

"Borax", and "Mi......................

Borelli, Andreas.............................. 33

Borvin, Claude................................ 75

Boucher.......................................... 9 9

Boullangier..................................... 75

Bourdat, Sebastian........................... 75

Bow, The..................................... r

Bremeister, J...................................108

Brescia........................................5, 19

Breton, I.e...................................... 75

Bridge, The.................................... 9

Prit ton..........................................1 136

Brown, James................................ 9

Brown, James................................. 9 !

Buch stadter.....................................103

Budiani, Javietta............................ 34

\section{C}

Cahusac......................................... $9^{\text {I }}$

Camilas, Camile de .......................... 34

Cappa, Giofreda.............................. 34

Carter, John..................................... 91

Cassino, Antonius.............................. 94

Castagnery, Andrea.......................... 76

Castagnery ................................... 75

Castagnery, Jean Paul...................... 76

Castro......................................... 34

Celionatus, Johannes..................... 35

Challoner, Thomas......................... 9

Chanot, Georges ................................ 76

Chanot, George................................. 76

Chanot............................................ 76

Chapuy, Augustinus............................ 76

Charles II., his band of twenty-four Violins........................................ 136

Cherutti....................................... 35

Chesterfield, Lord, his dictum on Fiddling....................................1 40

Chevrier....................................... 76 
PAGE.

Christa, Joseph Paul......................109

Christophori, Bartolomeo............. 35

Cinderella Violoncello.................... 54

Circapa, 'Thomaso.......................... 35

Clark....................................... $9^{\text {I }}$

Claudot, Charles........................... 76

Cole, James................................. gr

Cole, Thomas................................ gr

Collier, Samuel.............................. $9^{r}$

Collier, Thomas.......................... $9^{r}$

Collingwood, Joseph..................... gr

Contreras, Joseph......................... 35

Conway, ivilliam.......................... 91

Corelli.........................................135

Corsby.................................... 9r

Corsby, George........................... 9 $9^{\mathbf{r}}$

Costa, Pietro della............................. 35

Coussemaker............................, , 2

Cramond, Charles......................... gr

Crask, George.............................. 9 I

Cremonese Mlasters........................ 6

Cross, Nathaniel......................... gr

Crowther, John......................... 9r

Crwth, The.............................. I

Cuni........................................... $7^{6}$

Cuthbert...................................... 9r

Cythara...

\section{D}

Darche

Dardelli, Pietro.............................. 35

David........................................ 76

Davidson................................... $9^{r}$

Davis, Richard.............................. gr

Davis, William........................... gr

Dearlove, Mark............................ gr

De Comble, Ambroise..................... 76

Delany, John.............................. $9^{2}$

Dennis, Jesse............................... $9^{2}$

Despont, Antoine.......................... 77

"Devil's Sonata,", Origin of Tartini's................................. 67

Dickenson, Edward......................... $9^{2}$

Dickenson, John.............................. $9^{2}$

Diehl............................................109

Diehl, $\mathrm{N}$ icholas................................ 109

Ditton....................................... $9^{2}$

Dodd, Thomas (i ) .............................. $9^{2}$

Dodd, Thomas iii.)....................... 93

" Dolphin," 'The Stradiuarius.......... 68

Dominicelli.................................. 35

Dorant, William......................... 93

Dragonetti, Domenico......................158

Duiffoprugcar, Gaspard.................. 35

Duke, Richard (i.)........................ 93

Duke, Richaró (ii.)....................... 94

Duncan...................................... 94

Durfel.

\section{E}

Earliest Makers of

English School.

French School...

German School.............................. 72

Italian School......................... 15
Eberle, Jean Ulric.......................... 100

Eberti, Tomasso................................. 36

Edlınger..................................... rog

Edlinger, Joseph Joachim .............. rog

Eglington...................................... 94

" Elector Stajners "......................... ry4

Filsler, Joseph...............................109

English Makers........................... 88

English tichool, The..................... $8_{3}$

English Sitrings............................. II

Entlusiasm, Artistic....................... 66

Ernst, François H.......................

Ettrick Shepherd and the Violin....... 68

Evans, Richard............................ 94

\section{$\mathbf{F}$}

Falaise..................................... 77

Falco.......................................... $3^{6}$

Farinato, Paul............................... 36

Febbre...................................... rog

Fendt........................................ 77

Fendt, Bernard............................ 94

Fendt, Bernard Simon....................... 95

Fendt, Francis................................. 96

Fendt, Jacob................................ 95

Fendt, Martin................................ 95

Fendt, William............................. 96

Ferguson, Donald....................... 96

Fichtold, Hans.............................. 109

Fichtold, Martinus...............................109

Ficker......................................

Ficker, Johann C.............................. $3^{6}$

Ficker, Johann Christian................ rog

Fiddle Marks.............................. 51

Fiddler, To a Bad............................ 75

Fiddle shot through the body.......... 51

Fiddle Trade, The............................ 69

Findlay, James............................... 96

Fiorillo, Giovanni.............................. $3^{6}$

Firth.........................................

Fischer, Zacharie..........................109

Fleury, Benoist............................... 77

Florentus, Florinus......................... $3^{6}$

Forster, Simon Andrew............... 97

Forster, William (i.)......................... 96

Forster, William (ii.)..................... 96

Forster, William (iii.)...................... 97

Forster, William (iv.) .................... 97

Fourrier, Nicholas.......................... 77

Frankland...................................... 98

French Makers............................... 75

French School........................... $7^{2}$

French Strings................................ II

Frey, Hans................................. 109

Fritsche, Samuel............................ rog

Fritz, Hans.............................. I09

Furber.......................................... 98

G.

Gabrielli, Giovanni Baptista........... 36

Gaetano, Antonızzio ..................... 36

Gaetano, Pasto............................ 36

Gagliano, Alessandro........................ 36

Gagliano, Nicholas...................... 37 


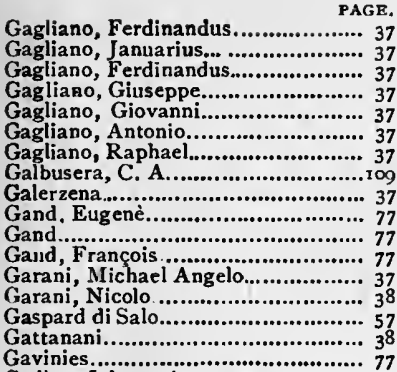

Gedler, Johann Antony..................... ro9

Gedler, Johann Benedict................... Io9

"George Eliot" on Stradiuarius...... 66

George IV. and Haydn...................... 67

Gerle, Jean.......................................109

German Makers............................... 108

German School................................1c6

German Strings.............................. II

Gibbs, James...................................... $9^{8}$

Gilkes, Samuel.................................. 98

Gilkes, William ................................ $9^{8}$

Giordane ........................................ $3^{8}$

Gobetti, Franciscus........................... 38

Gofriller, Francisco......................... 39

Gofriller, Matteo............................... $3^{8}$

Gough, Walter................................. 98

Gragnani, Antonius.......................... 39

Grancino, Francisco.......................... 39

Grancino, Giovanni ..................... 39

Grancino, Giovanni Baptista............. 39

Grancino, Paolo............................... 39

"Grand Amati" "................................. 29

Grimm...............................................109

Grobitz........................................... 109

Grosset Paul..................................... 78

Guadagnini, Lorenzo.................... 39

Guadagnini, Johannes Baptista....... 40

Guadagnini, Giovanni Battista ......... 4 I

Guadagnini, Giuseppe..................... 4 I

Guadagnini of Milan......................... $4 \mathrm{I}$

Guadagnini of Turin....................... 41

Guarnerins, Andreas....................... 4r

Guarnerius, Joseph, son of Andrea. 42

Guarnerius, Joseph Anthony........... 43

Guarnerius, Petrus (i.)...................... 43

Guarnerius, Petrus (ii.)................... 43

"Guarnerius" at a Discount.............. 56

Guersan, Louis............................... $7^{8}$

Gugemmos.......................................109

Guidantus, Giovanni F.................... 50

Guletto...................................... 50

\section{$\mathrm{H}$}

Hamberger, Joseph.

Hamm

Hottfried.................109

Hansel, John Anthony....................... Io

Hardie, Matthew............................... 98

Hardie, Thomas.............................. 98
Hare, Joseph PAGE.

Harham....................................... 98

Harris, Charles................................. 98

Hart, John Thomas.......................... 99

Hassert (i.)......................................rro

Hassert (ii.)................................... 1 10

Haydn and George IV.....................167

Heesom, Edward.............................. 99

Helmore, Charles.................................. ז 10

Hildehrant, Michael C........................110

Hill, Joseph (i.).............................100

Fill, Joseph (ii )............................100

Hili, Lockey......................................100

Hill, William .....................................100

Hill, W. E.....................................100

Hillmer............................................ п ro

Hoffmann, Martin.............................. r 10

Holloway, J...................................100

Holmes, Oliver Wendell, on the Oi...... Masters......................................1 74

Hornstainer, Matthias........................ r ro

House of Stradiuarius.......................6 63

Hiiller, Augustine............................. ro

Hume, Richard...................................100

Humel, Christian ............................. r to

Hiinger, Christopher F..................... r ro

\section{I}

Italian Instruments, introduction into Great Britain........................ 18

Italian Makers................................ 25

Italian School.................................... I5

Italian Strings................................ II

Italian Varnish................................ 2 ז

\section{$\mathrm{J}$}

Jacobi............................................ I I

Jacobs (i.).......................................1 1 Jacobs (ii.)................................... 1 10 Jaye, Henry....................................... 100 Jay, Henry....................................... 100 Jay, Thomas....................................100 Jenkins, John...............................1 36 Johnson, Dr., and the Violin............ 64 Johnson, John................................. 100 Jonson, Ben, on the "Crowd "......... 2 Juliano, Francisco............................ 50

\section{K}

Kambl, Johann C.............................1 10 Kennedy, Alex...................................100

Kennedy, John................................... Ior

Kennedy, Thomas ........................... 101

Kerlino.............................................. 50

Kiaposse........................................ r ro

Kirschschlag...................................... I I0

Klotz, Joseph................................. II 1

Kloz, Egitia......................................... I 1 I

Kloz, George..................................... II

Kloz, Matthias................................... I I

Kloz, Sebastian.................................. I Ir

Kniti, Joseph.................................... It 
PAGE,

Kohl, Jean.................................... I 10

Kolditz, Matthias J.......................... 1 10

Koliker....................................... 10

K riner, Joseph............................. I I

L

Lagetto...................................... 78

Lambert........................................ 78

Landulphus, Carolus.......................... 50

Lansa, Antonio M......................... 5

Lecler........................................... 78

Leigh Hunt on Paganini................. $6 \mathrm{r}$

Lentz, Johann $N$............................. Ior

Lewis, Edward.................................. ror

Lidl, Antoinie................................. I I

Linarolli .................................... 51

Linings.......................................... 8

Living Stradiuariuses...................... 53

Loly, Jacovo................................ 51

Longfellow on Stradiuarius.............. 60

Lott, John F.................................

Lott, George F ................................. Ior

Lott, John F.................................. xor

Louis........................................... 78

Louvet....................................... $7^{8}$

Lupot, François............................. 78

Lupot, Nicholas............................. 78

Lute.......................................... 1

Lyre......................................... x

Macintosh..................................... ror

Maggini, Giovanni P.................... 5r

Maggini, Pietro............................... 52

Majer, Ándrea F............................... I I I

Maldonner..................................... I I

Mansiell...................................... I I

Mantegatia, Petrus Johannes ............ 52

Marratti, C. B........................... 52

Mariani, Antonio............................ 52

Marshall, John................................ Io1

Martin........................................ ror

Mayer, Andrea F............................. I I I

Medard, Franciscus......................... 79

Medard, Jean................................ 79

Medard, Nicholas........................... 79

Medical View of Violins...................164

Meusidler, Jean................................. I I

Mezzadie............................................ 52

Mier............................................. ror

"Mighty Venetian," The.............. 52

Millar, Alexander............................ ro2

Mirecourt and its " copies "........... 74

Miremont.................................... 79

Missing Scroll, The......................... 49

Modessier...................................... 80

Mohr, Ptilip...............................11

Monday Popular Concerts................144

Montade, Gregory.......................... 52

Montagnana, Dominicus.................. 52

Morella, Moreato............................ 54

Morrison, John............................... 102

Motto on a Cremona.................... PAGE.

Muller........................................... 54

Murdoch, Alex.............................. ro2

Musical Union, The...................... 44

Musician, A................................... 66

Musicians, Royal Society of............. 42

N

Namy............................................. 8 80

Naylor............................................ roz

Neck of the Violin............................ 9

Nicholas............................................. 80

Niggel............................................ 80

Norboru, John.................................. roz

Norman, Barak...............................102

Norris, John.................................... 102

Nut, The......................................... 10

Ohberg, Johann..............................x1x

Orchestral Music, Thackeray on.....162

"Orfeo de Monteferde" "...................134

Orpheus............................................ I

Ott, Jean.........................................

Otro................................................ $1 x x$

Otto, Jacob Augustus........................xrx

Ouvrard............................................ 80

\section{$\mathbf{P}$}

Paganini and Guarnerius del Jesù...12o

Paganini, Leigh Hunt on.................. 6 r

Painful Operation, A............................155

Pamphilon, Edward........................ ro3

Panormo, Vicenzo........................... 54

Panormo, Gerirge Lewis......................103

Panormo, Joseph..............................103

Panormo, Louis..................................103

Panormo, Vincent...........................103

Pansani........................................... 55

Parker, Daniel.................................. ro3

Parth, Andreas N. ..........................11

Pasta, Gaetano................................... 56

Paul, Saint ......................................... 80

Pearce, James................................ ro3

Pemberton, Edward.......................... ro3

Perry and Wilkinson......................... ro3

Pfretzschner, Carl F.......................... I rx

Pfretzschner, Gotlob...........................

"Philharmonic," The.......................142

Pichol............................................ 80

Picino............................................... 56

Piecings in works of Old Masters.... 7

Pierrot........................................... 80

Pierray, Claude................................. 80

Piete, Noel......................................... 50

Piqne................................................ 80

Plack, F......................................1

Platner, Milichael.............................

"Pleasures of Imagination "...............559

Pons ....................................... 8r

Pope Pius IX. and the Musician....... 164

Possen, Lauscrim..........................112 
PAGR.

Powell, Thomas.............................103

Preston, John..................................103

"Prison Fiddles "......................47, 49

Progress of the Violin, Sketch of..... 133

Purfing of Amati........................... 27

\section{Q}

Quack Violin Doctors...................... 10

Quartett Association, The.................144 Quick recovery of a Stolen Tenor.... 55 Quinte, The.

\section{R}

Racceris 56

Raf...............................................112

Rambeaux ..................................... 81

Rambouts, Peter...............................112

Rant.................................................. 81

Raphael, Nella................................ 56

Rauch, Jacques...............................112

Rauch, Sebastian................................112

Rauch ...........................................1 12

Rayman, Jacob...............................104

Reade, Charles, and Louis Tarisio..125

Rebec, The.

Reichel, Johann C.............................. I r2

Reggieri.............................................5 56

Reichel, Johann G.........................1 12

Reinault.......................................... 8 8

Remy.............................................. 81 81

Renisto.............................................. 56

Repairers, pretended..................... 10

"Romance of Fiddle dealing"..........124

Rook, Joseph...................................104

Ross (i.) ............................................104

Ross (ii.)..........................................104

Roth, Christian...............................112

Rovelli................................................ 56

Royal Amateur, A............................. $6_{3}$

Royal Academy of Music................143

Rudger............................................... 56

Rugerius, Guido................................ 56

Rugerius, Johannes Baptiste............ 56

Rugerius, Pietro Giacomo............... 57

Rugerius, Vicenzo............................ 57

Ruggerius, Franciscus...................... 56

Ruppert, Francis............................ I I2

\section{S}

Sackbut and Trombone

Salle............................................ 8 $\mathbf{r}$

Salo, Gaspard di............................. 57

Saloman .......................................... 54

Salzar............................................ 81

Sancti, Giovanni............................. 59

Sanctus Seraphino............................ 59

Sanoni, Giovanni.............................. 59

Sanzo......................................... 59

Sapino............................................. 59

Saunier...................................... 81

Scheinlein, Jean Michael................ II2

Scheinlein, Matthias F.....................112
Schlick PAGB.

Schmidt........................................ II

Schönger, Francis......................... IIn

Schönger, George............................. I I2

Schorn, Jacob..............................112

Schorn, Johann.............................112

Schott, Martin .............................. II2

Scroll, The Missing....................... 49

Shaw.........................................104

Simpson, John...............................104

"Slab Back," The........................ 6

"Small-Coal Man," Thomas Britton.1 $3^{6}$

Smith, Henry.............................104

Smith, Thomas............................. ro

Smith, William.............................. 04

"Sonata del Diavolo," Tartini's..... 67

Soquer, Louis................................ 8

Sound-bar, The............................ 8

Sound-post .................................. 8

South Kensington Museum ............ 2

Speiler.........................................112

Spohr, and his "Guarnerius" ".........167

Stainer, Jacob..............................112

Statelman, Daniel.........................155

Statelman, Johann J..................... I I5

Stew-pans, Lully and the................. 35

Stolen "Strad," A........................152

Stolen Tenor................................. 53

Storioni, Laurentius......................... 59

"Strad," The Long........................... 65

Stradiuarius, Antonius.................... 60

Stradiuarius, Franciscus.................. 70

Stradiuarius, Omobono................... 7o

Stradiuariuses, Living.................. 53

Stradiuarius, Betts'......................... 60

Straube........................................115

Strauss, Joseph.............................115

Strings......................................... I I

Sursano, Spiritus........................... 70

Sylvestre.................................. 8r

\section{$\mathbf{T}$}

Tarisio, Louis.................................122

Taylor............................................104

Techler, David ............................... $7^{\circ}$

Testore, Carlo Giuseppe................. 70

Testore, Carlo Antonio..................... 7 r

Testore, Paolo Antonio................. $\mathbf{7}^{\mathbf{I}}$

Thackeray on Orchestral Music......162

Theress........................................ 81

Thibout .................................... 81

Thompson, Robert.........................104

Thorowgood, Henry.......................105

Tintoret and the Violin..................133

Titian and the Violin.....................133

Tobin, Richard (i.).......................105

Tobin, Richard (ii.)....................... ros

Tomb of Stradiuarius.................... $6 \mathbf{r}$

Tononi, Felice................................... $7^{\mathbf{s}}$

Tononi, Carlo Antonio ................... $7 \mathbf{7}$

Tononi, Giovanni......................... 71

Tononi, Guido.................................. 7x

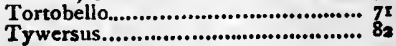


U

PAGE.

Union, The Musical......................144

Urquhart........................................ 105

\section{V}

Vaillot.

Valentine, William.

Valler.

Varnish.

Veron.

Vettrin

Vibrecht, Gys bert.

Vielle. The

Viol da Gamba,................................

Viol d'Amour, The.......................... 3

Vimercati, Paolo............................... 7i

Vogel, Wolfgang.................................115

Vogler, Johann George.......................1 115

Vuillaume, John................................ 82

Vuillaume, J. B............................. 82
Vuillaume, N. F. PAGR.

W

Wagner, Joseph. 115

Walmsley, Peter...............................105

Wandering Scroll, The.....................150

Weickert......................................... I I5

Weiss, Jacob...................................115

Wenger, G. F...............................115

Weymann, Cornelius............................ Irs

Withalm, Leopold..............................115

Withers, Edward............................205

$\mathbf{Y}$

Young.............................................. 105

Z

Zanetto, Peregrino........................... $7 x$ Zanti, Alessandro........................... $7 x$ 



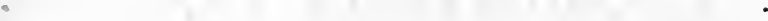


UICSB IIRRARY<smiles>[Y4][SeH][SeH]</smiles> 


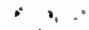

UC SOUTHEAN REGIONAL LIBRARY FACILITY

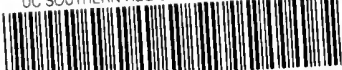

A 0006071096 


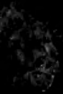

